\title{
Hot Dry Rock Geothermal Energy Development Program
}

\author{
Annual Report \\ Fiscal Year 1979 \\ Compiled and Edited by \\ G. M. Cremer \\ R. B. Duffield* \\ M. C. Smith \\ M. G. Wilson \\ Contributors \\ Hot Dry Rock Program Staff
}

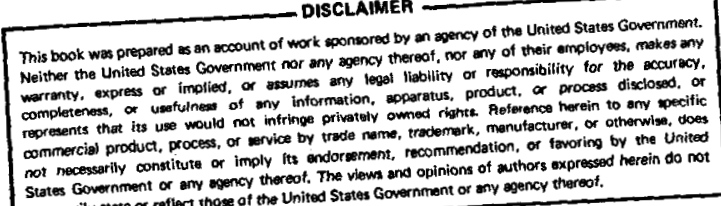

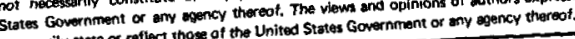

"P. O. Box 451, Norwood, CO 81425. 


\section{DISCLAIMER}

This report was prepared as an account of work sponsored by an agency of the United States Government. Neither the United States Government nor any agency Thereof, nor any of their employees, makes any warranty, express or implied, or assumes any legal liability or responsibility for the accuracy, completeness, or usefulness of any information, apparatus, product, or process disclosed, or represents that its use would not infringe privately owned rights. Reference herein to any specific commercial product, process, or service by trade name, trademark, manufacturer, or otherwise does not necessarily constitute or imply its endorsement, recommendation, or favoring by the United States Government or any agency thereof. The views and opinions of authors expressed herein do not necessarily state or reflect those of the United States Government or any agency thereof. 


\section{DISCLAIMER}

Portions of this document may be illegible in electronic image products. Images are produced from the best available original document. 


\section{CONTENTS}

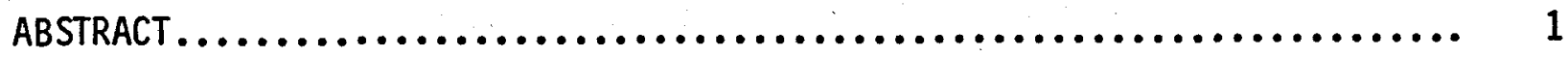

1. EXECUTIVE SUMMARY................................ 2

2. INTRODUCTION AND BACKGROUND ......................... 14

3. PROGRAM PLANNING ANd MANAGEMENT .......................... 19

3.1. Time-Phased Long-Range Objectives.................... 19

3.2. FY79 Objectives................................ 20

3.2.1. Program Management........................... 20

3.2.2. Determination of Resource Potential.............. 21

3.2.3. Site Characterization and Selection............... 21

3.2.4. Fenton Hill (Site 1) Project................... 21

3.2.5. Materials, Equipment, and Instrument Development..... 22

3.2.6 Analytical and Laboratory Support................ 22

3.2.7 Environmental and Institutional Activities......... 23

3.2.8 Economics and Precommercialization............... 23

3.3. Management Activities........................... 23

3.4. Phase III--Electricity Generation Pilot Plant at Fenton Hill. 26

3.5. Program Development Counci1......................... 27

3.5.1. Membership and Meeting Schedule................. 27

3.5.2. PDC Executive Committee...................... 28

3.5.3. PDC Site Selection Committee..................... 30

3.5.4. PDC Reservoir Committee...................... 30

3.6 International Participation....................... 30

3.6.1. U.S.-Italy Bilateral Agreement................. 31

3.6.2. U.S.-International Energy Agency (IEA) Agreement..... 31

4. FENTON HILL PROJECT OPERATIONS ....................... 33

4.1. Research (Phase I) System Rework and Operations............ 33

4.1.1. Run Segment 3 Test at High Back Pressure........... 35

4.1.2. Run Segment 4 Workover...................... 39

4.1.3. Sumary of Current Status and Future P.lans......... 49

4.2. Engineering Deve lopment (Phase II) System.............. 50

4.2 .1 Drilling of EE-2......................... 51

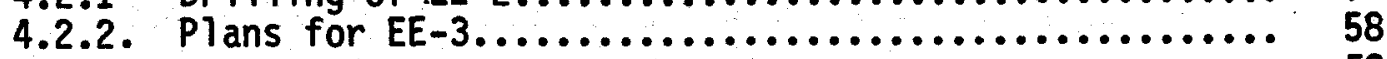

4.2.3. Loop Design............................... 58

4.3. Environmental Surveillance......................... 60

4.3.1. Hydrologic ................................ 61

4.3.2. Seismic.................................. 61

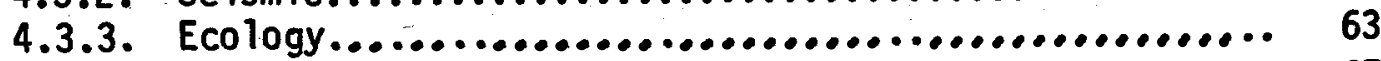

4.3.4. Climatological........................... 67 
5. RESERVOIR ENGINEERING AND MODELING...................... 73

5.1. Fracture and Borehole Mapping......................... 73

5.1.1. Microse ismic Investigations.................. 75

5.1.2. Acoustic Wave Interactions with Water-Filled Self-propped Fractures........................... 84

5.1.3. Superconducting Magnetic Techniques.............. 87

5.1.4. Radar Imaging................................ 92

5.1.5. In Situ Stress Measurements................. 97

5.2. Reservoir Properties................................. 99

5.2.1. Core Studies............................. 99

5.2.2. Dissolution Kinetics.......................... 102

5.2.3. Rock Physics................................ 105

5.2.4. Rock Mechanics.............................. 107

5.2.5. Permeability, Porosity, and Pore Compressibility..... 110

5.3. Reservoir Modeling................................. 113

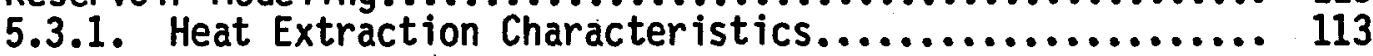

5.3.2. Flow and Pressurization in Fractured Rock............ 120

5.3.3. Flow Modeling at Wellbore/Fracture Intersections..... 129

5.3.4. Wellbore Heat Transmission...................... 136

5.3.5. Interwe 11 Tracer Studies......................... 138

5.3.6. Geochemical Modeling.......................... 139

5.3.7. Feasibility of Downhole Rock Fracturing with

Impulsive Pressure Disturbances................. 143

6. DRILLING AND COMPLETION TECHNIQUE DEVELOPMENT $\ldots \ldots \ldots \ldots \ldots \ldots \ldots \ldots 152$

6.1. Directional Drilling................................... 152

6.1.1. Downhole Motors............................ 152

6.1.2. Steering Tools............................ 153

6.2. Drill Bit Performance.............................. 153

6.3. Packers and Fracturing Systems...................... 155

6.4. Cementing....................................... 159

7. INSTRUMENT AND EqUIPMENT DEVELOPMENT $\ldots \ldots \ldots \ldots \ldots \ldots \ldots \ldots \ldots \ldots, 162$

7.1. Caliper Toor.................................... 162

7.2. Spinner....................................... 163

7.3. Dewar (Controlled-Environment Enclosure)............... 165

7.4. Downhole Injector and Gamma-Ray Detector............... 165

7.5. Downhole Detonator Acoustic Source.................... 166

7.6. Geophone Sonde................................ 168 
7.7 Instrumentation Cable Samples for Evaluation.............. 169

7.8 Downhole Instrumentation/Industrial Contracts............. 174

7.8.1. Borehole Optical Survey System................... 174

7.8.2. Acoustic Transceiver......................... 175

7.8.3 In Situ Stress Measurement................... 176

8. INSTITUTIONAL AND INDUSTRIALIZATION ACTIVITIES.............. 177

8.1. Economics...................................... 177

8.2. Legal Status.................................... 177

8.3. Regulatory Constraints............................ 178

8.4. Environmental.................................... 178

8.5. Drilling Equipment and Information................... 179

8.6. Industrialization Planning and University Participation..... 179

9. RESOURCE EVALUATION AND SITE SELECTION................... 181

9.1. Introduction..................................... 181

9.2. Exploration Philosophy............................ 182

9.3 Work in Progress...................................... 184

9.3.1. Evaluation of Resource Potential................. 184

9.3.2. Site Selection................................. 188

9.3.3. Target Prospect Selection........................ 189

9.4 Sumary of Site Presentations............................ 190

9.4.1. At lantic Coastal Plain......................... 190

9.4.2. Aquarius Plateau, Arizona...................... 190

9.4.3. Buffalo and Syracuse, New York................. 191

9.4.4. Cascade Range, Washington and Oregon--General Case... 191

9.4.5. Snake River Plain, Idaho...................... 192

9.4.6. Springerville, Arizona....................... 192

9.4.7. Zuni Uplift and Volcanic Field, New Mexico.......... 193

9.5. Recommendations of the HDR Site Selection Panel............ 193

9.6. Selection of Two Areas for Detailed Geological and

Geophysical Investigation................................ 194

9.7. Target Prospect Descriptions........................... 194

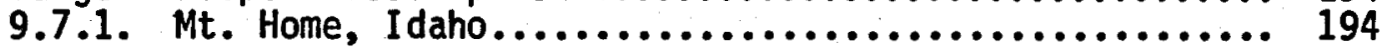

9.7.2. Crisfield, Maryland, to Wallops Is land, Virginia..... 196

9.8. Site 2 Selection and Development..................... 198 
10. FISCAL YEAR 1980 OBJECTIVES AND PLANS................... 202

10.1. Fenton Hill Project................................. 202

10.1.1. Fenton Hill Phase I.........................., 202

10.1.2. Fenton Hill Phase II....................... 202

10.2. Site-2 Project.................................. 203

10.2.1. Site Selection................................ 203

10.2.2. Site-2 Development........................ 204

10.3. Other Program Elements........................... 204

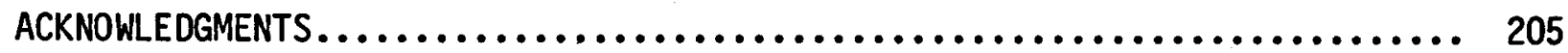

REFERENCES............................................ 206

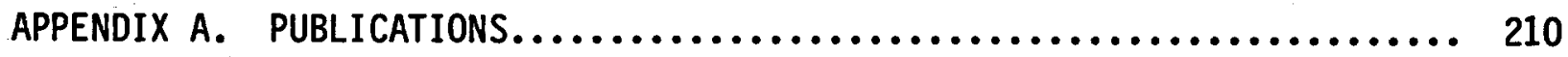

APPENDIX B. INTERNATIONAL ENERGY AGENCY IMPLEMENTING AGREE-

MENT FOR A PROGRAMME OF RESEARCH, DEVELOPMENT,

AND DEMONSTRATION ON HOT DRY ROCK TECHNOLOGY............ 213

APPENDIX C. SECOND ANNUAL HOT DRY ROCK GEOTHERMAL ENERGY

INFORMATION CONFERENCE, SANTA FE, NEW MEXICO ........... 230

APPENDIX D. FIELD EXPERIMENTS CONDUCTED DURING FY79 $\ldots \ldots \ldots \ldots \ldots \ldots \ldots 234$

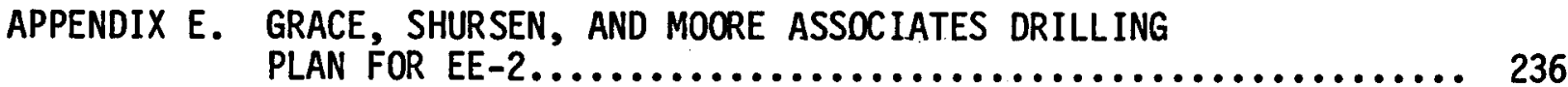

APPENDIX F. INSTRUMENT DEVELOPMENT EXPERIMENTS DURING FY79.......... 237

APPENDIX G. RESEARCH EVALUATION AND SITE SELECTION................ 239 
HOT DRY ROCK GEOTHERMAL ENERGY DEVELOPMENT PROGRAM

ANNUAL REPORT

FISCAL YEAR 1979

Compiled and Edited by

G. M. Cremer

R. B. Duffield

M. C. Smith

M. G. Wilson

Contributors

Hot Dry Rock Program Staff

\section{ABSTRACT}

The U.S. Department of Energy formally established a nationwide Hot Dry Rock Geothermal Energy Development Program at the beginning of FY79. The Los Alamos Scientific Laboratory's Fenton Hill Project is still the principal center for developing methods, equipment, and instrumentation for creating and utilizing HDR geothermal reservoirs. The search for a second site for a similar experimental system in a different geological environment has been intensified, as have the identification and characterization of other HDR areas that may prove suitable for either experimental or commercial development.

The Phase I fracture system was enlarged during FY79 and will be flowtested extensively during FY80. Drilling of the injection well of the Phase II system began at Fenton $\mathrm{Hi} 11$ in April 1979.

Environmental monitoring of the Fenton Hill area continued through FY79. The environmental studies indicate that the hot dry rock operations have caused no significant environmental impact. Other supporting activities included rock physics, rock mechanics, fracture mapping, and instrumentation development.

Two closely related activities--evaluation of the potential HDR energy resource of the U.S. and the selection of a site for development of a second experimental heat-extraction system generally similar to that at Fenton Hill-have resulted in the collection of geology, hydrology, and heat-flow data on some level of field activity in 30 states. The resource-evaluation activity included reconnaissance field studies and a listing and preliminary characterization of U.S. geothermal areas in which HDR energy extraction methods may be applicable. The selection of Site 2 has taken into account such legal, institutional, and economic factors as land ownership and use, proximity to possible users, permitting and licensing requirements and procedures, environmental issues, areal extent of the geothermal area, and visibility to and apparent interest by potential industrial developers.

An agreement through the International Energy Agency resulted in direct participation in and partial financial support of the Fenton Hill Project by representatives of the West German energy organization (KFA-Jülich). 


\section{EXECUTIVE SUMMARY (M. C. Smith)}

Formal establishment by the U.S. Department of Energy (DOE) of a nationwide Hot Dry Rock Geothermal Energy Development Program (HDR Program) occurred at the beginning of $F Y 79$ and has resulted in significant broadening of HDR activities in the United States. The Los Alamos Scientific Laboratory's (LASL's) Fenton Hill Project is still the principal center for developing methods, equipment, and instrumentation for creating and utilizing HDR geothermal reservoirs. However, the search for a second site for a similar experimental system in a different geological environment has been intensified during FY79, as have the identification and characterization of other HDR areas that may prove suitable for either experimental or commercial deve lopment.

Under a management agreement among the DOE Division of Geothermal Energy (DGE), the DOE Albuquerque Operations Office (ALOO), and LASL, an HDR Program office has been established at LASL. The Program Manager at LASL reports to a Program Director at DOE/DGE Headquarters in Washington and works closely with an Associate Program Manager at AL00.

A national Hot Dry Rock Program Development Council (PDC), advisory to the Program Office, has been formed. Its governing entity is an executive comittee that, in addition to reviewing the HDR Program and advising its management, has organized special technical committees to assist in site selection and in reservoir engineering activities. Additional technical committees will be formed as appropriate.

Through the International Energy Agency, an agreement has been reached for direct participation in and partial financial support of the Fenton Hill Project by representatives of the West German energy organization (KFAJulich). A similar agreement is being negotiated with the government of Japan. Cooperation with ENEL, the Italian National Energy Agency, in research and development on HDR systems and geothermal well stimulation has continued through FY79.

At the end of FY78, Run Segment 3--an investigation of the effects of operating the Phase I(research) system with relatively high back pressure on the production well--was in progress at Fenton Hill. After 38 days of closed-loop operation, the run was terminated prematurely because of final failure of casing cement in the injection well. Operation in this mode 
significantly reduced flow impedance through the fracture system and favored flow from it into the recovery well at deeper positions, but produced no measurable change in effective heat-transfer area.

Dye and radioactive-isotope tracer studies were made for several purposes in the Phase I system during FY79. Tracer profiles and residence-time distributions were used to identify changes in the fracture system, particularly with regard to flow patterns, fracture volumes and areas, fluid dispersion, and the appearance of new injection and production zones. Sodium fluorescein dye was used in most such experiments, but injections of $82_{\mathrm{Br}}$ and ${ }^{131_{\mathrm{I}}}$ were also used, primarily to locate damaged regions of casing cement and to quantify flow fractions entering and leaving the fracture system at various points. Together with geophysical information, results of these experiments were used to develop a consistent model of the fracture system as well as to assist in designing a recementing operation for the injection well (EE-1).

Recementing of the EE- 1 casing was accomplished using Class $H$ cement with 80\% silica flour, and was apparently successful. In this operation, the main fluid-entry point into the fracture system--behind the EE-1 casing--was intentionally sealed. Fluid pressure was then used to extend upward a hydraulic fracture previously produced in the open-hole section below the casing. It intersected the complex system of fractures from which heat had been extracted in previous flow experiments when most of the fluid was injected at a level about $200 \mathrm{~m}(650 \mathrm{ft})$ higher. This enlarged fracture system will be flow-tested extensively during FY80.

During fracture extension, excellent acoustic signals were received by an oriented triaxial geophone system stationed at $2695 \mathrm{~m}(8842 \mathrm{ft})$ depth in the production well (GT-2B). Analysis of a fraction of the very large number of signals recorded indicates that a useful map of the extended, nearly vertical fracture can be constructed from them.

Small-scale demonstrations of the utilization of HDR thermal energy both for generating electricity and for direct-heat applications are planned for the enlarged Phase I system. During FY79, Barber-Nichols Engineering designed and began fabricating a skid-mounted $60 \mathrm{~kW}(\mathrm{e})$ turbo-alternator operating on a Freon-114 binary power cycle, with all heat-rejection to air. It will be installed on a bypass from the main circulation loop.

Drilling of the injection well (EE-2) of the Phase II (engineering) system began at Fenton $\mathrm{Hill}$ in April 1979 and continued through the fiscal 
year. On September 30, 1979, it had reached a depth of $3068 \mathrm{~m}(10067 \mathrm{ft}$ ) and was being drilled at 12.25-in. diameter in granitic rock using tungstencarbide-insert roller-cone bits. In the meantime, preliminary designs have been completed for the companion production well (EE-3) and for a $50 \mathrm{MW}$ (thermal) heat-rejection system through which the two wells will be connected at the surface.

The Phase II system will consist of two parallel boreholes inclined in their lower, open-hole sections at $35^{\circ}$ to the vertical and in this region separated by a vertical distance of about $300 \mathrm{~m}(980 \mathrm{ft})$. At a depth of about $4.3 \mathrm{~km}$ (14 $000 \mathrm{ft})$, they will be connected through a series of parallel, vertical, hydraulic fractures produced in granitic rock at a temperature of about $275^{\circ} \mathrm{C}\left(525^{\circ} \mathrm{F}\right)$. It is hoped that, with control of flow distribution among these fractures, a rate of heat extraction approximately ten times that possible with the Phase I system can be maintained for at least ten years with a power drawdown no greater than $10 \%$. If this is accomplished, the Fenton Hill demonstration of a hydraulically fractured HDR heat-extraction system will be considered to have reached a successful conclusion.

Plains Electric Generation and Transmission Cooperative, Inc., has expressed a firm interest in constructing and operating a 4 to $10 \operatorname{MW}(e)$ electrical-generating pilot plant at Fenton $\mathrm{Hill}$ if the Phase II HDR system proves capable of supporting it and if there are no insurmountable economic, environmental, or institutional barriers to doing so. Their proposal to DOE/DGE for funding of an initial feasibility study in the latter areas has been approved and the study is expected to begin in FY80.

Drilling in volcanic and sedimentary formations in the upper section of EE-2 was done with steel-tooth bits, which performed well. Drilling in the granitic basement rock is being done with carbide-button-insert roller-cone bits, which are performing reasonably well. To this point, in intervals of continuous rotary drilling, they have given an average advance rate of about $3 \mathrm{~m} / \mathrm{h}(10 \mathrm{ft} / \mathrm{h})$ and an average bit life of about $67 \mathrm{~m}(220 \mathrm{ft})$.

Directional drilling in EE-2 is being done principally with downhole motors attached below a "bent sub" at the bottom of a nonrotating drill pipe. Carbide-insert tricone bits are used. Three types of downhole motors have been tried. (1) Smith International's Dyna-Drills performed satisfactorily until, at about $2500 \mathrm{~m}(8200 \mathrm{ft})$, the downhole temperature became high enough to cause thermal damage to the elastomeric stator. (2) Baker Service Tool's 
downhole drilling motor performed well down to about $3000 \mathrm{~m}(9800 \mathrm{ft})$, where its performance became marginal. (3) In its first field trials, the Maurer Engineering Co. Turbodrill--developed under LASL subcontract--was found to require considerable operator experience before it began to perform sat isfactorily. However, during the last few runs of FY79, it operated successfully at depths down to $3050 \mathrm{~m}$ (10 $000 \mathrm{ft})$, and generally it gave over $30 \mathrm{~m}$ (100 ft) of penetration per run.

Three cormercial "steering" devices have so far been tried during directional drilling in EE-2, each of which gives real-time information at the surface concerning bit orientation downhole. Eastman Whipstock's DOT tool, specially heat-shielded for this application, was used successfully from 2520 to $2936 \mathrm{~m}$ ( 8268 to $9632 \mathrm{ft}$ ), where it had apparently reached its temperature limit. Sperry-Sun's "Hadies" tool proved to be inadequately thermally protected for use at the latter depth. Scientific Drilling Control's "Eye" performed satisfactorily at $2936 \mathrm{~m}(9632 \mathrm{ft})$, but showed signs that it was affected by heat at $3059 \mathrm{~m}(10035 \mathrm{ft})$. However, at that depth, marginal performance could be maintained by operating it only intermittently during drilling.

Environmental monitoring of the Fenton $\mathrm{Hill}$ area continued through FY79, and seismic coverage of it was significantly improved. For the first time at Fenton Hill, during high back-pressure experiments in the Phase I system, two microearthquakes were detected at the surface, which appeared to be associated with the underground heat-extraction loop. Each had a local magnitude of approximately -1, too small by a factor of about 10000 to be felt at the surface. Therefore, the observations are reassuring with regard to sensitivity of the surveillance system rather than alarming with regard to seismic risk of the experiments being conducted.

Meteorological data collection also continued through FY79 at Fenton Hill, primarily to establish a local climatic baseline against which possible changes induced by future larger-scale developments there can be compared.

No effect of the Fenton Hill operation has been detected on the hydrology or water quality of the area or--outside of the site actually occupied by surface facilities--on its ecology.

Cores from GT-2 have been thoroughly examined by optical microscopy and microprobe analysis. In the upper part of the granitic section, mineral fillings, which seal the ancient fractures, are principally carbonates. Lower 
in the hole they are primarily potassium feldspar containing isolated pockets of calcite. No chlorine or fluorine have been found, supporting the conclusion that these elements appear in the circulating fluid of the Phase I loop primarily as a result of flushing out of connate waters rather than from dissolution of minerals.

Modeling of the geochemical behavior of the Phase I loop during the FY78 75-day test has been quite successfu1. However, it requires the assumption that most of the fluid follows a low-impedance path along which most of the heat is extracted, but (because of cooling) there is little mineral dissolution, while the rest of the fluid follows a hotter path where most of the mineral dissolution occurs, but little heat is extracted. Presumably it is along the latter path that connate water is displaced.

Dissolution kinetics and mineral solubilities have been investigated in the laboratory at 175 to $275^{\circ} \mathrm{C}$ in agitated-bath experiments using cuttings from EE-1 and in a titanium circulation loop using Tijeras Canyon granite-which, in mineral content, is very similar to that at Fenton Hill. Formation of colloidal particles of amorphous silica has been observed in both types of experiments, and has also been noted in solution samples from the Fenton Hill loop. Although this indicates the possibility of scaling in well casings and surface plumbing, none has so far been detected.

A continuous-flow laboratory test, run for 48 days at $193^{\circ} \mathrm{C}$ on a GT-2 core sample, produced a small decrease in its permeability. However, flow rate through the sample was very low and little mineral dissolution occurred, so that the significance of this result is not apparent.

Rock-physics studies during FY79 were concentrated on analysis of the effects of pressure-induced changes in crack characteristics (volume, shape, and distribution) on acoustic velocity, attenuation, and transmitted frequency band. Because of the importance of fracture mapping to efficient completion of underground circulation systems, considerable effort at LASL and (under subcontract) elsewhere has been given to analyzing, interpreting, and predicting the behavior during transmission through fractured rock of acoustic signals produced either by the fracturing events or by a signal generator in a borehole.

As has been mentioned, the acoustic signals generated during fracture extension can now be used with confidence to map the resulting fracture. In the absence of such events, previous experiments have shown that it may be 
possible to map fractures away from the borehole by generating acoustic signals in the hole and detecting the attenuated signal reflected from the fracture surface. Therefore, based on a preliminary LASL design, Simplec has designed and is now fabricating a high-temperature magnetostrictive transceiver intended to transmit acoustic signals from a downhole sonde and detect the returning signal by means of a receiver mounted in the same sonde. Other possible fracture-mapping systems are also being investigated.

- The magnetostrictive transmitter in the above tool may also be usable to generate acoustic signals in one hole, which are detected by another instrument in a second hole, the character of the received signal yielding information concerning both the relative positions of the two holes and the presence or absence of fractures in the rock between them. The possibility of accomplishing this has been demonstrated at Fenton Hill by firing explosive detonators in one hole and detecting them with a LASL geophone sonde in the other. A LASL detonator rack and firing module has been used for this purpose, which can detonate up to 12 charges sequentially at any desired depth. The surface control unit was designed and fabricated by Reynolds Industries.

- The feasibility of developing a borehole optical survey system (a high-temperature television camera) for examining casing and borehole walls--including indentification of fracture intersections-has been investigated individually by Hydro Products and by Measurement Analysis Corporation. Both considered such a tool feasible, and both submitted preliminary designs for it. The Metals Analysis Corporation system was selected for detailed design and testing of critical components, which is now in progress.

- Theoretical, laboratory, and field experiments indicate that a pulsed radar system may be capable of identifying fractures in granite at distances up to $100 \mathrm{~m}(330 \mathrm{ft})$ from the borehole. A subcontract has, therefore, been executed with $R$. Unterberger of Texas A\&M for design of a downhole radar tool that might be used for that purpose.

A LASL theoretical and laboratory study indicates that it may be possible to determine fracture orientation by observing the local magnetic anomaly produced by filling the fracture with a suspension 
of ferromagnetic particles in water. However, no attempt has been made to incorporate the very sensitive magnetic-detection instruments into a downhole tool.

- A sensitive caliper tool, capable of detecting 1-mm variations in a borehole wall, has been designed and fabricated at LASL. The prototype tool has three independent arms at $120^{\circ}$ intervals, but can easily be modified to have six arms. It has been used at Fenton Hill to locate intersections of fractures with the wellbores as well as for casing inspections and other purposes.

Rock mechanics investigations during FY79 have been largely laboratory measurements of fracture toughness and elastic moduli and studies of slow crack growth in granite samples. Good correlations of tensile modulus and fracture toughness have been found and preliminary measurements indicate an increase in Poisson's ratio and a decrease in Young's-modulus nonlinearity with increasing effective stress (decreasing pore pressure). Because in situ stress condition is a principal factor in controlling fracturing and crack-extension behavior and the orientation of the resulting fracture system, two types of downhole stress-measuring tools are currently being investigated. (1) Under subcontract to Texas A\&M, a downhole sonde is being developed in which a mechanical system developed there by Earl Campbell will be used to measure strain relaxation in the borehole wall as a hole is drilled into it. The associated electronic systems will be provided by LASL. (2) At the University of Wisconsin, $R$. $V$. de $l a$ Cruz is developing a very sensitive caliper tool with a built-in downhole recorder that can be used to measure the changes in borehole dimensions that would result from controlled changes in fluid pressure in the borehole. In conjunction with measurements of the least principal stress made by repressuring hydraulic fractures, this should permit evaluation of the intermediate in situ compressive stress.

An existing continuum-mechanics computer code is being modified to permit prediction of the changes in the initial stress field within a HDR reservoir that will be produced by pressurizing the fractures, the resulting porepressure field, and the thermal stresses induced by cooling.

More detailed numerical analyses have been made of heat extraction during the 75-day flow test in the Phase I loop, taking into account the measured temperature, flow rates through the two main entrances into the production well, observed impedances, and changes of these with time. Although some 
simplifying assumptions are still involved, excellent agreement between calculated and observed drawdown behavior was achieved by assuming a self-propped main fracture with a radius of $60 \mathrm{~m}(200 \mathrm{ft})$, a constant aperture of $0.2 \mathrm{~mm}$ $(0.008 \mathrm{in.})$, and an inlet located $25 \mathrm{~m}(82 \mathrm{ft})$ above the bottom of the fracture. These appear to be realistic values.

A previously developed wellbore heat-transmission computer code has been extended to permit prediction of fluid temperatures during countercurrent flow as occurs during drilling and cementing operations. Agreement with recent experimental data is excellent. The code is needed particularly to establish water-circulation schedules for cooling the wellbore before and after cementing casing in wells EE-2 and EE-3.

Analysis of the flow behavior of water in a rough-walled fracture indicates that, for most flow conditions so far used in the Phase I system, nonlinear flow laws should be expected--as has, in fact, been observed. Laboratory studies of accelerated flow as a fluid approaches the outlet from the fracture system and of the transition from converging radial flow to linear flow up the wellbore has produced new information on flow patterns and pressure drops as functions of velocity. This will be useful in designing the Phase II system.

In addition to the instrumentation developments mentioned above, several others have been undertaken either by LASL or by subcontractors.

- A purchased Worth Well high-temperature spinner tool has been modified by LASL to increase sensitivity, resolution, and repeatability. It has been used successfully to measure flow rates at intersections of fractures with the two Phase I wellbores.

- A tracer-injector sonde has been developed by LASL in which the tracer is contained in a quartz ampoule, which is crushed mechanically at any desired downhole position to release its contents. It has been used particularly with radioactive ${ }^{82} \mathrm{Br}$ to trace fluid flow in the boreholes and fracture system and behind the casing. A garma-ray detector, purchased from Worth Well and mounted in the same sonde, is used to follow the migration of the radioactive material.

- A LASL-designed metal dewar containing a fusible-alloy heat sink has been fabricated and tested by Mechanics Research, Inc. It is used in various downhole sondes to protect power supplies and 
electronic components against elevated temperatures, and has been tested satisfactorily for 12 hours at $275^{\circ} \mathrm{C}$.

- The LASL downhole geophone sonde has been repackaged to utilize this dewar, which in that sonde contains a battery pack and amplifiers, an inclinometer used to determine sonde orientation in inclined holes, and a switching system to permit multiplexing to the surface of signals from the geophones, the inclinometer, a temperature sensor inside the dewar, and a casing-bottom locator used to provide a depth reference.

However, the greatest problem with downhole measurements in high-temperature geothermal wells is still the requirement for an armored multi-conductor or coaxial cable capable of transmitting electrical signals reliably to the surface during prolonged exposures to temperatures up to at least $275^{\circ} \mathrm{C}$ and pressures up to $60 \mathrm{MPa}$ ( $8500 \mathrm{psi})$. A joint program has been organized with the U.S. Geological Survey (USGS) and Sandia Laboratories in which specially manufactured 1000-ft samples of various candidate cables will be procured and tested under realistic conditions of temperature, pressure, and tensile load.

In preparation for hydraulic fracturing in the Phase II system, subcontracts were arranged for fabrication of two types of high-temperature openhole straddle-packer assemblies. Guiberson Division of Dresser Industries has successfully tested a compression-type packer in casing at $275^{\circ} \mathrm{C}$ and 34.5 $\mathrm{MPa}$ (5000 psi) differential pressure. Two of their packer-assembly mandrels, with 18 redress kits, have been procured for possible open-hole use at Fenton Hill. Lynes, Inc., has developed an inflation-type packer and tested it at $265^{\circ} \mathrm{C}$ and $34.5 \mathrm{MPa}$ (5000 psi). One Lynes mandrel assembly and eight sets of two packer elements have been procured. Another packer concept, the use of an easily drillable cemented-in liner/hanger assembly, is also being investigated.

A hole-completion system intended to permit sequential production of several parallel hydraulic fractures and subsequent control of flow rate through each of them, was inserted into the open-hole section of .EE-1. Known as Pack/Perf, it is manufactured by Completion Technology Company and uses cement-inflated packers to permit insertion through casing and subsequent inflation to seal a considerably larger hole. Due to failure of a wiper plug, injection of cement slurry did not inflate the packers. It did, however, cause partial setting of the liner hanger at the top of the assembly, making 
it impossible to remove the assembly intact. Part of it was retrieved, the rest was pushed to the bottom of the hole.

Other fracturing methods are, of course, possible instead of or in conjunction with the use of hydraulic fracturing. One of these is to use rapid gas-generation (the KINE-FRAC method) to produce localized fractures in the uncased borehole, which does not require the use of packers. Several KINE-FRAC attempts were made near the bottom of EE-1 with some hardware problems, but with apparent general success so $f a r$ as burning the gas-generating propellant was concerned. Results could not be fully evaluated because junk from the Pack/Perf assembly interfered with downhole diagnostics. However, pumping tests indicated no change in flow-circulation paths as a result of the KINE-FRAC treatments.

Several methods have been suggested for initiating fractures around a borehole by generating impulsive pressure waves that would travel down the cased wellbore into the region where fracturing was desired. An analysis of such methods indicates that several of them might work, but that all of them involved major equipment or operational difficulties. Although the associated safety issues are recognized, the conclusion reached was that, if static fluid pressurization is inadequate, the use of decoupled explosive charges in the borehole appears to be superior to the other dynamic methods considered with regard to convenience, cost, and pressure and energy levels attained.

In expanding the HDR Program beyond the Fenton Hill Project, much information has been collected on geology, hydrology, and heat flow elsewhere, and some level of field activity is now being supported in 30 states in order to extend that information. Two closely related activities are involved-evaluation of the potential HDR energy resource of the United States and the selection of a site for development of a second experimental heat-extraction system generally similar to that at Fenton Hill.

The resource-evaluation activity includes reconnaissance field studies done largely by individuals and consortia from academic and industrial organizations, and data collection and analysis by the HDR Program Office. All aspects of this work are closely coordinated with the geothermal resource assessment program of the USGS.

An intermediate product of resource evaluation is a listing and preliminary characterization of U.S. geothermal areas within which HDR energy extraction methods may be applicable. In addition to estimating the quantity 
of useful thermal energy that might be present in each, the Program Office attempts to identify those which might be especially suitable for relatively quick and economical development either experimentally or by industry. The most promising of these prospect areas are reviewed with the P.DC Site Selection Committee and with DOE/DGE, and specific areas are selected for detailed investigation as possible locations for HDR Experimental site 2. During FY79, subcontracts were let to two industrial organizations for investigation of two limited areas of about $260 \mathrm{~km}^{2}\left(100 \mathrm{mi}^{2}\right)$ each. One, on the Delmarva (Delaware-Maryland-Virginia) Peninsula, is being examined by d'Appolonia Consulting Engineers as a possible location for an HDR system that would produce relatively low-temperature heat for direct use. The other, near Mountain Home, Idaho, is being investigated by Harding-Lawson Associates as a possible source of heat at a temperature high enough for generating electricity. The Delmarva area includes a well drilled for DOE/DGE at Crisfield, Maryland, to investigate hydrothermal aquifers. The HDR Program arranged to have the well extended into the metavolcanic basement rock, and determined that the basement rock had very low permeability (about 10,D) and could be hydraulically fractured at moderate pumping pressure (about $11.3 \mathrm{MPa}$, or 1670 psi). The Mountain Home area is on the northern edge of the Snake River Plain, in a region of relatively high heat flow. It contains an exploratory hole $2950 \mathrm{~m}$ ( $9676 \mathrm{ft}$ ) deep (drilled by a petroleum company), which was dry and had a bottomhole temperature of $204^{\circ} \mathrm{C}$.

Other possible locations for HDR Site 2 are expected to appear as a result of the reconnaissance investigations described above, the paraliel investigations of the USGS, and the offering of "wells of opportunity"--which are usually hot, dry holes drilled in unsuccessful explorations for hydrothermal reservoirs. All of these will be considered in the final siteselection process.

In the meantime, a solicitation of interest has been issued for an industrial contractor to undertake development and operation of HDR Experimental Site 2, for which the HDR Program Office will serve only as Project Manager and Technical Adviser. A draft request for proposals for the Site 2 contract has been prepared and submitted to the DOE, ALOO.

In addition to geologic factors, the final selection of Site 2 must take into account such legal, institutional, and economic factors as land ownership and use, proximity to possible users, permitting and licensing requirements 
and procedures, environmental issues, areal extent of the geothermal area, and visibility to and apparent interest by potential industrial developers. As each new candidate area is identified, these factors are investigated for it. Related activities that are not site-specific include the following.

- "An Industrial Assessment of the Economic Feasibility of Hot Dry Rock Geothermal Systems." This is a two-year study being conducted by Bechte 1 National, Inc. It is intended primarily to identify the conditions under which HDR systems would be economically attractive for industrial development, but should also provide guidance to the HDR Program in its effort to establish such conditions.

- An investigation of existing legislation concerning geothermal energy, particularly as it does and does not apply to the heat contained in HDR thermal reservoirs. This includes consideration of constraints arising from existing water law, and recommendations concerning new or improved legislation that might facilitate geothermal development.

- An "Environmental Analysis of the Fenton Hill Hot Dry Rock Geothermal Test Site," which reports the conclusion that HDR operations over the years at Fenton Hill have produced no adverse environmental impacts. This extrapolates to the broader conclusion that environmental residuals from generally similar operations elsewhere can be expected to be minimal.

The Second Annual Hot Dry Rock Information Conference was held in Santa Fe, New Mexico, on September 18 and 19, 1979. This is the major, annual, public review of the progress of the HDR Program and of its position at the end of the fiscal year. One and one-half days of technical sessions were followed by a special tour of Fenton Hill. Approximately 230 attendees participated in the conference, representing a broad spectrum of industrial firms, investment interests, research and development organizations, government agencies, and representatives from 11 other countries. 


\section{INTRODUCTION AND BACKGROUND}

Several factors have combined to make the energy problem of the United States more, rather than less, acute during recent years. Among these are continuing difficulties in siting and constructing nuclear power plants; a growing concern for the environmental and social consequences of mining, transporting, and burning coal; increasing costs and uncertainties of importing foreign petroleum; and a continuous decrease in domestic reserves of natural gas. One result is a greater awareness of the importance to the United States' energy future of its nearly inexhaustible energy sources, one of which is hot dry rock (HDR) geothermal energy.

In the context of geothermal energy, "hot dry rock" is defined as naturally heated, unmelted crustal rock, which does not produce natural steam or hot water at comercially economic rates. At varying depths, hot dry rock is everywhere beneath the earth's surface, at temperatures that, when not high enough for generating electricity, would often be usefur for such direct applications as space heating, agriculture, and food and chemical processing. Estimates indicate that beneath the land surface of the U.S. at depths $<10 \mathrm{~km}$, the hot dry rock resource base contains 232 million quads of energy*, with $>40 \%$ ( 13 million quads) at temperatures above $150^{\circ} \mathrm{C}$. If as much as $2 \%$ of this vast resource base could be exploited economically, it would supply the entire country's nontransportation energy needs at the present rate of consumption for more than 2000 years.

Recognizing the magnitude of the HDR resource base and that its exploitation would principally involve the application of existing or only slightly modified equipment and engineering methods, in 1970 LASL initiated a feasibility study of an underground heat-extraction system in low-permeability hot rock using hydraulic fracturing to produce a flow connection between two drilled holes. This study was continued through FY71, and in FY72 under U.S. Atomic Energy Commission (AEC) sponsorship, a search was conducted for a nearby location suitable for initial experiments to investigate the concept.

* 1 quad of energy $=1$ quadri]lion $\left(10^{15}\right)$ Btu $\approx 334 \mathrm{MW}$-centuries $\simeq 10^{18} \mathrm{~J}$. 
An appropriate site was found on the Jemez Plateau about $30-\mathrm{km}$ west of Los Alamos in Barley Canyon near Fenton Hill, and a slim exploratory hole (Geothermal Test Hole 1 or GT-1) was drilled there that penetrated $2143 \mathrm{~m}$ into granitic basement rock. The bottomhole temperature was $100.4^{\circ} \mathrm{C}$, and in FY73 we determined that hydraulic fractures could be created in the basement rock at moderate pumping pressures and that the permeability of the rock was low enough to successfully contain a pressurized-water heat-extraction loop. Accordingly, during FY74 and FY75 a second, deeper exploratory hole (GT-2) was drilled at Fenton Hill, about $2.5-\mathrm{km}$ south of GT-1 in a location more favorable for development of a large experimental system. This hole reached a depth of $2928 \mathrm{~m}$ and a rock temperature of $197^{\circ} \mathrm{C}$. A long series of hydraulic-fracturing and pressurization tests confirmed the feasibility of fracturing the basement rock at moderate pumping pressures and the ability of the fracture system to contain pressurized water without excessive losses.

In FY75 and FY76, under sponsorship of the Energy Research and Development Administration (ERDA), a second hole (Energy Extraction 1 or EE-1) was drilled directionally to intersect the largest of the hydraulic fractures initiated from the first hole. The second wellbore bottomed at 3064 in where the rock temperature was $205^{\circ} \mathrm{C}$. It did not intersect the fracture, but by fracturing again from EE-1, a high-impedance flow connection was established between the two holes.

During FY76 and FY77 an intensive investigation of this system was conducted, which included a study of the geometry of the wellbores and fracture system. From the information collected in that study, we concluded that the flow impedance of the system could probably be greatly reduced by directionally redrilling the lower part of the first hole (GT-2) to intersect the relatively large fracture that had been produced from the second hole (EE-1). This was accomplished and the flow impedance was reduced from 110 bars $s / \ell$ to 40 bars $s / l$. We considered, however, that this impedance was still undesirably high. Accordingly, the hole was redrilled again along a lower trajectory (GT-2B), and a much improved flow connection was established with an impedance of 17 bars $\mathrm{s} / \ell$, which was sufficiently low that heatextraction tests could proceed. This GT-2B/EE-1 wellbore-fracture system is generically called the Phase I Fenton Hill system.

In parallel with the redrilling and with intensive development of downhole instruments and system-mapping techniques, a surface facility was 
constructed to permit continuous recirculation of water through the underground loop and to dissipate the heat brought to the surface by that circulation. A preliminary experiment (with some temporary components) was conducted at the end of FY78 in a 96-h run during which the temperature of the recovered fluid rose to $130^{\circ} \mathrm{C}$, and the rate of heat recovery reached $3.2 \mathrm{MW}$ (thermal).

During FY79, after completion of the surface facility with more suitable components, a 75-day flow test was conducted in the Phase I Fenton Hill system. As would be expected from a relatively small fractured reservoir, temperature drawdown of the produced fluid was relatively rapid--and was modeled satisfactorily as the behavior predicted for a simply fractured reservoir with an effective heat-transfer area of $\sim 8000 \mathrm{~m}^{2}$. Downhole flow impedance decreased monotonically during the test so that, with a constant pressure differential between the injection (EE-1) and recovery (GT-2) wells, flow rate through the system increased continuously to the maximum rate that the surface system could accommodate. The increase in flow rate was sufficient to more than compensate for the decrease in temperature, so that the rate of heat extraction from the hot dry rock reservoir increased with time to about $5 \mathrm{MW}$ (thermal), and thereafter--at reduced flow rate--remained nearly constant between 4 and $5 \mathrm{MW}$.

Rate of water loss from the Phase I underground loop decreased continuously throughout the 75-day test, to less than $2 \%$ of the flow rate through the system, and there was no evidence of any effect of loop operation on the local aquifers or the general hydrology of the area. Quality of the recirculated water remained good, at $<2000$ parts per million total dissolved solids, and--with very sensitive monitoring--no induced seismic events could be detected at the earth's surface.

Subsequently, a 28-day flow test was run with relatively high back pressure on the production well (GT-2). It was terminated prematurely by deterioration of the cement around the casing of the injection well (EE-1), but demonstrated a further significant decrease in flow impedance from maintenance of relatively high pressure throughout the underground loop.

Results of these pioneering experiments were sufficiently encouraging so that, during the latter part of FY78, the DOE Division of Geothermal Energy authorized expansion of the hot dry rock project into a federal program of national scope, embracing the Fenton Hill operation, but also including the 
evaluation of hot dry rock resources elsewhere throughout the United States and the development of at least one more experimental heat-extraction system in an environment different from that at Fenton Hill. An organizational framework for management of this expanded program was created at LASL near the end of FY78 in preparation for formal establishment of the program at the beginning of FY79. The specific objectives of the federal program are as follows.

(1) In the short term (by the early 1980s) to determine--in concert with the U.S. Geological Survey (USGS)--the magnitude and distribution of the economically accessible hot dry rock resource throughout the United States. This requires a nationwide investigation of conductive heat flow as a function of location, of rock properties (especially permeability) at depths at which commercially useful temperatures would be encountered locally, and of the difficulty and cost of drilling to those depths and of completing commercial-scale heat-extraction systems in the potential reservoir formations.

(2) Also in the short term, to provide a preliminary assessment that all requisite technologies for creating and operating hot dry rock energy systems either exist or are within reach of engineering development. This will require further experiments at Fenton $\mathrm{Hill}$ to demonstrate that, in low-permeability granitic rock, a hot dry rock system can be created that is capable of producing heat at a useful temperature and rate and over an economically attractive lifetime. It will also require similar experiments and demonstrations in other locations where temperature, rate, and lifetime requirements may be different and where the physical and chemical nature of the reservoir rock may require development of underground fluid-circulation systems different from the hydraulically fractured, pressurized loop being investigated at Fenton Hill.

(3) In the mid-term (by the mid-1980s) to develop and demonstrate the necessary technologies, requiring demonstrations sufficient in number, variety, and scale to convince the potential users of relatively low-grade heat that HDR systems are useful, reliable, and economically viable.

(4) In the long term (1ate 1980s and beyond) to define and conduct such program activities as are necessary to foster the growth of a hot dry rock energy-producing industry. In addition to the technical and 
economic matters considered above, this will require investigations (as functions of location) of the legal, environmental, and other institutional problems facing a developing hot dry rock industry, and development and implementation of an approach to solving or circumventing those problems. A strong technology transfer activity will also be needed to make the useful results of the program available to their potential users as promptly as is possible.

In all of these areas, there has been significant activity and progress before and during FY78. For each of them, the state of affairs at the beginning of FY79 and the progress made during that fiscal year are surmarized in the pages that follow. 


\section{PROGRAM PLANNING AND MANAGEMENT}

\subsection{Time-Phased Long-Range Objectives}

In FY79, DOE expanded the Fenton Hill Hot Dry Rock Geothermal Demonstration Project into a nationwide program--"Hot Dry Rock Geothermal Energy Development Program (HDR Program)." The stated objective of this broadened HDR Program is

"...to determine the potential of hot dry rock geothermal energy as a significant alternate energy source and to provide for its timely development, if warranted."

The philosophy of this general objective has been developed into specific, time-phased objectives.

The evolution of the HDR Program--from the research and development stage through eventual commercialization--is guided by these sequential objectives.

Early 1980s

- In cooperation with the U.S. Geologic Survey (USGS), determine the potential of the HDR resource underlying the United States, emphasizing the fraction lying at shallow depths, and identify near potential users for economic feasibility.

- Provide a preliminary assessment determining if all requisite technologies are either industrially in place or are within the rea $\mathrm{lm}$ of engineering deve lopment.

Mid-1980s

- Deve lop and demonstrate these required technologies in both their engineering and economic aspects.

\section{Late 1980s and Beyond}

- Conduct Program activities and provide necessary support to industry to promote commercial production of HDR-derived electric and thermal power.

Based upon these objectives, an 8-year program plan has been developed. The Program plan comprises eight major elements, that are scheduled as shown in Fig. 3-1. The Program's key milestone is indicated by the star at the end of FY86 in the program management element. At this milestone--predicated upon commercial utilization (pilot electric power plant) of the reservoir at the 


\section{HOT DRY ROCK GEOTHERMAL ENERGY DEVELOPMENT PROGRAM LONG RANGE PLAN}

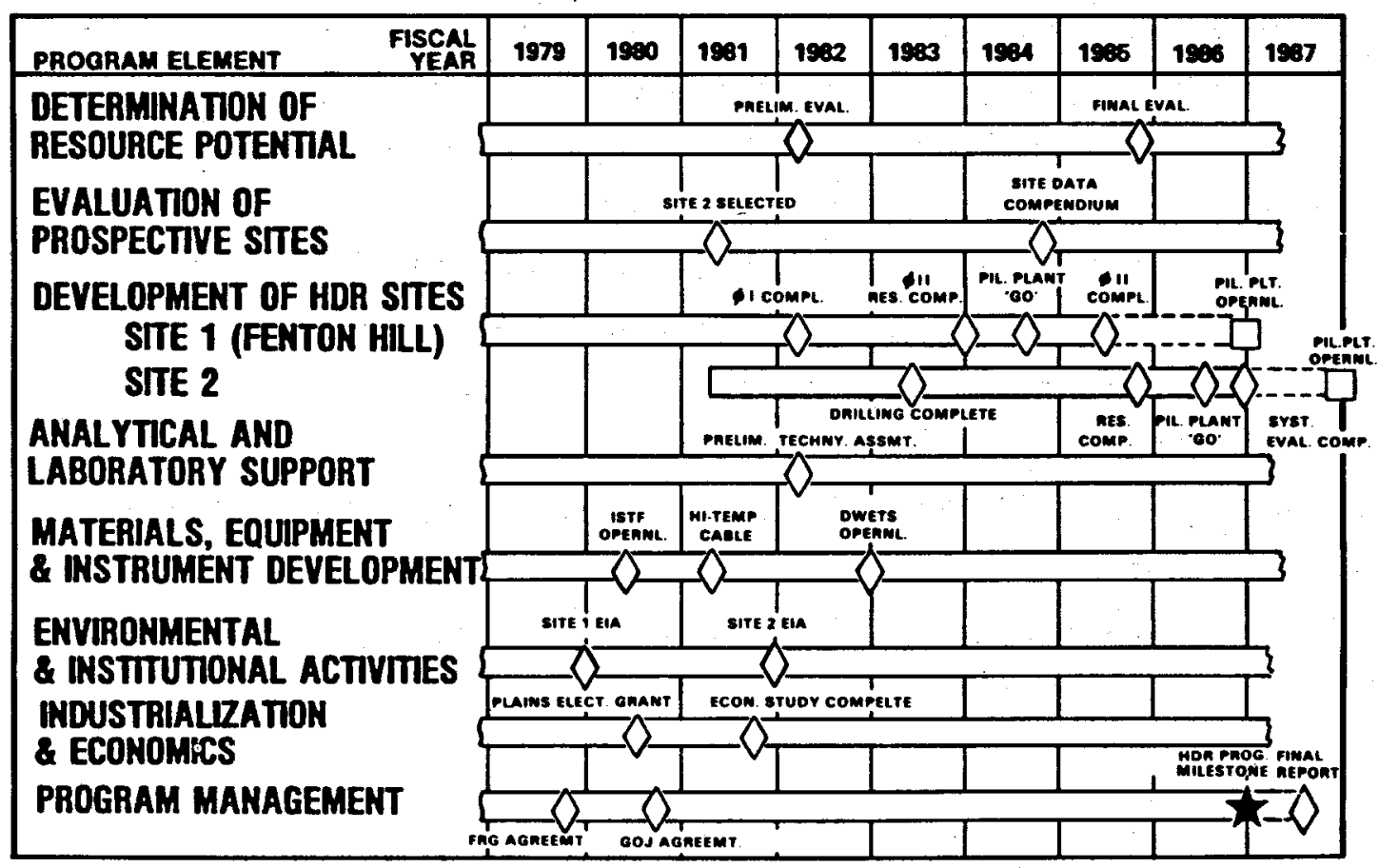

Fig. 3-1.

Hot Dry Rock Program. Plan for FY79 to FY86.

first HDR demonstration site (Fenton Hill, New Mexico); completion and assessment of a similar reservoir creaced at a second demonstration site; and a final evaluation of the resource potential--a knowledgeable decision can be made on continuing the thrust toward commercialization of HDR. The timely execution of this schedule is, of course, contingent upon the continued successful development and demonstration of the technology and upon congressional appropriation of adequate funds each fiscal year.

\subsection{FY79 Objectives}

The following set of goals, spanning all of the program elements, was undertaken during FY79.

3.2.1. Program Management. In the program management area, the formal establishment of an HDR Program Office at LASL--a task begun about mid-FY78-was completed and consumated with the signing of a written management 
agreement among the DOE/DGE, LASL, and the DOE Albuquerque Operations Office. A finalized first edition of the HDR Program Plan was to be prepared by LASL and approved and published by DOE. The HDR Program Office was also to assist the DOE in continuing its negotiations with the Federal Republic of Germany (FRG) and the government of Japan (GOJ) toward their respective direct participation in the Fenton Hill Project.

3.2.2. Determination of Resource Potential. Planned effort in this program element included continued collection and analys is of pertinent geologic and geophysical data from all 50 states with supplementary field work in specific areas of interest within Alabama, Arizona, the Atlantic Coastal Plain, Colorado, Florida, Idaho, Kansas, Louisiana, Mississippi, Nebraska, New Mexico, New York, Oregon, Utah, and Wyoming. The field work was to consist primarily of heat-flow and deep-electrical measurements which, when coupled with existing data, would permit the construction of a preliminary thermal gradient map of the U.S.--one of the first steps prerequisite to an assessment of the HDR resource.

3.2.3. Site Characterization and Selection. A derivative of the "resource potential" effort is the characterization and selection of specific prospect areas for future development of HDR sites. In FY79, the objective was to nominate and characterize at least ten candidate areas from which two prospects might be selected for more intensive geophysical study in FY78-80. The work was to be subcontracted to exploration companies familiar with the selected prospect areas.

3.2.4. Fenton Hill (Site 1) Project. During FY79, it was planned to complete the evaluation of the Research System (Phase I) and to begin construction of the Engineering System (Phase II) reservoir.

In the Research System, Run Segment 3--begun in September 1978 to evaluate the effects of operation at high mean downhole pressure--was in progress at the beginning of FY79. In the course of this high-pressure energy extraction test, it was discovered that a significant leak had developed in the already degraded cement behind the lower casing in the EE-1 well. Hence, it was decided to terminate Run Segment 3 prematurely. The EE-1 casing was recemented and a series of experiments was performed attempting to reactivate 
a fracture formerly initiated lower in the EE-1 well to drive it upward to connect with the GT-2B we11; Run Segment 4 was then conducted to evaluate the success of these workover operations in the EE-1 well.

Drilling of the first (injection) well for the Phase II Engineering System was planned to begin early in April 1979. This new we11, EE-2, was to be drilled to a depth corresponding to a bottomhole temperature of at least $275^{\circ} \mathrm{C}$, with the lower section to be slant-drilled at an angle of about $35^{\circ}$ off vertical. The rig was then to be skidded over one of the research system wells that was to be deepened by redrilling to complete the engineering system well pair. (Late in the fiscal year, when it was known that additional funds would become available via FRG participation, it was planned instead to drill a second new well, EE-3, from the surface to complete the engineering system and, thus, to leave the research system intact for further experimentation.)

3.2.5. Materials, Equipment, and Instrument Development. The Fr79 objectives in this program element included completion of development and field test of drilling-related hardware necessary to the construction of the deeper and hotter Phase II reservoir. Preeminent was a high-temperature downhole drilling motor, "Turbodrill". Development would continue on high-temperature instruments, particularly the downhole magnetostrictive acoustic transceiver and the borehole optical survey system. Feasibility studies were to be conducted on several advanced, single-well, fracturemapping concepts. An additional objective for FY79 was completion of the prototype configuration Instrument Sonde Test Facility (ISTF), an in-ground autoclave for simulating the downhole environment. It would ultimately be capable of accommodating tools and instruments up to $7.6 \mathrm{~m}(25 \mathrm{ft})$ long under test temperatures and pressures of $300^{\circ} \mathrm{C}\left(572^{\circ} \mathrm{F}\right)$ and $69 \mathrm{MPa}(10000 \mathrm{psi})$, respectively.

3.2.6. Analytical and Laboratory Support. Objectives for the year were to continue development of reservoir engineering techniques and to formulate and conduct appropriate downhole experiments in the research system to validate these techniques. Included in this effort was refinement of theoretical modeling, rock properties measurements, rock dissolution studies, and supporting data reduction and analysis. 
3.2.7. Environmental and Institutional Activities. It was planned to begin compilation in FY79 of laws regulations, permitting requirements, and other institutional data governing HDR site development on a state-by-state basis. These data will be required in both resource evaluation and site characterization. A preliminary legal study of geothermal resource definitions as applicable to HDR and a brief marketing strategy study were scheduled to commence in FY79.

An expanded Environmental Analysis Report (EAR) was to be produced as part of an updating of the Memorandum of Understanding between the USDA/USFS and DOE/LASL concerning the Fenton Hill site. This EAR was to be followed by a formal Environmental Impact Analysis (EIA) to be prepared for DOE by Oak Ridge National Laboratory (ORNL).

3.2.8. Economics and Precommercialization. A major FY79 program objective was to subcontract a two-year comprehensive HDR economics study to extend, from the industrial viewpoint, the preliminary economic studies conducted by LASL in conjunction with the University of New Mexico. The study was to be let to a consortium representing the exploration, developer, and user industries for maximum breadth and credibility.

Precommercialization objectives included continued extensive liaison with industry, continued publication of industry-oriented reports and news bulletins, and conducting of the second annual HDR Industrial Information Conference schedule for September 1979 in Santa Fe, New Mexico.

\subsection{Management Activities}

Program management activities for the year were of a widely varied nature and ever responsive to the DOE mandate. Constitution of the HDR Program Office was completed early in the fiscal year. A formal management agreement between LASL and the DOE defined the roles and responsibilities of the parties. The following officers were named: Allan J. Jelacic (DOEHQ/DGE), Program Director; Gregory J. Nunz (LASL/G-DO), Program Manager; and W. Porter Grace (DOE-ALOO/SPD), Associate Program Manager. Morton C. Smith (LASL/G-DO) was subsequently designated Deputy Program Manager. The program organization is shown in Fig. 3-2.

A National Hot Dry Rock Program Development Council (PDC), advisory to the Program Office, was formed. The complexion of this council is primarily 


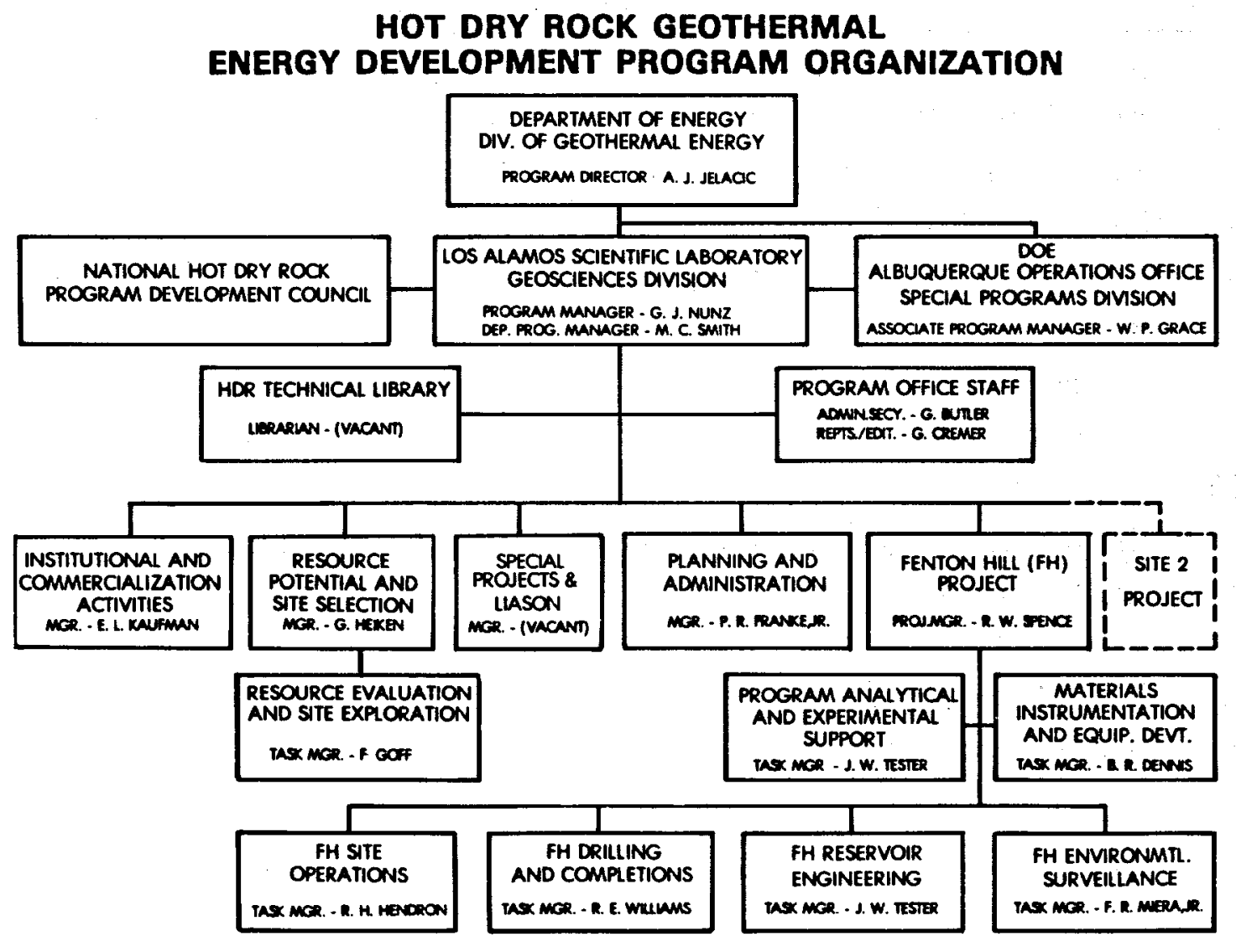

Fig. 3-2.

Program management organization and key personnel for the HDR Program.

industrial, to assure maintaining the thrust of the Program toward commercialization. Also represented are the USGS and university staff. The governing PDC entity is its Executive Committee whose FY79 membership is given in Fig. 3-3. Its function is to advise and guide the Program Office in management of the Program. The PDC Executive Committee met thrice in FY79: November 1978 and May and September 1979. Under the aegis of this Executive Comittee, various technical comittees will be constituted as needed and disbanded when their purpose is fulfilled. The first of such committees to be formed was a Site Selection Comittee (established in November 1978), whose function is to assist the Program's resource evaluation and site characterization staff with its tasks and make site prospect recommendations to the HDR Program Office. A reservoir Engineering Committee was formed in September 1979. It will assist the Program staff responsible in this area with the 


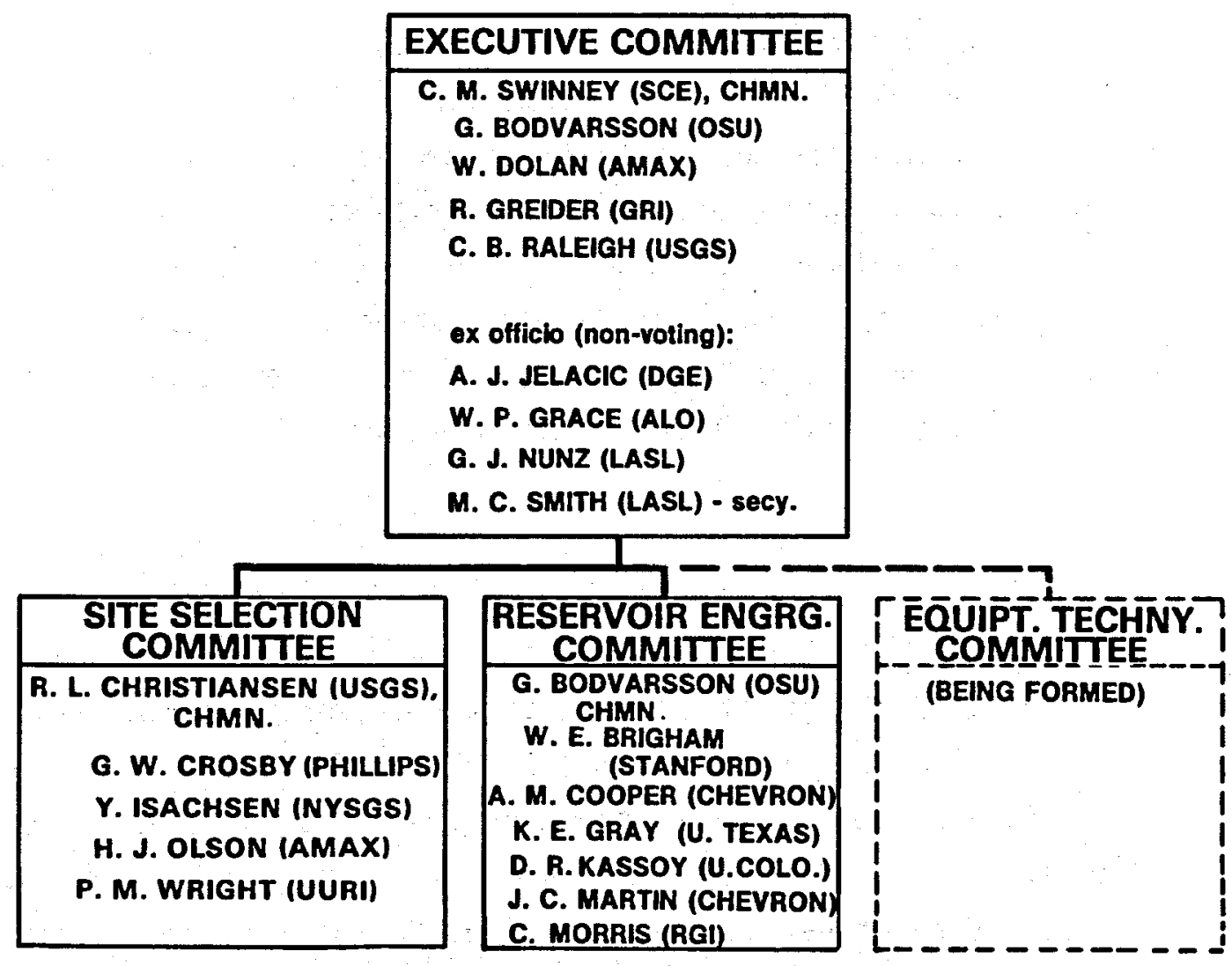

Fig. 3-3.

Organization of the National HDR Program Development Council.

planning, creation, and test of the Fenton Hill Phase II reservoir and the reservoir to be established at Site 2.

A fifth draft version of the HDR Program Plan was prepared for, and submitted to, DGE in September 1979. This document is currently being reviewed. A detailed annual Operating $P 1$ an for FY 80 was also submitted at the end of the fiscal year. Many other publications have been printed and are listed in App. A.

The HDR Program Office continued to assist the DGE in negotiations with representatives of the West German energy organization (KFA-Jülich) and the Japanese energy agency (MITI/AIST) toward their prospective direct participation--under the auspices of the International Energy Agency (IEA)--in the Fenton Hill Project. Negotiations with the West German government were completed and a formal agreement (see App. B) between KFA-Jülich and the DOE 
was signed in Paris in September 1979. Negotiations are continuing with the Japanese government and a similar agreement is anticipated in FY80.

The second annual HDR Industrial Information Conference (see Appendix C) was held in Santa Fe, New Mexico, on 17-18 September 1979. Like its predecessor, this HDR Program-sponsored conference was well attended by representatives of the exploration, development, and support industries, and by interested utilities. This annual conference affords a direct and highly interactive channel for communicating most recent developments in HDR technology to the future industrial user intrastructure.

\subsection{Phase III--Electricity Generation Pilot Plant at Fenton Hill}

In the spring and sumer of 1979, discussions were held by members of the Program Office with representatives of Public Service Company of New Mexico (PNM) and Plains Electric Generation and Transmission Cooperative, Inc. (Plains). The purpose of these discussions was to acquaint these utility companies with the state of development of HDR at Fenton $\mathrm{Hill}$ and elicit their interest in pursuing the establishment of a 4-10 MWe pilot plant at the Fenton Hill site. The DOE-DGE guidance had precluded planning for funding the construction of this facility, but was flexible in terms of supporting the necessary preliminary studies. The advice of the Program Development Council was that ultimate commercialization of HDR would require demonstrating not only the extraction of thermal energy, but also the installation and operation of an actual power plant.

Although PNM expressed interest in the project, their ability to commit resources was limited by virtue of their heavy involvement in the Baca project. Plains was strongly interested and submitted a proposal to conduct an initial feasiblity study. The principal elements of the study are to

1. Define the requirements for obtaining leases, both surface and subsurface, necessary for conducting the project including the potential for expansion of the reservoir beyond that being developed by DOE and LASL;

2. Determine the regulatory requirements of Federal, State, and local agencies for licenses, permits, and approvals needed to build and operate the plant; 
3. Determine the requirements for obtaining and the availability of water rights and appropriations for operating the HDR reservoir and the pilot plant;

4. Develop preliminary cost estimates for constructing the pilot plant and auxiliary facilities, and define several alternative financing arrangements therefore;

5. Define means whereby surface and subsurface facilities and improvements vested in the federal government can be transferred to Plains;

6. Determine the environmental requirements of all regulatory agencies in Task 2 including, but not limited to, monitoring data collection, analysis, and documentation.

The proposal was reviewed by DOE-DGE and announced as approved by Bennie DiBona on September 17, 1979, at the 2nd Annual Hot Dry Rock Geothermal Conference in Santa Fe, New Mexico. The work will be supported by a DOE grant, which is expected to be awarded in FY80 and amounting to $\$ 121800$ for a 12-month effort.

\subsection{Program Deve lopment Council}

3.5.1. Membership and Meeting Schedule. To provide for objective external review of the progress of the HDR Program and to advise the Program Management Office concerning program activities and planning, a national HOR Program Development Council. (PDC) was organized in FY78. The Executive Conmittee of the PDC consists of the following.

Dr. C. M. Swinney, Southern California Edison Company, Chairman

Prof. Gunnar. Bodvarsson, Oregon State University

Mr. William Dolan, AMAX Exploration, Inc.

Mr. Bob Greider, Geothermal Resources International, Inc.

Dr. C. B. Raleigh (Alternate: Dr. L. J. P. Muffler),

US Geological Survey

Dr. A. J. Jelacic, DOE/DGE (ex officio)

Mr. W. P. Grace, DOE/ALO (ex officio)

Mr. G. J. Nunz, LASL (ex officio)

Mr. M. C. Smith, LASL, Secretary 
The first meeting of this committee was held at LASL on June 8, 1978. The second meeting was held at LASL on November 17, 1978, jointly with the first meeting of a newly formed Site Selection Committee consisting of the following.

Dr. R. L. Christiansen, US Geological Survey, Chairman

Dr. G. W. Crosby, Phillips Petroleum Company

Dr. Y. Isachsen, New York State Geological Survey

Dr. H. J. 01son, AMAX Exploration, Inc.

Dr. P. M. Wright, University of Utah Research Institute.

A second separate meeting of the Site Selection Committee was held at LASL on February 1-2, 1979, as is discussed below.

A third meeting of the Executive Committee was held at LASL on May 3, 1979. Subsequently, an HDR Reservoir Committee was formed with the following membership.

Prof. Gunnar Bodvarsson, Oregon State University, Chairman

Prof. William E. Brigham, Stanford University

Mr. A. M. Cooper (Alternate: Dr. John C. Martin),

Chevron Resources Co.

Prof. K. E. Gray, University of Texas at Austin

Prof. David R. Kassoy, University of Colorado

Mr. Charles Morris, Republic Geothermal, Inc.

Several members of each of these three committees participated in the Second Annual HDR Geothermal Information Conference held in Santa Fe, New Mexico, on September 17-18, 1979, which was followed on September 19 by a joint meeting at LASL of the Executive and Reservoir Committees.

3.5.2. PDC Executive Committee. At its first meeting, the Executive Committee was briefed in considerable detail on the history, progress, status, and plans of the LASL HDR Project and the federal HDR Program of which the LASL Project is, to this point, the major component. At each subsequent meeting it has been informed of progress and problems that have occurred since the last previous one, and between meetings Committee members have been sent several successive drafts of the HOR Program $P 1$ an and a variety of other program documents. They have been kept informed concerning all major aspects of the overall program, and in the meetings have discussed, cormented on, and made recommendations concerning most of them. They have also organized the 
Site Selection and Reservoir Comittees to deal in greater detail and on a long-term basis with certain areas of major and continuing concern, and contemplate formation of additional committees in other areas as the need becomes evident--in particular, formation of an Instrumentation Committee is currently being considered.

The need for additional heat-extraction experiments and demonstrations elsewhere than at Fenton $\mathrm{Hill}$, and possible locations for such field operations, have received particular attention from the Executive Committee. Recognizing a high probability that reservoir characteristics will be significantly different at other sites, they have recommended that at least one more large-scale heat-extraction experiment be undertaken elsewhere, and that the search for a suitable (not necessarily "ideal") second site proceed promptly and vigorously. As part of this search, they have recommended increased attention to "wells of opportunity," and offered their services in helping to arrange access to such wells. The criteria for selection of future sites have been reviewed and discussed in depth, and the importance of experiments in rock types different from that at Fenton $\mathrm{Hill--to}$ demonstrate the broad distribution of large, useful, HDR reservoirs--has been emphasized. However, to reduce risk to the overall program and to demonstrate the direct transferability of technology developed at Fenton $\mathrm{Hill}$, they have felt that Site 2 should not be greatly different with regard to reservoir characteristics from Fenton Hill. This implies a need for future development of more than one additional site to investigate the problems that will arise when larger differences in the reservoir do appear.

Although the Committee has felt that successful long-term heat-extraction experiments would satisfy the technical community with regard to both the state of technology and the comercial viability of HDR energy systems, they have also recognized an important need for an impact of such successes on a much larger nontechnical audience. They have, therefore, recomended that at least one electrical-generating pilot plant be constructed and operated as part of the HDR Program, with the further recommendation that a decision concerning plant type not be made until the characteristics of the geothermal heat supply are well understood.

More immediate needs and problems of the LASL Project have been discussed in depth among LASL personnel and the Executive Committee, including such areas as drilling, cementing, creation of large accessible fracture 
surfaces, direct uses of geothermal heat, economic viability, environmental effects and responsibilities, legal and institutional constraints, instrumentation and hardware requirements, program schedules and budgets, and interactions with the U.S. and international geothermal comunities. Many useful suggestions and recommendations have resulted.

3.5.3. PDC Site Selection Committee. At its first meeting on November 17, 1978, the Site Selection Committee met jointly with the Executive Committee and was briefed on the background, activities, and plans of the HDR Program, with particular emphasis on the selection of sites for detailed investigation and possible future development under the federal program. At its second and separate meeting February 1-2, 1979, the Site Selection Committee considered in detail the available geological information and the institutional characteristics of seven potential HDR areas, and ranked them according to their apparent promise as locations for a second major HDR energy extraction experiment. The areas considered and the recommendations of the Committee are discussed in Sec. 9 of this report.

3.5.4. PDC Reservoir Committee. On September 19, 1979, the Reservoir Committee met jointly with the Executive Committee for background discussions of the LASL Project and the federal HDR Program, and then adjourned to a separate meeting for more detailed discussions of LASL activities in the reservoir engineering and modeling areas (which are summarized in Sec. 5 of this report). This was primarily a familiarization and organizational meeting, and a second meeting of a workshop type was arranged for the Committee early in FY80.

\subsection{International Participation}

Because other indigenous energy sources are extremely limited in many countries, there has been steadily increasing international interest in the hot dry rock geothermal resource since the earliest days of the LASL Project. This has resulted in many visits to the Project by foreign scientists, engineers, and media representatives; detailed briefings of official representatives from several foreign countries; direct participation in the LASL Project by a number of foreign scientists; participation by the HDR Program 
staff in international conferences, meetings, and symposia; and both formal and informal arrangements for cooperation in development of hot dry rock geothermal technology.

3.6.1. U.S.-Italy Bilateral Agreement. An agreement signed in Rome June 3, 1975, provides for cooperation in geothermal energy research and development between the U.S. Energy Research and Development Administration (now DOE, the U.S. Department of Energy) and Ente Nazionale per l' Energia Elettrica (ENEL, the Italian National Electrical Agency). The initial period of this agreement is five years and it provides for cooperative programs in several geothermal areas, including "Project 1, Stimulation of Hot Dry Rock and Hydrothermal Reservoirs." This project is implemented for DOE by the Hot Dry Rock and Geothermal Well Stimulation Projects based at LASL, and for ENEL by their Centro di Ricerca Geotermica in Pisa.

During FY79 there has been a continuing exchange of reports and communications between LASL and ENEL and an exchange of personnel that has permitted representatives of each organization to observe, review, and participate in the activities of the other. In November 1978, P. Ceron and C. Cataldi of ENEL and P. Berry and E. M. Dantini of the University of Rome spent three days at LASL reviewing ENEL and LASL activities related to the bilateral agreement, conferring with LASL personnel on technical matters of mutual interest, and observing LASL geothermal projects in the Laboratory and at Fenton Hil1. During January 1979, D. W. Brown of LASL visited several research groups and a number of geothermal exploration, development, and production areas in northern Italy, and observed drilling operations in Sasso-22, the deep exploratory well in the Larderello-Travale steam field. During September and October 1979, C. Cataldi of ENEL attended the HDR Geothermal Conference in Santa Fe, participated in LASL activities both at the Laboratory and at Fenton Hill, and visited a large number of research organizations, geothermal operations, equipment manufacturers, and service companies throughout the western United States.

3.6.2. U.S.-International Energy Agency (IEA) Agreement. Largely as a result of interactions that occurred during the formation and prosecution of the NATO-CCMS Geothermal Pilot Study (which included a Hot Dry Rock Project) in the period 1973-1977, a strong interest in the possibilities of hot dry 
rock energy systems developed in Europe. This led to initiation of a hot dry rock study by the Commisssion of European Communities and also to the formation of an independent Man-Made Geothermal Energy Systems (MAGES) Cormittee composed largely of individuals interested in hot dry rock, but from countries who were not members of the European community. The background work done by the MAGES group led to formation, under the auspices of IEA, of a panel on Dry Hot Rock Technology, whose proposal for an IEA-MAGES Project was subsequently accepted by IEA. In addition to supporting HDR-related projects in several European countries, the IEA on September 19, 1979, adopted an "Implementing Agreement for a Programe of Research, Development and Demonstration on Hot Dry Rock Technology." This agreement provides for participation in and financial support of the LASL Fenton Hill Project by representatives of interested IEA countries and of other countries and international organizations invited by the governing board of IEA to participate. Its initial period is four years and it became effective October 1, 1979 (the first day of FY80). Initial contracting parties under this agreement are Kernforschungsanlage Jülich GmbH for the Federal Republic of Germany and the Department of Energy for the U.S.A. Possible participation by the Government of Japan is also now being considered.

In addition to information exchange, the U.S.-IEA agreement provides for assignment of up to three experts from each contracting party to participate in the Fenton Hill Project for periods up to four years and of up to three additional experts at any one time for shorter periods (3 to 6 months); for representation by each contracting party--in proportion to its financial contribution--on a Steering Committee that will periodically review progress of the Fenton Hill Project and must approve any substantial changes in its activities or schedule; and for annual financial contributions by each contracting party other than DOE of $25 \%$ of the DOE funding of the Fenton Hill Project budget up to a maximum individual contribution of $\$ 2.5$ million per year and a maximum total contribution of $50 \%$ of the DOE Project costs. 


\section{FENTON HILL PROJECT OPERATIONS}

4.1. Research (Phase I) System Rework and Operations (B. R. Dennis and Geothermal Operations Staff; J. W. Tester and GeothermaT Technology Staff)

The Fenton Hill geothermal facilities were used for certain important research and testing operations during $F Y 79$ as was the case in previous years. The EE-1/GT-2B wellbore-fracture system was used during FY78 in a 75-day heat-extraction experiment to demonstrate the feasibility of heat production at the surface from hot dry rock at depth. That experiment was Run Segment 2 in the continuing series of heat-extraction runs at Fenton Hill. Table 4-I lists certain of the run segments carried out in the past and includes some that are planned for the future. Appendix D lists the field experiments conducted during FY79.

Run Segment 3 began in September 1978 and was in progress at the beginning of FY79. This experiment was designed to observe the effect on system performance of maintaining the production borehole (GT-2B) at a high back pressure of $96 \mathrm{bar}(1400 \mathrm{psi})$. The operation of a heat-extraction system under such conditions has been of interest since the beginning of the HDR

\section{TABLE 4-I}

\section{FENTON HILL PHASE I RESEARCH OPERATIONS}

\section{Run Segment No. Date of Execution}

1

2

3

4

5
September 1977

January-April 1978

September-0ctober 1978

January 1979

Schedu led October-November 1979

Scheduled ear ly 1980
Experiment Conditions

First heat-extraction run of the EE-1/GT-2B fracture system (low back pressure).

75-day heat-extraction experiment (low back pressure).

28-day heat-extraction experiment (high back pressure).

Recementing of EE-1 (followed by hydraulic frac in .EE-1).

First heat-extraction expt. using the new 1 arger EE-1/GT-2B fracture system (low back pressure).

Extended heat-extraction experiment using the new system. 
Project. Run Segment 3 was terminated on October 27, 1978, when it became apparent that continued deterioration of the cement behind the EE-1 casing was occurring, thereby allowing significant quantities of water to flow up the casing annulus from which it could escape to the surface or enter porous zones downhole. Consequently, a recementing operation on the EE-1 casing was undertaken and was successfully completed in January 1979.

The success of the cementing job was significant because it isolated the open-hole section of EE-1 below the lower end of the casing at $9600 \mathrm{ft}$ and prevented any further fluid flow up the casing annulus above this point. This made $\sim 600 \mathrm{ft}$ of open hole in the wellbore available for experiments. This proved to be most useful.

The series of experiments and tests performed after the cementing is referred to as the Segment 4 workover. They are described in this section and occupied the period February-October 1979. Included were the following: (1) a tracer $\left({ }^{82} \mathrm{Br}\right)$ flow test to verify the integrity of the casing cement job (Expt. 194); (2) a series of tests of a fracture-initiation technique utilizing rapid gas generation to pressurize localized sections of wellbore (the KINE-FRAC method); (3) a massive hydraulic fracture test performed with the objective of producing new accessible heat-transfer surface in a fracture or fractures; (4) an attempt to connect the open-hole section of EE-1 with the open-hole section of GT-2B (a vertical distance of some $300 \mathrm{~m}$ ) and simultaneously to provide an opportunity to test the ability of the downhole acoustic equipment to detect and localize the acoustic events that should accompany fracture generation/extension; (5) a test of a downhole system of wellbore completion (the PACK/PERF system plus a sliding valve assembly by Otis), which would make possible the attainment of two engineering objectives: (a) the isolation of a selected length of the open hole for fracture initiation and (b) control of flow at a selected wellbore/fracture connection.

Reference is made at this point to Fig. 4-1, a schematic representation of the positions of the two boreholes EE-1 and GT-2B in space, with the positions of various fractures that intersect the boreholes. It is to be emphasized that the geometry shown is a simplification of what in reality is a complex reservoir. However, this representation is consistent with the observations that have been made during extensive field testing. The flow distribution noted on the figure is that observed during experiments carried out in the fall of 1978 . 


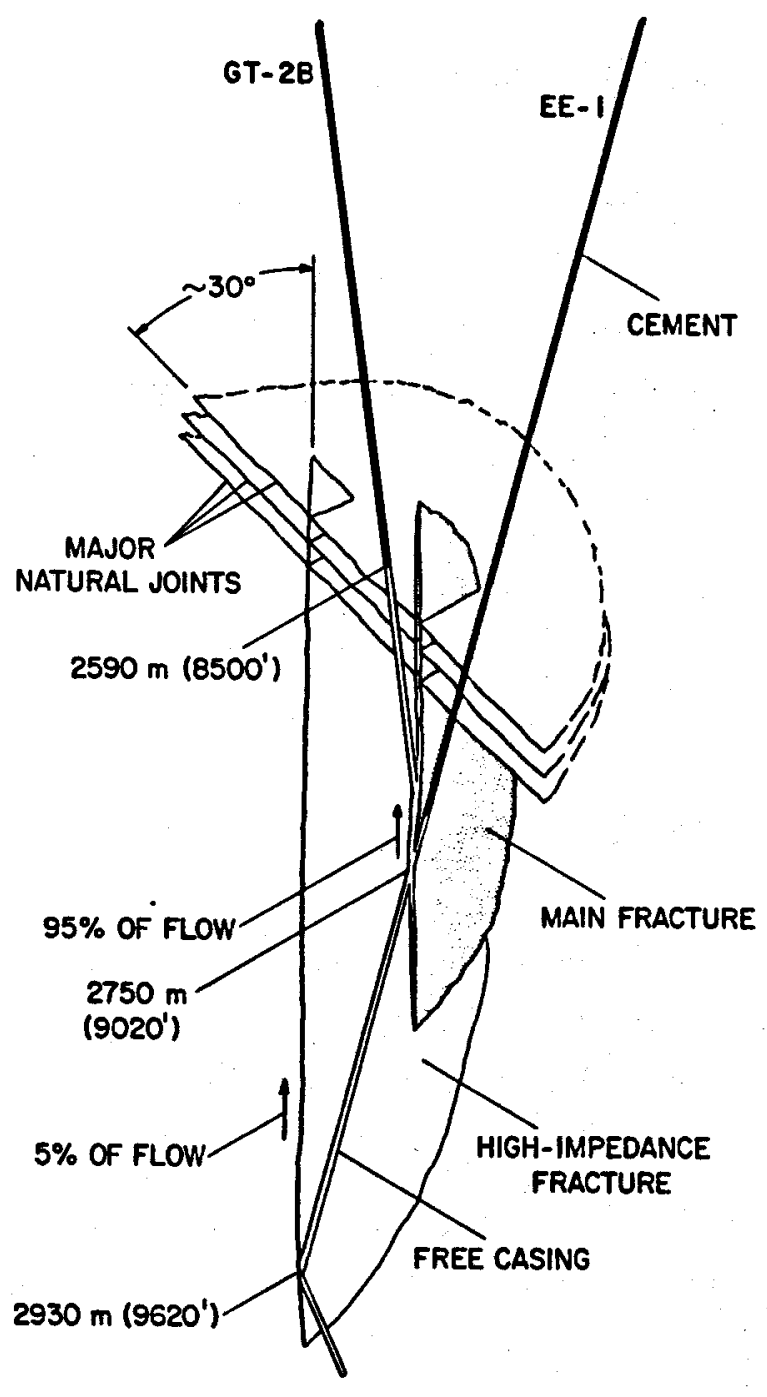

Fig. 4-1.

Elevation view of the Phase I (EE-1/FT-2B) reservoir system, May 1977-January 1979.

It may be helpful to refer to Fig. 4-1 in connection with the descriptions of experiments performed in EE-1/GT-2B that are the subject of this section. The distribution of flow indicated in the figure is that which was measured during Run Segment 2. During that run, $295 \%$ of the flow left EE-1 at $9020 \mathrm{ft}$ and entered GT-2B by the paths connected to the upper vertical fracture with only $\sim 5 \%$ entering the lower section of the reservoir. After the recementing of EE-1 in January 1979, the first of these flow paths was blocked. It was an objective of the massive hydraulic fracturing operation conducted in March 1979 to develop the lower fracture connection at $2930 \mathrm{~m}(9620 \mathrm{ft})$ in EE-1 to provide a much larger heat-transfer area. As is detailed here, this test was successful.

4.1.1. Run Segment 3 Test at High Back Pressure. The fracture-wellobore system having its main injection zone in EE-1 at 2760-m (9020-ft) depth and its production zones in GT-2B from 2650 to $2720 \mathrm{~m}$ ( 8700 to $8900 \mathrm{ft}$ ) was studied under closed-10op circulation conditions similar to those of the Run Segment 2, 75-day test, except that a high back pressure was established and maintained in GT-2B. Operating conditions and results for these two runs are listed in Tables 4-II and 4-III, respectively. Figure 4-1 shows an elevation view schematic of the wellbore fracturesystem connections.

During Run Segment 3, the flow duration was considerably shorter (28 days) and the initial mean reservoir temperature considerably lower than in Run 
TABLE 4-II a

RUN SEGMENT 2. 75-DAY LOW BACK-PRESSURE TEST OPERATING CONDITIONS

$\begin{array}{ll}\text { Injection Pressure (EE-1) } & 90-55 \mathrm{bar}(1300-800 \mathrm{psi}) \\ \text { Production Pressure (GT-2) } & 12 \mathrm{bar} \text { ( } 180 \mathrm{psi}) \\ \text { Buoyancy } \Delta P \text { Effect } & 18-8 \mathrm{bar}(265-120 \mathrm{psi}) \\ \text { Injection Flow Rate } & 7.9-14.5 \mathrm{~kg} / \mathrm{s}(125-230, \mathrm{gpm}) \\ \text { Power Produced } & 2-5 \mathrm{MW}(\mathrm{t}) \\ \text { Initial Reservoir Temperature } & 174^{\circ} \mathrm{C}\end{array}$

TABLE 4-IIb

RUN SEGMENT 3. 28-DAY HIGH BACK-PRESSURE TEST OPERATING CONDITIONS

\begin{tabular}{|c|c|}
\hline Injection Pressure (EE-1) & 90 bar (1300 psi) \\
\hline Production Pressure (GT-2) & 96 bar (1400 psi) \\
\hline Buoyancy $\triangle P$ Effect & $16-9$ bar $(225-135$ psi) \\
\hline Injection Flow Rates & $6.3-9.5 \mathrm{~kg} / \mathrm{s}(100-150 \mathrm{gpm})$ \\
\hline $\begin{array}{l}\text { Power Produced } \\
\text { Initial Reservoir Temperature }\end{array}$ & $\begin{array}{l}1.5 \mathrm{MW}(\mathrm{t}) \\
135^{\circ} \mathrm{C}\end{array}$ \\
\hline
\end{tabular}

TABLE 4-III

PHASE I FIELD TESTS, FENTON HILL, NEW MEXICO 5-10 MW( $\mathrm{t}), 185^{\circ} \mathrm{C}$, CLOSED-CIRCULATION LOOP

Run Segment 2

F low Impedance

Flow Distribution

Water Loss

Fluid Geochemistry Heat-Transfer Area
16 to $3 \mathrm{bar}-\mathrm{s} / \mathrm{l}$

(15 to $3 \mathrm{psi} / \mathrm{gpm}$ ) Well-mixed Multiple Production Zones

$0.2 \mathrm{~kg} / \mathrm{s}$ (<3 gpm)

ح2000 ppm TDS

$8000 \mathrm{~m}^{2}$
Run Segment 3

2 to $0.4 \mathrm{bar}-\mathrm{s} / \mathrm{l}$

(2 to $0.4 \mathrm{psi} / \mathrm{gpm}$ )

Well-mixed Multiple Production Zones

$0.2-0.6 \mathrm{~kg} / \mathrm{s} \quad(\sim 3-10 \mathrm{gpm})$ $<500$ ppm TDS

$8000 \mathrm{~m}^{2}$ 
Segment 2. The experiment was eventually terminated because of an increasing rate of flow behind the EE-1 casing above $\sim 2740 \mathrm{~m}(9000 \mathrm{ft})$ due to the deterioration of the cement between the casing and the EE-1 wellbore.

The primary objectives of Run Segment 3 were to see if continued flow under the imposed high back pressure in GT-2B would (a) increase the accessible heat-transfer area and (b) decrease the system flow impedance. During the experiment the EE-1 surface pressure was kept nearly constant at $\sim 91.7$ bar ( $1330 \mathrm{psi}$ ) and the GT-2B surface pressure was also kept constant at 296.9 bar ( 1405 psi). The GT-2B reservoir outlet temperature decreased steadily from $136^{\circ} \mathrm{C}$ to $98^{\circ} \mathrm{C}$ as shown in Fig. 4-2. An effective heattransfer area of $8000 \mathrm{~m}^{2}$ for each side of the fracture was found to match the drawdown data. Since this is essentially the same area as was empirically determined for the previous 75-day test, it can be concluded that operation in the high backpressure mode did not result in appreciable increase in the heattransfer area of the system.

A comparison of spinner surveys at low and high back-pressure flows, as shown in Fig. 4-3, indicates a definite shift in the entry points of fluid into the GT-2B wellbore from the fracture system. The high backpressure mode of operation favors entry points lower down in the wellbore, suggesting (as seen in Fig. 4-1) that opening the near-vertical connection from the EE-1 injection point at $9020 \mathrm{ft}$ to the exit point at $8920 \mathrm{ft}$ in GT-2B is controlled by a

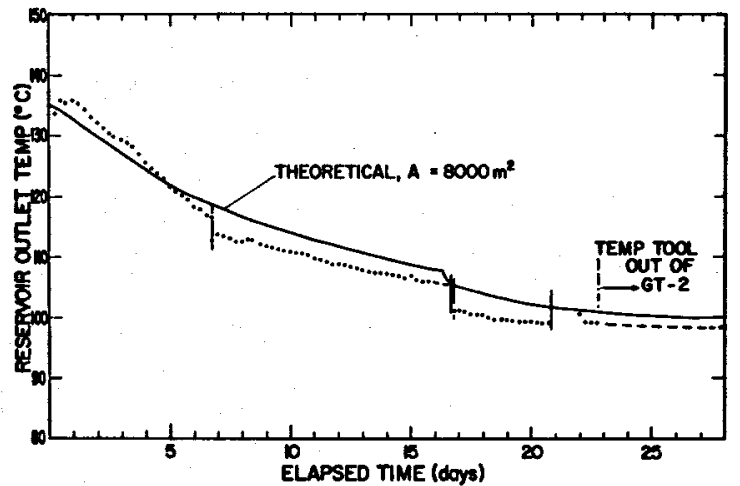

Fig. 4-2.

Measured downhole temperature at 8500 ft cable depth in GT-2B during high back-pressure heat-extraction test.

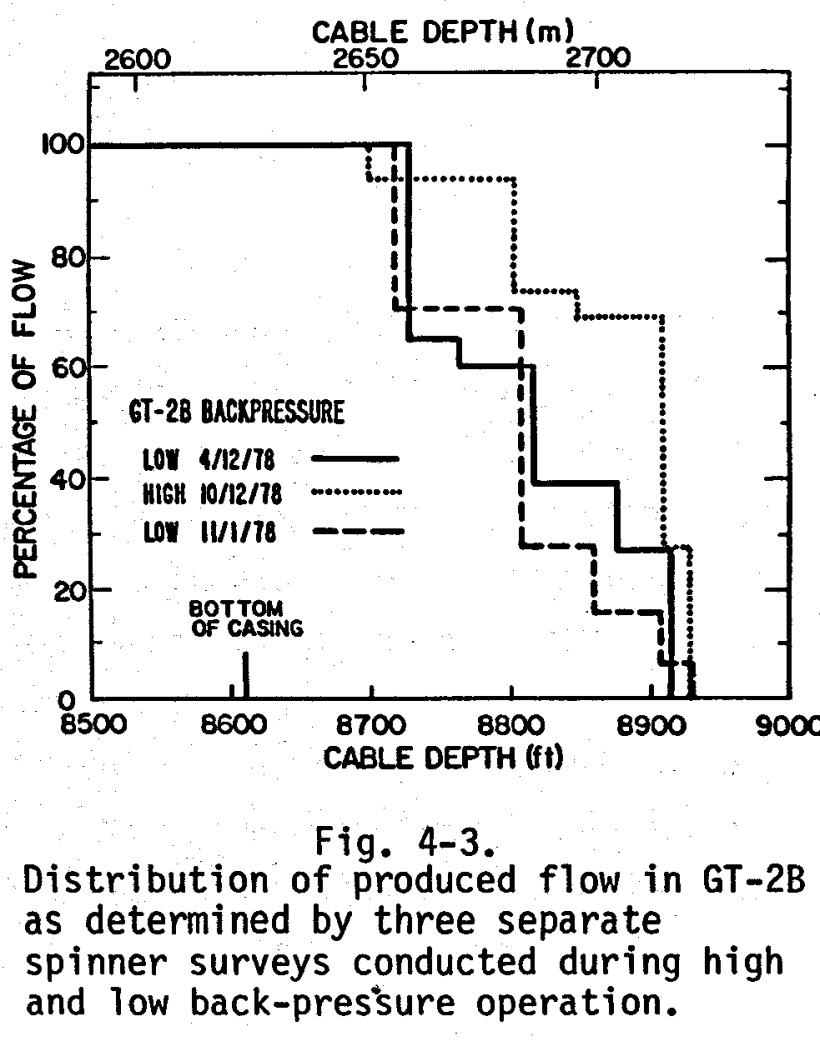


stress level close to the estimated value for the least principal horizontal earth stress, $\mathrm{S}_{3}$. On the other hand, opening of the $30^{\circ}$ off-vertical connections requires higher pressure levels because the lithostatic earth stress, $S_{1}$, also contributes to the closure stress.

Figure 4-4 shows that the system flow impedance did decrease in the course of the high back-pressure flow experiment. At the end of the previous 75-day flow experiment the impedance had dropped to $\sim 3.3 \mathrm{bar}-\mathrm{s} / \mathrm{l}$ ( $\sim 3 \mathrm{psi} / \mathrm{gpm}$ ),

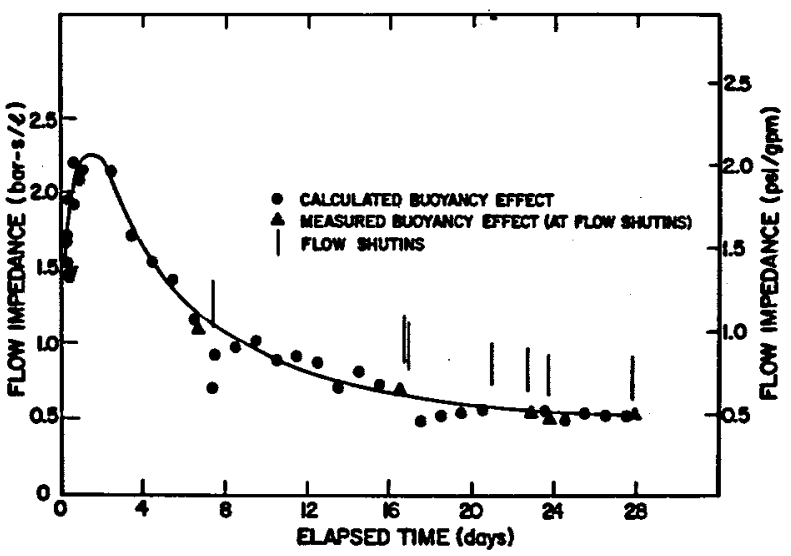
although subsequent measurements showed that the impedance had "recovered" to $\sim 6.54 \mathrm{bar}-\mathrm{s} / \mathrm{l}(\sim 6 \mathrm{psi} / \mathrm{gpm})$. As can be seen from Fig. 4-4, after a transient period of a day or two, the impedance dropped from an initial value of $\sim 2.18 \mathrm{bar}-\mathrm{s} / \mathrm{l}(\sim 2 \mathrm{psi} / \mathrm{gpm})$ to a value $\sim 0.55$ bar-s/l ( $0.5 \mathrm{psi} / \mathrm{gpm})$. Thus, the high back-pressure mode of operation definitely decreased the system flow impedance.

There could be at least two contributing causes for the observed steady decrease in flow impedance. First, during the course of the experiment the GT-2B water temperature steadily dropped; as a result of the temperature decrease, the effective downhole pressure in GT-2B increased. Such a pressure increase, particularly at pressures approaching $S_{3}$, might well open up fracture regions that were closed under lower pressure conditions. Second, the gradual decrease in rock temperature during the course of the experiment could result in the widening of fracture openings. For example, the decrease in the reservoir flow impedance during the 75-day test can be directly correlated with the decrease in the reservoir outlet temperature during that test.

Some days after the termination of Run Segment 3, with GT-2B at low pressure 215.8 bar ( 230 psi), the system impedance was measured in Expt. 190. The measured impedance was $\sim 6.54 \mathrm{bar}-\mathrm{s} / \mathrm{\ell}(\sim 6 \mathrm{psi} / \mathrm{gpm})$, very similar to that measured some weeks after the 75-day flow experiment.

Both reversible and irreversible components of the flow impedance were effective during Run Segments 2 and 3 . The strong correlation of measured 
impedance with mean reservoir temperature and pressurization levels shows a reversible fracture compressibility effect. In addition, permanent changes were observed that could be attributed to the opening of new joints and microfractures as well as to additional shear displacement of fracture faces. Localized chemical dissolution may also play a role in these irreversible effects.

The water-loss rate over the 28-day period of Run Segment 3 was greater than that in the previous 75-day test. This additional water loss arose from an increased flow behind the EE-1 casing to a near-surface high-permeability aquifer, which was subsequently identified. When this effect is eliminated, the loss rates are comparable. A detailed account of the Run Segment 3 test and its implications for future HDR reservoir systems is given in a forthcoming report by Brown et al. 1

\subsubsection{Run Segment 4 Workover.}

Recementing of EE-1: A workover rig was mobilized for the recementing operation in February 1979. After several months of independent testing of various Southwest Research Institute (SWRI) formulations of a silica hydrothermal setting cement by SWRI and the National Bureau of Standards (NBS) in cooperation with the DGE Geothermal Cement Development Program, significant uncertainties remained as to the potential quality of the SWRI polymer cement. Consequently, it was decided to substitute a silica-stablized Portland Type-G cement designed and tested by Halliburton. The cementing operation was successful and after extensive pressurization and thermal cycling over the past two months, it appears to have completely isolated the $2760-\mathrm{m}(9050-\mathrm{ft})$ injection region of $\mathrm{EE}-1$, as well as sealed the region from 2626 to $2743 \mathrm{~m}$. A comprehensive cement-bond $\log$ was run by Schlumberger and shows an adequate seal behind the casing. This is shown, for example, by the before-and-after cement bond logs reproduced in Fig. 4-5 for the region 2623-2926 $m$ (8606-9600 ft) in EE-1.

Operations in the open-hole region of EE-1 subsequently began. During the removal of the cement plug and reverse circulation of the sand pad that was used to keep cement out of the open-hole section, the appearance of numerous large $(2-5 \mathrm{~cm})$ fragments of granite was noted apparently resulting from the mechanical action of an undersized drill bit. This method of providing samples of the reservoir is currently being evaluated. 


\section{${ }^{82} \mathrm{Br}$ Tracer and Flow Test} (Expt. 194). This experiment followed the completion of the EE-1 recementing operation, which sealed the approaches to the extensive fracture system at $\sim 2760 \mathrm{~m}(9050 \mathrm{ft}$ ) behind the casing in EE-1. The $A \sqrt{k B / \beta_{0}}-$ product determined from the initial EE-1 pumping during Expt. 194 was $9.2 \mathrm{~cm}^{3}$, within $5 \%$ of the value obtained on December 3, 1975, during: Expt. 105. Initial evidence of the activation of the 2753-m (9030-ft) fracture system in EE-1 or of any other fractures above the bottom of the casing at $2926 \mathrm{~m}(9600 \mathrm{ft})$ did not appear until Expt. 114, February 14, 1976. Consequently, the present behavior suggests that the injected flow now enters only the original $2932 \mathrm{~m} \quad(9620 \mathrm{ft}) \quad$ EE-1 fracture located below the casing.

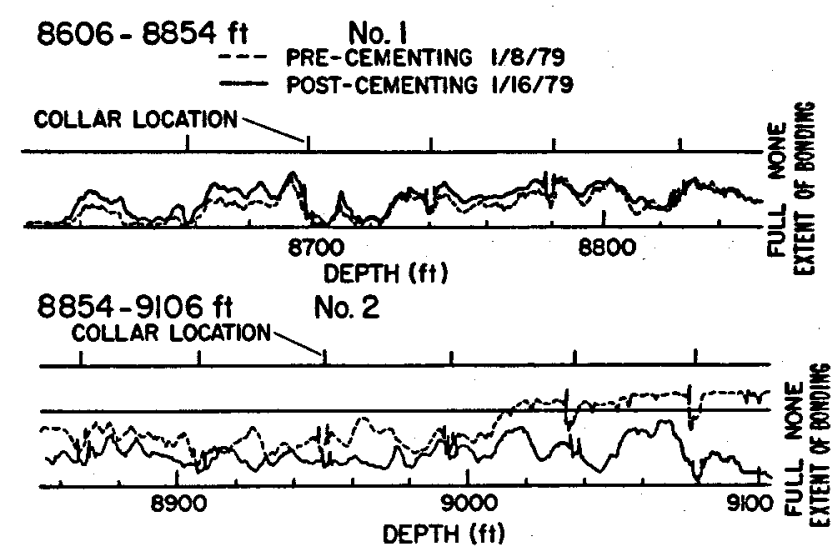

$9106-9356 \mathrm{ft} \quad \mathrm{Na} 3$

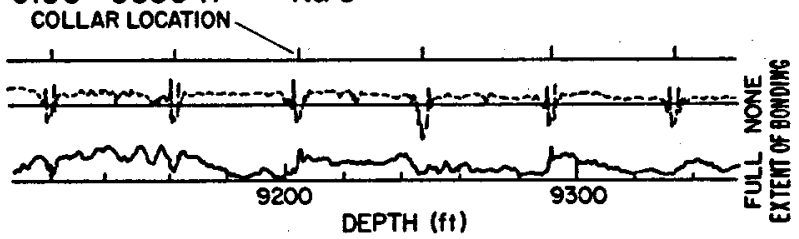

$9356-9600 \mathrm{ft}$ No. 4

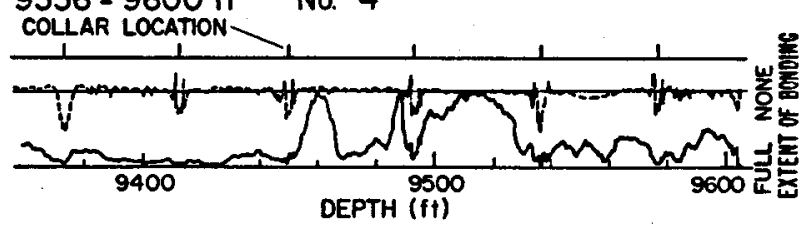

Fig. 4-5.

Pre- and post-cementing cement bond logs in EE-1.

The measured circulating impedance was $149 \mathrm{bar}-\mathrm{s} / \mathrm{l}$ (137 psi/gpm) within 5\% of the impedance reported for the fracture system before activation of fractures above $2926 \mathrm{~m}$. Analysis of the GT-2B pressure rise after shut-in suggests that cross flow enters the same GT-2B fracture/joint system that existed before recementing of the EE-1.

The ${ }^{82} \mathrm{Br}$ tracer studies indicate that injected water flows to a depth of at least $2932 \mathrm{~m}(9620 \mathrm{ft})$, true vertical depth, before entering the formation. This depth is $21 \mathrm{~m}(70 \mathrm{ft}$ ) below the casing and is nearly coincident with the bottom of the recently emplaced cement, verifying its integrity. Although this depth is somewhat below the position of an acceptable maximum in-flow for the original EE-1 fracture $(22760 \mathrm{~m})$, it may be near the bottom of this fracture's communication with EE-1. Furthermore, some of the flow injected during the current experiment may have entered as high as $2926 \mathrm{~m}$ $(9600 \mathrm{ft})$. In the other well, GT-2B, the tracer appears at the same depths 
previously identified by temperature and spinner surveys, approximately 2621, 2652, and $2713 \mathrm{~m}(8600,8700$, and $8900 \mathrm{ft})$, further confirming that communication with the existing GT-2B/EE-1 fracture system has been achieved.

Kine-Frac Operation. This sequence of operations was designed to evaluate the Kine-Frac technique of fracture initiation with gas pressurization by rapid combustion in restricted regions of the open-hole section of EE-1. This method, developed by the Kine-Tech Corporation for initiating fractures and stimulating production in oil and gas wells, was modified for use in our reservoir. The Kine-Frac method uses a relatively slow deflagration process, which should more closely meet optimal conditions for fracture initiation. Since presurrization is restricted to a localized region around the tool, it may be an effective way of isolating certain wellbore regions and eliminating the need for "straddle" packers.

The zones were selected on the basis of a correlation between several anomalies observed on geophysical logs and the drilling rate as shown in Fig. 4-6. Different regions were selected to provide information on formation conditions varying from competent, unfractured rock to previously fractured zones.

The Kine-Frac technique was tested in the EE-1 borehole at six different depths. Successful ignition of the gas-generating material was achieved in 9 out of 10 firings. The system was designed to reach 1170 bar (17.000 psi) in $3 \mathrm{~ms}$ with sustained pressurization for $500 \mathrm{~ms}$. Leakage of water into the region between the igniter and the active material prevented deflagration in the one unsuccessful test. Because no downhole pressure transducer was used, only indirect methods of verifying ignition could be used.

One test for successful ignition consisted of "feeling" the cable during firing. A sharp tug downward occurred a few seconds after the fire

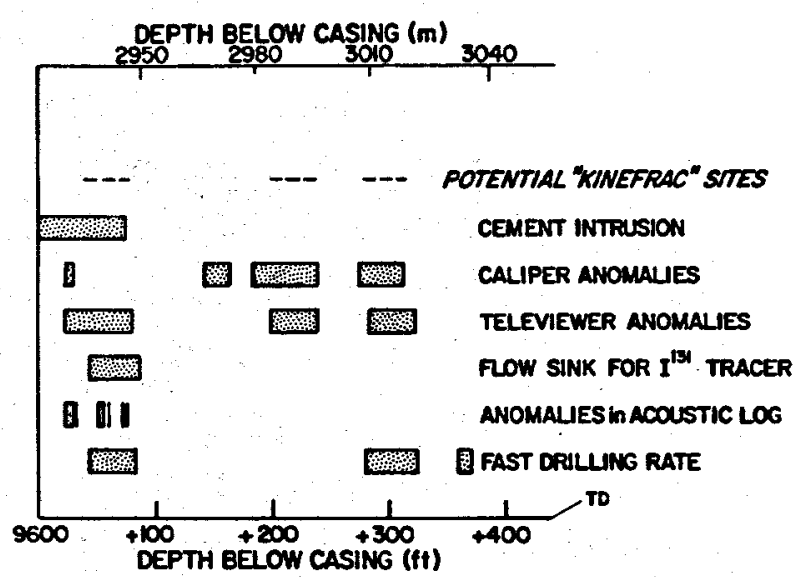

Fig. 4-6. Correlation between geophysical logging and drilling rate anomalies in the openhole section of EE-1 from 2743-2926 m $(9000-9600 \mathrm{ft})$. 
signal in the majority of the tests. The first two shots gave evidence of preignition (cable tug). The apparent preignition occurred at the bottom station, where the rock temperature was highest.

A second method of verifying ignition was to examine the tool itself after firing. The support structure for the gas-generator tubing suffered measurable damage in each of the successful firings. The first two shots employed 7/32-in. airplane cable that, after ignition, was completely severed a few inches below the igniter, leaving the sinker bar in the hole. Subsequent shots were supported on a heavy-walled black-iron tube, 1-1/4-in. o.d. This tube, on returning to the surface after firing, was bent in a direction away from the gas generator, so that straightening was required after each shot. The presence of mechanical action on the support structure was used as a measure of successful firing.

The third method employed in determining whether successful firing had occurred was through the use of a downhole geophone array in GT-2B and a vertical geophone strapped to the EE-1 casing at the surface. The results from these measurements were mixed; however, strong signals were received by both sets of instruments during the last few shots. The direct travel path for acoustic waves was over $305 \mathrm{~m}(1000 \mathrm{ft})$. However, it is possible that the signals observed in GT-2B were guided borehole surface waves in EE-1 radiating to the GT-2B array. All signals were recorded on high-speed magnetic tape and wil be analyzed in the near future.

Flow tests consisting of a programed pumping sequence after each set of firings at a given depth were conducted to see if changes in the pressurevolume pumped characteristics of the borehole had occurred. None were noted.

Table 4-IV is a listing of data from each shot. Considerable variation is noticeable in the various listings that might indicate uneven performance by the gas-generating system. The diagnostics available at this writing are not good enough to judge the effectiveness of the method. To do so will require that we process the present acoustic data and then repeat the use of the Kine-Frac tool with two pressure transducers located near the tool. In EE-1 and GT-2B this would characterize the pressure pulse and, along with accurate timing, could differentiate the dominant mode of acoustic transmission to the GT-2B geophone array. The shape of the pressure pulse with time after a second firing at the same station might indicate the nature of the rock failure from the first firing. 
TABLE 4-IV

KINE-FRAC SHOTS IN EE-1

Cable Time of

No. (ft) Pulse

Cable

Acoustic Tool Support

Response Response Behavior Other Remarks

$\underline{2 / 26 / 79}$

$19952 \quad 11: 35: 00$

?

Cable severed 3 prefiring cable jerks

$29952 \quad 14: 13: 00$

? none

Cable severed 2 prefiring cable jerks

$\underline{2 / 27 / 79}$

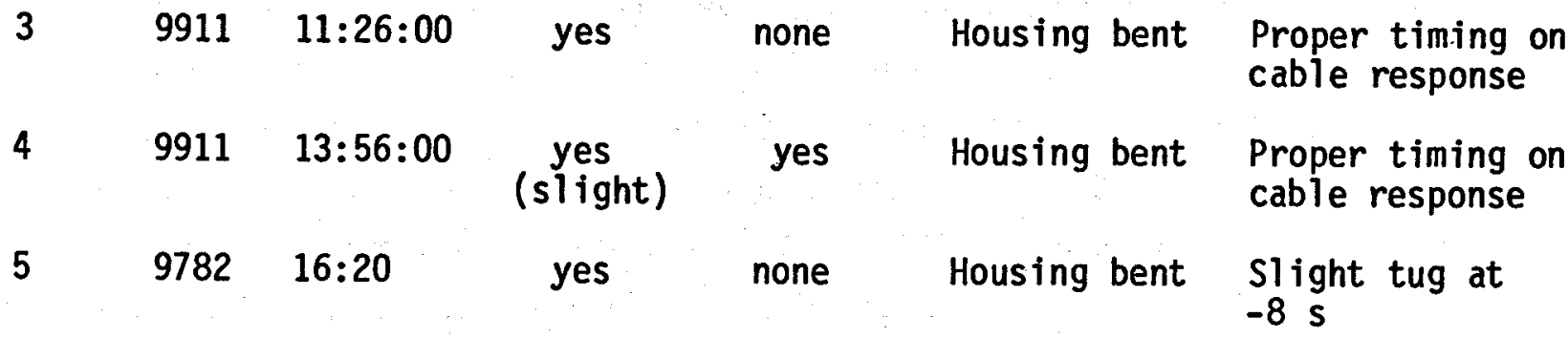

$2 / 28 / 79$

\begin{tabular}{|c|c|c|c|c|c|}
\hline 9782 & $11: 00: 30$ & no & yes & Housing bent & slight tug \\
\hline 9667 & $12: 59: 00$ & no & none & No change & $\begin{array}{l}\text { Igniter burned, } \\
\text { gas propellant } \\
\text { intact }\end{array}$ \\
\hline 9667 & $14: 45: 00$ & yes & yes & Housing bent & $\begin{array}{l}\text { Double tug, } \\
\text { water surge, } \\
\text { proper timing on } \\
\text { cable and acous- } \\
\text { tic response }\end{array}$ \\
\hline 9657 & $16: 10: 00$ & yes & yes & Housing bent & " " " " " \\
\hline 9647 & $17: 29: 00$ & yes & yes & Housing bent & " " " " \\
\hline
\end{tabular}

Shots $6,7,7 \mathrm{a}, 8$, and 9 were fired by applying full voltage $(300 \mathrm{~V}, 3-1 / 2 \mathrm{~A})$ to circuit through firing key rather than raising voltage through rheostat.

All depths are for the mid-point of the 20 -ft-long charges. 
Although the Kine-Frac tests had some obvious shortcomings, it was the first time the method was tested at $\sim 200^{\circ} \mathrm{C}$ and 300 bar hydrostatic pressure. It appears that, in addition to improved downhole diagnostics, some development of the tool hardware for our borehole environment will be required.

Massive Hydraulic Fracturing (MHF) and Associated Flow Testing (Expt. 195, 203, and 204). The objectives for pre-MHF Flow Test Expt. 203 (March 14, 1979) were (1) to determine pressurization and breakdown behavior at a $27 \mathrm{l} / \mathrm{s}$ (10 bbl/min) injection rate for $\sim 4 \mathrm{~h}$ and to estimate the maximum flow rate allowable with the 207-bar (3000-psi) casing pressure limit for the MHF operation, and (2) downhole seismic measurements during pressurization, using the Sperry-Sun multishot magnetic compass for orientation.

For MHF Expt. 195 (March 21, 1979) the objectives were the following.

(1) Extend and/or enlarge fractures originating from the open-hole region of EE-1 at 2920 to $3050 \mathrm{~m}$ (9600 to $10000 \mathrm{ft}$ ), to provide an improved connection with GT-2B. A maximum pumping rate of 40-53 $\mathrm{l} / \mathrm{s}(15-20 \mathrm{bbl} / \mathrm{min})$ for a total injection of 757000 \& (200 200 gal) was anticipated.

(2) Downhole seismic measurements with lead-azide detonator orientation for passive microseismic event mapping.

(3) $A \sqrt{\mathrm{kB} / \beta_{0}}$ measurement at an 8- //s (3-bbl/min) injection rate.

(4) Formation breakdown possible with extended pressurization to 207 bar (3000 psi).

The post-MHF Flow Test Expt. 204 (March 22, 1979) was designed to measure the high back-pressure flow impedance in the reworked EE-1/GT-2B system using $27-l / s(10-b b 1 / m i n)$ injection rate.

In the pre-MHF Flow Test, Expt. 203, successful orientation of the package was obtained with the Sperry-Sun system. Because a pressure lock at GT-2 was not used in Expt. 203, the geophone package could not immediately be removed from the wellhead because of a high $(6-\ell / \mathrm{s}$ or $>100-\mathrm{gpm})$ venting rate and high back pressure at GT-2.

The geophone package was located at a 2695-m (8842-ft) cable depth and remained in place for about $5 \mathrm{~h}$ of the pumping phase at $27 \mathrm{l} / \mathrm{s}$. This time was selected because of the anticipated lifetime of the Sperry-Sun tool at the downhole temperature. After $5 \mathrm{~h}$ of pumping, the package was returned to the surface and parked. Excellent seismic signals were obtained within $1 / 2 \mathrm{~h}$ of 
the start of pumping and continued at a high, steady rate throughout the 5-h observation period. After $5 \mathrm{~h}$, approximately $500000 \mathrm{l}$ (132 000 ga1) had been injected.

Apart from the initial transients caused by trouble with the rented pumping equipment, the injection flow into EE-1 was maintained at a $27 \mathrm{l} / \mathrm{s}$ nominal rate. After $\sim 30 \mathrm{~min}$, the EE-1 pressure reached 193 bar (2800 psi), rose to $198 \mathrm{bar}(2880 \mathrm{psi}$ ) after $11 / 2 \mathrm{~h}$, and declined slightly to a minimum 188 bar (2730 psi) after $5 \mathrm{~h}$, when the system was shut in to repair a blownout pressure transducer connection at EE-1. Pumping was resumed in 15 min and continued until a final shut in at 147 bar (2130 psi) after $\sim 61 / 2 \mathrm{~h}$ of total pumping. No $A \sqrt{\mathrm{k}} \bar{B}$ was obtained due to complex early transients, and no apparent formation breakdown occurred. Impedances were not measured because the GT-2 shut-in pressure responded erratically for essentially the entire pumping period.

For MHF Expt. 195 and post-MHF Expt. 204, the GT-2 pressure-lock system was installed to allow removal of the geophone package with the system pressurized. The initial pump-up with Western was steady at $8 \mathrm{l} / \mathrm{s}(3 \mathrm{bbl} / \mathrm{min})$ with a good value of $\sim 56 \mathrm{~cm}^{3}$ for $A \mathrm{k}$ normalized to a $\beta_{0}=2.7 \times 10^{-5}$ $\mathrm{MPa}^{-1}$. This represents an increase of $670 \%$ over the $9 \mathrm{~cm}^{3}$ measured in Expt. 194. Somewhat unexpected was the initial decrease in injection rate from $42 \mathrm{l} / \mathrm{s}$ (16 bbl/min) to $30 \mathrm{l} / \mathrm{s}$ (12 bbl/min) required to avoid overpressurization of the EE-1 casing string. After an additional 1-1/2 $h$ of pumping at $30 \mathrm{l} / \mathrm{s}$, increased injection rates up to $42 \mathrm{l} / \mathrm{s}$ were required to maintain 207 bar (3000 psi). Although many mechanisms could cause this effect, the most plausible causes are (1) decreased wellbore impedance due to a "washout" of the cement in the 2941-m (9650-ft) zone; (2) development of new injection zones (fractures in the EE-1 open-hole section); (3) fracture propagation, likely upward to a region of lower earth stress $\left(\mathrm{S}_{3}\right)$; and (4) increasing rate of inflation of the old GT-2 fracture system with a decreasing (pressure-dependent) transient impedance between EE-1 and GT-2B. Without results from flowing temperature, tracer, and/or spinner surveys and knowledge of the in situ stress, it is impossible to tell exactly where and what fraction of flow leaves the wellbore and how fractures are growing--if at all. These diagnostic tests will be conducted later.

In all three flow periods (Expts. 203, 195, and 204) no classical formation breakdown occurred with a reduction in pressures to near $s_{3}$, which 
has been estimated to be approximately 103 bar (1500 psi). However, we may be completely wrong in expecting a classical breakdown. Naturally sealed fractures in GT-2, GT-2A, GT-2B, and EE-1 have shown similar sluggish pressurization curves. However, the 207 bar (3000 psi) casing-pressure limit was a serious limitation for the entire MHF operation. Higher pressures ( 345 bar) and higher injection rates ( $\sim 50 \mathrm{bbl} / \mathrm{min})$ may be required to propagate fractures over long distances.

Geophone coverage was formally terminated when $0.2 \mathrm{M}$ gal had been pumped after $\sim 6-1 / 2 \mathrm{~h}$, and the injection flow rate was reduced to $27 \mathrm{l} / \mathrm{s}$. The geophone package was returned to the surface and secured in the GT-2 pressure lock. At 2:00 p.m. on March 22, venting began with the GT-2 wellhead pressure at 96 bar (1400 psi). The GT-2 back pressure was controlled between 96 bar and 103 bar (1500 psi) by regulating the outflow. From 2:00 p.m. to 3:10 p.m., leaks and other minor problems interfered with the venting process. After 3:10 p.m. the operation was quite stable with manual flow adjustments to keep the back pressure below 103 bar. The maximum flow rate observed at GT-2 was $\sim 6 \mathrm{l} / \mathrm{s}(\sim 100 \mathrm{gpm})$. Impedances (uncorrected for buoyancy) decreased from 15 to $13 \mathrm{bar}-\mathrm{s} / \mathrm{l}$ (14 to $12 \mathrm{psi} / \mathrm{gpm}$ ) during the venting period.

Seismic monitoring in GT-2B with an oriented triaxial geophone array, during the apparent enlargement $(227 \mathrm{l} / \mathrm{s})$ of the fracture system below the casing in EE-1 in Expts. 203 and 195, produced a unique history of events covering the inflation of the system from an initial size of 11000 to 757000 2. The two successive experiments are expected to provide valuable information about the possible growth of a fracture and its subsequent reinflation.

The initial pressurization during Expt. 203 at an average rate of $27 \mathrm{l} / \mathrm{s}$ for a total of $635000 \ell(168000$ gal) produced a steady train of microseismic signals throughout the entire pumping period. The temporal density of these signals, obtained from a chart recording, is shown in Fig: 4-7. Several Polaroid pictures of the output of a Biomation digital oscilloscope showed these signals to have well-defined phases and distinct first motions, which can provide a source location if a source mechanism is chosen. These signals, recorded on magnetic tape, have not been completely processed so that a comprehensive history of the seismic behavior of Expt. 203 is still to be determined. 
The reinflation of the downhole system during Expt. 195 was accomplished at higher flow rates (11-16 bbl $\min$ ) and with a greater total volume pumped $(757.000 \ell)$ than during initial pressurization. The seismic behavior of this experiment was greatly different from that during Expt. 203. As shown in Fig. 4-7, significant microseismic activity was not observed unti1 $227000 \ell$ (60 000 gal) had been injected, in contrast to Expt. 203 in which an almost immediate seismic

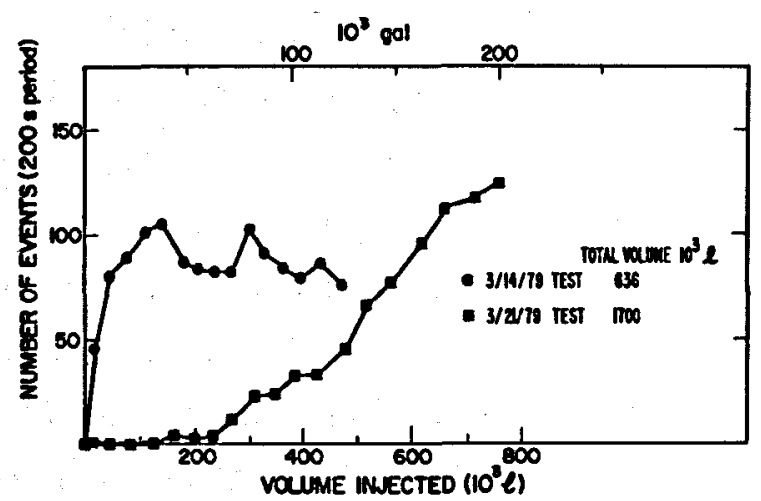

Fig. 4-7.

Microseismic activity associated with high rate injection into $\mathrm{EE}-1$ as estimated by on-line lowfrequency recording. response was observed when pumping began. After an initial quiescent period, the microseismic event rate rose steadily, and finally approached a value $50 \%$ greater than that seen in Expt. 203. This increase in event rate appears to be proportional to the increase in the EE-1 injection rate. As in Expt. 203, Polaroid records (Fig. 4-8) show we 11-defined signals. Orientation of the geophone array in GT-2B, stationed at $2696 \mathrm{~m}(8844 \mathrm{ft})$, was accomplished by measurement of the sense of first

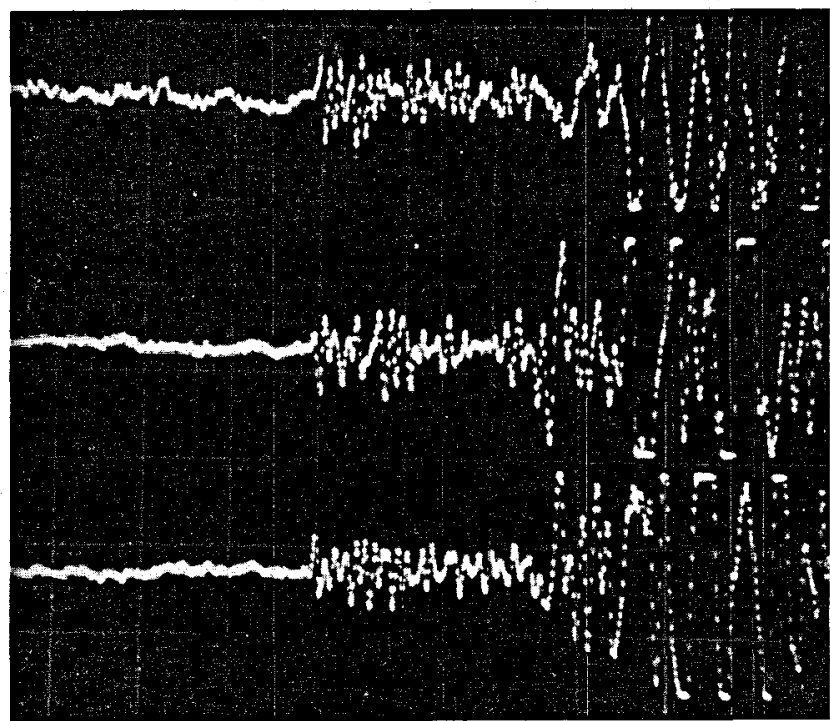

2 hrs into pumping

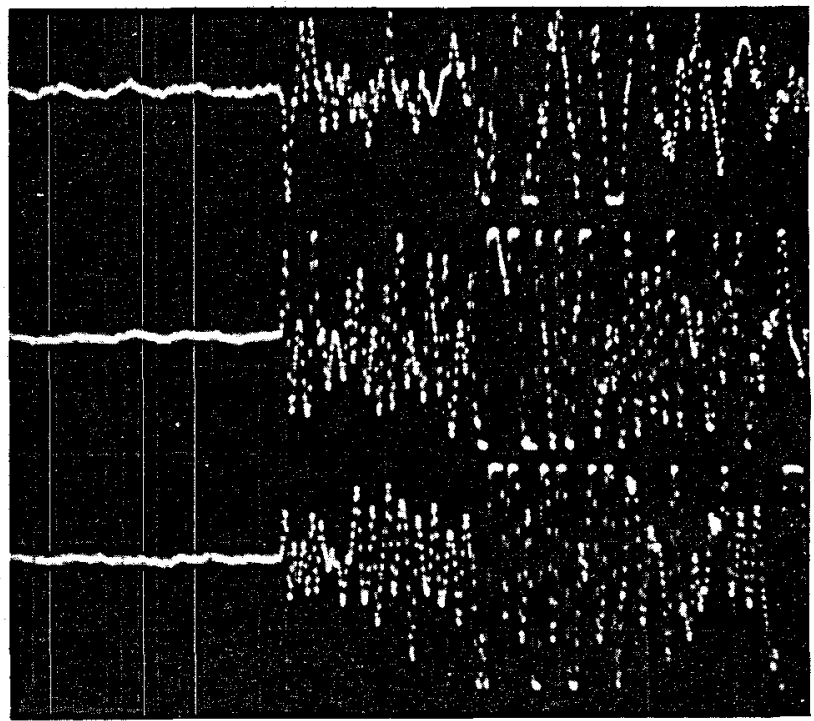

$41 / 2$ hrs into pumping

Fig. 4-8.

Typical signals (recorded from an oriented downhole triaxial geophone array) that accompanied hydraulic fracturing in deep basement rock. 
motions from several lead-azide detonators fired in $\mathrm{EE}-1$, at the same true depth. An extensive series of Polaroid records, over 70 in number, was obtained during the entire seismic observation period. Examination of these records shows an apparent decrease in the time between first arrivals of the two phases ( $P$ and $S$ ) with increasing pumping time. This behavior could be interpreted as representing growth of a fracture toward the geophone array. In addition, coupling the S-P delay-time data with a first-motion analysis of the three components has given a preliminary indication of a vertical, planar, microseismic source. However, a note of caution concerning this preliminary interpretation is appropriate. Although a number of signals were examined, they represent only a small fraction of the signals recorded. The more detailed analys is that followed indicated that the Polaroid sequence was representative; that is, the quality and quantity of signals obtained were such that an excellent map of the source of acoustic events was subsequently produced from the data. These results are discussed in detail in Section 5.1.1.

Further flow experiments giving information concerning the eventual mass production rate and long-term water losses that may occur during low or high back-pressure operation of this system will be of considerable value in the design and management of the new Phase II system. Sustained operation during heat extraction with these high back pressures may be undesirable because of excessive water losses. However, our present interpretation of the system behavior suggests that water is being consumed in two ways: first, to inflate or extend a new EE-1 fracture system; and second, to inflate the GT-2B system, which we have already characterized in Run Segments 1-3.

If pumping were to continue with the GT-2B pressure at 96 bar (1400 'psi), the water loss from that side of the system would be expected to decrease rapidly from $6 \mathrm{l} / \mathrm{s}(100 \mathrm{gpm})$ on the first day to less than $2 \mathrm{l} / \mathrm{s}(35 . \mathrm{gpm})$ on the eighth day, as was observed in Run Segment 3. Because of high EE-1 injection pressure ( $2600 \mathrm{psi}$ ) at the end of the massive hydraulic fracture experiment, the long-term trend of water loss from this system is not known. However, even at this high EE-1 pressure, long-term water-loss rates may still drop off significantly, as previously occurred for the old system operating at 90 bar ( 1300 psi) in Run Segment 2 (75-day test). 
Test of the Well-Completion System (Pack/Perf Four Sliding Valves). An unsuccessful attempt was made to install a cement-inflatable packer and downhole valve system that would have created three isolated regions of EE-1 for fracture initiation, propagation, and flow-control studies. The events surrounding this particular failure centered around cementing difficulties rather than with the packer and valve mechanism, which were never actually tested (see Sec. 6.3 for details).

4.1.3. Summary of Current Status and Future Plans. The high backpressure heat-extraction experiment did not increase the accessible heattransfer area, but did produce a change in flow impedance over the course of the experiment by approximately a factor of four (2 psi/gpm $\rightarrow 0.5 \mathrm{psi} / \mathrm{gpm})$. A large part of this impedance change appeared to be reversible with temperature and/or pressure of the reservoir.

The recemeriting operation on the bottom $600 \mathrm{ft}$ of the EE-1 casing was successful. This operation isolated the lower open-hole section of .EE-1 and made possible the experiments that led to the new, larger EE-1/GT-2B system.

A tracer $\left({ }^{82} \mathrm{Br}\right)$ flow experiment after completion of recementing showed that flow out of EE-1 occurred at $2932 \mathrm{~m}(9620 \mathrm{ft})$ and that flow up along the casing annulus has been eliminated.

Kine-Frac shots made at various locations in the bottom open-hole section of EE-1 were not successful in the initiation of new flow connections.

The most striking accomplishment of the EE-1 workover program is the successful connection of the wellbores EE-1 and GT-2B by a fracture over a wellbore separation distance of some $300 \mathrm{~m}$. This fracture connection was activated by the MHF operation and characterized by flow experiments carried out before and after the fracture was made. Figure 4-9 is a schematic representation of GT-2B/EE-1 fracture system following the MHF operation. It has evolved from the earlier system shown in Fig. 4-1. The significance of this result is that it demonstrates that the large heat-transfer areas required for large HDR heat-extraction systems can probably be produced in hot crystalline rock by more-or-less standard hydraulic fracturing techniques. A wellbore separation distance of $300 \mathrm{~m}$ is approximately the target for the initial Phase II Fenton $\mathrm{Hill}$ system. 
Seismic detection equipment was operated downhole during a large part of the massive hydraulic fractures test. Acoustic (or microseismic) events were detected during fracture inflation at a rate that approached one event per second at maximum (see Sec. 5.1).

The geophone package was oriented successfully by response to detonator shots fired in EE-1. This should allow mapping of the events detected during fracture extension (see Sec. 5.1).

It will be a major objective of the FY80 program to characterize this newly activated EE-1/GT-2B system. Future tests will attempt to determine the effective heat-transfer area, the flow impedance, the dispersion and mixing, the geochemistry, and the rate of water loss during long-term (3- to 6-month) circulation.

Some re-evaluation of techniques for fracture initiation (such as Kine-Frac) and for flow control into fractures will occur in FY80.

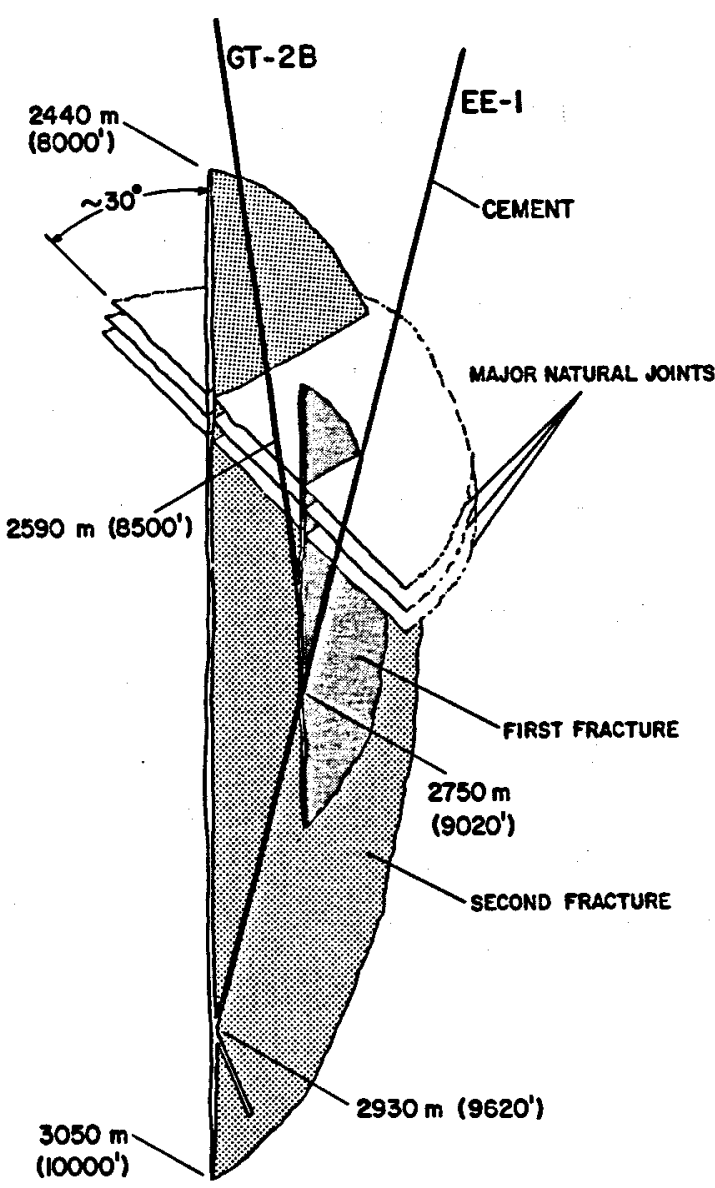

Fig. 4-9. Gt-2B/EE-1 fracture system.

4.2. Engineering Development (Phase II) System (J. H. Hill, R. E. Williams, and Geothermal Operations Staff)

The creation of a new and larger heat-extraction system, the Phase II system, at Fenton $\mathrm{Hill}$ was begun in FY79. Its objectives are a minimum rock temperature of $250^{\circ} \mathrm{C}$, thermal power of $20 \mathrm{MW}$ or greater, and thermal drawdown not to exceed $20 \%$ in 10 years of continuous operation. Planning of the necessary drilling and fracturing operations began in FY78. Completion is planned for FY80.

Certain engineering activities required by this new system were performed during FY79 and are covered in this section. These activities include the 
drilling of EE-2 (partially completed in FY79), the preparation of a drilling plan for the second hole (EE-3), and the design and procurement of portions of the surface facilities for the new higher power heatextraction loop.

4.2.1. Drilling of EE-2. The Phase II system at Fenton Hill will comprise two new deep holes directionally drilled so that they can be connected together by multiple, paralle1, planar fractures that provide a total heat-transfer surface of at least $500000 \mathrm{~m}^{2}$. A schematic of the wellbore/fracture system is shown in Fig. 4-10. Drilling of EE-2 began in April 1978 and the drilling of EE-3 will begin in calendar year 1980 .

The drilling $p l a n$ for EE-2 specifies drilling to approximately $4300 \mathrm{~m}$ (14 000 $\mathrm{ft}$ ), a depth that--based on the thermal gradient measured in the existing holes-should reach rock at the required temperature. - The hole is to be substantially vertical in its upper section, most of the drilling being done with 12-1/4-in. bits, but is then to be deviated, starting at approximately $1975 \mathrm{~m}(6500 \mathrm{ft})$, to produce an open section approximately $610 \mathrm{~m}$ (2000 ft) in length and $8-3 / 4$ inch in diameter, inclined at approximately $35^{\circ}$ to the vertical. This lower section is to constitute the heat-producing zone.

To aid in the planning and execution of the drilling program, LASL has

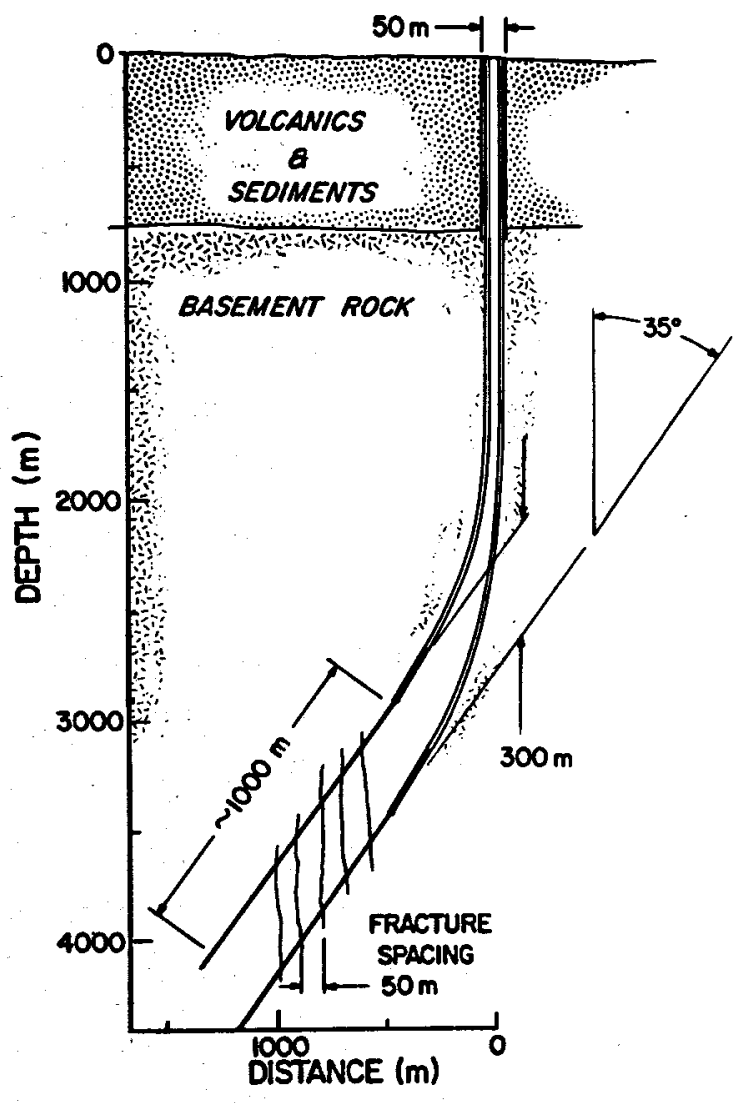

(a)

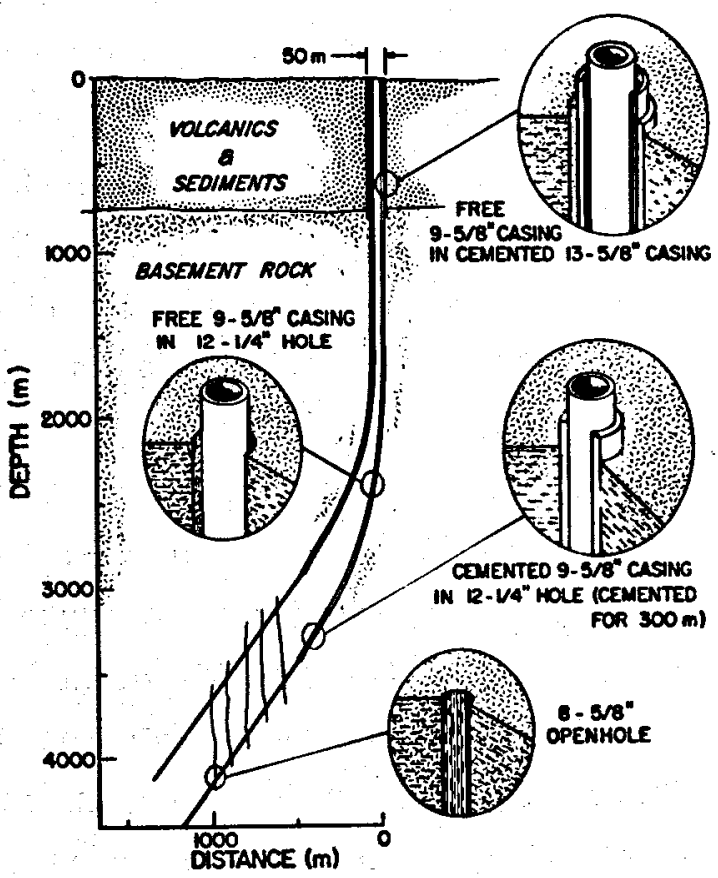

(b)

Fig. 4-10.

Phase II (EE-2) wellbore fracture system. 
retained under contract the firm of Grace, Shursen, and Moore Associates (GSM) of Amarillo, Texas. A detailed drilling program for EE-2 was prepared by GSM and submitted to LASL on October 1, 1978. Appendix E is a tabular summary of the drilling plan that has been extracted from the document prepared by GSM.

As was the case in previous drilling campaigns at Fenton Hill, the drilling is being done by a comercial operator (in this case; Brinkerhoff/ Signal). The drilling contract was let by DOE/ALOO and the work is covered by Davis Bacon Act requirements. Technical responsibility rests with LASL.

The plan used in drilling the hole follows the major features of the plan prepared by GSM, although some changes have been made. The most important departures from the plan have been necessary due to equipment and formation problems encountered in the field. These have had a strong affect on schedule and cost. The problems and the steps required to deal with them are covered below in the drilling history.

Site preparation for the drilling of EE-2 at Fenton Hill started in February 1979 and was completed by the end of the first week in March. Preparatory work included the placement of 28-in. conductor pipe to a depth of $83 \mathrm{ft}$. The Brinkerhoff-Signal drilling rig (No. 56) was mobilized on site and started the drilling of EE-2 on April 3, 1979.

Drilling of EE-2 progressed to $10067 \mathrm{ft}$ below the rig floor (Kelly bushing) by the end of FY79 (September 30, 1979). Initial drilling was done with 26-in.-diam 3-cone roller bits, steel-toothed, through the conductor pipe to a depth of $21785 \mathrm{ft}$. A 20-in.-diam surface casing was then placed and cemented in this hole. Drilling continued through and below the surface casing using 17-1/2-in.-diam drill bits, both steel-toothed and tungstencarbide button type, to a depth of $22593 \mathrm{ft}$. At this depth an intermediate casing, 13-3/8-in. diam was set and cemented in place. Below the intermediate casing, drilling was with 12-1/4-in.-diam tungsten-carbide button roller cone bits to 10 067-ft depth on September 30, 1979. It is planned to set 9 5/8-in. casing inside the 12-1/4-in. hole at a later date.

The planned depth for the 12-1/4-in.diam hole and its casing is 11576 $\mathrm{ft}$, followed by $\sim 40 \mathrm{ft}$ of transition diameter to the final 8-3/4-in. diam, which will be drilled to total depth (TD). This final diameter is to remain as uncased open hole with the 9-5/8-in. production casing set and cemented above it. 
Problems have occurred during drilling, which have delayed the operation to various degrees. Figure 4-11 is a plot of EE-2 hole penetration vs date and days since start of drilling. This figure indicates, by use of reference letters, events of significance as drilling progressed; these events are described below in chronological order. Depths are stated as measured along the rig's drill string from the top of the Kelly bushing. Elevation at that point is $8719.76 \mathrm{ft}$

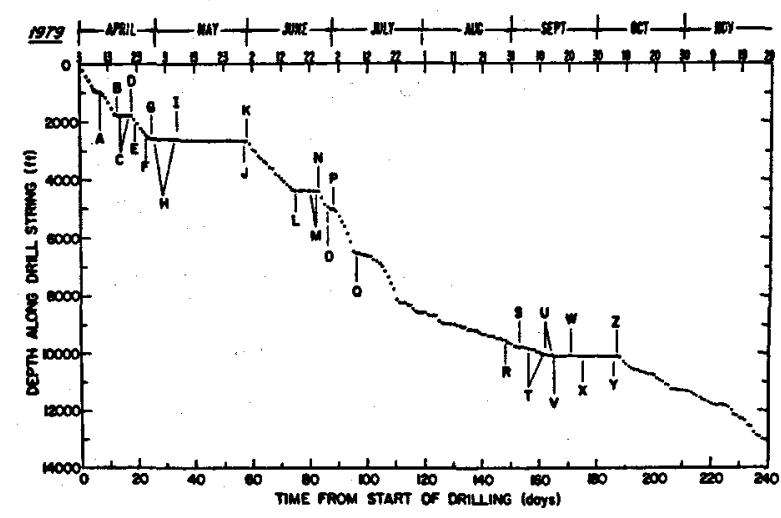
above mean sea level and $\sim 27 \mathrm{ft}$ above ground level.

Event

A

B

C

D

E

\section{Description}

While drilling 26-in.-diam hole, drilling fluid circulation was lost to the formation at $1037 \mathrm{ft}$. Loss zone was plugged by pumped lost circulation material (cotton-seed hulls).

B Completed drilling of 26-in.-diam hole for 20-in.-diam surface casing to $1785 \mathrm{ft}$. Penetration rate average was $137.3 \mathrm{ft} /$ day.

A 20-in.-diam surface casing was run to $1785 \mathrm{ft}$, cemented in place, and welded to the wellhead landing base at the cellar floor level.

Drilling resumed through and below the 20-in. casing using a 17-1/2-in.-diam bit, for the 13-3/8-in.-diam intermediate casing. While drilling to the day's depth of $1909 \mathrm{ft}$, a second drilling-fluid circulation loss occurred. This loss was determined to be between $1883 \mathrm{ft}$ and $1890 \mathrm{ft}$. Lost circulation material was pumped and successfully halted the loss of drilling fluids. Drilling resumed.

F A third loss of circulating fluids occurred at $2354 \mathrm{ft}$. Drilling continued without returns to $2463 \mathrm{ft}$. First indications of granite required change from steel-toothed bits to tungsten-carbide insert button bits at this depth. 
Drilling of 17-1/2-in.-diam hole completed at $2593 \mathrm{ft}$ at an average rate of $101 \mathrm{ft} /$ day. First indications of a cavern, which is thought to be between $2354 \mathrm{ft}$ and $2360 \mathrm{ft}$. Plan was formulated to cement a plug through the cavern region.

Attempts to set cement plugs below the cavern region and above the surface of the granite were unsuccessful. After considerable reaming of caved and sloughed material coming from the open hole, an attempt was made to run the 13-3/8-in. casing. This attempt had to be abandoned when it was found impossible to lower the casing below about $2260 \mathrm{ft}$. Following more reaming, the running and landing of the 13-3/8-in. casing was finally achieved. The first attempt to cement the bottom of this casing failed, apparently because of cementing hardware failure. A second attempt apparently worked, as did the cementing of an upper stage of the casing string at $1762 \mathrm{ft}$.

Shortly after the cement from the above cementing operation had been drilled out, there were definite indications of structural damage to the 13-3/8-in. casing. The damage appeared to be in two regions: the first started at $\sim 2380 \mathrm{ft}$ in the region between the cavern and the surface of the granite; the second was a region we 11 into the granite, approximately in the 2430 to $2465-\mathrm{ft}$ region. Continued drilling and reaming in the $2380-\mathrm{ft}$ region resulted in a complete loss of circulation, presumably because a gap had been drilled in the casing body. Cementing operations plus drilling finally resulted in what was essentially a sidetracking operation. Somewhere in the 2380 to $2420-\mathrm{ft}$ region, a new hole was started into the granite and the original hole below ح2405 ft was abandoned. Drilling resumed (after setting a cement plug) with 12-1/4-in.diam bits. The fifth loss of circulation occurred at $2405 \mathrm{ft}$, sixth at $2499 \mathrm{ft}$, seventh at $2602 \mathrm{ft}$, and eighth at $2641 \mathrm{ft}$. Each loss of drilling fluids required a cement plug.

$\mathrm{J}$ After the eighth loss of drilling fluids, a massive cementing attempt was planned and implemented. The cementing attempt was successful and stopped the loss path into the cavern. 
$K \quad$ Continued drilling (12-1/4 in.) increased the hole depth to 4340 ft. At that depth, drilling was interrupted by a break in the drill string.

$L \quad$ The broken portion of the drill string was removed from the hole with the use of a special retrieval device. After trying to resume drilling, two blades of a reamer/stabilizer tool broke loose and fell to the bottom of EE-2. The blades were ground up by a milling cutter to facilitate removal.

Drilling once again started with penetration from $4340 \mathrm{ft}$ to 4362 $\mathrm{ft}$ at which depth a ninth loss of circulation fluids occurred. This loss was at $22400 \mathrm{ft}$; a cement plug successfully blocked the loss, which was through a break in the 13-3/8-in. intermediate casing.

Drilling resumed through the cement plug to $4855 \mathrm{ft}$.

A test run of the Maurer turbodrill was made to check it out for future use as a directional drilling tool. The test run drilled $57 \mathrm{ft}$ of hole to $4912 \mathrm{ft}$ and was considered successful. A return to rotary drilling followed.

At $5012 \mathrm{ft}$, while drilling, a crossover sub in the drill collar string broke. The broken portion of the drill string was removed from the hole. Drilling was resumed to $6492 \mathrm{ft}$. Rotary drilling was halted to allow planned use of downhole motors for changing the hole direction toward the northeast and to build the inclination angle to $\sim 35^{\circ}$ to the vertical.

Q Directional drilling with a series of downhole motors (Dyna-Drill, Baker, and Maurer turbodrili) started at $6492 \mathrm{ft}$.

$R$ The initial directional drilling effort was completed at a hole depth of $9531 \mathrm{ft}$. Some rotary drilling and reaming runs were made during the period between " $Q$ " and " $R$ " to straighten the hole and remove hole taper caused by the fast rotation and bit wear of downhole motors.

S Drilling with a rotary drill string continued to $9766 \mathrm{ft}$ with unacceptable drift in direction to the north. At this depth it was decided to make a corrective run to change direction more toward the east. This run was made with the Maurer turbodrill motor, and was followed by a run with the Baker motor to a depth of $9835 \mathrm{ft}$. 
A second attempt to correct the hole direction was made using the Maurer turbodrill motor. This attempt changed direction enough to the east (N7OE) by the time $10035 \mathrm{ft}$ was reached so that rotary drill string drilling was resumed. While reaming to the bottom of EE-2 (10 $035 \mathrm{ft})$, the tenth loss of circulating fluids occurred. This loss was at the 1797-ft depth. A cement plug was set at the loss depth and it successfully stopped the fluid loss.

Rotary drilling resumed, after drilling through the cement plug, and to a depth of $10067 \mathrm{ft}$, when a drill-pipe twistoff occurred. Recovery operations were immediately undertaken.

W A wireline cable and tool were run downhole into the stuck dri11pipe string to measure torque and stretch of the stressed drill pipe. The cable parted approximately $8000 \mathrm{ft}$ above the tool and a prolonged fishing operation was necessary.

$x$ The drill pipe above the wireline break was removed from the hole and then, with the use of a three-pronged retrieval tool (Fig. 4-12), the wireline was grappled (Fig. 4-13) and brought to the surface.

Y After several unsuccessful attempts, the remaining stuck drill string was recovered from the hole.

Z Rotary drilling with 12-1/4-in.-diam bits was resumed at $10067 \mathrm{ft}$.

The drilling of EE-2 was not completed during the period covered by this report. However, some comments on the operation to this point may be useful. A comparison of the actual drilling history of EE-2 (Fig. 4-11) with the plan as proposed by GSM (App. E) shows that the major aspects of the plan were indeed followed in the field, but that the amount of time taken to drill the hole has exceeded the target by a considerable amount. (Approximately 160 days were required to reach a depth of $10000 \mathrm{ft} v \mathrm{vs}$ the target of approximately 60 days.)

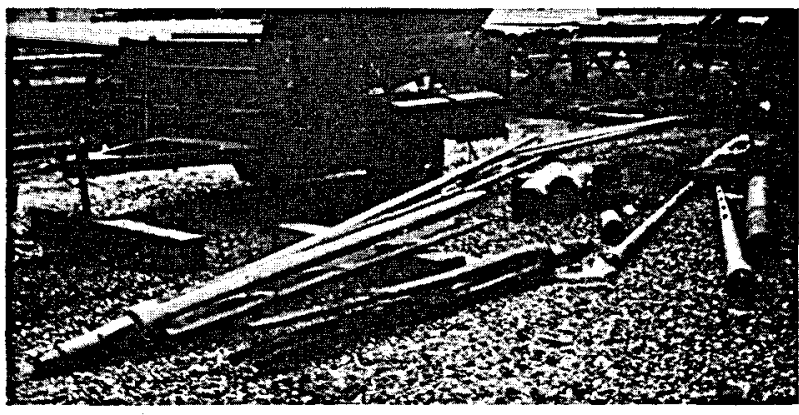

Fig. 4-12. Three-pronged retrieval tool. 
An examination of the drilling history shows that the following items contributed in large part to deviations from the schedule.

1. The occurrence of repeated episodes of lost circulation. Each of these interrupted drilling and consumed time while remedial action was taken. There is evidence to indicate that the 13-3/8-in. casing was damaged during installation in the hole or soon thereafter and that this resulted in lost circulation on later occasions. Total lost time was approximately 30 days.

2. Twist-offs and/or other types of failure of the drill string while drilling was in progress. On each of these occasions, elaborate and time-consuming retrieval operations were required. Total lost time was approximate $1 y$ 36 days.

3. Directional drilling was necessary to bring the hole to the desired trajectory. Downhole motors were the principal tool used to deviate the hole (see Sec. 6.1). The several types of motors used actually performed well and the hole direction was controlled as desired. However, the total amount of time consumed in bringing the hole to the desired direction was considerably longer than had been scheduled. Several factors contributed to this.

It had been planned that directional work with a downhole motor would deviate the hole from the vertical direction to the required trajectory $\left(35^{\circ}\right.$ from vertical, direction approximately $N 45^{\circ} E$ ) over a short period of drilling, and that drilling along that trajectory could continue with rotary drilling. However, it was deemed advisable to turn EE-2 away from the EE-1/GT-2B system before massive hydraulic fracture experiments were begun in the latter system. Therefore, directional drilling was begun at a depth of $6500 \mathrm{ft}$ and continued to over $10000 \mathrm{ft}$. 
This required some 30 separate runs with downhole motors over a drilling distance of some $1600 \mathrm{ft}$, interspersed with rotary drilling. This was a time-consuming process.

- It was usually necessary to execute a reaming run following a run with the downhole motor in order to bring the hole back to gauge and to remove unacceptably sharp radius of curvature.

- Use of the downhole motor to deviate the hole in the desired direction requires that a downhole steering tool relay accurate information on bit/hole orientation to the drilling engineer on a real-time basis. Considerable difficulty was encountered in the field with failure of the steering tools available for this use in EE-2 (see Sec. 6.1).

4. Bit performance was fair. To drill from $2593 \mathrm{ft}$ to $10037 \mathrm{ft}$ totally in granite, some 63 button insert bits were required (average distance drilled approximately $118 \mathrm{ft}$ ). The GSM plan had called for the use of a much smaller number. An important consideration in bit life was the large distance drilled with downhole motors. However, even taking this fact into consideration, bit performance was less effective than had been projected.

Unfortunate events of the types identified above in drilling EE-2 are by no means uncommon in the drilling of deep holes. However, their occurrence has dramatic and unfortunate effects on the total cost of completing the hole. Taking advantage of the experience gained so far, strong efforts to minimize controllable items of drilling cost will be made in the future.

4.2.2. Plans for EE-3. Preliminary engineering plans have been drawn up for the second wellbore, EE-3, of the Phase II system. These plans will be modified so that the experience gained in drilling EE-2 can be utilized effectively.

4.2.3. Loop Design. The new Phase II heat-extraction system using the EE-2/EE-3 reservoir will require new and/or modified surface components to operate at a power level higher than that of the Phase I system. Steps were taken in FY79 to design the new loop and to initiate procurement of the needed components.

The Phase II loop is being designed to have a heat-rejection capability of $50 \mathrm{MW}(\mathrm{th})$. The design flow rate is $1000 \mathrm{gpm}$ of geothermal fluid with a reservoir in let pressure of 3000 psi maximum. 
Figure 4-14 is a simplified schematic of the loop that will be used during Phase II. Figure 4-15 is more detailed. Starting with the pump station, the operation is as follows. (1) The pumps furnish the head and flow rate required. (2) The inlet control valve adjusts the flow rate to the inlet hole. (3) As the water is circulated through the fracture system, heat is transferred to the water. (4)

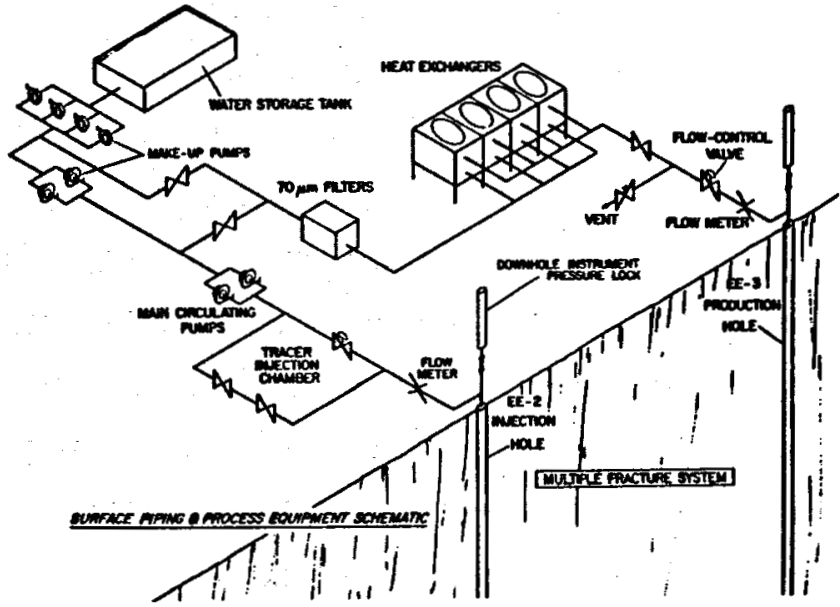

Fig. 4-14.

Simplified schematic of the loop that will be used during Phase II (EE-2).

The outlet control valve main-

tains the desired back pressure on the outlet hole and, hence, in the fracture. (5) The air-cooled heat exchangers reject the heat previously added to the water. (6) The cooled water is returned to the pump inlet. In addition, a makeup water system is provided. This system supplies the water to initially charge the loop initially, and will make up losses during subsequent operations.

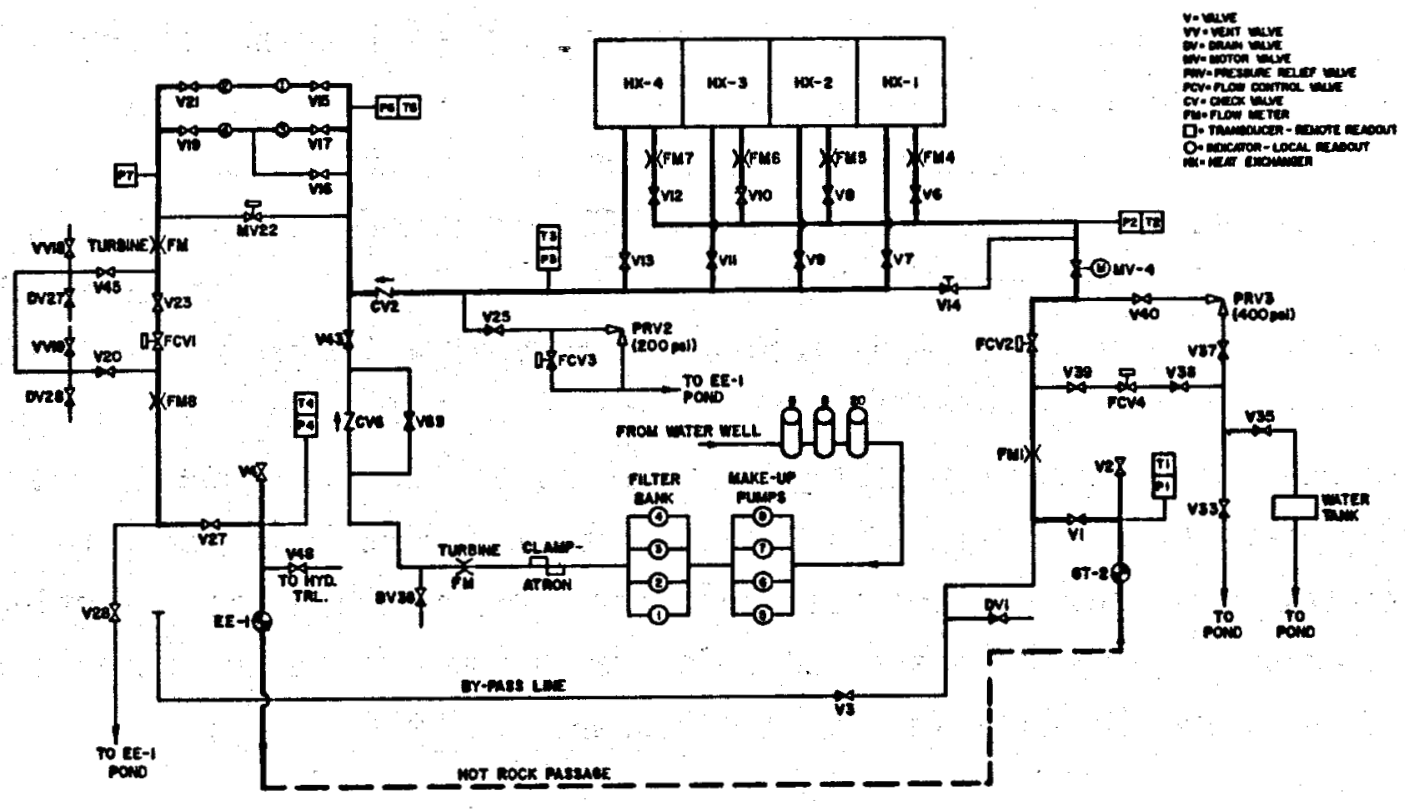

Fig. 4-15.

Detailed schematic of Phase II loop. 
It has been evident that the existing water supply system at Fenton Hill is inadequate for a $50 \mathrm{MW}(\mathrm{t})$ system. A higher capacity well and pump were deemed desirable as well as a much larger storage capacity. These two problems were treated separately.

The present water well is capable of producing $\sim 45 \mathrm{gpm}$. This we 11 , in addition to furnishing water for loop operation, is used for all domestic water at the site. For Phase II operations, a 250-gpm well and pump were thought to be adequate. The specifications for these were written and, at the end of the fiscal year, the contract for them was out for bids. An associated problem is water rights and the DOE is pursuing this problem. Up to seventyfive acre feet per year may be needed initially to operate the Phase II system.

The existing storage capacity is $\sim 500000$ igallons. Up to five million gallons are needed for Phase II operations. Three methods of storage were considered--a dam, a surface tank, and a pond. The dam was rejected because of the complications in obtaining approval to construct such a structure. The storage tank was eliminated because of its high cost. This left the pond. Site location and preliminary engineering drawings have been prepared for it, and efforts to hire an architect-engineer to design the pond are in progress. The we11, pond, and distribution system will be delineated in this design.

\subsection{Environmental Surveillance}

This section provides an overview of ongoing environmental surveillance activities and research efforts in hydrology, seismology, ecology, and climatology. These projects address environmental concerns and requirements regarding the technological development of HDR geothermal resources in general as well as the environmental effects of the Fenton Hill operation. Major efforts of the program have emphasized an integrated and comprehensive assessment to promote a better understanding of environmental issues associated with HDR. Our objectives are to identify areas of potential concern and to suggest or develop methodologies for mitigation of any undesirable impacts to ensure environmental acceptability and readiness for commercialization. Portions of the environmental programs described below are currently being funded through DOE's Office of Health and Environmental Research (OHER). 
4.3.1. Hydrologic. Water quality data from surface and ground-water stations located in the Jemez Mountains and from holding ponds at the Fenton Hill site (Fig. 4-16) have been compiled and analyzed for 1978 and a portion of 1979, and are reported in detail elsewhere. ${ }^{2}$ There have been slight variations in the chemical quality at individual stations. However, these variations in water quality are within normal seasonal fluctuations. The quality of water from the surface water stations has reflected the chemical quality associated with base flow in the drainage area, while the ground-water quality has reflected the rock type of the aquifer. In comparison with chemical data before 1978, no significant change in the quality of water has occurred. ${ }^{3-7}$

Evaluation of the aquifer furnishing water to the Fenton Hill site indicates a transmissivity of about $1200 \mathrm{~m}^{2} /$ day. The specific capacity over a five-day test was $28 \mathrm{l} / \mathrm{s} / \mathrm{m}$ of drawdown. There was a slight increase in total dissolved solids in the well water between 1977 and 1978. A water balance of amount produced at the site indicates $7 \%$ of the water lost to evaporation from the ponds, $31 \%$ lost by infiltration into tuff beneath the ponds, $21 \%$ of the water discharged from the ponds, and $41 \%$ used for downhole experiments, drilling operations, and general site use.

\subsubsection{Seismic. LASL has} maintained seismic coverage of the Fenton Hill HDR site for the last six years. $2,8,9$ A detailed description of the seismic network design and instrumentation may be obtained from Ref. ${ }^{2}$. Initially, there were too few stations to locate events, earthquakes, or explosions smaller

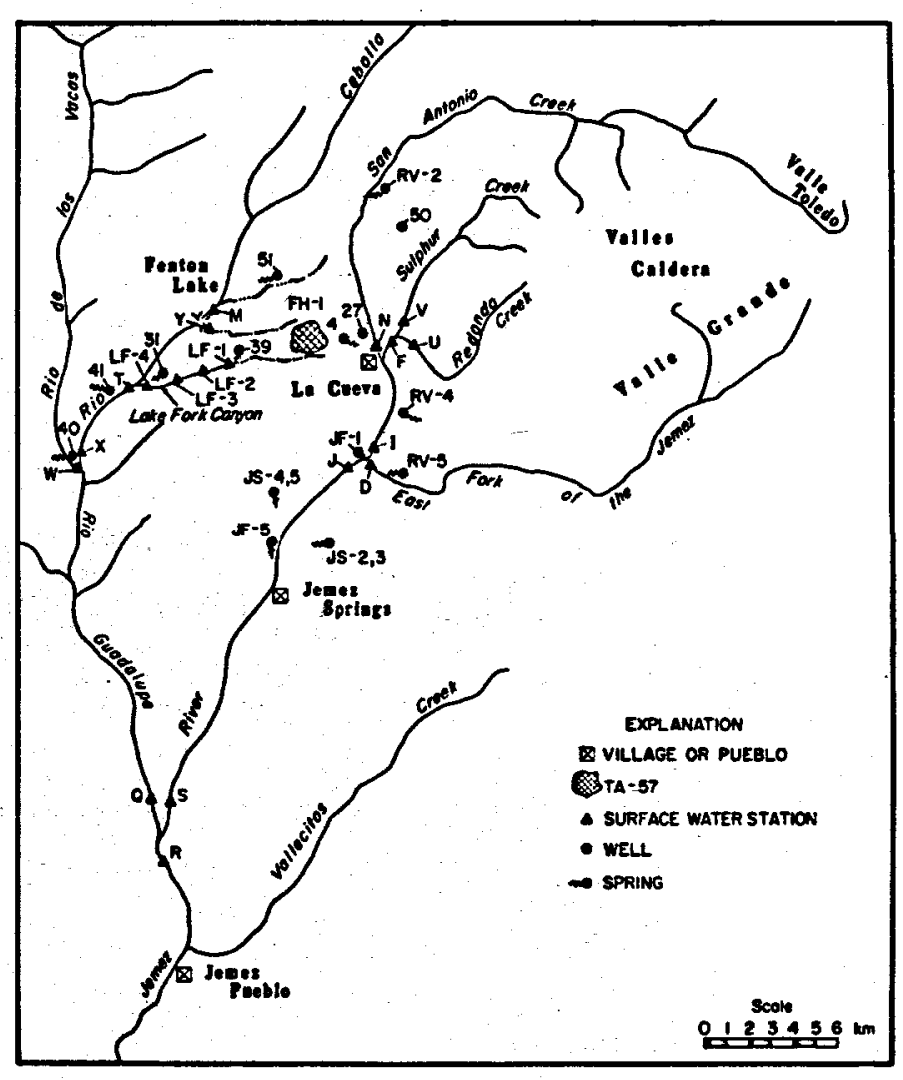

Fiğ. 4-16. Water quality monitoring locations in the vicinity of the HDR Site (TA-57). 
than magnitude $M_{L}=2$, and most locations were less precise than $\pm 10 \mathrm{~km}$. During FY79, several more stations were installed to provide comprehensive coverage for events occurring within a few tens of kilometers of the HDR project site. Detectability of events within a few kilometers is now close to $M_{L}=3$, except during brief periods of adverse noise levels, and location precision is better than one kilometer. Figure 4-17 shows present station locations for the regional and close-in seismic monitoring network. Magnification levels at $10 \mathrm{~Hz}$ are about 350 thousand for the shallow-well stations \30 $\mathrm{m}$ deep (crossed circles), and twice that for the deep-well stations between $150 \mathrm{~m}$ and $230 \mathrm{~m}$ deep (open circles). In addition to the continuous recording of downwell stations, there are five surface stations approximately $750 \mathrm{~m}$ from the geothermal wells from which signals are transmitted by cable to the onsite Control and Data Acquisition (CDA) trailer during pumping experiments. Four additional stations were installed this year, S-1, S-2, S-3, and Well C. Station JOAQ was also installed to improve focal depth determinations for

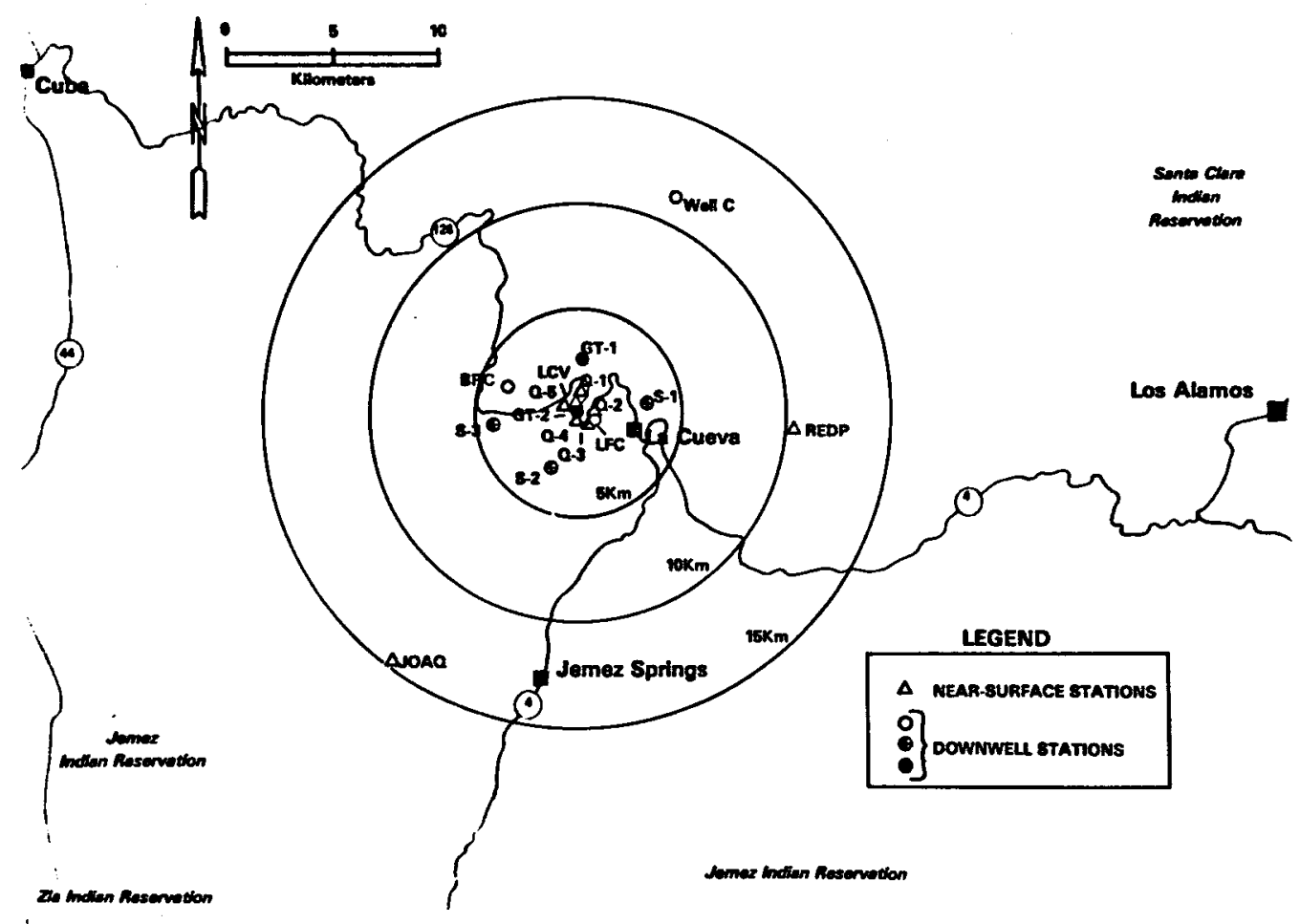

Fig. 4-17.

Fenton Hill area seismic stations. Downwell station depths are indicated by symbols: $10 \mathrm{~m}$ to $30 \mathrm{~m}$ for open circles, $150 \mathrm{~m}$ to $230 \mathrm{~m}$ for crossed circles and $785 \mathrm{~m}$ for solid circles. 
earthquakes occurring in an area $18 \mathrm{~km}$ south southwest of the Fenton Hill HDR site. More than 150 microearthquakes attributed to natural events during the past 15 months have been located in that area.

The regional seismic network located 21 earthquakes within $40 \mathrm{~km}$ of the Fenton Hill HDR site during FY79, as shown in Fig. 4-18. The largest ones were magnitude $M_{L}=1.4$ microearthquakes (Table 4-V) and the focal depths for the nearest events with $M_{L} \geq 1.0$ were computed to be deeper than $6 \mathrm{~km}$.

The only events detected by surface seismic stations that were related to the HDR reservoir during FY79 were two $M_{L} \simeq-1$ microearthquakes that occurred during an experiment in March 1979 when the highest wellhead pressure was about $21 \mathrm{MPa}$. These are the first induced events, since the drilling of GT-2 at Fenton $\mathrm{Hill}$, to be detected above background noise levels at three or more stations. (During the writing of this report in FY80, about seven more $M_{L} \simeq-1$ induced microearthquakes were detected by several surface stations.)

Although we are unable to predict the magnitudes of earthquakes that might be induced by the HDR project, we find a great deal of comfort in the observations to date--namely, we have raised the pore fluid pressure in the vicinity of the wells approximately $20 \mathrm{MPa}$ above hydrostatic pressure, and the largest events that have been induced are several order of magnitude below human preceptibility.

\subsubsection{Ecology. Ecological} investigations of the environs surrounding the Fenton Hill HDR site have been conducted since 1976. These studies were initiated to accomplish four major objectives: (1) establish baseline inventories of ecosystem components; (2) identify and quantify key ecosystem

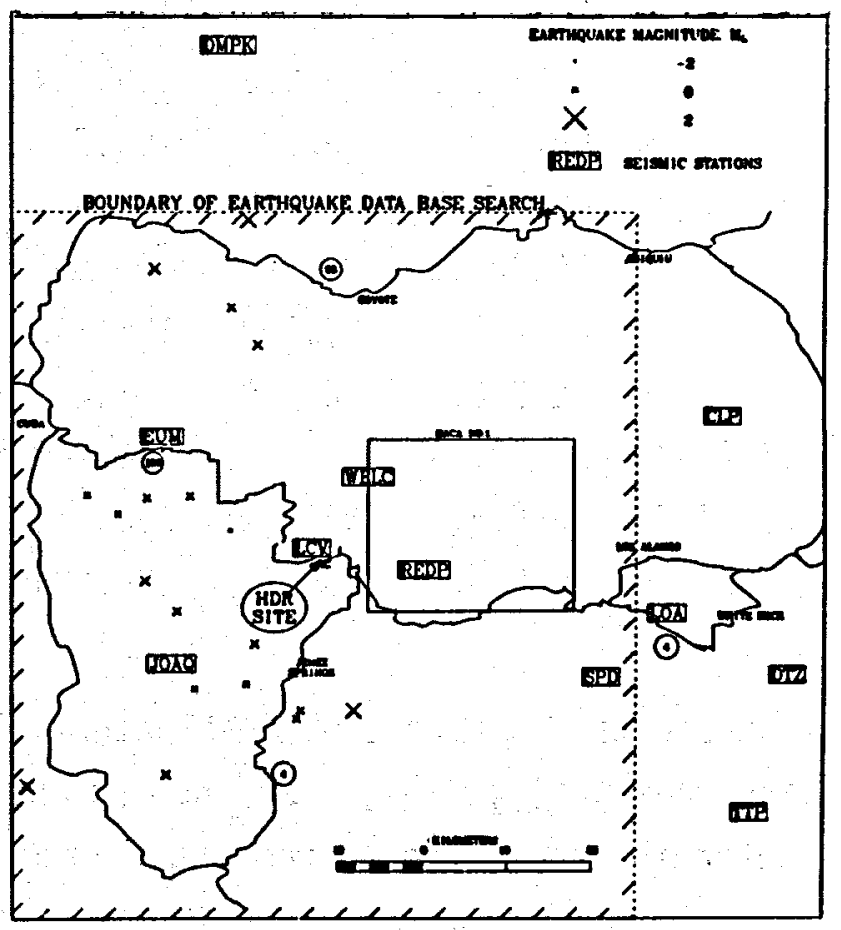

Fig. 4-18. Epicenters of earthquakes located within $40 \mathrm{~km}$ of the HDR Site during FY79. 


\section{TABLE : 4-V}

NETWORK LOCATED EARTHQUAKES DURING FY79.

\begin{tabular}{|c|c|c|c|c|c|c|}
\hline Date & Time & Latitude & Longitude & $\begin{array}{c}\text { Richter } \\
\text { Magnitude } \\
M_{L}\end{array}$ & Depth & Location \\
\hline $10-07-78$ & 231319.3 & 36.111 & 106.738 & 0.7 & 4.6 & NE of Eum \\
\hline $10-10-78$ & 073407.3 & 35.745 & 106.805 & 0.0 & -- & Jemez Swarm Area-Poor \\
\hline $10-29-78$ & 085551.4 & 35.950 & 106.920 & 0.0 & -- & Senorito Area \\
\hline $10-30-78$ & 054614.1 & 35.947 & 106.856 & 0.3 & 9.1 & Senorito Area \\
\hline $11-05-78$ & 000527.8 & 35.750 & 106.750 & -0.4 & 22.9 & Jemez Swarm Area-Poor \\
\hline $11-05-78$ & 064024.6 & 35.750 & 106.750 & -0.4 & 12.7 & Jemez Swarm Area-Poor \\
\hline $11-23-78$ & 050847.6 & 35.750 & 106.750 & 0.0 & 21.5 & Jemez Swarm Area-Poor \\
\hline $12-03-78$ & 035923.0 & 35.653 & 106.836 & 0.7 & 10.7 & Just $N$ W of San Ysidro \\
\hline $12-15-78$ & 001512.1 & 35.949 & 106.810 & 0.3 & 9.2 & Senorito Area \\
\hline $12-26-78$ & 030802.4 & 35.931 & 106.887 & 0.0 & 14.8 & Senor ito Area \\
\hline $01-17-79$ & 113226.3 & 36.242 & 106.748 & 1.4 & 6.9 & Gallina Area \\
\hline $01-20-79$ & 140407.1 & 35.860 & 106.858 & 0.7 & 6.4 & $N$ of Joaq-Fair \\
\hline $01-20-79$ & 151730.9 & 35.828 & 106.824 & 0.5 & 1.1 & $N$ of Joaq \\
\hline $04-07-79$ & 081707.5 & 35.722 & 106.635 & 1.4 & 12.6 & Just.$S$ Jemez Spgs-Fa \\
\hline $04-17-79$ & 090144.2 & 35.713 & 106.696 & 0.3 & 9.8 & Just S Jemez Spgs \\
\hline $04-17-79$ & 102425.6 & 35.722 & 106.692 & 0.3 & 8.5 & Just $S$ Jemez Spgs-Fa \\
\hline $06-13-79$ & 022251.0 & 35.793 & 106.741 & 0.5 & 9.8 & Jemez Swarm Area-Fair \\
\hline $06-25-79$ & 121726.2 & 36.250 & 106.433 & 1.0 & 14.9 & Abiquiu Lake \\
\hline $06-28-79$ & 231239.4 & 36.150 & 106.766 & 0.5 & 13.2 & Gallina Area-Fair \\
\hline $08-14-79$ & 185654.5 & 36.191 & 106.848 & 1.0 & 7.4 & Near Gallina \\
\hline $08-17-79$ & 185538.0 & 35.641 & 106.984 & 1.4 & 7.9 & San Luis Area \\
\hline
\end{tabular}

components from control and potential site impact areas; (3) determine the environmental pathways of the effluents produced by HDR operations; and (4) determine the effects from the Fenton Hill HDR site development and operations on habitat disruptance and natural resources. Studies to date have primarily focused on quantifying the flora and fauna compositions of the area and on a preliminary evaluation of usage of the area by elk and avian species. Results obtained have been reported on an annual basis. ${ }^{2,9}$ Findings to date are discussed here on studies of the flora and fauna. 
The HDR facility is located in a grass-forb complex, which was revegetated with native pasture grasses following a wildfire in 1971. This complex is interspersed with aspen thickets and surrounded by a mixed coniferous forest in various stages of maturity. During 1976, studies of the understory vegetation and small mamals of the region were initiated to define natural variation within this ecosystem, which is highly diverse and undergoing rapid successional changes. Location of the study areas and measurement methodologies used are presented in detail elsewhere. ${ }^{10}$

Tables 4-VI and 4-VII present coverage and frequency of occurrence values for the most common plant species encountered at the Fenton Hill site during 1977 and 1978 in each of the three vegetation types. The grass-forb comunity

TABLE 4-VI

FREQUENCY OF OCCURRENCE OF FLORA SURROUNDING THE HDR.SITE

\begin{tabular}{|c|c|c|c|c|c|c|}
\hline Species & \multicolumn{2}{|c|}{$\begin{array}{lr}\text { Grass } & \text { Forb } \\
77 & 78 \\
\end{array}$} & \multicolumn{2}{|c|}{$\begin{array}{cc}\text { Mixed Conifer } \\
77\end{array}$} & \multicolumn{2}{|c|}{$77^{\text {Aspen }} 78$} \\
\hline Achillea lanulosa & 12.5 & 9.0 & 11.7 & 9.0 & - & 2.0 \\
\hline Agropyron trachycaulum & 2.5 & - & - & - & - & - \\
\hline Arctostaphylos uva-ursi & - & 3.0 & - & 24.0 & - & - \\
\hline Berber is repens & - & 10.0 & - & 1.0 & - & 24.0 \\
\hline Bromus inermis & - & 1.0 & 16.7 & - & - & - \\
\hline Chimaphila umbellata & - & - & - & 6.0 & $-\cdots$ & 10.0 \\
\hline Dactylis glomerata & 40.0 & 13.0 & - & - & 15.0 & 6.0 \\
\hline Festuca pacifica & - & 3.0 & - & - & - & - \\
\hline Fragaria bracteata & - & 6.0 & - & 13.0 & - & - \\
\hline Koeleria cristata & 3.8 & - & 41.7 & - & 12.0 & - \\
\hline Medicago sativa & 1.3 & - & - & - & - & - \\
\hline Melilotus albus & 2.5 & - & - & - & - & - \\
\hline Muh lenbergia montana & - & - & 10.0 & - & - & - \\
\hline Phleum pratense & 41.3 & 9.0 & - & - & 9.0 & 5.0 \\
\hline Potentilla spp & - & - & - & 1.0 & - & - \\
\hline Senecio spp & - & - & - & 3.0 & - & - \\
\hline Sitanion hystrix & - & 2.0 & - & 2.0 & - & - \\
\hline Taraxacum laevigatum & - & - & 3.3 & - & - & - \\
\hline
\end{tabular}


TABLE 4-VII

MEAN COVERAGE OF COMMONLY OCCURRING VEGETATIVE SPECIES AT THE HDR SITE

\begin{tabular}{|c|c|c|c|c|c|c|}
\hline Species & \multicolumn{2}{|c|}{ Grass Forb } & \multicolumn{2}{|c|}{$\begin{array}{rr}\text { Mixed Conifer } \\
78\end{array}$} & \multicolumn{2}{|c|}{ Aspen } \\
\hline Achillea lanulosa & $15(<5-30)$ & $17(5-35)$ & $4(<5-10)$ & $7(<5-20)$ & - & $30(2.0-40)$ \\
\hline Agropyron trachycaulum & $60(30-90)$ & - & - & - & - & - \\
\hline Arctostaphylos uva-ursi & - & $30(10-35)$ & - & $27(5-65)$ & - & - \\
\hline Berberis repens & - & $11(<5-20)$ & - & $5(5)$ & - & $13(<5-40)$ \\
\hline Bromus inermis & - & $25(25)$ & $6(<5-10)$ & - & - & - \\
\hline Chimaphila umbellata & - & - & - & $5(5-10)$ & - & $7(<5-2.5)$ \\
\hline Dactylis glomerata & $18(5-55)$ & $16(5-35)$ & - & - & $24(10-50)$ & $7(<5-15)$ \\
\hline Festuca pacifica & - & $5(<5-10)$ & - & $12(<5-30)$ & - & - \\
\hline Fragarla bracteata & - & $9(5-20)$ & - & $3(<5-5)$ & - & - \\
\hline Koeleria cristata & $12(10-20)$ & - & $11(5-30)$ & - & $13(5-60)$ & - \\
\hline Medicago sativa & $20(20)$ & - & - & - & - & - \\
\hline Melilotus albus & $6(6)$ & - & - & - & - & - \\
\hline Muhlenbergia montana & - & - & $10(<5-20)$ & - & - & - \\
\hline Phleum pratense & $18(5-40)$ & $13(5-20)$ & - & - & $14(5-35)$ & $15(<5-45)$ \\
\hline Potentilla spp & - & - & - & $5(5)$ & - & - \\
\hline Senecio spp & - & - & - & $13(<5-35)$ & - & - \\
\hline Sitanion hystrix & - & $16(10-20)$ & - & $3(<5-5)$ & - & - \\
\hline Taraxacum laevigatum & - & - & $3(<5)$ & - & - & - \\
\hline
\end{tabular}

is dominated by members of the Gramineae family, with timothy (Phleum pratense) and orchard grass (Dactylis glomerata) occurring in plots most frequently in both years. The mixed conifer and aspen communities have a rich understory of shrubs and forbs, with grasses less dominant. Variances in values for all vegetative types between 1977 and 1978 were attributed to seasonal effects and different sampling times.

Results from three years of small mamal trapping indicate that the deer mouse (Peromyscus maniculatus) is the most trappable species across all community types studied. Other species frequently trapped include the least chipmunk (Eutamias minimus), golden mantled squirrel (Spermophilus lateral is), and the montane vole (Microtus montanus). The deer mouse comprised 95 to $100 \%$ of all captures in the grass-forb complex and greater than $50 \%$ of the captures in the remaining vegetation types. The abundance of small mammals doubled from 1976 to 1978, apparently a reflection of improved habitat as a result of the wildfire.

Results of all data gathered to date indicate no demonstrable effect or impact from operations conducted at Fenton Hill. Future program initiatives 
will evaluate and assess the potential impact from HDR effluents on selected species of flora and fauna, identified by these studies as key ecosystem components. Essential to these program efforts will also be identification of pathways and transfer mechanisms for HDR effluents.

4.3.4. Climatological. Meteorological data have been collected for three years at the Fenton Hill HDR geothermal site in support of environmental studies. One purpose of the data is to establish a local climatic baseline against which possible induced climate changes may be evaluated. Also, it is important to have estimates of the wind field to maintain the capability to assess the transport of airborne pollutants that may emanate from the drilling and heat-exchange operations. In view of proposed expansion of a geothermal industry in the Valles caldera area, good estimates of the meteorological structure will be invaluable in identifying the correct sources of trace gases such as $\mathrm{H}_{2} \mathrm{~S}$. An additional requirement for meteorological data is in engineering design and operational safety questions (e.g., temperature, pressure, wind chill, structural wind loading). As industrial activity increases in the Valles Caldera, the Fenton Hill meteorological site will become an important baseline station in a network of observation sites. With these considerations in mind we have conducted analys is on the first three years of record and designed an expanded measurement system that will allow us to address a broader range of questions.

Surface Meteorological Survey. Winds and temperatures have been recorded since 1976 by means of a mechanical weather station mounted on a $15-m$ tower. Pressure and humidity have been recorded during 1979 in an instrument shelter at $1.5 \mathrm{~m}$ above ground. The tower and shelter are located on the Fenton Hill site. Supplemental upper air data were collected using pilot balloons on an approx imately weekly case study basis.

The Fenton Hill site is at $2651-m$ elevation on a relatively flat knoll that separates two major canyons. Southeast through west to northwest of the knoll is quite unobstructed, although winds with significant northerly or easter ly components must pass over or around topography above $3300 \mathrm{~m}$. Several questions of topographic influence enter into the analysis of wind observations. If we can determine some topographic driving influence such as drainage or obstacle flow phenomena, then we have a basis for estimating the region 
of representativeness of a single wind station and a basis for estimating air. trajectories and potential pollution receptor locations.

Figure 4-19 shows wind roses for each season compiled from the three-year record. Winter has a west to northwest predominance that gradually diminishes through spring to a southerly maximum occurrence in sumer. Autumn and spring wind roses are quite similar. A breakdown of the winter wind rose by diurnal periods was also examined. The most distinctive difference from day to night is the growth of a northerly maximum in the moderate speed range (1.5 to 3.0 $\mathrm{m} / \mathrm{sat}$ night. The sumer nighttime winds reflect a dominant component from the southeast that turns to southerly and westerly dominance during the day accompanied by an increase in wind speed. A secondary maximum occurrence of northerly flow at night is similar to the winter night case.

We can attempt to identify the major driving forces for the winds and to distinguish diurnal and seasonal differences in driving force that relate to the variations in winds. The daytime winds generally reflect the large-scale pressure gradient flow, which exhibits westerly dominance throughout the year in northern New Mexico. The winter northwesterly and sumer southerly components are consistent with the seasonal pressure patterns. The situation at night becomes more complicated. Some nights, local temperature differences on sloping surfaces produce local circulations that are generally shallow and frequently are decoupled from wind fields that exist above by virtue of stable vertical temperature lapse rates that strongly damp turbulent momentum transfer; other nights, the mechanical turbulence generated by the interaction of the large-scale winds with the ground is sufficient to overwhe im the locally driven winds. Two features of the wind roses reflect local wind patterns on perhaps two different scales. First, the northerly wind in both winter and sumer lines up with a weakly defined topographic channel between the San Pedro mountains and Redondo Peak and also with San Antonio Creek Canyon that borders the site. The other characteristic feature is an easterly component that exists at night, but is seldom observed during the day. The easterly wind appears to be vectorially added to the existing gradient flow producing resultant winds that include northeast and southeast directions. The source of the easterly component could be a slope wind induced by Redondo Peak or the initial stages of drainage flow into one of two canyons that border the site on the northeast and south sides, respectively. 

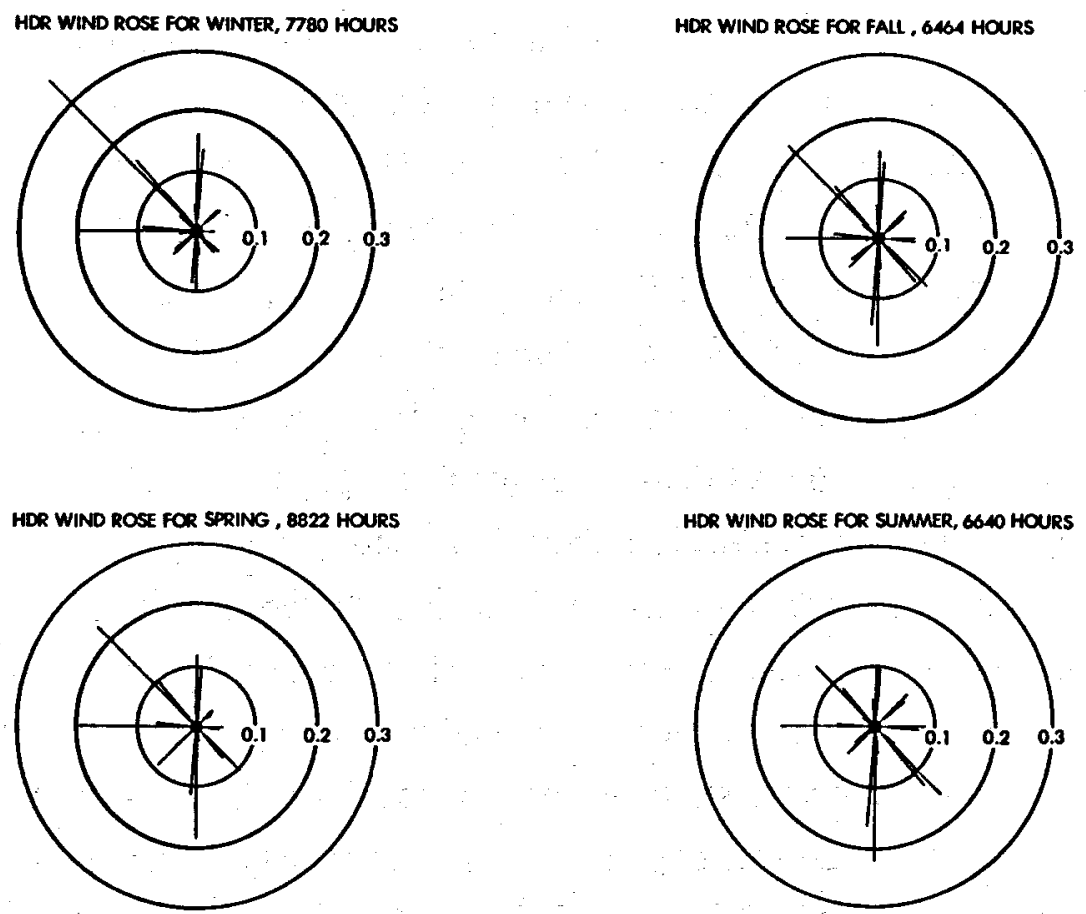

Fig. 4-19.

HDR wind rose by season based on three years of recorded wind data.
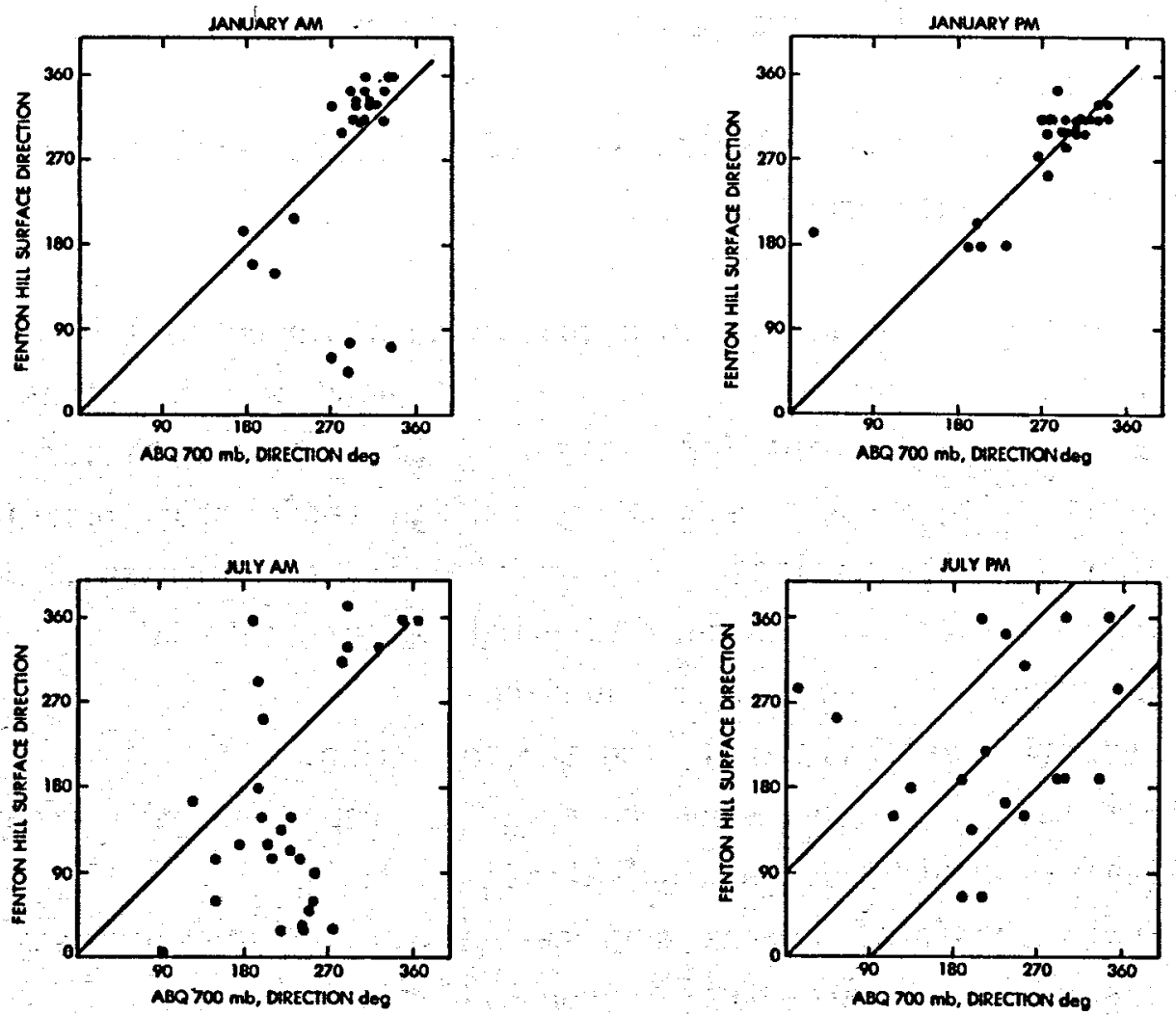

Fig. 4-20.

Scatter diagram of Fenton $\mathrm{Hill}$ and Albuquerque wind directions. 
In an effort to relate surface-based wind observations to an indicator of the large-scale synoptic flow, a pair of one-month winter and sumer season samples was selected and scatter diagrams (Fig. 4-20) were made. The 700 millibar (approximately $3 \mathrm{~km}$ above sea leve1) wind direction from the Albuquerque radiosondes at 0500 MST and 1700 MST were chosen to represent the free-air wind direction near the altitude of Fenton Hill, and concurrent surface winds at Fenton $\mathrm{Hill}$ are plotted against this indicator. The winter afternoon shows a good correlation between large-scale flow and the surface winds. At night, the correlation remains good except for two departures. There is a tendency for the Fenton Hill winds to be shifted about $30^{\circ}$ to the north from the free-air wind direction. This could be the result of channeling between Redondo Peak and the San Pedro mountains. The other exception is a small cluster of points showing northeasterly surface flow with west to northwest wind in the free atmosphere. The easterly component may reflect a decoupled surface wind of local origin. The summer nocturnal winds are essentially uncorrelated with the free-air wind directions (Fig. 4-20). The correlation between daytime wind directions is not much higher. Apparently, some nonpersistent local effect (e.g., thermal convection) has an influence on the local surface winds.

Table 4-VIII presents selected statistics on temperature and precipitation for the three-year record of data.

Winds Aloft Survey. Surface meteorological data tends to be influenced by local topographic and vegetative features. A good way to assess the usefulness of a measurement point for estimating trajectories that cover an area about the point is to obtain vertical soundings above that location. Local influences that dominate winds near the ground tend to diminish with altitude, leaving a greater spatial coherence of wind measurements at several hundred meters above ground. A program of soundings for winds aloft was established to address several questions, including the following.

How we 11 do Albuquerque upper winds represent the free-air winds (above boundary domination) at Fenton Hi11?

How representative are surface-based tower measurements for plume transport est imates from Fenton Hill site?

Are there consistencies in the structure of the wind profiles that can lead to an understanding of the basic phenomena governing the 
TABLE 4-VIII

FENTON HILL METEOROLOGICAL DATA FOR 1976, 1977, AND 1978

\begin{tabular}{|c|c|c|c|c|c|c|c|c|c|c|}
\hline \multirow[b]{3}{*}{ Month/Year } & \multicolumn{7}{|c|}{ Temperatures $(\mathrm{C})$} & \multicolumn{3}{|c|}{ Precipitation (mm) } \\
\hline & \multirow[b]{2}{*}{$\begin{array}{l}\text { Daily } \\
\text { Max. }\end{array}$} & \multicolumn{2}{|c|}{ Average } & \multicolumn{4}{|c|}{ Extreme } & \multirow[b]{2}{*}{ Total } & \multirow[b]{2}{*}{$\begin{array}{c}\text { Greatest } \\
\text { Day } \\
\end{array}$} & \\
\hline & & $\begin{array}{l}\text { Dailly } \\
\text { Min. }\end{array}$ & Monthly & Highest & Date & Lowest & Date & & & Date \\
\hline January 1976 & $\mathbf{0}$ & -10 & -6 & 8 & 28 & -22 & 2 & 4.8 & 3.3 & 24 \\
\hline February & 1 & -6 & -3 & 8 & 1 & -16 & 21 & 41.4 & 11.4 & 13 \\
\hline March & 1 & -7 & -3 & 9 & 25 & -17 & 5 & 17.5 & 4.3 & 28 \\
\hline April & 6 & -2 & 2 & 12 & 10 & -13 & 17 & 21.1 & 10.4 & 15 \\
\hline May & 12 & 2 & 7 & 18 & 15 & -6 & 8 & 45.0 & 21.8 & 6 \\
\hline June & 19 & 8 & 14 & 26 & 28 & 2 & 15 & 6.1 & 3.5 & 6 \\
\hline July & 19 & 10 & 14 & 25 & 10 & 4 & 24 & 74.9 & 18.8 & 21 \\
\hline August & 18 & 9 & 13 & 23 & 12 & 4 & 2 & 69.1 & 15.8 & 18 \\
\hline September & 14 & 6 & 10 & 22 & 4 & -1 & 28 & 45.7 & 10.7 & 20 \\
\hline October & 7 & 0 & 3 & 18 & 10 & -7 & 19 & 4.8 & 3.3 & 23 \\
\hline November & 2 & -2 & -1 & 12 & 6 & -23 & 28 & 17.5 & 17.5 & 27 \\
\hline December & 1 & -7 & -4 & 8 & 3 & -13 & 6 & 8.6 & 5.3 & 31 \\
\hline January 1977 & 3 & -9 & -8 & 10 & 19 & -20 & 9 & 48.5 & 11.4 & 1 \\
\hline February & 2 & -7 & -3 & 9 & 20 & -16 & 26 & 17.0 & 8.9 & 2 \\
\hline March & 0 & -8 & -4 & 9 & 8 & -15 & 3 & 16.0 & 8.9 & 4 \\
\hline April & 7 & -1 & 3 & 14 & 8 & -12 & 4 & 45.3 & 12.2 & 3 \\
\hline May & 12 & 2 & 8 & 20 & 31 & -2 & 15 & 25.4 & 16.8 & 12 \\
\hline June & 21 & 11 & 16 & 26 & 17 & 6 & 7 & 6.4 & 2.5 & 24 \\
\hline July & 20 & 11 & 15 & 26 & 30 & 5 & 9 & 76.2 & 17.5 & 4 \\
\hline August & 20 & 11 & 15 & 26 & 2 & 7 & 12 & 113.8 & 33.8 & 15 \\
\hline September & 15 & 8 & 11 & 22 & 8 & 3 & 12 & 26.9 & 13.0 & 12 \\
\hline October & 12 & 4 & 7 & 17 & 4 & -3 & 11 & 8.1 & 4.1 & 6 \\
\hline November & 2 & -2 & 1 & 11 & 3 & -17 & 9 & 25.4 & 15.0 & 6 \\
\hline December & 0 & -6 & -4 & 8 & 11 & -17 & 20 & 14.5 & 4.1 & 28 \\
\hline \multicolumn{11}{|l|}{ January 1978} \\
\hline February & -1 & -8 & -6 & 9 & 22 & -22 & 18 & 49.5 & 16.0 & 11 \\
\hline March & 3 & -3 & 0 & 14 & 31 & -12 & 15 & 35.1 & 10.4 & 2 \\
\hline April & 8 & 0 & 4 & 14 & 24 & -6 & 10 & 3.8 & 2.0 & 8 \\
\hline May & 11 & 3 & 7 & 20 & 30 & -7 & 7 & 71.6 & 38.1 & 2 \\
\hline June & 20 & 9 & 15 & 26 & 24 & 3 & 3 & 8.9 & 3.8 & 28 \\
\hline July & 19 & 11 & 17 & 26 & 15 & 7 & 24 & 26.7 & 6.4 & 22 \\
\hline August & 14 & 7 & 13 & 23 & 12 & 4 & 30 & 49.5 & 16.5 & 24 \\
\hline September & 15 & 6 & 10 & 21 & 4 & -1 & 21 & 46.5 & 25.4 & 24 \\
\hline October & 10 & 4 & 9 & 17 & 1 & -1 & 14 & 48.0 & 21.6 & 21 \\
\hline November & - & - & - & - & - & - & - & 95.3 & 27.9 & 4 \\
\hline December & - & - & - & - & - & - & - & 74.4 & 18.5 & 6 \\
\hline
\end{tabular}

The technique required to measure wind aloft is a labor-intensive manual method so that the data set is smaller than from surface observations. A series of soundings was made on an approximately weekly basis, when weather 
permitted, between February and September 1979. Surface-wind directions are we 11 correlated with the winds aloft. The root-mean-square departure between the two sets of observations is only 26.6 degress. Winds at three altitudes were chosen for comparison with Albuquerque winds at equivalent heights. The levels 3.0, 3.5, and $4.0 \mathrm{~km}$ above sea level (MSL) represent elevations near the major ridge tops in the area, near the highest peak, and well above topographic obstacles, respectively. The standard deviation of the departures between Fenton $\mathrm{Hill}$ and Albuquerque wind directions decreases with altitude, suggesting some terrain effect at $3.0 \mathrm{~km}$ that is significantly reduced by $4.0 \mathrm{~km} \mathrm{MSL}$. The mean and standard deviation of departures are given in Table 4-IX.

Meteorological Measurement System. An updated tower-based meteorological observation and recording system has been designed and recently installed at the Fenton Hill site. In addition to wind direction and speed and temperature at two levels $(6 \mathrm{~m}$ and $18 \mathrm{~m})$, precipitation, humidity, and pressure are recorded hourly on magnetic tape casettes. The new system will run concurrently with the existing tower for a comparison period of six months to document changes in the data that may arise from differences in location, instrumentation, recording, and reduction methods.

TABLE 4-IX

MEAN AND STANDARD DEVIATION OF DEPARTURES BETWEEN

SIMULTANEOUS PAIRS OF WIND DIRECTION OBSERVATIONS

Observation Pair

Fenton $\mathrm{Hi} 113.0 \mathrm{~km}$

$A B Q 3.0 \mathrm{~km}$

Fenton $\mathrm{Hill} 3.5 \mathrm{~km}$

$A B Q 3.5 \mathrm{~km}$

Fenton $\mathrm{Hill} 4.0 \mathrm{~km}$

$A B Q 4.0 \mathrm{~km}$
Mean, degrees

12.5

$-0.5$

1.5

$-2.0$
Standard Deviation, degrees 
5.1. Fracture and Borehole Mapping (LASL Contributors: J. Albright, R. Butler, C. Pearson, R. Potter, R. Aamodt, R. Spence, W. Overton; Outside Contributors: K. Aki, Massachusetts Institute of Technology; M. Fehler, Oregon State University; J. Achenbach, Northwestern University; R. de la Cruz, University of Wisconsin; R. Unterberger, Texas A\&M University; E. Hoskin; Texas A\&M University)

During FY79, emphasis was focused principally on the characterization of reservoir seismicity during massive injections of fluids and on feasibility studies preparatory to the design and fabrication of advanced electromagnetic (em) survey tools for determining fracture orientation near the wellbore intersection.

Two massive fluid injections in EE-1, Expt. 195 and 203, took place in March 1979 for the purpose of enlarging the active heat-exchange area of the Phase I system and stimulating connections to the fractures comprising the GT-2B production (see also Sec. 4.1.). Associated with the injections was a high rate of microseismicity, which was observed using a triaxial geophone package positioned in the then shut-in GT-2B well. The microearthquake signals were of sufficient quality and number that their study has led to substantially increased understanding of rock failure in the reservoir (Sec. 5.1.1.). Preparatory to the March experiments, substantial progress had been made in developing computer codes to rapidly process microseismic signals.

Initial measurements have been completed at LASL of the slight magnetic field anomalies produced by magnetic fluids confined in simulated fractures of a nature inferred to exist in the Fenton Hill reservoir (Sec. 5.1.3.) In theory, the polarization of the fluids by the earth's magnetic field is dependent on the orientation of the fracture with respect to magnetic north. The consequent local anomaly distorts the local earth's field and shifts the local field's derivatives. Field derivative values, measured using a rotating gradiometer, were found in agreement with values predicted from theory. Associated with this effort will be tests of the overall capability of the detection system, a combined gradiometer and superconducting quantuminterference device (SQUID), to measure slight fields in the magnetically noisy environment of the earth's field.

Both laboratory and field measurements have been made to determine the attenuation of microwave frequency radar in granite (Sec. 5.1.4.). Measurements of the permitivity and loss tangent at $S, C$, and $X$ frequencies of 
dry GT-2 and EE-1 samples carried out at the National Bureau of -Standards has precluded the possibility of penetration depths greater than $100 \mathrm{~m}$ in dry granite. Penetration in wet granite is expected to be less. Measurements on saturated Fenton $\mathrm{Hill}$ samples are planned in FY80. The preliminary measurements of continuous wave frequency modulation ( $\mathrm{CW}-\mathrm{FM}$ ) and pulse microwave radar propagation through in situ and recently quarried granite were made under contract by Professor R. Unterberger (Texas A\&M). In these measurements no attempt was made to measure signal losses due to the poor coupling between granite and transmitters made for air coupling, nor has an effort been made to increase signal strength by increased transmitter power or to increase signal quality through computer processing. Nonetheless, the transmission of $4.3 \mathrm{GHz}$ radar signals through $4.2 \mathrm{~m}(14 \mathrm{ft})$ of granite using a $1 \mathrm{~W} \mathrm{cW}$ system has been demonstrated. Unterberger's work in developing design specifications for a downhole logging tool will continue in FY80.

Because in situ stresses constrain hydraulic fracture orientation, means are being investigated for measuring stresses downhole. One method under consideration involves overcoring or "trepanning," a process in which a cylindrical core is bored into the wellbore walls. From the measured strain changes and the known elastic moduli of the rock, it is possible to infer the local stress. Under contract to LASL, Earl R. Hoskin (Texas A\&M) is preparing the design for a stress measuring tool capable of operating in the Fenton Hill downhole environment. Fabrication of the tool will start in FY80.

Additional contract work supported our long-range objectives in detecting and mapping fractures through analys is of transducer-generated signals that have intersected fluid-filled fractures. As part of a larger university contract considering many research topics of importance in understanding hot dry rock reservoirs, Jan Achenbach (Northwestern University) has studied the scatter of acoustic signals of the nature produced using commercial logging tools by the edges of fluid-filled fractures. Analytic solutions were obtained for the diffraction field in the forward direction associated with the scattering of acoustic waves by a semi-infinite fluid-filled fracture. To facilitate machine calculations, an approximate solution based on elastodynamic ray theory that is valid at high frequency was developed. Insofar as this aspect of the work deals only with scattering from crack tips, (a single fracture, regular geometries, and homogeneous rock) further development of the 
theory is necessary before it can be meaningfully applied to the Fenton Hill data. Of immediate importance, however, are the calculations that have been made of reflection and transmission coefficients for water-filled, propped fractures (Sec. 5.1.2.). The difference in value of these coefficients from those of a completely open fracture have been expressed in terms of the ratio of effective-to-normal shearing viscosity. These calculations have opened the possibility of acoustically measuring the degree of propping that exists in a fracture once the location of the fracture has been determined.

Throughout FY79, routine use was made of temperature, spinner, caliper, iodine tracer, and comercial cement bond logs. In particular, data from the latter four types of surveys were heavily relied upon in the EE-1 recementing program and the selection of the installation site for the Pack-Perf assembly in Run Segment 3. Similarily, data obtained using temperature and spinner surveys in GT-2B has enabled constraints to be established for physical models of the Phase II system operation in high and low back-pressure operating modes.

In FY80 renewed emphasis will be placed on efforts to map the fracture system near EE-1 and GT-2B. These efforts will be facilitated by the use of acoustic transceiver surveying tools designed by LASL for that specific application. The tools, designed for operation at temperatures up to $275^{\circ} \mathrm{C}$, have been fabricated by Simplex, Inc., Dallas, Texas, and are scheduled for delivery in January 1980. If the high-temperature capability of the tools is realized, they will represent the sole surveying tools of this nature available in the nation.

5.1.1. Microseismic Investigations. The two massive injections into the reservoir through the $2932-\mathrm{m}(9620-\mathrm{ft})$ fracture intersection in EE-1 occurred on March 14 and 21, 1979. During both injections, a LASL-designed and fabricated triaxial geophone station installed in GT-2B at $2685 \mathrm{~m}(8810 \mathrm{ft})--\mathrm{a}$ position $247 \mathrm{~m}(810 \mathrm{ft})$ almost vertically above the injection point--detected microseismic activity resulting from rock failure. The cumulative number of microseismic events, the microseismic occurrence rate, and the distance from the injection point of microseismic foci far exceeded those observed formerly in the reservoir. These phenomena are commensurate with the scale of the March injections in comparison with the single, largest previous injection that occurred in June $1976 .^{9}$ Table 5 -I shows the differences between these 
TABLE 5-I

OPERATING CONDITIONS DURING WHICH MICROSEISMIC EVENTS WERE DETECTED

$\begin{array}{cccccr}\text { Expt. } & \begin{array}{c}\text { Measurement } \\ \text { Date }\end{array} & \begin{array}{c}\text { Volume } \\ \text { Injected } \\ \text { into EE-1 } \\ \left(\mathrm{m}^{3}\right)\end{array} & \begin{array}{c}\text { Maximum } \\ \text { Injection } \\ \text { Rate }\end{array} & \begin{array}{c}\text { Nominal Peak } \\ \text { Pressure } \\ \text { (bar) }\end{array} & \begin{array}{c}\text { GT-2 } \\ \text { EE-1 }\end{array} \\ \text { 129B } & 29 \text { June } 1976 & 189 & 16 \ell / \mathrm{s} & 72 & 120 \\ 203 & 14 \text { March } 1979 & 636 & 32 \ell / \mathrm{s} & 55 & 198 \\ 195 & 21 \text { March } 1979 & 758 & 51 \mathrm{l} / \mathrm{s} & 67 & 207\end{array}$

injections. The volume of water injected and peak wellhead pressure were somewhat larger during the second March injection; both greatly exceeded the June 1976 injection. The higher EE-1 wellhead pressure on March 21 (and hence the highest reservoir pressure to date) was maintained by a substantially greater flow rate.

Great numbers of microseismic signals of the nature shown in Fig. 5-1 were detected during the March injections. The magnitude of the largest events observed has been estimated using two independent methods. The firsi is based on an empirical relation between signal coda length (signal duration) and magnitude derived for earthquakes detected within the North Central New Mexico regional earthquake monitoring system maintained by LASL. 11 Microseismic signals of a duration less than $0.2 \mathrm{~s}$, which are common at Fenton Hill, are not detected by elements of the regional array, so that magnitude assignments outside the range of tested validity can be made only by extrapolation. An additional shortcoming of the coda length method is that it is essentially uncalibrated in a range where locally variable geologic conditions may have significant effect. The second method, likewise, is based on an empirical relationship between microseismic magnitude and

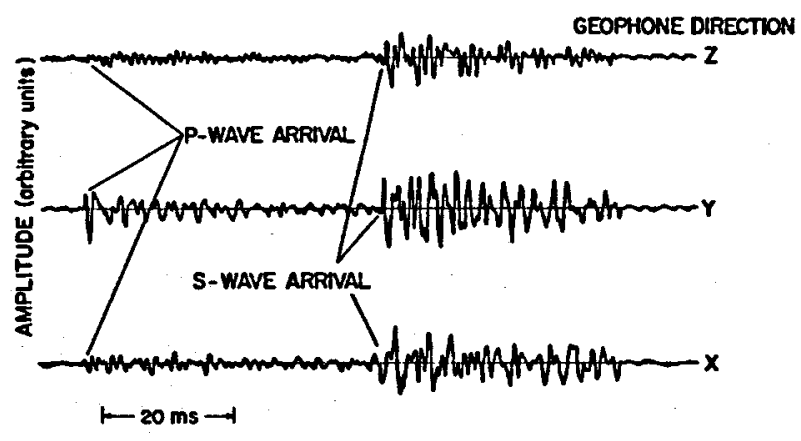

Fig. 5-1. Microseismic signal detected by geostation during Expt. 203. 
seismic moment established for tremors in deep mine workings. ${ }^{12}$ The seismic moment is a derivative parameter calculated from the displacement amplitude spectra of the microseismic signals assuming that simplistic assumptions of microearthquake energy release hold. Comparable magnitude estimates of -1 were obtained using both the coda length and spectral methods.

Reservoir Seismicity. The microse ismic signals detected during hydraulic stimulation of the reservoir have amplitude components at frequencies as high as $1200 \mathrm{~Hz}$. This precludes detailed analys is of low-resolution strip-chart records. However, the characteristic appearance of signals that are microseismic in origin-impulsive onset on each component of the triaxial geophone array followed by an exponential time decay--enable the occurrence of a microearthquake to be conveniently determined directly from visual inspection of low-resolution records. In measuring the microearthquake occurrence rate, all microse ismic-like events are counted. Figure 4-7, gives the occurrence rate so determined during each of the two massive injections in March as a function of injected fluid volume. The seismicity associated with the two injections is distinctly different. Rock failure started almost immediately following the initiation of injection on March 14 and continued at a uniform, although slightly decreasing, rate thereafter. The decrease is apparently indicative of the attainment of an equilibrium release, rate of seismic energy under constant injection wellhead conditions. This rate decreases slowly, probably because of nonseismic energy losses such as the compression and parting of rock about a new fracture as fluid pressure increases. The system was shut in near the end of the monitoring period. Seismicity continued, but at an accelerated decline rate.

The first indication of rock failure during the second injection did not appear until almost $200 \mathrm{~m}^{3}$ of fluid had been injected into the reservoir. The microseismic occurrence rate then increased slowly throughout the monitoring period. Since the initiation of rock failure during short-term, high flow-rate injections depend on the pressure near the extremities of the fracture; the onset delay quite plausibly results from the slow pressure rise in the system resulting from the first injection on March 14. The monitoring period apparently did not extend long enough for the period of equilibrium release rate to be observed. 
Location of Microseismic activity. The first arrival seen in- records of a microseismic event is the compressional or P-wave. The P-wave arrival is followed by a second prominent arrival, the shear or S-wave. Independent knowledge of the propagation velocity in the reservoir rock of the respective waves enables the distance to the microseismic focus, the origination point of the microseismic signal, to be directly calculated from the delay time between the arrival of the two waves. The particle motion at the monitoring station on arrival of the P-wave is polarized in the direction of propagation. The determination of signal polarization then constrains the direction to microseismic focus to be one of two directions diametrically opposite. Figure 5-2 illustrates the problem. Two microseismic events having reversed first motions at rock failure and located at diametrically opposite locations with respect to the geophone package, produce identical initial displacement at the geophone location and are indistinguishable. Maps of microseismic foci developed using single-station seismometry are always degenerate; two locations are inherently possible. We call this the centrosymetric ambiguity in focus location. Often, in monitoring induced seismicity controlled to the extent that the rock volume affected can be predicted, simple placement of the monitoring point outside of that volume removes the centrosymetry. The control in the measurement then makes one of the two possible directions likely. At the Fenton Hill site, for example, there would be little chance for ambiguity if a $200 \mathrm{~m}^{3}$ injection were monitored at $200 \mathrm{~m}$ from the injection point. The ambiguity is also removed if the sense of the first motion at the rock-failure surface and the attitude of the surface, its strike and dip, were known. If, however, surfaces of different attitudes are formed during injection or if the direction of successive first motions along fractures are not identical, the ambiguity cannot be removed.

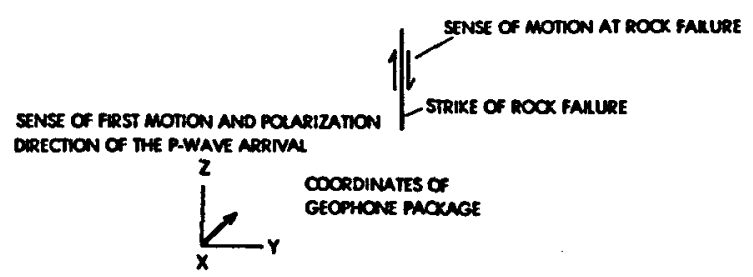

Only a small fraction of all microseismic signals detected can be processed for interpretation. This number usually amounts to less than $5 \%$ of the total, primarily because we use only a single-station se ismometry.

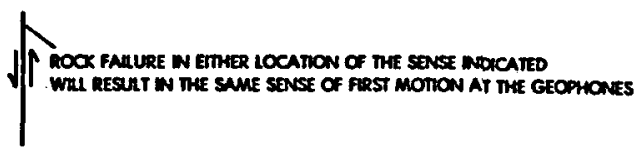

Fig. 5-2.

The centriosymmetric ambiguity in determining azimuth to microearthquake forms. 
Signals from which microseismic foci were used in this study had impulsive P-wave arrivals on at least one geophone channel and an amplitude generally in excess of ambient noise by a factor of at least ten. Signal polarization exceeds four, measured in terms of the ratio of the major to the minor polarization axes in space. Similarly, signals amenable to analysis were characterized by clearly discernible S-arrivals. Compater algorithms were used to automatically determine the inclination and azimuth of $P$-wave polarization from digitized analogue records of microseismic signals once a $P$-wave arrival was identified by inspection. The delay time between $P$ - and S-wave arrivals was visually determined from digitized records.

Focal-point maps of the microseismic events that occurred during the March injections are given in Fig. 5-3 and 5-4. In the preparation of each map, the centrosymetric ambiguity is ignored on the assumption that the position of the geophone package, $300 \mathrm{~m}$ above the injection point, effectively places the focus of all events below the monitoring point. The axes appearing in each figure represent the direction of the horizontal geophones axes during each measurement in relation to the magnetic coordinates at the location of the geophone package. In Expt. 203, the axial directions were determined from photographic records of the geophone sonde orientation obtained with a SperrySun tool attached to the sonde. Signal polarizations from detonations at known locations in EE-1 were used in ascertaining the axial directions in Expt. 195. The origin of the coordinates in each projection is the location of the geophone sonde.

Stereographic projections of the foci of microseismic events that occurred during each injection are given in Fig. 5-3. The projections give inclination and azimuth to each event. The inclination to events varies from $90^{\circ}$ (vertical) at the origin to $0^{\circ}$ at the circumference of the circle. There are several useful purposes of sterographic projections. More events can be used in their composition. Only microseismic signals with clearly discernible P-wave arrivals are necessary. Because knowledge of the distances to events is not required, signals with poorly defined S-wave arrivals can also be used. Also, several tests can be immediately applied to determine if simple concepts of the geometry of the fractured rock volume hold. A single vertical fracture along which microseismic event occur would appear as a line in stereographic projection if an imaginary planar extension of the plane contains the location of the geophone package. If a fracture were inclined and its imaginary planar 

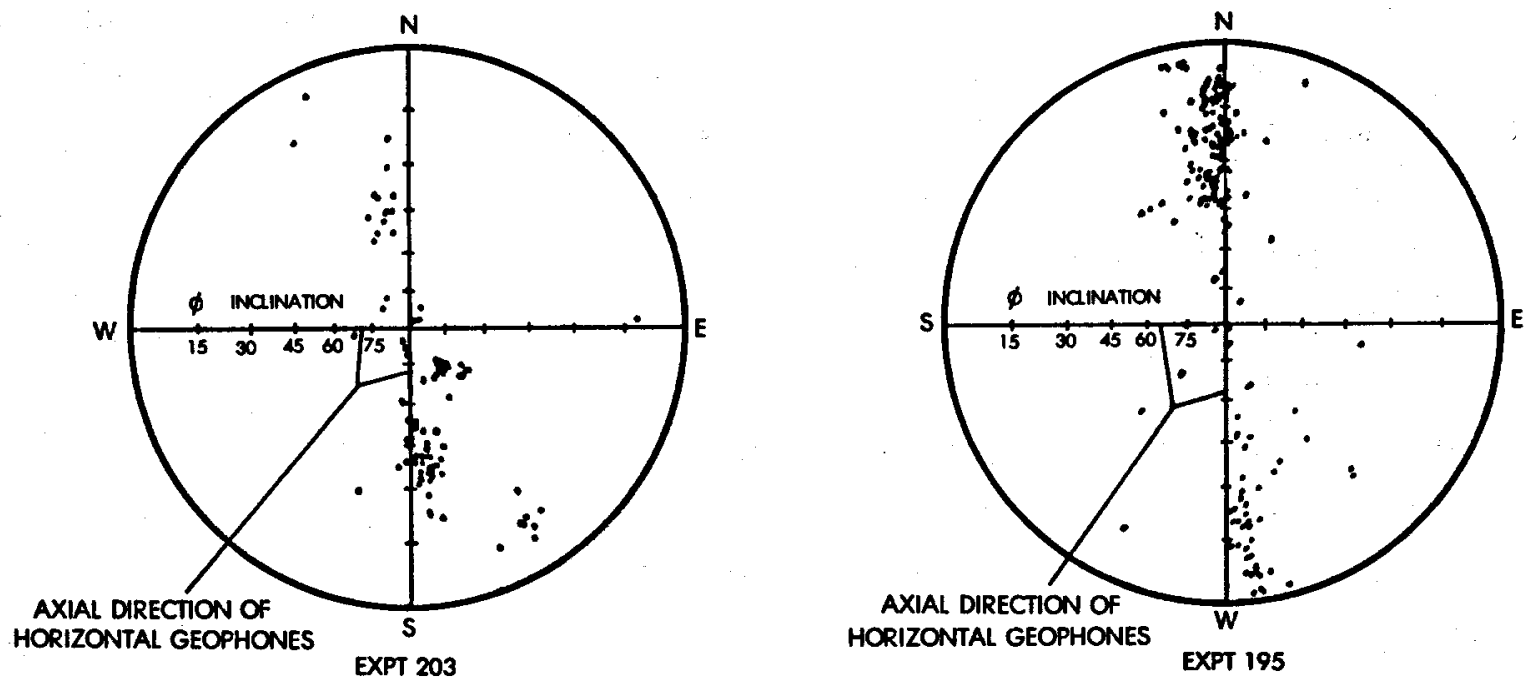

Fig. 5-3.

P-wave arrival--first motion stereographic projection.
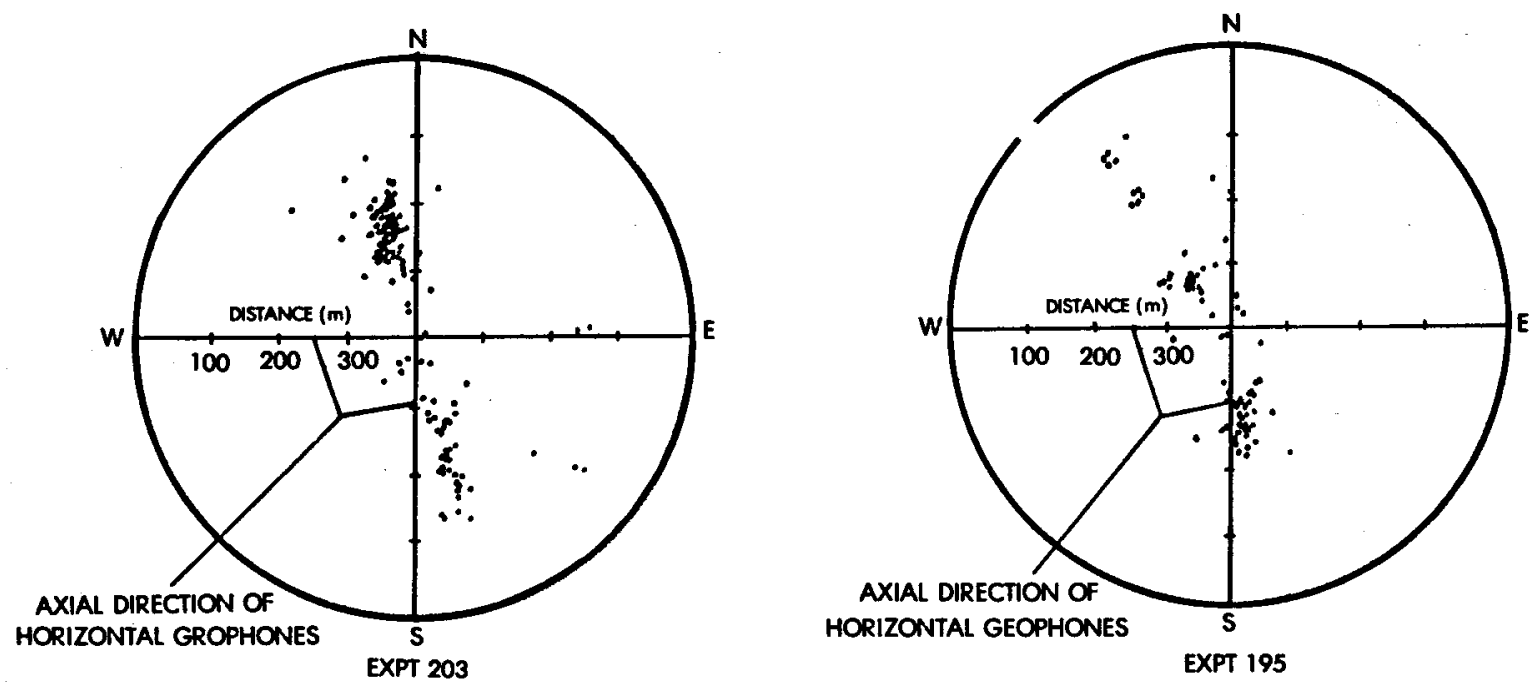

Fig. 5-4.

Projection to horizontal plane of foci.

extension contained the geophone package, an arc would be seen in projection. If the geophone package were not contained in the fracture plane in eitner of these cases, or if the foci of microseismic did not result from rock failure along a single plane, an area of foci would appear in projection. As seen in the actual projections, both of the last two propositions are possible. Statistical tests of each indicate that rock failure occurred in a nearly vertical zone having dips of $85^{\circ}$ and $89^{\circ}$ in independent determinations of 


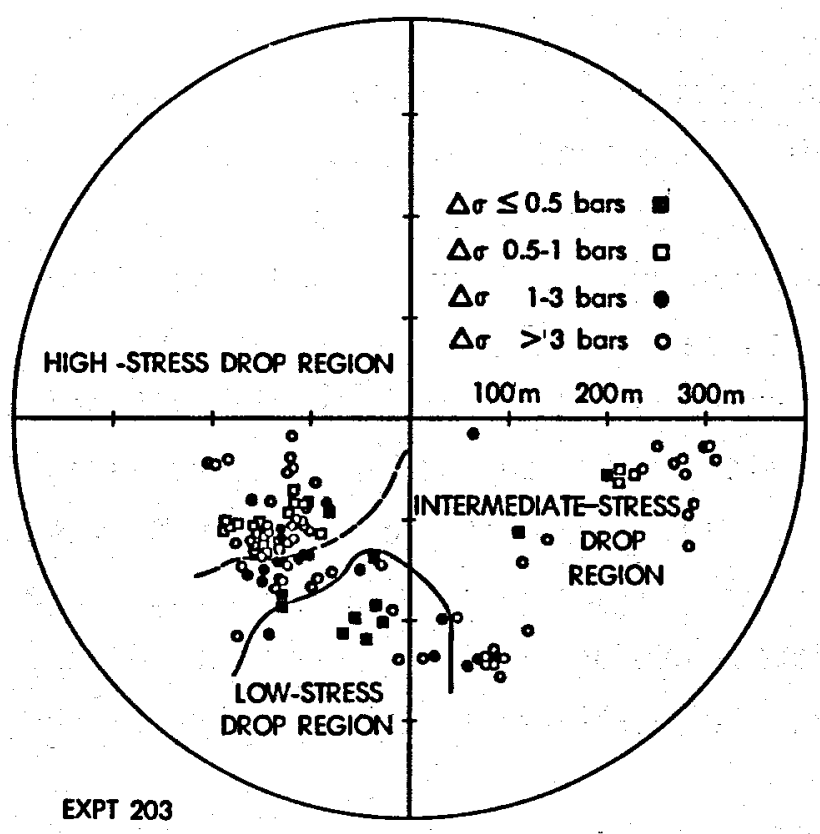

Fig. 5-5.

Event location projected to fracture plane for Expt. 203.

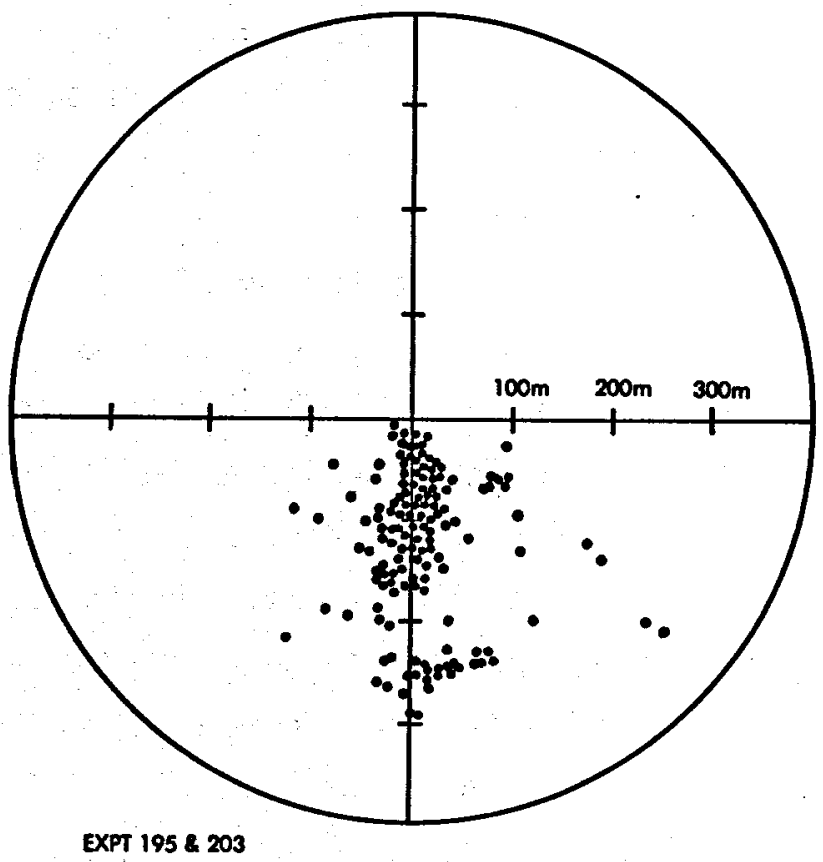

Fig. 5-6.

Event location projected perpendicular to fracture plane for Expts. 195 and 203.

seismicity that occurred during the two injections. Further, the zone was at least $100-\mathrm{m}$ wide and in its imaginary extension contained the location of the geophone package. A difference in seismicity during the two injections can be noted in Fig. 5-3. Seismicity progressed to lower angles, approaching the horizontal plane defined by the geophone axes, from the first to the second injection. The strike of the seismic zone was measured to be $29^{0}$ north northwest in the first injection and $18^{\circ}$ north northwest in the second.

A projection of microseismic foci to the horizontal plane defined by the geophone axes is shown in Fig. 5-4. Normal and parallel projections to the zone of seismicity are given in Figs. 5-5 and 5-6. In horizontal as well as normal projection, one sees that few microearthquakes occurred near the injection point or within roughly $100 \mathrm{~m}$ of the geophone package. The few events that did occur were characterized by low stress drops. This region is essentially the limit of the seismicity observed during the relatively small injections into the reservoir in 1975-76. Similarly, this region was probably the site of heat extraction during the 75-day test. These observations taken collectively suggest that rock failure at that location is extensive enough so that shearing stresses of the magnitude necessary for further failure (microseismic events) cannot develop. 
During both injections, the earliest seismicity occurred close to the injection point in EE-1 and progressed upward and outward. The spatial progression can be visualized as a moving localized volume of microseismic activity rather than that of a moving line of activity, again suggesting multiplicity in fracture surfaces or fractured zones. During each injection, microseismic activity was detected at distances as great as $300 \mathrm{~m}$ from the downhole geophone. This distance does not appear to represent the ultimate range for which magnitude -1 microseismic foci can be determined using single-station seismometry. A significant reduction in signal strength must have occurred for signals impinging on the geophone site, because these necessarily passed through the pressurized production fractures in GT-2B. Consequently, the future development of hydraulically fractured regions in the reservoir can be further traced.

Spectral Measurements. The amplitude displacement spectrum of most se ismic events is characterized by a constant low-frequency constant spectral amplitude trend, $\Omega_{0}$, and a high-frequency trend in which power decreases with increasing frequency as $1 / \omega^{2}$, where $\omega$ is frequency. The amplitude displacement spectrum of a typical microseismic signal is shown in Fig. 5-7. The frequency at which the two trends intersect is called the corner frequency $f_{c}$. Study of the spectra can give information about the properties of the microearthquakes at their source. Parameters that are commonly estimated are the source dimension, $r$, the stress drop $\Delta \sigma$, and the seismic moment, Mo. In examining the signals from Expt. 195 and 203, the expressions first proposed by Brune ${ }^{13}$ were used. Brune's expressions for the calculation of source parameters have become standard in comparative seismology. The relevant formulae are

$$
\begin{aligned}
r & =\frac{2.34}{2 \pi} \beta \frac{1}{f_{c}} \\
M_{0} & =\frac{4 \pi \rho R \beta^{3} \Omega_{0}}{K R_{\theta \phi}} \\
\Delta \sigma & =\frac{7}{16} \frac{M_{0}}{r^{3}},
\end{aligned}
$$

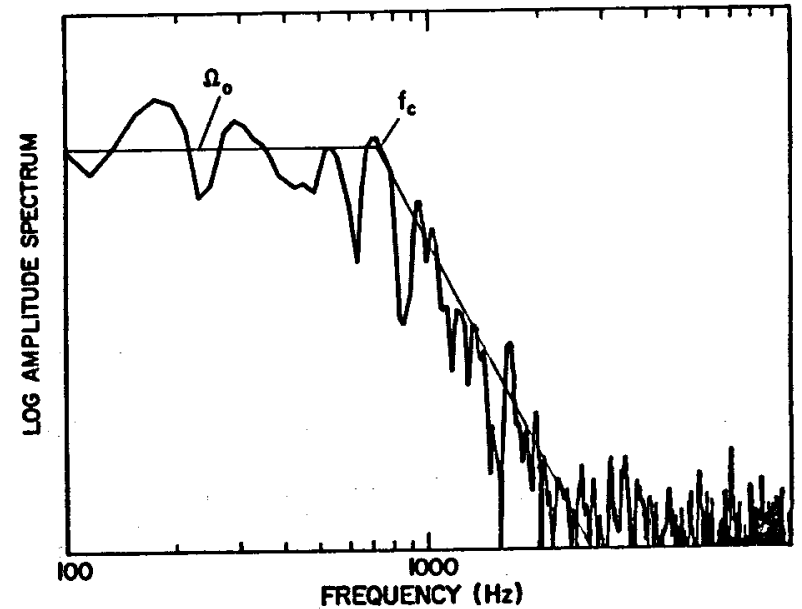

Fig. 5-7.

Typical displacement amplitude spectra microseismic signal detected in Expt. 203. 
where

$$
\begin{aligned}
& r=\text { source radius (circular area assumed), } \\
& B=\text { shear-wave velocity, } \\
& f_{C}=\text { corner frequency, } \\
& M_{0}=\text { seismic moment, } \\
& \rho=\text { density, } \\
& R=\text { distance from detector to source, } \\
& \Omega_{0}=\text { constant low-frequency displacement amplitude, } \\
& K=\text { surface-reflection amplification factor, } \\
& R_{\theta \phi}=\text { shear-wave radiation correction factor, and } \\
& \Delta \sigma=\text { stress drop. }
\end{aligned}
$$

A root-mean-square value of 0.4 was used for $R_{\theta \phi}$ since the radiation pattern of microearthquakes cannot be deduced from a single measurement made at the geophone-package location. As the geophone package was positioned at depth and not near ground level, $K$ was assumed equal to 1 . No attempt was made to take into account the effect of seismic radiation reflected at fluid-filled cracks along ray paths from microearthquake foci to the geophone station, although this may result in a correction similar to $K$.

Table 5-II gives a summary of the average source parameter values for the microearthquakes that occurred at selected intervals during both injections. The first 15 signals detected following the indicated time were used in the analysis. The values listed are based on the assumptions that the surface areas of rock failure are circular and that the failure propagated at shear velocity. Given this as the case, the theoretical estimates of phenomena at the microseismic source are failure areas having radii on the order of three $m$ or less, stress drop accompanying failure of 0.5 to 1.8 bars, and seismic moments of $4-12 \times 10^{-13}$ dyne $-\mathrm{cm}$. The last parameter was used in estimating event magn itude.

The early part of Expt. 203 had proportionally many more events with stress drops less than 1 bar than did events occurring later in the experiment. This observation is illustrated in Fig. 5-8, where histograms are plotted for those events occurring after 115 min from the start of pumping and for all events that occurred in Expt. 203. This difference may be related to the movement in the locus of seismicity from the region around the fluid injection point, where some of the in situ stresses had been relieved during previous reservoir pressurizations, to more distant regions where the in situ shear stress were larger. 
TABLE 5-II

MHF SOURCE PARAMETERS*

\begin{tabular}{|c|c|c|c|c|}
\hline $\begin{array}{c}\text { Time, } t \text { (min) } \\
43 \\
55 \\
60 \\
115 \\
180 \\
245 \\
310\end{array}$ & $\begin{array}{c}\text { Radius, } R(\mathrm{~m}) \\
3.4 \\
3.1 \\
3.2 \\
3.0 \\
2.1 \\
2.3 \\
2.1\end{array}$ & $\begin{array}{c}\text { Moment, } M_{0} \times 10^{13} \\
\text { (Dyne }-\mathrm{cm} \text { ) } \\
11.0 \\
7.0 \\
10.0 \\
10.0 \\
6.0 \\
8.0 \\
5.0\end{array}$ & $\begin{array}{c}\text { Stress Drop, } \\
\text { (bars) } \\
0.8 \\
0.5 \\
0.7 \\
1.0 \\
1.8 \\
1.6 \\
1.7\end{array}$ & $\begin{array}{l}\text { L40 000 } \\
\text { INJECTION }\end{array}$ \\
\hline $\begin{array}{l}215 \\
265 \\
315 \\
360\end{array}$ & $\begin{array}{l}2.1 \\
1.9 \\
2.0 \\
1.9\end{array}$ & $\begin{array}{r}7.1 \\
4.6 \\
4.2 \\
12.7\end{array}$ & $\begin{array}{l}1.7 \\
1.2 \\
1.2 \\
1.7\end{array}$ & $\begin{array}{l}675000 \\
\text { INJECTION }\end{array}$ \\
\hline 15-event a & & $\begin{array}{l}f_{s}=597 \mathrm{~Hz} \\
f_{p}=812 \mathrm{~Hz} \\
f_{s} / f_{p}=0.75\end{array}$ & & \\
\hline
\end{tabular}

5.1.2. Acoustic Wave Interactions with Water-filled Selfpropped Fractures. Transmission and reflection coefficients for $P$-wave and $S$-wave incidence on a waterfilled fracture have been calculated for the case of smooth planar cracks of infinite extent. ${ }^{9}$ A better approximation to actual conditions on the faces of the water-filled self-propped fracture when a propagating wave motion intersects the crack, assumes that incident waves may give rise to contact and siiding of contact areas. A cross section of such a crack is sketched in Fig. 5-9.

As a simple but reasonable model for the resistance to relative tangential motion of the crack faces, we propose the relation

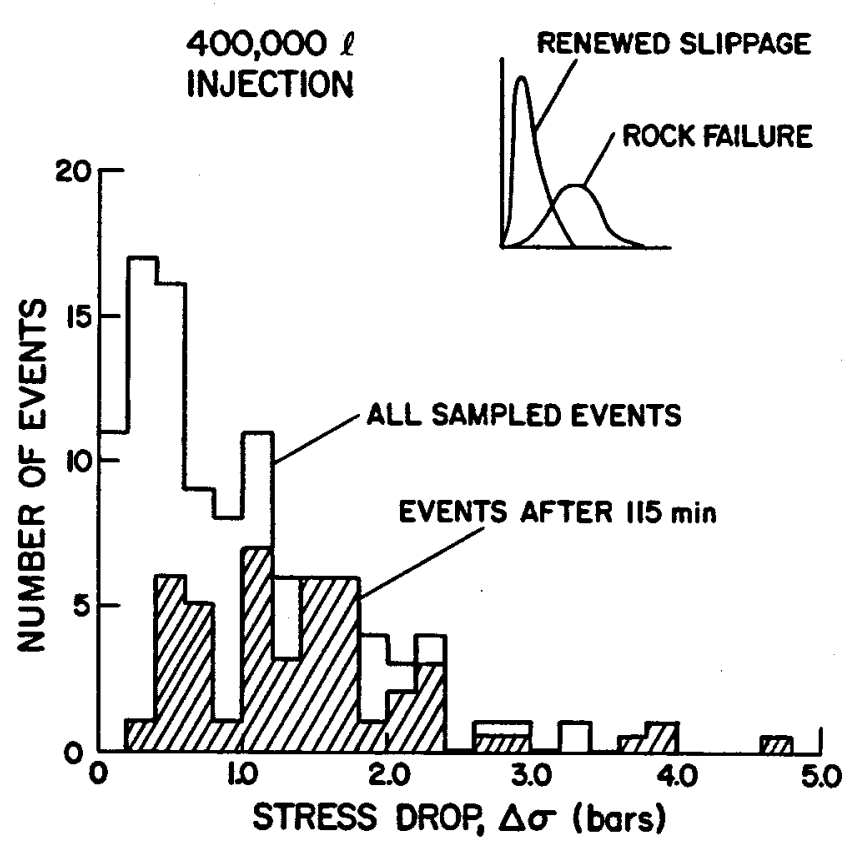

Fig. 5-8. Microseismic events during Expt. 203.

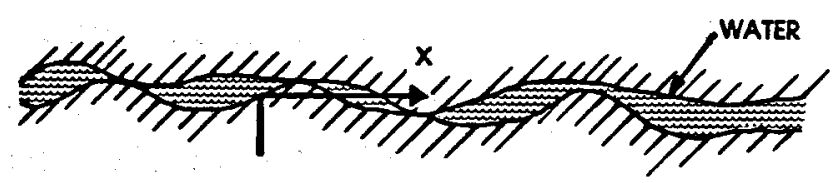

Fig. 5-9.

Cross section of water-filled crack. 


$$
\tau_{x z}^{+}=n_{T}\left[\dot{u}_{x}^{+}-\dot{u}_{x}^{-}\right]
$$

Here it is assumed that the shear stress $\tau_{x z}$ is continuous, i.e.,

$$
\tau_{x z}^{+}=\tau, \overline{x z},
$$

where the + and - notation defines a field variable at $z=0^{+}$and $z=0^{-}$ (upper and lower crack face), respectively. Equations (5.1) and (5.2) imply that the inertia of the water layer is neglected, which is acceptable for wave lengths that are large compared to the thickness of the water layer. The viscosity implied by $n_{T}$ and the time derivatives of the displacements at the upper and lower crack-faces includes the viscosity of the water as well as damping effects due to sliding of contact areas.

A similar relation is proposed for the normal stress and the normal displacements, i.e.,

$$
\tau_{z}^{+}=\tau_{z}^{-} \equiv \eta_{N}\left[\dot{u}_{z}^{+}-\dot{u}_{z}^{-}\right]
$$

As the crack faces come closer or separate, water is displaced. The water flows in between contact areas, and it is pushed into (or drawn from) pores in the rock. The operative mechanism is thought to be similar to that of a piston in a cylinder with a perforated bottom; hence, Eq. $(5.3)$ is expected to be a reasonable approximation.

Equations (5.1) through (5.3) can, of course, easily be extended to the three-dimensional case of a flat crack by adding

$$
\tau_{y z}^{+}=\tau_{y z}^{-} \equiv n_{T}\left[\dot{u}_{y}^{+}-\dot{u}_{y}^{-}\right]
$$

Reflection and transmission of plane waves. A good deal of insight into the interaction of an incident wave with a water-filled crack modeled by the boundary conditions Eq. (5.1) through (5.4) can be obtained by considering the local reflection and transmission of a plane longitudinal wave. This problem is two-dimensional in nature, and the geometry is shown in Fig. 5-10. The computation of reflection and transmission coefficients is facilitated by 
decomposition of the problem statement into symmetric and antisymetric considerations. The complete theoretical development ${ }^{14}$ results in expressions that give reflection and transmission coefficients for longitudinal waves in terms of incident angle and the effective viscosities included in Eq. (5.3) and (5.4). The coefficients for which numerical

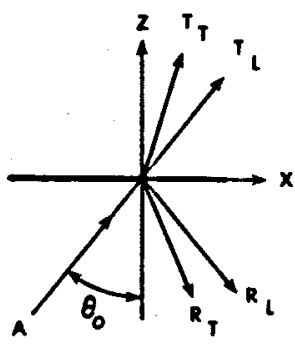

(a)

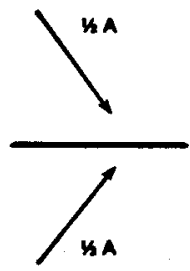

(b)

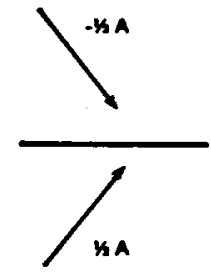

(c) results have been obtained dealing with longitudinal wave incidence are $R_{T}$, $R_{L}, T_{T}$, and $T_{L}$ where $R$ and $T$ represent reflected and transmitted waves and the subscripts $T$ and $L$ stand for longitudinal and transverse waves, respectively. The following values were used in the computations and are believed to be representative of the in situ conditions at Fenton Hill.

$$
\begin{aligned}
C_{L}= & 6.0 \times 10^{3} \mathrm{~m} / \mathrm{s} ; C_{T}=3.5 \times 10^{3} \mathrm{~m} / \mathrm{s} \\
\lambda & =3.1 \times 10^{10} \mathrm{~Pa} ; \mu=3.3 \times 10^{10} \mathrm{~Pa} .
\end{aligned}
$$

Fig. 5-10.

Longitudinal wave incident on a water-filled crack.

In addition, a shear viscosity is given as $n=0.0014$ poise $=0.00014 \mathrm{~Pa} . \mathrm{s}$. Assuming an average crack opening of $1 \mathrm{~cm}$, this value of $\eta$ corresponds to $\eta_{T}=0.014 \mathrm{~Pa} . \mathrm{s} / \mathrm{m}$, which corresponds to $\mu / c_{L} \eta_{T}=0.393 \times 10^{9}$ (dimensionless). This large crack aperture was used in order to exaggerate the effects of crack irregularity. These numbers were used as input parameters in numerical computations of the reflection and transmission coefficients. The coefficients were computed as functions of the angle of incidence $\theta_{0}$ and the dimension less ratio $n_{N} / n_{T}$.

The results of the numerical computations are shown in Fig. 5-11. The angle of incidence varies from $\theta_{0}=0$ to $\theta_{0}=\pi / 2$, and $n_{N} / n_{T}$ varies from $10^{5}$ to $10^{15}$. For $n_{N} / n_{T}=10^{5}$, very little wave motion is transmitted at all angles of incidence, and the water-filled crack acts essentially as an empty stress-free crack. It is noted that significant changes of the reflection and transmission coefficients take place in the range $10^{7}<n_{N} / n_{T}<10^{10}$. As $n_{N} / n_{T}$ approaches $10^{10}$, the resistance 

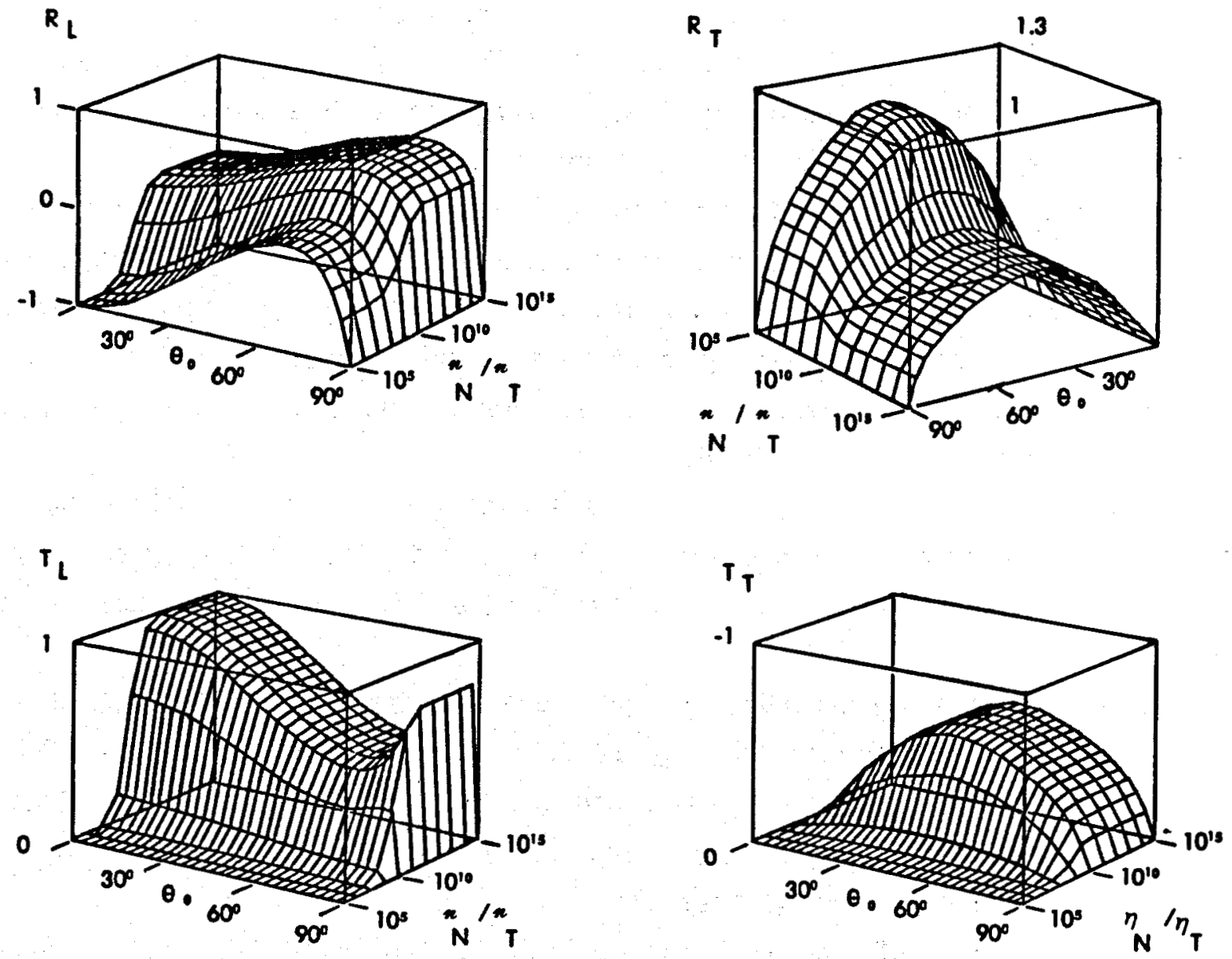

Fig. 5-11.

Reflection and transmission coefficients vs $\theta_{0}$ and $n_{N} / n_{T}$.

to normal crack-opening displacements becomes very large. Thus, for normal incidence $\left(\theta_{0}=0\right) \quad R_{L}$ decreases to zero, while $T_{L}$ increases to unity as $n_{N} / n_{T}$ increases, which implies that all wave motion is transmitted. of course, for oblique incidence $R_{L} \neq 0$ and $T_{L}<1$ when $n_{N} / \eta_{T}>10^{10}$ because of the weak resistance to tangential crack-opening displacements.

The diagram presented in Fig. 5-11 may be used to estimate the angle of inclination of the crack $p l$ ane relative to the line connecting the source and the receiver. The position of the crack plane should be inferred from arrival times of the transverse wave.

5.1.3. Superconducting Magnetic Techniques. The feasibility of forcing magnetic ferrofluid into the hydraulically fractured crack and then determining the orientation of the crack was addressed in a recent study. ${ }^{15}$ 
The ferrofluid in the crack would disturb the local earth's magnetic field and introduce a localized magnetic anomaly. In particular, the localized anomaly would shift the local magnetic-field derivatives in such a way as to characterize the direction of the crack with respect to magnetic north.

A superconducting magnetic gradiometer rotating about a horizontal axis could be used to measure the characteristic magnetic-field-derivative pattern, and hence, determine the crack orientation. The gradiometer signal would be detected by a superconducting quantum-interference device (SQUID). Dther magnetic field derivative-measuring systems were found not to have adequate sensitivity for the problem at hand.

A feasibility experiment was carried out at ground level, rather than in the geothermal borehole. A hydraulically fractured crack filled with ferrofluid was simulated by a 1- to 2-mm-thick sheet formed between two lucite panels.

The single-axis superconducting gradiometer SQUID system was purchased from S.H.E., Inc., and arrived in May 1979. A single-axis magnetometer SQUID system was constructed as well as a nonmagnetic platform and a nonmagnetic rotating table and cradle for supporting the liquid-helium dewar. A nonmagnetic instrument house was also assembled.

The manufacture of the ferromagnetic fluid (colloidal magnetite ferrofluid) was completed August 1, 1979. A total of 36 gal was produced at a cost of $\$ 7000$. Adapting a Bureau of Mines patented process, we used $\mathrm{FeCl}_{2} \mathrm{HH}_{2} \mathrm{O}$ and $\mathrm{FeCl}_{3} 6 \mathrm{H}_{2} \mathrm{O}$ solutions reduced by $\mathrm{NH}_{4} \mathrm{OH}$ to produce magnetite particles presumed to be $\mathrm{FeOFe}_{3} \mathrm{O4}$ crystallites of less than $0.1 \mathrm{~m}$ colloidal size. The particles were peptized by oleic acid and suspended in jet $A$ fuel (goodquality kerosene). The magnetic susceptibility of the suspension was in the range 0.15 to 0.5 and compared well with that of commercial magnetite ferrofluid, which has a susceptibility in the range of 0.5 to about 1.0. The latter is priced at $\$ 800$ per liter in small commercial quantities. The susceptibility of our locally produced ferrofluid could be increased by simply evaporating excess kerosene. It appears that mass production techniques could be developed to produce sufficient quantities for use in a geothermal borehole experiment for less than perhaps $\$ 10$ per liter.

Our early superconducting gradiometer measurements were plagued by strong interfering magnetic signals that made detailed measurements impossible. This was believed due to the operation of a deep-well electric drilling rig at a 
site only 2.1 miles away. Attempts to trim and balance the superconducting gradiometer in August and early September were unsuccessful until the problem was solved by the use of high-purity-aluminum eddy-current shielding around the liquid helium dewar. Subsequently the trim and balance measurements were successfully completed. After this step, the measurements of the gradiometer rotation patterns could be carried out without difficulty. Meanwhile, the drilling was shut down and the interfering signals were no longer observed.

The initial measurements were made of the (background) signal, i.e., the superconducting gradiometer magnetic-derivative signal without any ferrofluid in the lucite panels. After filling the lucite panels to form a ferrofluid sheet, the measurements were repeated for many different orientations of the sheet. The difference

$$
\Delta S \text { = signal with ferrofluid - background }
$$

could then be obtained for any desired orientation of the panel array. The array was manually shifted to various orientations, beginning at $15^{\circ}$ from magnetic north, at $30^{\circ}$ intervals. Near $270^{\circ}$, we used $15^{\circ}$ intervals. Meanwhile, the gradiometer-rotation data were recorded at $10^{\circ}$ intervals.

Experimental results for a sheet orientation of $285^{\circ}$ are shown in Fig. 5-12. For the $x$ 's the edge of the ferrofluid sheet nearest the gradiometer was $1.19 \mathrm{~m}$ away. For the circles and squares, the edge was $0.58 \mathrm{~m}$ and $0.57 \mathrm{~m}$, respectively, from the gradiometer center. These results show clearly the decay of the gradiometer signal amplitude with respect to distance of the nearest sheet edge. We note that doubling the nearest edge distance from $0.58 \mathrm{~m}$ to $1.19 \mathrm{~m}$ decreases $\Delta S$ by a factor of 5 to 8 , which suggests the cube dependence of the theory. In the case of future actual borehole measurements, the nearest-edge distance will be only about $0.15 \mathrm{~m}$ away. Thus, $\Delta \mathrm{S}$ will be 1 arger by a factor of about 60 , so that the rotation data should be more reliable than that shown in Fig. 5-12.

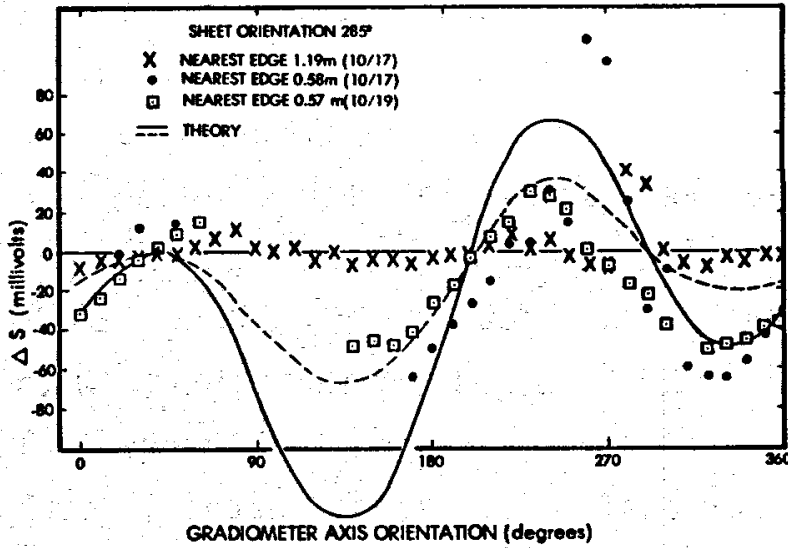

Fig. 5-12.

Experimental and theoretical results showing the net magnetic gradient signal strength as a function gradiometer orientation for a fixed fracture orientation of $285^{\circ}$. 
Some of the scatter in the data of Fig. 5-12 is believed dure to changes in the gradient background with respect to time. In our measurements, the time lapse between background and signal-with-ferrofluid data acquisition varied from six $h$ to two days. In a future borehole application, the background gradient signal could be measured at the surface simultaneously with the signal-with-ferrofluid measurements in the borehole. Thus, the usual diurnal changes in the background could be accounted for at all times.

Figure 5-12 also shows the theoretical curve for $285^{\circ}$ for an arbitrary amplitude (solid curve) and one-half this amplitude (dashed curve). The experimental data for the $0.58-\mathrm{m}$ and $0.57-\mathrm{m}$ nearest-edge distances are seen to agree only qualitatively with theory. We expect improved agreement when the time lapse between background and signal with ferrofluid is decreased.

Figure 5-13 shows rotation results for three different sheet orientations, $285^{\circ}, 270^{\circ}$, and $255^{\circ}$, and a comparison with the theoretical curve for $270^{\circ}$ best fitted to the $270^{\circ}$ experimental data by adjustment of the amplitude. In all cases, we have renormalized the data to zero at $0^{\circ}$ gradiometer axis orientation to make the comparison convenient. We see immediately, by visual inspection, that the $285^{\circ}$ and $255^{\circ}$ data are distinctly different from the $270^{\circ}$ data. However, there are at least two formal methods that can be used to determine which set of experimental data is best fitted by which theoretical curve. These are (1) an autocorrelation of the experimental data with various theoretical functions to determine maximum correlation; and (2) least-squares adjustment of the amplitude of various theoretical functions to best fit the experimental data to give the smallest variance.

We show in Table 5-III the results of autocorrelating the experimental data for $255^{\circ}, 270^{\circ}$, and $285^{\circ}$ panel orientations with each of the corresponding theoretical functions. For this purpose, both data and functions are normalized to zero at $0^{\circ}$ orientation.

In obtaining the results, numerical integrations were performed using the theoretical data (except for normalization to zero amplitude at $0^{\circ}$

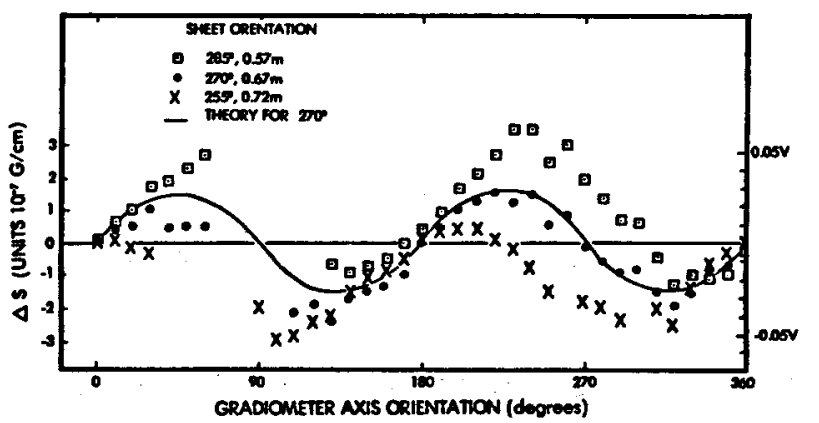

Fig. 5-13.

Experimental and theoretical results showing the net magnetic gradient signal strength as a function gradiometer orientation for the three fracture orientations $\left(255^{\circ}, 270^{\circ}\right.$, and $285^{\circ}$. 
orientation) and the experimental data as measured, in volts, by the equipment. No prefactor has been used and conversion to $\mathrm{G} / \mathrm{cm}$ has not been necessary to obtain a meaningful correlation coefficient.

Table 5-III shows that the maximum correlation occurs when the theoretical function used is for the same orientation as the experimental data. However, the coefficient obtained for the case $270^{\circ}-270^{\circ}$ is nearly the same as that obtained for the case $270^{\circ}-285^{\circ}$. Thus, we could not distinguish the best theoretical function using autocorrelation alone.

To test the curve-fitting method, we have fitted the $255^{\circ}, 270^{\circ}$, and $285^{\circ}$ experimental data to the theoretical data for $270^{\circ}$ by simply adjusting the amplitude of the $270^{\circ}$ curve for best fit. The variances are determined by taking (sum of $\left.r_{i} 2 / n-1\right)^{1 / 2}$, where $r_{j}$ is the residual and $n$ is the number of experimental points in Fig. 5-13 for each case. These variances are shown in Table 5-IV.

The smallest variance of Table 5-IV clearly shows that the $270^{\circ}$ theory fits the $270^{\circ}$ experimental rotation data much better than either the $255^{\circ}$ or the $285^{\circ}$ data.

We have reached a number of conclusions on the basis of the superconducting gradiometer SQUID experiments conducted so $f a r$.

(1) The assumptions concerning the nature of the localized magnetic anomaly produced by filling the crack with ferrofluid are valid.

(2) The gradiometer signals observed experimentally agree qualitatively with theory, and in some cases semiquantitatively.

(3) It appears possible to determine the orientation of the crack to within $15^{\circ}$ when at least two methods of data analysis are employed.

TABLE 5-III

COEFFICIENTS OF THE CORRELATION BETWEEN THEORY AND EXPERIMENT

\begin{tabular}{llll} 
& \multicolumn{3}{c}{ Theory } \\
\cline { 2 - 4 } & ${\underline{255^{\circ}}}^{\circ}$ & $\underline{270^{\circ}}$ & $\underline{285^{\circ}}$ \\
$255^{\circ}$ & 0.104 & 0.051 & 0.032 \\
$270^{\circ}$ & 0.047 & 0.071 & 0.079 \\
$285^{\circ}$ & 0.006 & 0.069 & 0.107
\end{tabular}


TABLE 5-IV

VARIANCES FROM THE $270^{\circ}$ THEORY CURVE

$\underline{250}^{\circ} \quad \underline{270}^{\circ} \quad \underline{285}^{\circ}$

greater

$\begin{array}{lll}\text { than } 0.04 V & 0.009 V & 0.022 v\end{array}$

\subsubsection{Radar Imaging.}

Previous reviews of literature ${ }^{16-19}$ and discussions with active researchers in the radar-sounding field have indicated that a deep borehole adaptation of these electromagnetic techniques might have potential for HDR fracture-mapping applications. A conclusion that radar might indeed be feasible derives from the work done at Chevron Research prior to 1969 by Robert Unterberger. At Chevron an effort had been under way to adapt radar technology to oil-well logging applications. Subsequently, Unterberger joined the geophysics staff at Texas A\&M and continued his work; however, he then directed his concern to problems associated with the use of borehole radar in sounding salt domes and salt mines. In FY79, a LASL subcontract was negotiated with Texas A\&M to have a feasibility study conducted by Unterberger to assess the possibility of the use of a radar technique to map or image hydraulic fractures. An additional objective was to prepare a conceptual design of a suitable radar tool, if the granite electromagnetic (em) transmission indicated that a set of radar parameters and downhole configurations is possible. The primary problems were range of the radar (i.e., $\sim 100 \mathrm{~m}$ is expected) and resolution in defining a water-filled fracture of $\sim 0.1 \mathrm{~mm}$ in width.

Two approaches were taken in evaluating the question of range vs frequency. Samples of GT-2 and EE-1 cores and two other granites were measured at the National Bureau of Standards (NBS) at Boulder, Colorado, for their en transmission characteristics. The results are tabulated in Table 5-V.

These data are comparable to those determined for other granites and show that the losses are relatively high (e.g., $\tan \delta \equiv \sim 10^{-4}$ is that observed for salt), and that no low-loss region or window exists in the granite attenuation spectrum over the $\sim 2 \mathrm{GHz}$ to $10 \mathrm{GHz}$ frequency range. This indicates that the range will be limited and, therefore, a continuous-wave (cw) radar is probably 


\section{TABLE 5-V}

\section{NBS DETERMINATION OF GRANITE}

RADAR TRANSMISSION PROPERTIES

("Dry" Samples at Ambient Temperature and Pressure)

\begin{tabular}{|c|c|c|c|c|}
\hline $\begin{array}{r}\text { Granite } \\
\text { Sample } \\
\end{array}$ & $\begin{array}{l}\text { Densityy } \\
\left(\mathrm{g} / \mathrm{cm}^{3}\right)\end{array}$ & $\begin{array}{c}\text { Frequency } \\
\text { Range } \\
\text { (GHz) } \\
\end{array}$ & $\begin{array}{c}\text { Relative } \\
\text { Permittivity } \\
E^{\prime}\end{array}$ & $\begin{array}{c}\text { Loss Tangent } b \text {, } \\
\tan \delta\end{array}$ \\
\hline \multirow[t]{3}{*}{$\mathrm{EE}-1$} & 2.676 & S-B and $2.5-3.5$ & $5.71 \pm 0.03$ & $0.013 \pm 0.004$ \\
\hline & & $C-B$ and $5.0-6.5$ & $5.66 \pm 0.05$ & $0.0115 \pm 0.004$ \\
\hline & & $X-B$ and $9.0-11.0$ & $5.72 \pm 0.05$ & $0.0115 \pm 0.003$ \\
\hline \multirow[t]{3}{*}{ GT-2 } & 2.697 & S-Band $2.5-3.5$ & $6.35 \pm 0.1$ & $0.032 \pm 0.01$ \\
\hline & & $C-B$ and $5.0-6.5$ & $6.25 \pm 0.1$ & $0.028 \pm 0.01$ \\
\hline & & $X-B$ and $9.0-11.0$ & (c) & (c) \\
\hline \multirow[t]{3}{*}{ Westerly } & 2.631 & S-B and $2.5-3.5$ & $5.61 \pm 0.04$ & $0.014 \pm 0.004$ \\
\hline & & $C-B$ and $5.0-6.5$ & $5.55 \pm 0.06$ & $0.012 \pm 0.004$ \\
\hline & & $X-B$ and $9.0-11.0$ & $5.48 \pm 0.05$ & $0.10 \pm 0.003$ \\
\hline \multirow[t]{3}{*}{ Berkeley } & 2.641 & $S-B$ and $2.5-3.5$ & $5.65 \pm 0.04$ & $0.009 \pm 0.004$ \\
\hline & & $C-B$ and $5.0-6.5$ & $5.63 \pm 0.08$ & $0.008 \pm 0.004$ \\
\hline & & $X-B$ and $9.0-11.0$ & $5.51 \pm 0.05$ & $0.007 \pm 0.004$ \\
\hline
\end{tabular}

a $E^{\prime}=\varepsilon^{\prime} / \varepsilon_{0}$ where the complex permitting $\varepsilon^{*}=\varepsilon^{\prime}-j \varepsilon^{\prime \prime}$ and $\varepsilon_{0}$ is the permittivity of free space $\equiv 8.85 \times 10^{-12} \mathrm{farad} / \mathrm{meter}$.

b $\tan \delta=\varepsilon^{\prime} / \varepsilon^{\prime \prime} ;$, and is related to the attenuation $\alpha=\frac{\pi \tan \delta}{\lambda} \mathrm{x}$ $\sqrt{\varepsilon^{1} / \varepsilon_{0} \cdot \mu^{1} / \mu_{0}}$, where $\mu \simeq 1$ is the relative magnetic permittivity $\lambda=\frac{V}{f}=\frac{\varepsilon^{\prime} \mu^{\prime}}{f}$, with $V$ the velocity of propagation in the rock.

c Resonance problem with GT-2 sample. 
not possible due to low power level. Although the NBS will repeat some determinations on wet samples and attempt to clear up certain resonance problems, it is unlikely that the new data will change these general conclusions.

Field transmission tests were conducted on large blocks of granite at three locations. The results are surmarized in Table 5-VI. In sumary, those results indicate that even for the high attenuation observed in granites, a C-band, CW low-power radar can penetrate a significant distance in granite; and the pulsed C-Band system must be tuned to the granite impedance before significant field data can be obtained; and no significant dispersion of the FM-CW radar beam was observed.

A preliminary set of design calculations was performed on a conceptual downhole tool configuration (Fig. 5-14) where the pulsed radar system parameters were taken to be those of a Foxtrot I (Model APN-171) altimeter as shown in Table 5-VII. A parametric study showed that a 100-m range was possible with the following.

$\frac{\text { Granite } \operatorname{Tan} \delta}{10^{-3}}$
$10^{-2}$

System Conditions

Simple signal conditioning and prototype Foxtrot I system will be adequate.

Will require signal stacking and lowering of front end noise to $10^{-13} \mathrm{~W}$.

The minimum range would be that of a pulse length, i.e., about $5 \mathrm{~m}$.

The projected mode of operation of the borehole radar is depicted in Fig. 5-15. The tool would be run in the wellbore before the fractures are formed and a set of axial stations occupied. Signal stacking could be accomplished at each station, and any background signals (e.g., from a tight, but mineral-filled fracture system) could be characterized. Following fracture formation the same stations would be occupied and the radar beam scans repeated. The net signals could be displayed on a real time azimuthal sweeping radial-range-scaled scope, Fig. 5-15(b) (i.e., PPI display). Therefore, a set of stations within a $30^{\circ}$ inclined borehole and a single vertical-plane fracture produces a set of parallel lines as the signal at each station is imaged on the scope face, and the orientation angle could be read directly from the photograph of the display. It is assumed that a north-triggered magnetometer orientation scanner* would be used. Resolution would limit the spacing of

* Similar to that used by Scott Keys (USGS) in the borehole "Televiewer" tool. 
TABLE 5-VI

\section{FIELD TESTS OF RADAR TRANSMISSION}

\begin{tabular}{|c|c|}
\hline Location & $\begin{array}{l}\text { Radar Type } \\
\text { and Frequency }\end{array}$ \\
\hline $\begin{array}{l}\text { Quarry at Marble } \\
\text { Falls, Texas } \\
\text { (Texas "Pink" } \\
\text { Granite) }\end{array}$ & $\begin{array}{l}\text { FM-CW } \\
\text { C-Band }(5 G \mathrm{~Hz})\end{array}$ \\
\hline $\begin{array}{l}\text { Terra Tek, Inc., } \\
\text { Salt Lake City } \\
\text { Utah }\end{array}$ & $\begin{array}{l}\text { FM-Cw } \\
C-B \text { and }\left(5 \mathrm{GHz}^{2}\right)\end{array}$ \\
\hline
\end{tabular}

Results

Remarks

Transmission through $6 \mathrm{ft} 3$ in. and $9 \mathrm{ft}$ of pink and $5 \mathrm{ft} 101 / 2$ in. of grey granites. No detectable signals through $13 \mathrm{ft}$ and/or $14 \mathrm{ft}$ of above granites.

Transmitted through a variety of rock types: Texas Pink and Sierra thite Granite; also sandstones, dolomite marble chalk, and limestone. Distances of 4 to $8 \mathrm{ft}$.

$\begin{array}{lr}\text { Quarry at } & \text { (a) } \begin{array}{l}\mathrm{FM}-\mathrm{CW} \\ \text { Raymond, }\end{array} \\ \text { California } & (5 \mathrm{BHz} \text { and } \\ & (\mathrm{Hz})\end{array}$

(a) Transmittal through $17 \mathrm{ft}$ with good signal output. Could not penetrate $56 \mathrm{ft}$ block.

(b) Pulsed, $4.3 \mathrm{GHz}, 100-$ $300 \mathrm{~K}$, Pulse frequency $10 \mathrm{kHz}$, and pulse length 35-100 ns.

(b) Problem with coupling to rock.

Small 1 W portable system. Good start.

Same equipment except transmittal signal observed on scope.

(a) Same 1 W system. Same results as

for Sierra White granite at Terra Tek.

(b) Apparently large mismatch with rock impedance loaded the output.
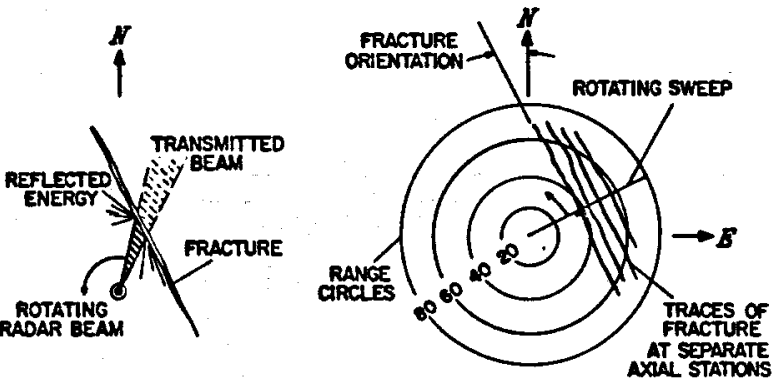

D-activates sigial OUTPUT

E-CONTROLS INTEGRATION TIME

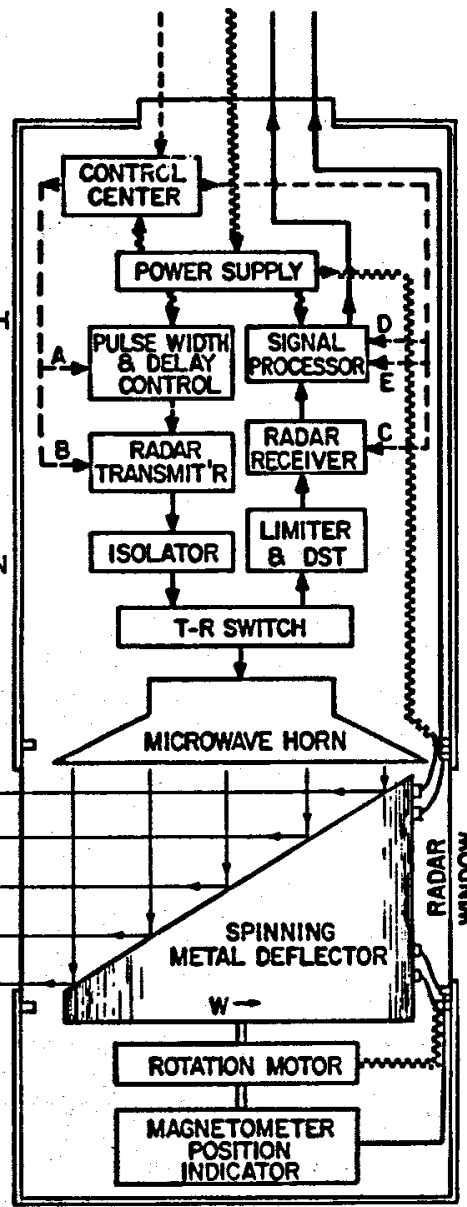

Fig. 5-14.

Conceptual downhole radar tool configuration. 
TABLE 5-VII

PARAMETERS OF THE FOXTROT I ALTIMETER RADAR SYSTEM - MODEL APN-171

Transmitter Frequency
Pulse Width $(0-1000 \mathrm{ft})$
Pulse Width $(1000-5000 \mathrm{ft})$
Peak Power $(0-1000 \mathrm{ft})$
Peak Power $(100-5000 \mathrm{ft})$
Pulsed Frequency
Receiver Bandwidth $(0-1000 \mathrm{ft})$
Receiver Bandwidth $(1000-5000 \mathrm{ft})$
Antenna Pattern $(3 \mathrm{~dB})$
Antenna Gain
Altitude Accuracy
Power Requirements

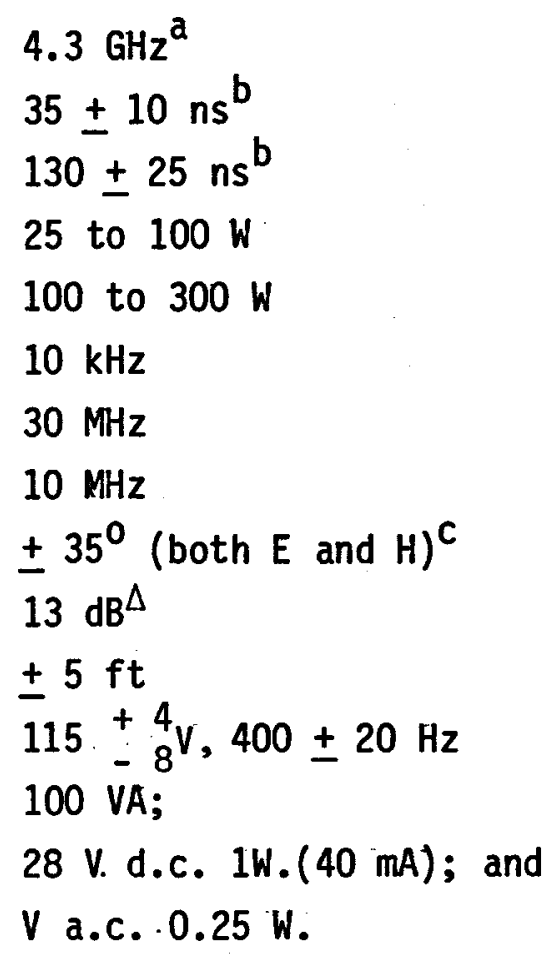

a air $-6.977 \mathrm{~cm}, 2.747$ in.; granite $=2.92 \mathrm{~cm}, 1.15$ in. (assumes $\varepsilon^{\circ} / \varepsilon_{0}$ $=5.7$ for EE-1 granite).

b Pulse length in air $\ell=10.5 \mathrm{~m}(35 \mathrm{ft})$, i.e., $1 \mathrm{ft} / \mathrm{ns}$; or $\ell^{\prime}=\ell \sqrt{\varepsilon^{\prime} / \varepsilon_{0}}=$ $4.4 \mathrm{~m}(15 \mathrm{ft})$ in granite.

c Calculated: $E$ beam $=40^{\circ}$

$\mathrm{H}$ beam $=26.7^{\circ}$

$\triangle \quad$ Calculated gain $=13.86 \mathrm{~dB}$

detectable fractures to about $10 \mathrm{~cm}(4 \mathrm{in.})$. It is also possible that the reflected signal will contain data on the crack width or aperture.

The results of the research indicate the following.

- Deve lopment of pulsed radar system of C- or X-band frequency should be pursued. 
- Field and laboratory tests of such pulsed systems on granite blocks should be continued.

- Optimization of radar parameters such as pulse length, maximum pulse power (lower pulse-rate frequency), and reflected pulse stacking should be studied with the goal of maximizing range.

- The reflection properties of water-filled fractures should be investigated.

- The techniques for matching the radar input to granite should be explored and a suitable method developed.

- The problems of losses in the water in the borehole and at the borehole/wall interface must be addressed.

- Development of detailed specifications for the subcomponents of a prototype tool can commence.

In sumary, the results thus far show that a radar fracture-mapping tool may be possible that will have a range of $100 \mathrm{~m}$ in granite. A concept that includes an azimuthally swept, pulsed radar beam may provide a direct online, surface readout of fracture orientation. Resolution of multiple fractures or complex fracture systems may be possible. Subsequent radar-imaging surveys after heat extraction may resolve the formation and growth of thermal-stressinduced fractures. A prefracturing survey is needed to define preexisting fracture structure, e.g., those fractures filled with minerals, so that the natural background can be distinguished from the subsequent hydraulic fracture system.

5.1.5. In Situ Stress Measurements.* The purpose of this study is development of a self-recording downhole caliper for extremely sensitive measurement of wellbore dimensions. Mechanical dial-indicating gauges capable of measuring strains in the 10 to 50 microinch-per-inch range exist, but are too fragile for downhole use. De la Cruz postulates that fragility increases with magnification of the original motion, and proposes development of one-toone (121) or one-to-five (125) downhole devices. (The latter would scribe

* Work done under contract to Prof. R. V. de la Cruz, University of WisconsinMadison. 
marks five units apart for a change of one unit of strain.) . The desired magnification will finally be obtained in the laboratory with a microscope.

The 121 and 125 gauges have the feature of automatic extension and retraction by the same clockwork mechanism that drives the recorder plate. The 121 gauge has been selected for fabrication and testing at this time, as it is more rugged and smaller than the 125 gauge. A laboratory test of the 121 gauge will be conducted, followed by design of a prototype downhole gauge if the laboratory measurements are successful.

- Feasibility of recording and reading deformation with mechanical gauges: A dial gauge was modified to scribe a polished brass plate with a mechanical magnification of $12 \mathrm{x}$. A variation of 0.001 in. at the input to the dial gauge was observed with a resolution that would be better than 100 microinches on the 125 guage.

- Range of values in field measurements: For a pressure of 3000 psi in a wellbore of radius $R=4.375$ in., drilled in rock with a Young's modulus, $E$, of $10^{6}$ psi and Poisson's ratio, $v$, of 0.25 , the radial deformation is calculated to be $16.5 \times 10^{-3}$ in.

- Downhole stress-measuring tool development: The strike of hydraulically induced fractures is thought to be controlled by earth stress--in particular, the fracture extends normal to the direction of the least principal stress. Thus, if the earth stresses at depth can be measured, the direction in which the wellbore should be drilled can be determined. Professor Earl Hoskins, Texas A\&M University, has contracted to design a tool that will press three strain gauges against the wellbore wall, drill a hole between the gauges, and observe the strain relief. From such data taken in different directions in the wellbore, earth stresses can be derived, provided that the elastic moduli of the rock are known. Three cores from Fenton Hill have been studied to determine these moduli. Moduli were measured in various directions and the influence of microcracks studied. Residual stresses of approximately 60 bar were measured by the trepanning technique in samples from 9000-ft depth. A report is being written on this work.

Design of the components of the stress measuring tool is complete and drawings are ready for the machine shop. Motors have not yet been chosen-delivery time on these has been three to four months in recent LASL orders-so the minimum time for tool readiness is probably about six months. 
5.2. Reservoir Properties. (LASL contributors: L. A. Blatz, C. C. Holley, A. W. Laughlin, C. J. Duffy, C. 0. Grigsby, B. H. Arney, T. J. Shankland, P. M. Halleck, J. D. Blacic, D. W. Brown, D. A. Counce; A. Kumnick, CaseWestern Reserve University; Northwestern University contributors: L. Keer, J. Weertman, Z. Bazant, S. Nemat Nasser)

5.2.1. Core Studies. Natural fractures and the minerals filling them are important in controlling some of the reservoir properties that in turn affect the behavior of HDR systems. The fracture fillings in cores from GT-2 were studied to provide information on their chemistry and mineralogy. Information on the fractures as well as the host rock is needed for evaluation of rock strength properties as well as for analysis of solubility in various fluids, which may be important with regard to enlarging the apertures of reservoir cracks to reduce flow impedance. In addition, variations in the composition of the water after circulation through the reservoir can be compared to laboratory observations of rock-water chemistry in an attempt to model the interactions taking place. For example, there is a great deal of interest in determining the source of the chloride that is observed in the water. ${ }^{20}$

Microprobe studies of the fracture fillings in cores from GT-2 are nearly finished. Following optical microscopy of all thin sections, probe sections were made of core samples with visible fractures, taking approximately one sample per thousand $\mathrm{ft}$ of depth from 900 to $2500 \mathrm{~m}(3000$ to $8000 \mathrm{ft}$ ) and two samples each from two cores in the main reservoir region from 2895 to $2930 \mathrm{~m}$ (9500 to $9600 \mathrm{ft}$ ).

A general pattern in fracture-filling minerals has emerged from this study. The fillings in the upper cores are carbonates (see Fig. 5-16a). Usually there are at least two compositions of carbonate, sometimes three, indicating deposition from successive hydrothermal fluids of different composition. Table 5-VIII gives the compositions of representative grains from each of the veins studied. The carbonate composition was probably influenced by the host rock. Siderite $\left(\mathrm{FeCO}_{3}\right)$ was deposited in the more mafic rock at $1824 \mathrm{~m}(5985 \mathrm{ft})$, whereas ankerite $\left(\mathrm{Ca}[\mathrm{Mg}, \mathrm{Fe}, \mathrm{Mn}]\left[\mathrm{CO}_{3}\right]_{2}\right)$ was deposited above and below that depth in less-mafic rock, but the range of compositions even in a single vein can be great.

In the reservoir, rock samples at 2895 to $2930 \mathrm{~m}$ (9522 to $9608 \mathrm{ft}$ ), pure potassium feldspar appears to be the dominant vein filling. Carbonate, which is pure calcite where it occurs, is in discontinuous large patches surrounded by microcrystalline potassium feldspar. As seen in Fig. 5-16b, the calcite 
TABLE 5-VIII

MICROPROBE ANALYSES OF VEIN MINERALS (GT-2) FROM SELECTED SAMPLES

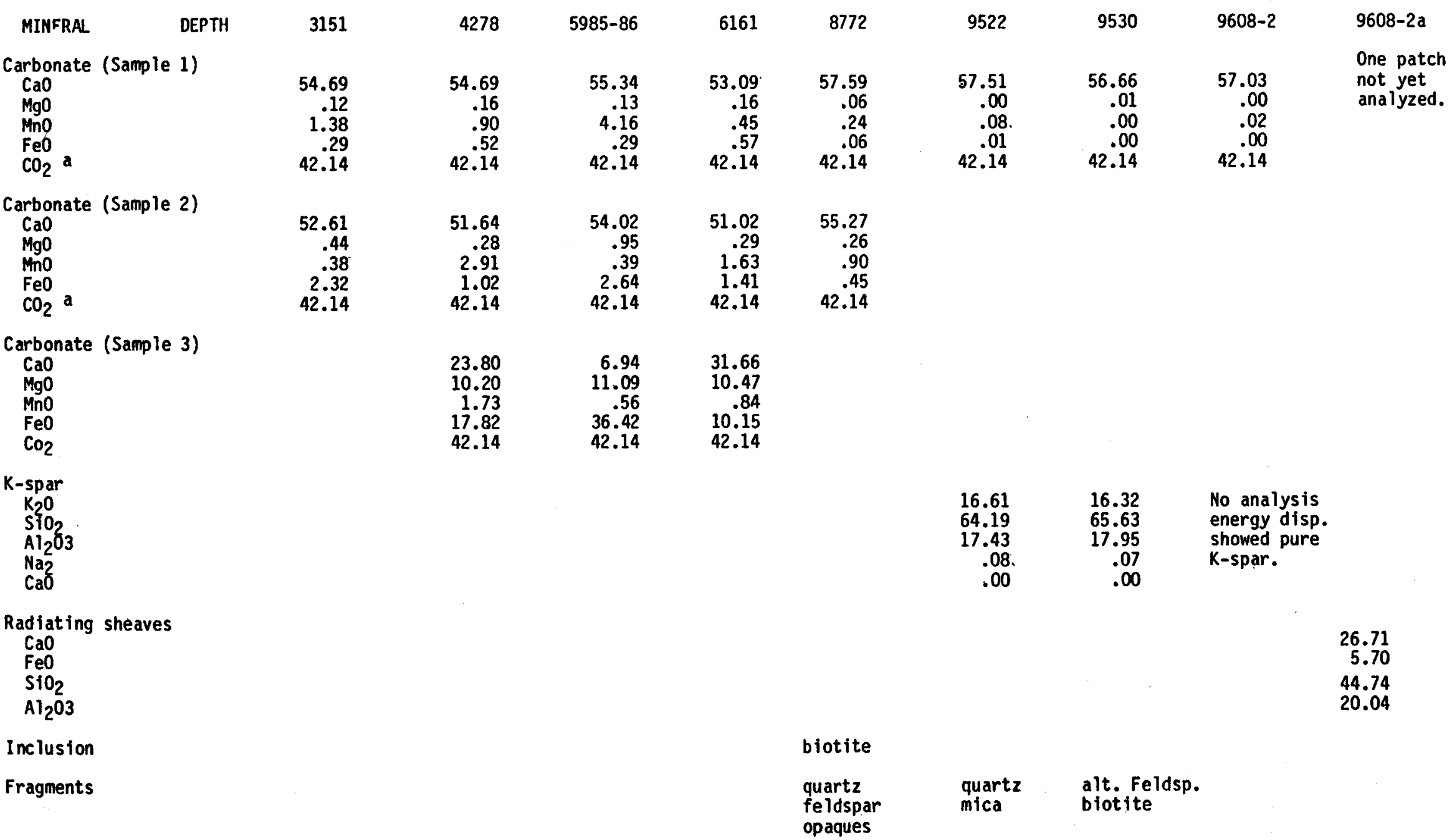

a $\mathrm{CO}_{2}$ fred at 42.14

Carbon $(C)$ cannot be measured on the microprobe. This is a compromise value between that for calcite and dolomite. 

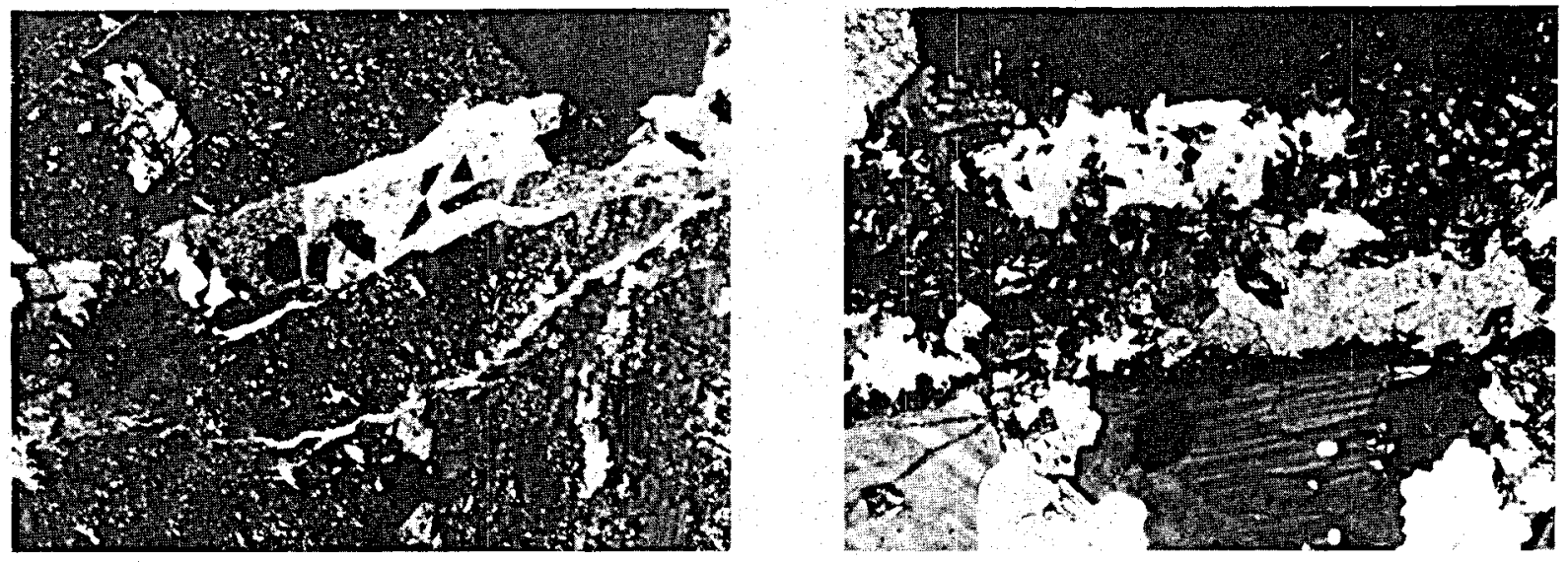

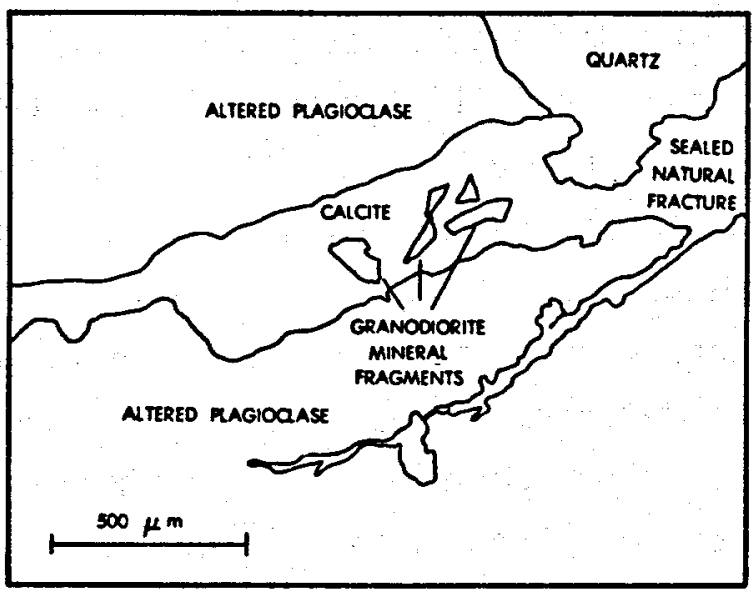

Fig. 5-16(a).

A natural fracture in a granodiorite matrix (here quartz and altered plagioclase sealed with calcite). Fracture filling material consists of large optically continuous calcite grains enclosing fragments of quartz, feldspar, and opaques broken off the matrix during fracturing.

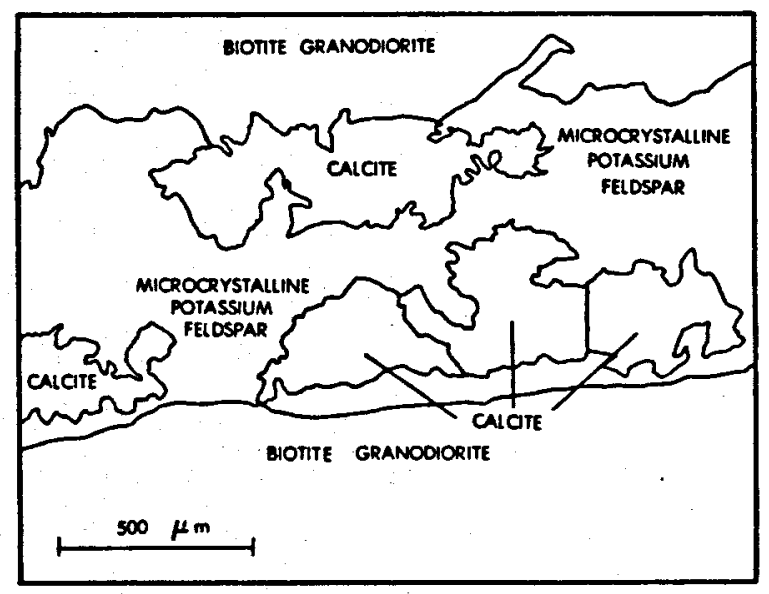

Fig. 5-16(b).

Calcite and potassium feldspar filled fracture in a biotite granodiorite matrix. Patches of optically continuous calcite in microcrystalline potassium feldspar are shown.

patches are often clustered in a few segments of the vein while the rest is filled with pure potassium feldspar. Calcite never extends completely across the vein and rarely extends to either edge of the vein. The veins may also contain brecciated material from the country rock surrounded by microcrystalline potassium feldspar. It is difficult to give relative percentages of carbonate and feldspar as they vary along a single vein as well as between veins. An average is probably 10 to $30 \%$ calcite, the rest is potassium 
feldspar. More important is that the calcite is in discontinuous patches. The feldspar, though microcrystalline, is physically continuous. Potassium feldspar is not observed as a fracture filling above this level. An as-yet-unidentified fibrous mineral appears only in the deepest section.

No chlorine or fluorine was detected in any of the fracture fillings, either in minerals or interstitially. A special chlorine "free" epoxy was used, but even that contained more chlorine than any mineral traversed either in the veins or in the rock. The source of the chlorine in solutions from the flow experiments more likely is existing pore fluid that was displaced during the pressurization and not a chemical dissolution effect. ${ }^{10}$

5.2.2. Dissolution Kinetics. Efforts continued during the fiscal year to characterize the dissolution kinetics and solubility of crystalline basement rock at temperatures of interest to the Phase I and II systems at Fenton Hill. The rate of interaction of water with granitic rock at $175^{\circ} \mathrm{C}$ to $275^{\circ} \mathrm{C}$ was studied in batch experiments using agitated autoclaves and in a circulating geothermal test loop constructed of titanium.

Autoclave Studies. Small autoclave reactors made of stainless steel with Teflon liners for use at $200^{\circ} \mathrm{C}$ and with titanium liners for use to $275^{\circ} \mathrm{C}$, were rocked gently in an oven or at the end of an aluminum bar. In the latter case heating was by means of band heaters. The ratio of rock (biotite granodiorite drill cuttings, 20 to 60 mesh, from well EE-1 at Fenton Hill) to water was typically $1 \mathrm{~g}$ to $15 \mathrm{~m}$. At the end of a run the reactor was quenched quickly and samples were taken for $\mathrm{pH}$ measurements and for silica analyses. For the determination of monomeric silica, the spectrophotometric method using ammonium molybdate was used. For total silica, atomic absorption was used as well as a modification of the spectrophotometric method in which the silica is depolymerized by first heating for one hour in the presence of hydrofluoric acid (HF) in a closed container, then using an aluminum ion addition to complex the fluoride ions, thus freeing silicon to form the silicomolybdate complex.

Experiments were conducted at 200, 235, 250, and $275^{\circ} \mathrm{C}$. For given conditions, experiments were repeated using the same rock sample, but with fresh distilled water. These successive experiments are referred to as the 
first extraction, second extraction, etc. The series at $275^{\circ} \mathrm{C}$ is most complete and the results are shown in Fig. 5-17. The following conclusions may be drawn.

(1) At equivalent exposure times, the amount of silica extracted is less for each successive extraction, although at 48 hours the first three extractions give about the same value. Presumably the quartz particles initially have active sites such as small surface particles, corners, and stressed regions, which give a higher initial rate of dissolution. After these have been removed a lower, more characteristic rate results. For the 48-h runs, enough silica is dissolved

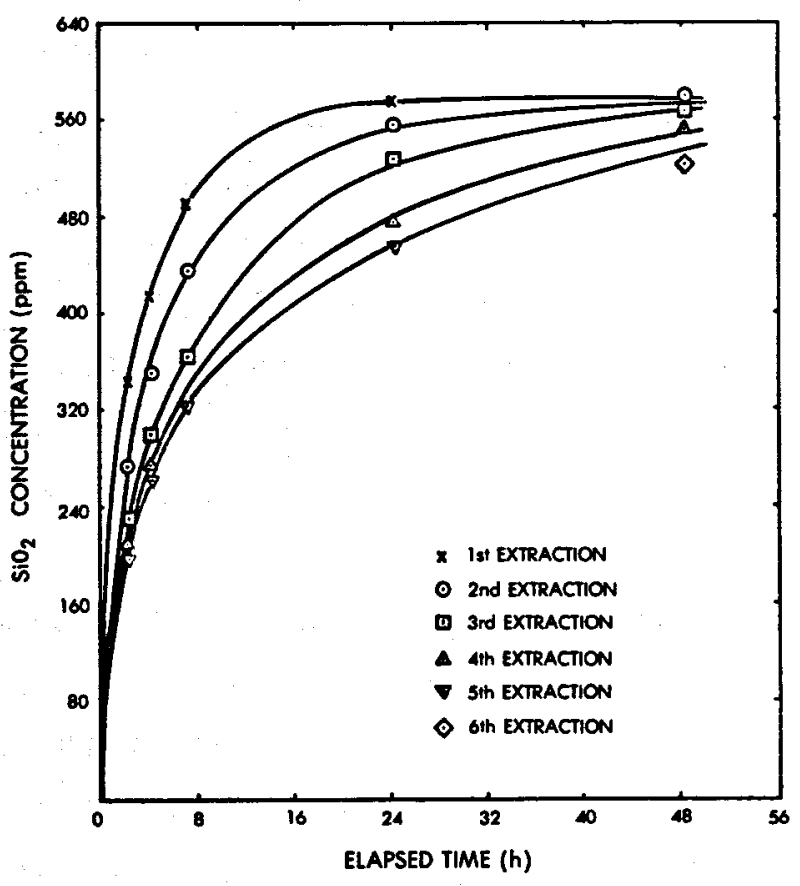

Fig. 5-17. Monomeric silica vs time. even during the first extraction to overcome this effect. The later fall-off in the $48-h$ runs may be caused by the significant reduction in the actual amount of quartz remaining in the rock because quartz is the primary reactive mineral species.

(2) The curves have a shape similar to that expected if the rate of dissolution obeyed the rate law

$$
\frac{d\left(\mathrm{SiO}_{2}\right)}{d t}=k a^{*}\left[\left(\mathrm{SiO}_{2}\right)_{s a t}-\left(\mathrm{SiO}_{2}\right)\right]
$$

where $a^{*}$ is the effective rock surface area to fluid volume ratio, $k$ is the dissolution rate constant, and $\left(\mathrm{SiO}_{2}\right)$ and $\left(\mathrm{SiO}_{2}\right)$ sat the actual and quartz controlled saturation concentration of dissolved silica. The integrated form is

$$
\text { en }\left[\frac{\left(\mathrm{SiO}_{2}\right)_{\mathrm{sat}}-\left(\mathrm{SiO}_{2}\right)}{\left(\mathrm{SiO}_{2}\right)_{\mathrm{sat}}}\right]=k a * t \text {. }
$$


Fig. 5-18 shows a plot of the data in this form where at $275^{\circ} \mathrm{C}\left(\mathrm{SiO}_{2}\right)$ sat $=643 \mathrm{ppm} \cdot{ }^{21}$ The points for 2, 4, and $7 \mathrm{~h}$ fall on straight lines. The points for 24 and $48 \mathrm{~h}$ indicate slower rates at these longer times, and the initial slopes indicate faster initial rates. These observations are consistent with the suggestion in the previous paragraph.

Circulating Geothermal Test Loop. This small loop was described previously. ${ }^{9}$ The interaction of water with Tijeras Canyon granite was studied at two different flow rates and three different temperatures by following the rate of buildup of monomeric silica in the solution. The ratio of rock (with particle sizes ranging from 3 to $15 \mathrm{~mm}$ ) to water was about $6 \mathrm{~kg}$ to $15 \mathrm{l}$. The results are shown in Fig. 5-19.

Initially, it was expected that at these temperatures, because of slower kinetic rates of dissolution compared to

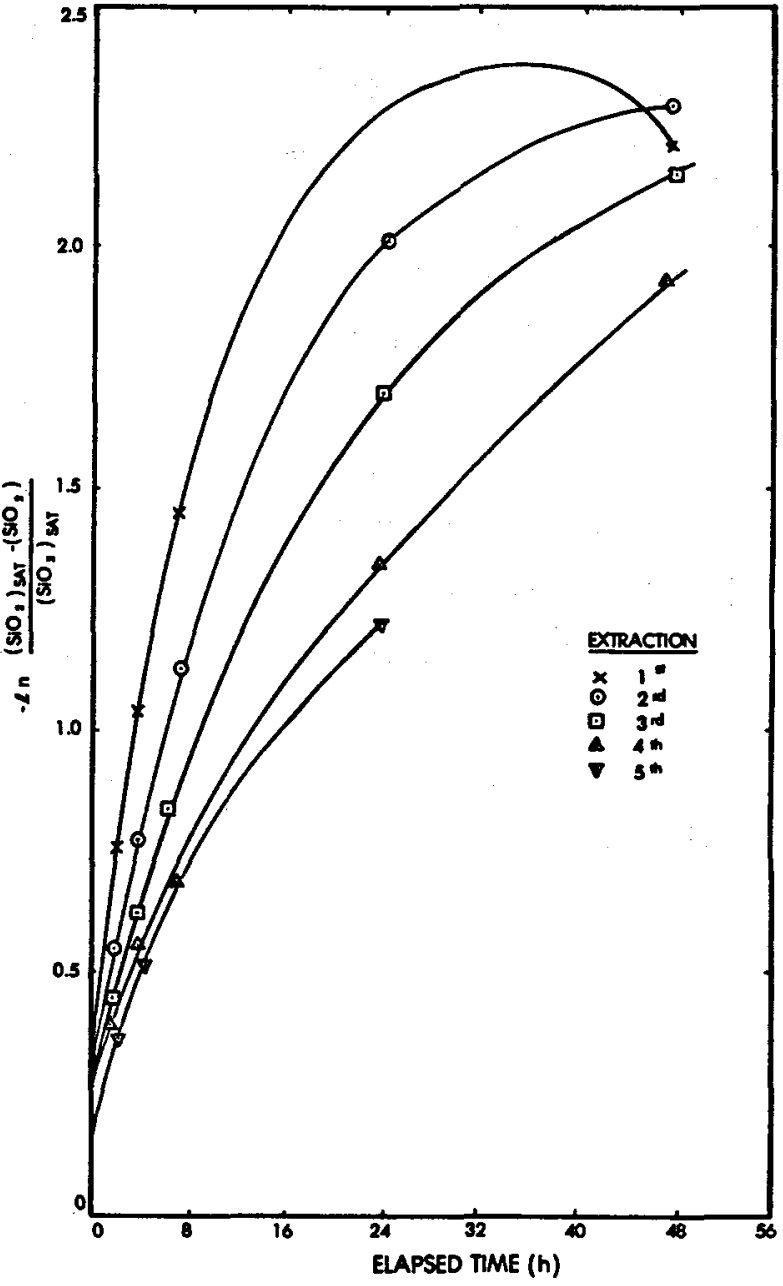

Fig. 5-18. Integrated rate equation compared with data. bulk mass transport rates, would not be an observable effect of flow rate--although at some higher temperature it would become important. However, for runs LTG-6 and LTG-7 it appeared that at $200^{\circ} \mathrm{C}$ a higher flow rate enhanced the rate of dissolution of silica. But for runs LTG-8 and LTG-9 at $175^{\circ} \mathrm{C}$ the effect was reversed. Apparently the reactivity of the rock falls off with successive experiments, an effect similar to that observed with the small autoclave reactors as described above.

Silica Colloid Formation. In the small autoclave experiments and in the loop experiments, the total silica concentration was higher than the monomeric silica concentration. Examination of the solutions with a light beam showed a Tyndall cone indicating the presence of colloidal particles. To learn more about this colloid, two liters of the related solution remaining in the rock 


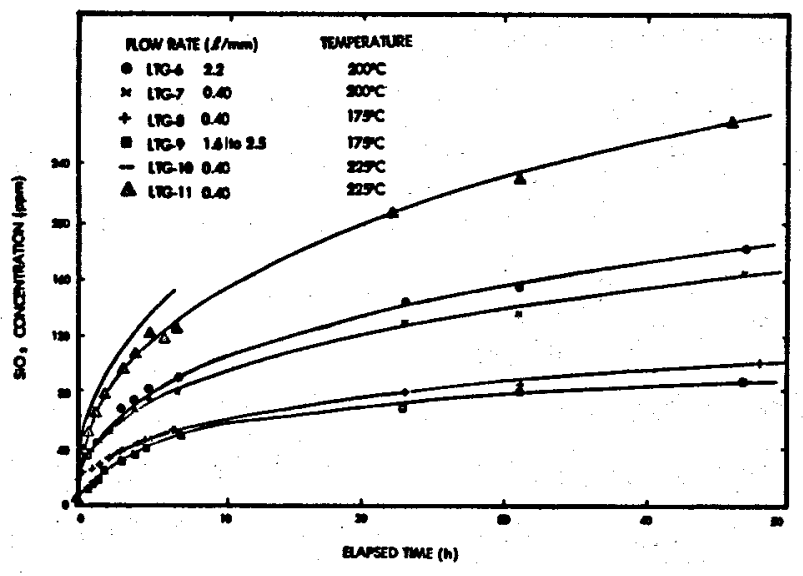

Fig. 5-19.

Silica buildup in model geothermal loop (Tijeras Canyon granite, distilled water).

reactor of the loop were filtered at the end of run LTG-10 successively through $10-\mu \mathrm{m}, 1.2-\mu \mathrm{m}, 0.1-\mu \mathrm{m}$, and 0.01-um filters. The solution was analyzed initially, and after each filtration, for monomeric silica and total silica. After filtration through the 0.1- $\mathrm{m}$ filter, there was no significant difference between the two analyses. The material on the $10 \mu \mathrm{m}$ filter consisted of amorphous silica, some chloritized biotite, a little chalcopyrite, possibly magnetite, with some evidence of cobalt and tungsten. The coarse Tijeras Canyon granite had been crushed in a rock crusher, and it seems likely that the tungsten and cobalt, if they were actually present, came from abrasion of the rock crusher. On the finer filters the material consisted of amorphous silica, chloritized biotite, and clay.

Two colloid solution samples taken from the Fenton $\mathrm{Hill}$ geothermal reservoir system were analyzed in the same way. The material on the filters contained appreciable amounts of amorphous silica, some clay, and probably a fair amount of organic material left over from the drilling operations.

\subsubsection{Rock Physics.}

This work in rock physics provides usable interpretations of changes in rock fabric with geothermal reservoir changes. Virtually all of the pore space created by pressurizing the reservoir is new porosity in the form of flattened volds. These newly opened cracks are described in terms of amount (crack density), volume (porosity), and shape (aspect ratio or flattening). The 0 'Connell-Budiansky ${ }^{22}$ models have been used because they afford information not only on changes of elastic parameters, but also on anelastic parameters such as the seismic quality or attenuation factor, $Q$, and--uniquely-the ir frequency dependence. 
Pressure-induced changes observed in between-hole measurements at Fenton Hill are as follows: P-velocity decreases of several percent; signal amplitude decreases of 3 to $35 \mathrm{db}$ over distances of 10 to $20 \mathrm{~m}$, i.e., attenuation increases of 0.3 to $3 \mathrm{db} / \mathrm{m}$; a frequency band in the range of $10 \mathrm{kHz}$; and indications of increasing attenuation with frequency. Thus, there are at least three sets of input data for interpretation.

Figure 5-20 shows the calculated frequency dependence of relative velocities and of attenuation in $\mathrm{db} / \mathrm{m}$ for cracks of aspect ratio $10^{-3}$, which is the ratio of the semiminor to semimajor axes of a flattened ellipsoidal crack. Attenuation is related to a seismic quality factor, Q, approximately by $20 \pi f /(Q V e n 10)$ where $f$ is frequency and $V$ is velocity. Figure $5-21$ is a similar calculation for a different aspect ratio, $10^{-4}$. In both figures three crack densities were used, $0.1,0.2$, and 0.3 (number of cracks per unit volume times major crack radius used) for $P_{-}$and S-velocities (solid and dashed lines, respectively).

Three sets of data on changes of velocity, attenuation, and frequency band can be used to set bounds on crack parameters. The 3 to $4 \%$ P-velocity drop can be induced by an increase in crack density of about 0.1 at $10 \mathrm{kHz}$ in going from

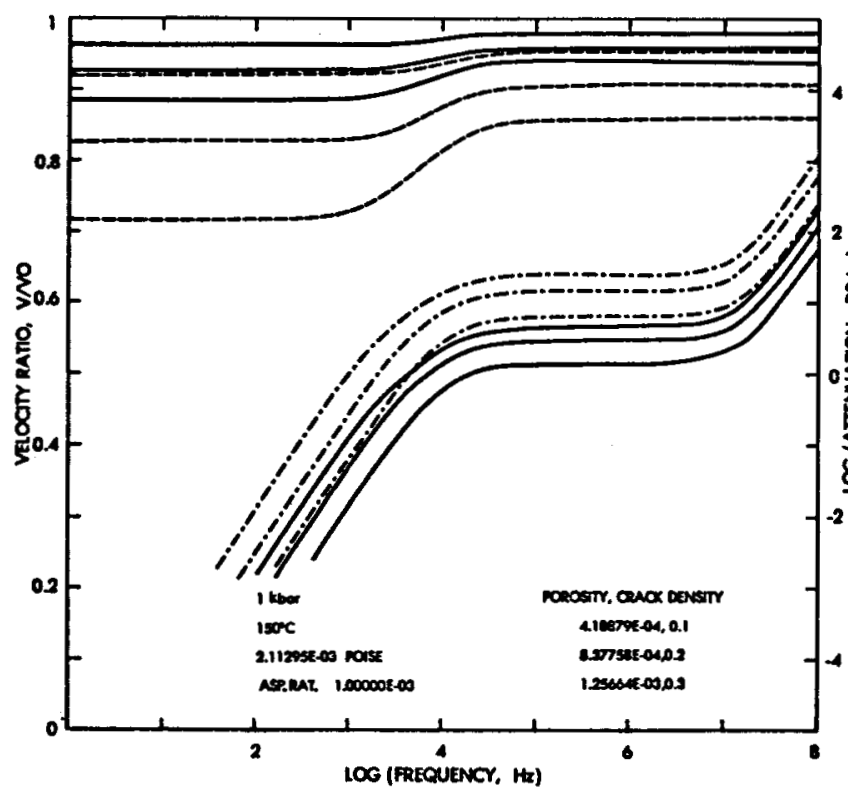

Fig. 5-20.

Relative velocity changes and attenuation in rock having fractures of dominant aspect ratio $10^{-3}$.

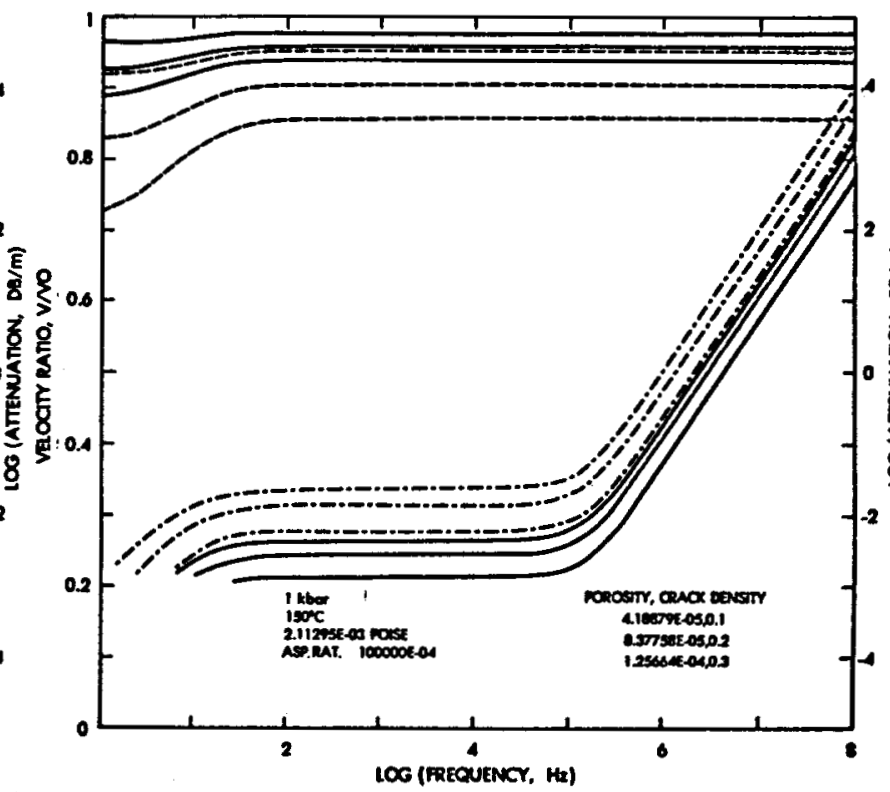

Fig. 5-21.

Relative velocity changes and attenuation in rock having fractures of dominant aspect ratio $10^{-4}$. 
the unpressurized to the inflated condition. If the native crack density were near zero--which is unlikely, given the previous pressuration history of the area--then 0.1 would be the pressurized crack density. It is possible to have observed attenuations of about $1 \mathrm{db} / \mathrm{m}$ in the $10-\mathrm{kHz}$ range and crack densities close to 0.1 if we assume an aspect ratio close to $10^{-3}$ as in Fig. $5-20$. The rising attenuation with frequency suggests that a slightly lower value might be more appropriate. A mean aspect ratio of $10^{-4}$ as illustrated in Fig. 5-21 yields far too low an attenuation to satisfy the data in this frequency band. Other calculations demonstrate that a distribution of aspect ratios is possible, although attenuation is slightly low for that. Finally, we note that porosities consistent with a crack density of about 0.1 and an aspect ratio slightly less than $10^{-3}$ would be in the vicinity of $3-4 \cdot 10$.

These models, in particular their ability to display frequency dispersion of elastic parameters, thus allow a better description of crack fabric in the Fenton Hill reservoir. - However, it is not possible to take into account anistropy, volume inhomogeneity of cracking along the ray paths, or scattering.

Finally, it should be possible to improve this description of crack texture by obtaining extended acoustic data on the frequency dependence of attenuation. Work on use of these models in interpretation of electrical properties is continuing.

\subsubsection{Rock Mechanics.}

Experimental Studies. Work during the fiscal year concentrated on fracture toughness and rock moduli measurements as well as on studies of slow crack growth in a number of granite samples. The objectives in this area of research are twofold. The first is to characterize the mechanical strength properties of reservoir rock from Fenton $\mathrm{Hill}$ and of other rock specimens used for fracturing and heat-transfer/fluid-flow studies; and, second, to improve our understanding of fracture initiation and propagation in crystalline basement rock.

Fracture toughness measurements at room temperature in air were made on quarried Westerly and Berkeley granite specimens using a three-point bend test technique to determine the effect of orientation (see Kumnick and Halleck for details $\left.{ }^{23}\right)$. The important results of this study showed that measured $K_{Q}$ toughness values of 1 to $2 \mathrm{MPa} \vee \mathrm{m}$ were consistent with previous measurements 
on Westerly granite and that $K_{Q}$ depends strongly on orientations as correlated to the three primary quarrying directions (head grain, rift, and intermediate grain planes). In addition, a good correlation between tensile modulus and $K_{Q}$ for each or ientation was obtained.

If $\mathrm{K}_{\mathrm{Q}}$ shows a strong directional dependence under in situ conditions in HDR reservoirs, primary hydraulic fracture and secondary thermal-stresscrack orientations may be influenced. Because of the correlation between modulus and $K_{Q}$, it may be possible to assess the degree of the directional effect from in situ modulus measurements (see Sec. 5.1.6).

Later studies in this area will focus on EE-2 and EE-3 core specimens and on quantifying the effects of environment and sample history on $\mathrm{K}_{Q}$. Parameters to be studied include thermal cycling, temperature $\left(25\right.$ to $300^{\circ} \mathrm{C}$ ), effective stress, and pore fluid pressure and chemistry.

Slow crack growth rates in Berkeley granite were also correlated to variations in the stress intensity factor. A plateau of constant growth rate exists where the effective stress intensity $K$ is between 0.7 and 0.9 of $K_{Q}$. Catastrophic failure occurs for $K \geq 0.93 K_{Q}$. Both of these effects have some orientation dependence. Long-term stability of fractured systems as well as the development of thermal stress cracks may be affected by this phenomenon.

In order to model thermal and pore pressure induced effects on reservoir performance, shear, compressive, tensile, and bulk-moduli, data are required for varying effective stresses. Laboratory measurements directed toward core material studies have been under way to establish suitable ranges of mechanical strength properties for parameter modeling studies. Preliminary measurements on Berkeley granite indicate an increase in Poisson's ratio and a decrease in Young's modulus nonlinearities with increasing effective stress (decreasing pore pressure). Future studies will be extended to high temperatures with core specimens from EE-2 and EE-3.

\section{Experimental Studies at LASL}

Studies at Northwestern University. Under separate subcontract researchers at Northwestern University have examined features of hydraulic fracture propagation and thermal stress cracking, which are important to the HDR program. The details of this work are reported in Ref. 14. The major conclusions are summarized below. 
- Interaction of Propagating Vertical Hydraulic Fractures with FreelySlipping Horizontal Joints. Using fracture mechanics analysis, J. Weertman found that if a joint was free to slip, i.e., incapable of resisting shear, the continued propagation of a vertical fracture could be stopped at its intersection with the joint because all of the injected fluid that previously had driven the fracture upward would imply flow into the joint.

- Interaction of Parallel Thermal Stress Cracks. When equidistant, parallel cooling cracks penetrate the rock surrounding a HDR reservoir, a linear fracture mechanics analysis suggests that when these cracks reach a critical depth, every other crack is arrested so the spacing between cracks doubles. The intermediate cracks then open about twice as wide and advance further as thermal cooling penetrates deeper. With further propagation the process repeats itself, so with continued cooling, fewer and fewer cracks continue propagating, but with ever-increasing openings.

The penetration depth-crack spacing ratio remains an unresolved issue. Z. Bazant and A. B. Wahab maintain that the ratio is particularly sensitive to the profile of temperature variation along the crack depth, so that if the cooling front becomes very steep, the depth-spacing ratio becomes very large. Thus more, but narrower, cracks will penetrate to a given depth. On the other hand, the analysis of S. Nemat-Nasser and L. M. Keer indicate that the depthto-spacing ratio is of order of magnitude one. Their analysis also indicates that the thermal cracks can curve, rather than remain parallel, so that crack intersections and potential rock fragmentation could occur.

- Interaction of Multiple Hydraulic Fractures. In some HDR reservoirs it may be desirable to create multiple, rather than single, fractures from the same pair of water injection and extraction wells. Multiple fracturing results in additional heat-transfer area and increased heat production without significantly increasing costs, but it requires that the propagating hydraulic fractures remain nearly parallel, without intersecting and possibly stopping further propagation of one or the other fracture. J. Dundurs has examined this problem with the aid of small-scale fracturing experiments in transparent epoxy blocks. He observed no significant interaction between two fractures; their planes during the major growth phases were practically parallel. 
Separate thermal cracking experiments appeared to corroborate : one of NematNasser and Keer's predictions, namely, thermal cracks did curve and tended to intersect, and the thermal crack pattern became coarser with increasing depth.

5.2.5. Permeability, Porosity, and Pore Compressibility. A 48-day continuous-flow laboratory experiment was performed on a sample of GT-2 core from $8904 \mathrm{ft}$. Effective confining pressure was maintained at $20 \pm 3 \mathrm{MPa}$ at a temperature of $193 \pm 2^{\circ} \mathrm{C}$. The permeability ranged from about $1.9 \cdot 10^{-20}$ $\mathrm{m}^{2}$ during the early part of the experiment to about $1.5 \cdot 10^{-20} \mathrm{~m}^{2}$ at the end. The average flow rate was approximately $0.5 \mathrm{~cm}^{3} /$ day of distilled water, which increased in mineral content after passing through the sample to approximately $100 \mathrm{ppm} \mathrm{Si,} 90 \mathrm{ppm} \mathrm{K,} 24 \mathrm{ppm} \mathrm{Na}, 1 \mathrm{ppm} \mathrm{Fe}$, and $0.5 \mathrm{ppm} \mathrm{Ca}$. Due to the low flow rate used, only a small amount of material was actually removed from the sample. This is reflected in the small change in permeability. However, it might be expected that dissolution of material would increase the porosity of the rock and hence its permeability. That this is not the case in this experiment may be due to two factors. Dissolution may be expected to proceed most rapidly at points of stress concentration. Such stress concentrations will be present at bridging points that tend to hold open the porosity, for example, in microcracks. Dissolution of these bridging points would tend to cause collapse of the porosity of the rock and reduction of its permeability. Formation of secondary minerals may also occur. These minerals will almost certainly be more hydrous than the original assemblage. The growth of this secondary mineral assemblage may increase the volume of the solid in the rock despite the removal of $\mathrm{Si}, \mathrm{K}$, and $\mathrm{Na}$. The growth of a secondary mineral assemblage may also change the character of the flow channels. Factors such as increased roughness of the channel walls may also decrease the effective permeability. Whatever the cause of the permeability decrease, it suggests that the matrix permeability in the HDR reservoir may decrease with time and may, therefore, contribute to a lessening of the water loss.

Two samples of granite from the Rosemanowes quarry in Cornwall, U.K., were examined. The permeabilities of three cores from each sample were measured. The results are shown in Figs. 5-22 and 5-23. The only conclusion 


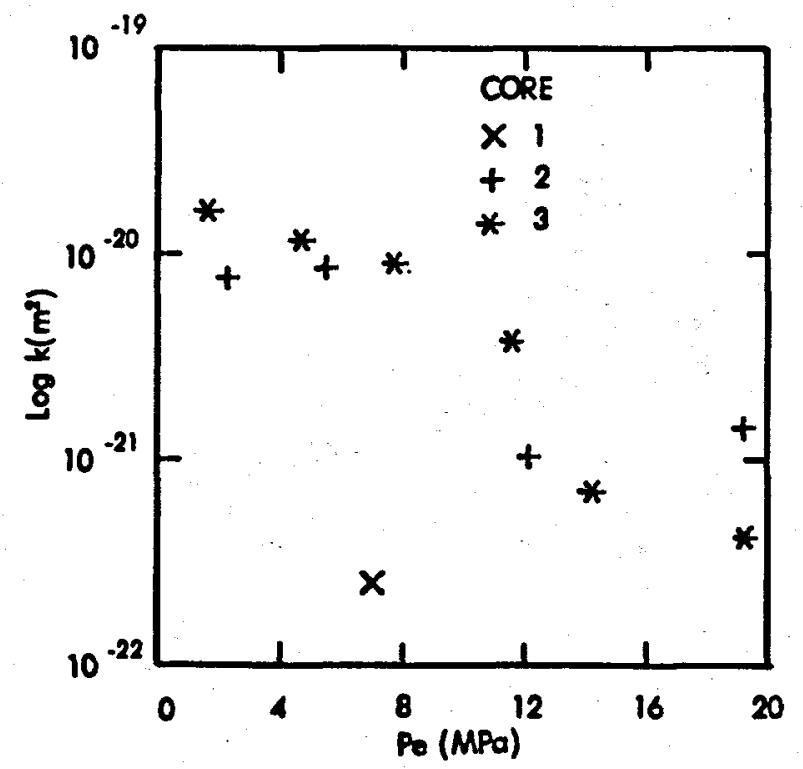

Fig. 5-22.

Permeability ( $k$ ) vs effective confining pressure $\left(\mathrm{Pe}_{\mathrm{e}}\right)$ for Rosemanowes granite RH9D 249.36 - 249.44.

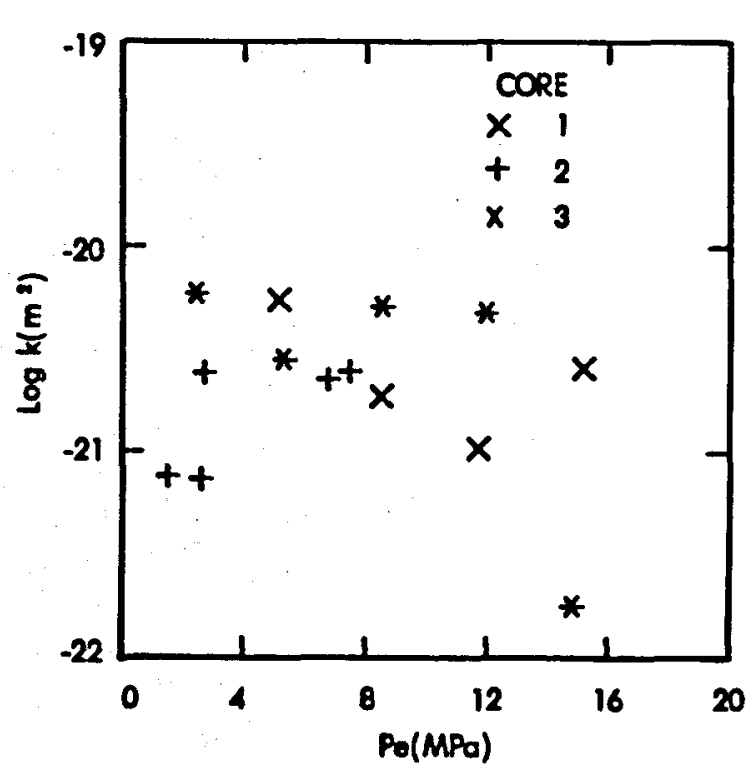

Fig. 5-23.

Permeability (k) vs effective confining pressure $\left(\mathrm{P}_{\mathrm{e}}\right)$ for Rosemanowes granite RH9D 303.14 - 303.20.

that should be drawn from these data is that the permeability is generally less than $10^{-20} \mathrm{~m}^{2}$. The absolute values of individual measurements are uncertain since the reliable lower limit for permeability measurement with the present apparatus is approximately $5 \cdot 10^{-21} \mathrm{~m}^{2}$. These samples are appreciably coarser grained than the others tested. Although not enough samples have been tested to draw definite conclusions, it seems plausible that among fresh granitic rocks larger grain size may generally correlate with lower permeability. This would follow if the flow channels in all such rocks were similar. The lower permeability would then be due to the smaller number of channels in the coarser grained rock.

Three orthogonally oriented specimens cut from a single handspecimensize sample of Berkeley Blue granite were also tested. The results are shown in Figs. 5-24 through 5-26. The permeability data for these specimens can be well represented by the equations

$$
\begin{aligned}
& k_{i}=2.32 \cdot 10^{-15} /\left(1+1.905 P_{e}\right)^{6}+3.32 \cdot 10^{-19} /\left(1+0.135 P_{e}\right)^{1.8}, \\
& k_{j}=5.95 \cdot 10^{-14} /\left(1+3.419 P_{e}\right)^{6}+6.92 \cdot 10^{-20} /\left(1+0.127 P_{e}\right)^{1.8} \text {, }
\end{aligned}
$$




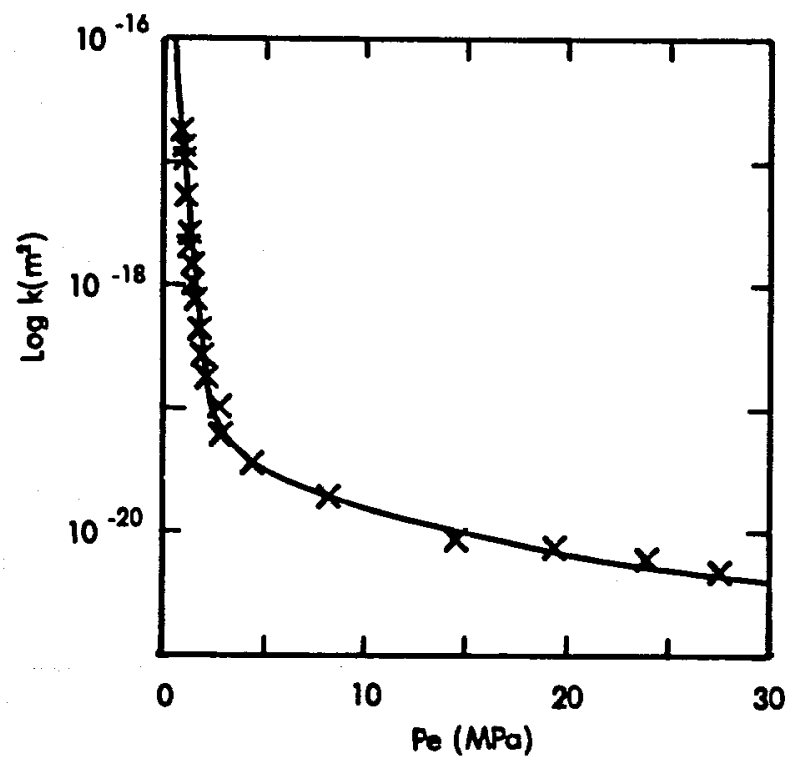

Fig. 5-24.

Permeability (k) vs effective confining pressure $\left(\mathrm{Pe}_{\mathrm{e}}\right)$ for Berkeley Blue granite, core A.

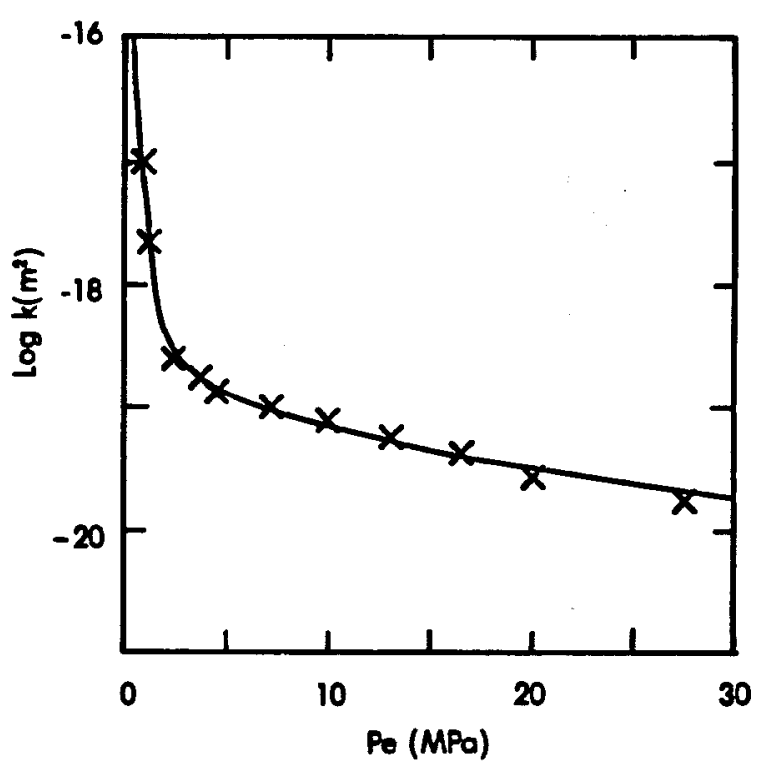

Fig. 5-25.

Permeability (k) vs effective confining pressure $\left(P_{e}\right)$ for Berkeley Blue granite, core $B$.

and

$\left.k_{k}=1.19 \cdot 10^{-8 /(1+25.34} \mathrm{P}_{\mathrm{e}}\right)^{6}$

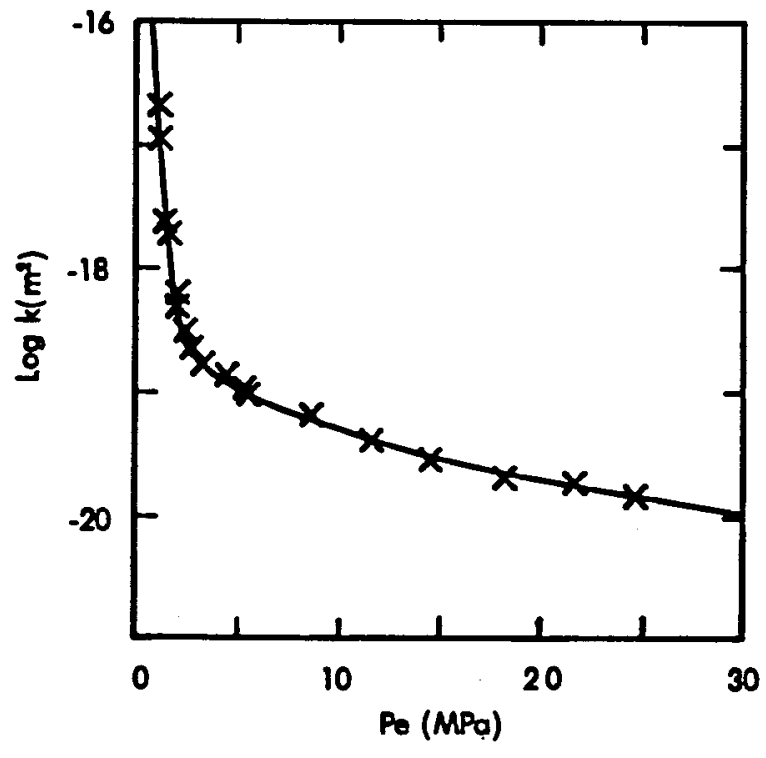

Fig. 5-26.

Permeability $(k)$ vs effective confining pressure $\left(\mathrm{Pe}_{\mathrm{e}}\right)$ for Berkeley Blue granite, core $C$.
$+4.01 \cdot 10^{-19} /\left(1+0.221 \mathrm{P}_{\mathrm{e}}\right)^{1.8}$,

where $k$ is the permeability and $P_{e}$ is the effective confining pressure.

The most striking feature of these data is the marked change in the derivative of $k$ with respect to $P_{e}$, which occurs at a $\mathrm{Pe}$ of 2 to $3 \mathrm{MPa}$. Further investigation would certainly be necessary to define the cause of this break. However, it may be due to the presence of two distinct sets of porosity: one, perhaps due to damage during quarrying, that effectively closes at low $\mathrm{P}_{e}$; the other, which is characteristic of the 
undisturbed rock, although not predominate at low pressures, is more difficult to close and dominates at high $P_{e}$. It is quite possible, however, that the break is due to a change in the way porosity closure is resisted.

A second rather striking feature of this rock is the almost order-ofmagnitude range in permeability of these three specimens at high $\mathrm{P}_{\mathrm{e}}$. It may be that this variation is due to differences in the specimens, but the uniform appearance of the specimens and their close proximity in the original sample suggests that the variation is due to a directional dependence of permeability. If the permeability of the rock is truly directionally dependent, it is rather remarkable since any foliation that may be present is extremely subtle.

The Berkeley Blue granite was tested to assess its similarity to rock from the HDR site. Since only a limited amount of rock is available from depth at Fenton Hill, it was hoped that the Berkeley Blue granite might be a useful substitute for the Fenton Hill granodiorite in mechanical property testing. At least with respect to permeability, the Berkeley Blue granite seems quite similar to the Fenton $\mathrm{Hill}$ granodiorite at effective confining pressures above 3 to $4 \mathrm{MPa}$. Earlier tests on the granodiorite did not show the break in slope of the permeability curve. However, a more detailed set of tests now under way suggests that this break is present, although at a slightly lower pressure.

5.3. Reservoir Modeling. (LASL contributors: H. D. Murphy, C. O. Grigsby, J. W. Tester, H. N. Fisher, G. Zyvoloski, N. Becker, R. M. Potter, R. L. Aamodt, D. W. Brown, R. J. Bridwell, R. Pearce; Outside contributions: F. Chambers, University of New Mexico; Y. C. Hsu, University of New Mexico)

5.3.1. Heat-Extraction Characteristics. The bulk of the results of Run Segment 2, the 75-day heat-extraction test conducted from January 27, 1978, to April 13, 1978, was reported in Ref. 2. Since that time more detailed numerical analyses utilizing more realistic multiple outlet fractures have been conducted and the results are summarized here. Additional discussion, including equations and a description of the numerical techniques, can be found in Ref. 24.

One of the diagnostic tests conducted before the heat-extraction experiment consisted of sequential temperature surveys in GT-2. Analys is of the temporal changes in the temperature vs depth curves yielded not only the 
depths of the communicating joints, but also the relative flow fraction provided by each joint. ${ }^{25}$ At least four joints were transmitting flow from GT-2, but most of the flow was transmitted by two major joints. The deepest of these was located at $2.70 \mathrm{~km}(8860 \mathrm{ft})$, i.e., $60 \mathrm{~m}$ above the main fracture connnection with EE-1, and transmitted approximately $20 \%$ of the flow. The second major joint was located $30 \mathrm{~m}$ above the first and transmitted about $80 \%$ of the flow. The physical geometry is depicted in Fig. 5-27.

With this information, estimates of the thermal drawdown were calculated for various trial values of fracture radii and vertical position of the fracture inlet. It could not be assumed that the inlet was located at the center of the fracture because earth stresses increase with depth so that during its creation the fracture could grow preferentially in the upward direction. The joints were assumed to intersect the main fracture vertically above the

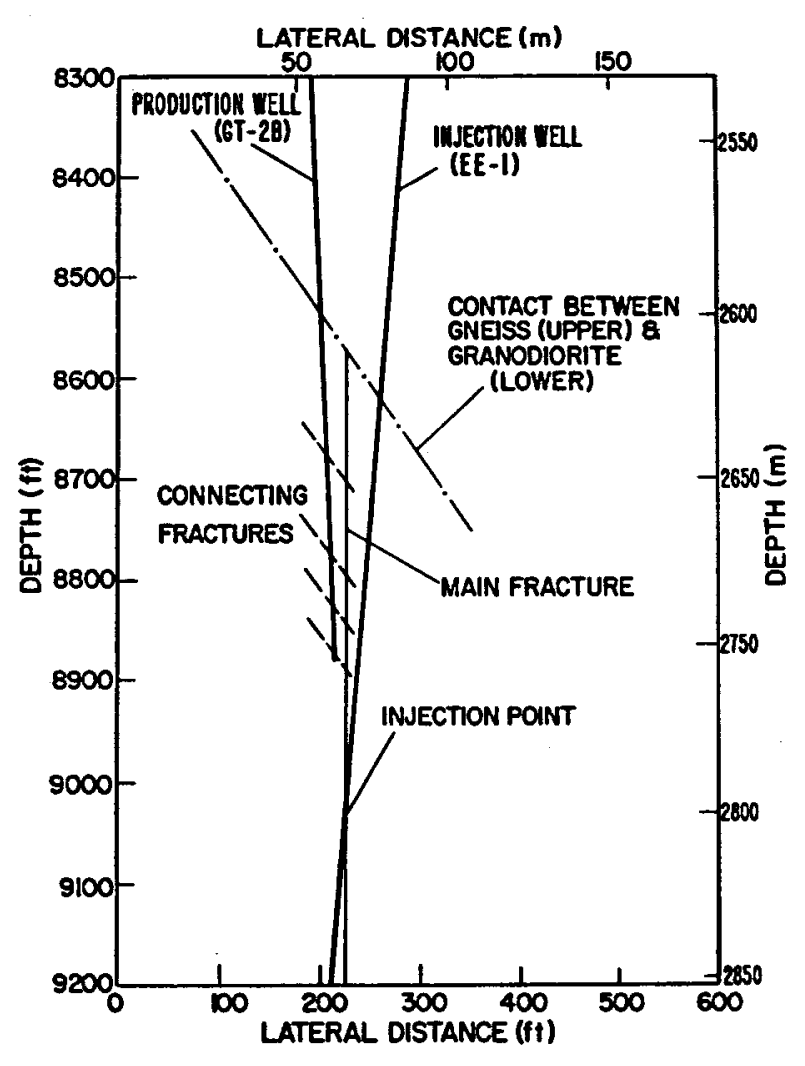

Fig. 5-27.

Elevation view of main hydraulic fracture and connecting natural fracture. inlet in EE-1, so that symmetry about this vertical line required modeling for only half the fracture (see Fig. 5-28). Furthermore, it was assumed that in the short lateral distance (Fig. 5-27) between GT-2 and the main fracture the depth of intersection of each joint with the fracture was the same as the depth of intersection with GT-2; that is, the effect of inclination of the joint from the horizontal, if any, was ignored. Two-hundred node points were used in the calculations, and for the fracture radius providing the best fit, the size of each calculation cell was 6 by $6 \mathrm{~m}$ in the fracture plane. As is suggested below, most of the observed impedance reduction is believed to be due to reduction of concentrated impedances within the 


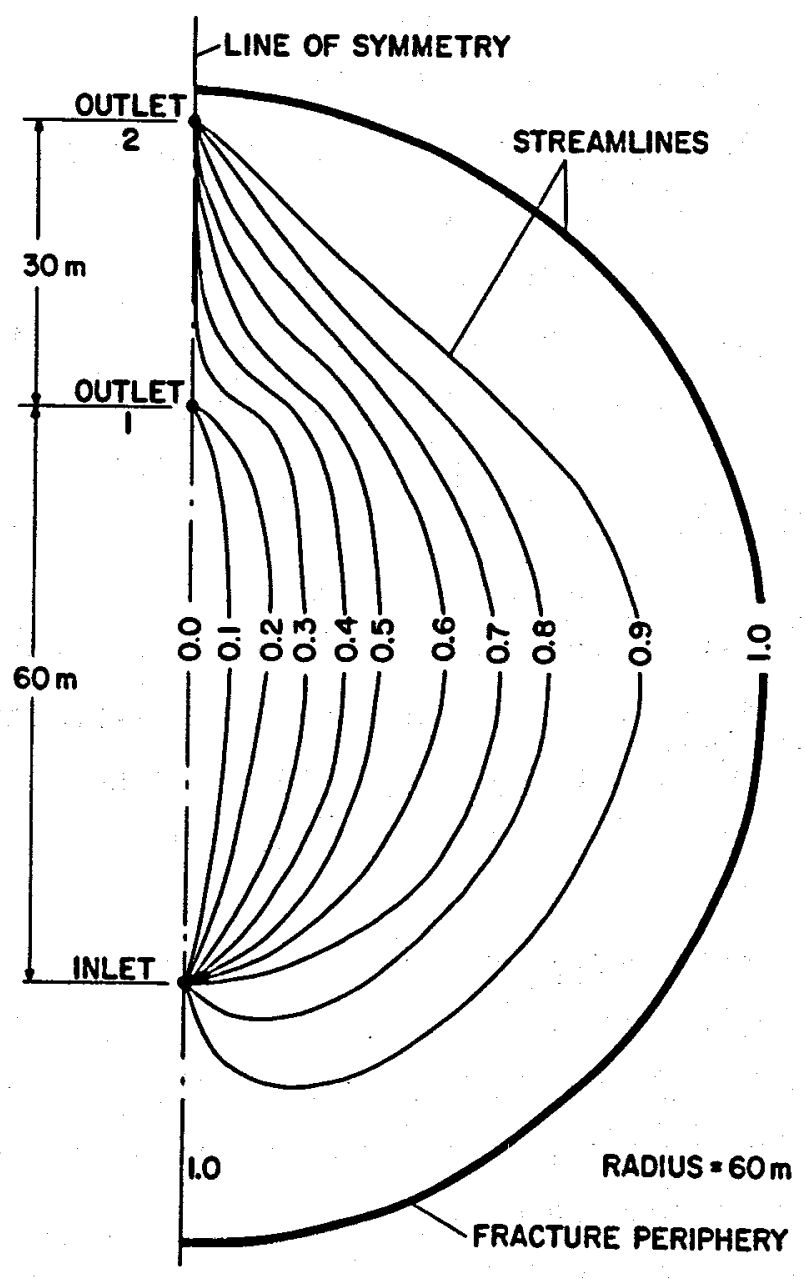

Fig. 5-28.

Flow streamlines for two-outlet mode1.

communicating joints. Thus, the self-propped main fracture aperture was adjusted until the calculated impedance was equal to the observed overall value at the end of the heatextraction experiment. It was found that a constant aperture of $0.2 \mathrm{~mm}$ $(0.008 \mathrm{in.})$ yielded the correct impedance. This value is in reasonable agreement with profilometer measurements of misaligned roughness asperities on fractured core specimens from the GT-2 we 11.26

In the calculations, the actual temporal variations of production and injection flow rates were utilized. The fracture inlet temperature was est imated from a wellbore heat-transmission calculation. Seventy-five days of operation were simulated with 25 time steps. These time increments were small in the beginning, but then were increased with time as the rate of temperature decline decreased. The mixed-mean fluid temperature required for comparison with measurements was calculated as the sum of the products of the flow-rate fraction and the computed temperature for the positions corresponding to the two communicating joints.

A fracture radius of $60 \mathrm{~m}$ with an inlet located $25 \mathrm{~m}$ above the fracture bottom resulted in a good fit to the measurements, and as shown in Fig. 5-29, the computed drawdown with this two-outlet model is indistinguishable from the uniform flow analytical result. 2,24 The analytical result corresponded to an equivalent radius of $50 \mathrm{~m}$, whereas the present result requires a radius of $60 \mathrm{~m}$. The explanation for this disparity is that in the analytical model the 


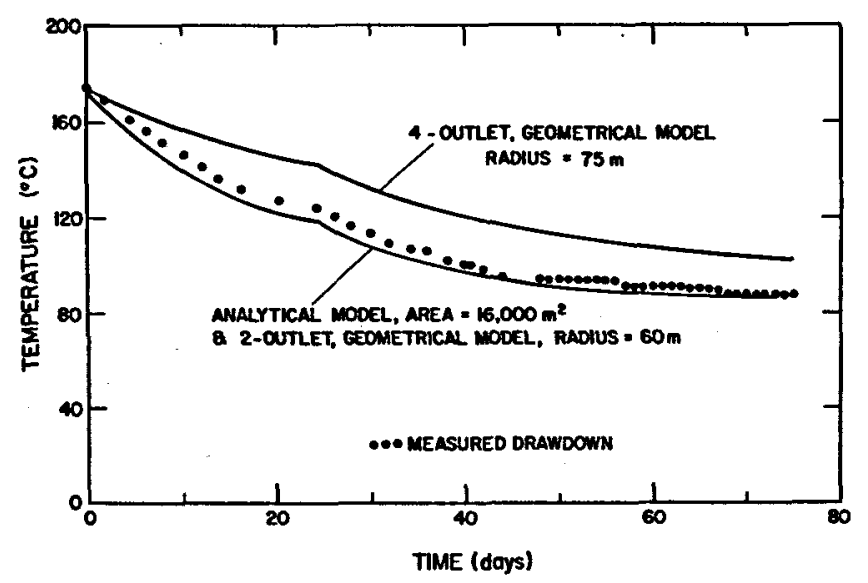

Fig. 5-29.

Comparison of measured and theoretical thermal drawdown.

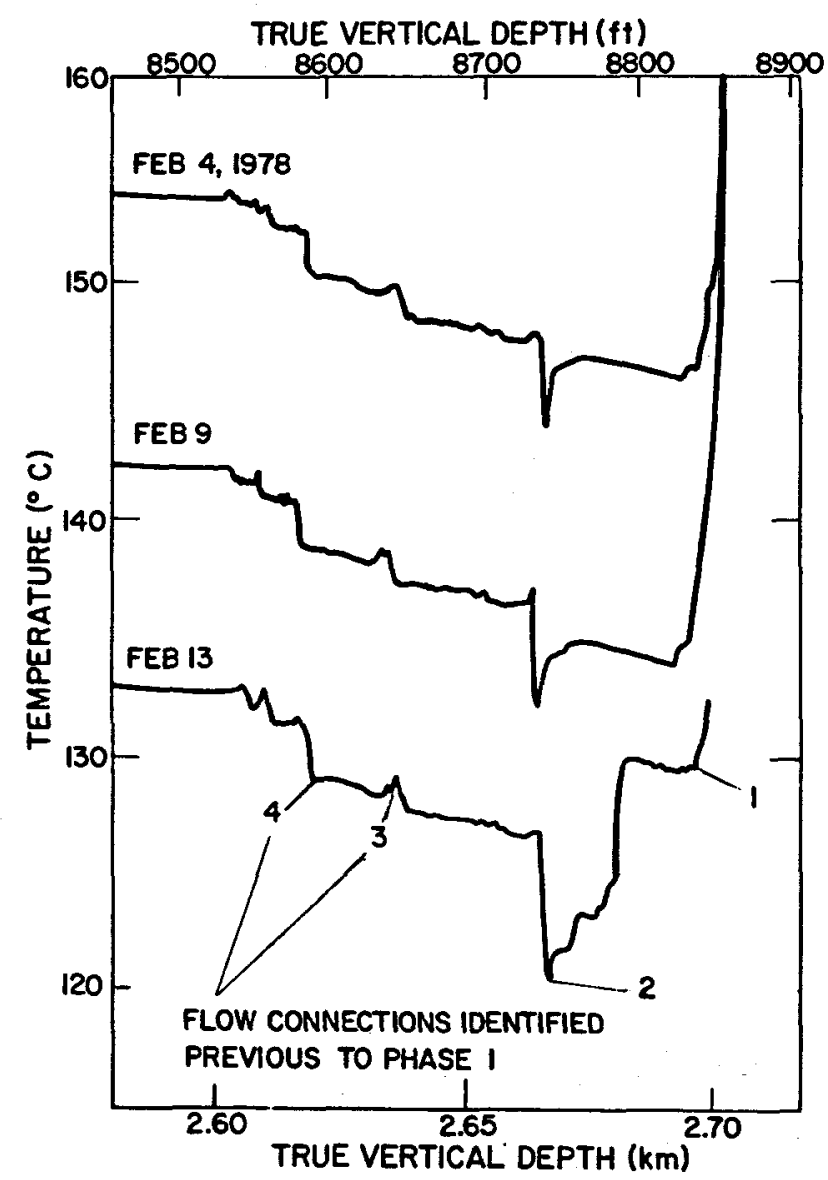

Fig. 5-30.

Temperature surveys in bottom section of producing well. rectangular geometry and uniform distribution of water at top and bottom result in streamline patterns that optimize the amount of heat that can be extracted from the available area. The flow patterns for the two-outlet model are shown in Fig. 5-28 for a particular time during heat extraction. The flow-rate fractions are written next to each streamline, with $10 \%$ of the total flow rate confined between each pair. of streamlines. The streamlines indicate that some regions of the fracture, particularly near the periphery, are not swept by as much flow as are those regions near the symmetry line, so that this peripheral region is not as effective in transferring heat.

Considering the excellent agreement of the measured and theoretical drawdowns and the plausible values of computed fracture aperture and entry location, one might conclude that the modeling is quite adequate, however, not all the data have been considered.

Figure 5-30 shows three temperature surveys taken in GT-2 with the downhole thermistor tool. Only the downhole region where the produced fluid enters the well is shown. The uppermost survey in the figure was obtained on February 4, 
1978, seven days after the start of heat extraction, while the middle and lower surveys were obtained after 12 and 16 days, respectively. Even a cursory look at these surveys indicates a complex reservoir-to-production we 11 connectivity. The major temperature changes at the depths specified as 1, 2, 3 , and 4 arrows are associated with the joints identified in earlier testing. More detailed surveys, in which digitized temperature data were obtained every $0.15 \mathrm{~m}(0.5 \mathrm{ft})$ showed that even these major connections had fine structure that changed with time. For example, both major connections, 1 and 2, actually consist of two joints each. At connection 2, a colder flow entered at the bottom, but $2 \mathrm{~m}$ farther up water at least $5^{\circ} \mathrm{C}$ hotter entered the well. The second survey, and even more visibly, the third survey showed the development of a new flow connection located between the previously established major connections 1 and 2, and in fact, the magnitude of the temperature change at $2.68 \mathrm{~km}(8800 \mathrm{ft})$ suggests that a major connection has developed there. This new connection is probably the result of opening a previously closed or calcite-filied natural fracture by means of thermal contraction and/or pressurization.

Near the end of the experiment the temperatures were low enough to permit the use of a conventional spinner tool to measure flow rates. This tool was run on the next-to-last day of the experiment in Fig. 5-31, and the results presented as flowrate fractions have been superimposed upon a temperature survey taken seven days before the end of the experiment. Instead of just two connections, as at the beginning, thermal contraction and pressurization have resulted in at least five major

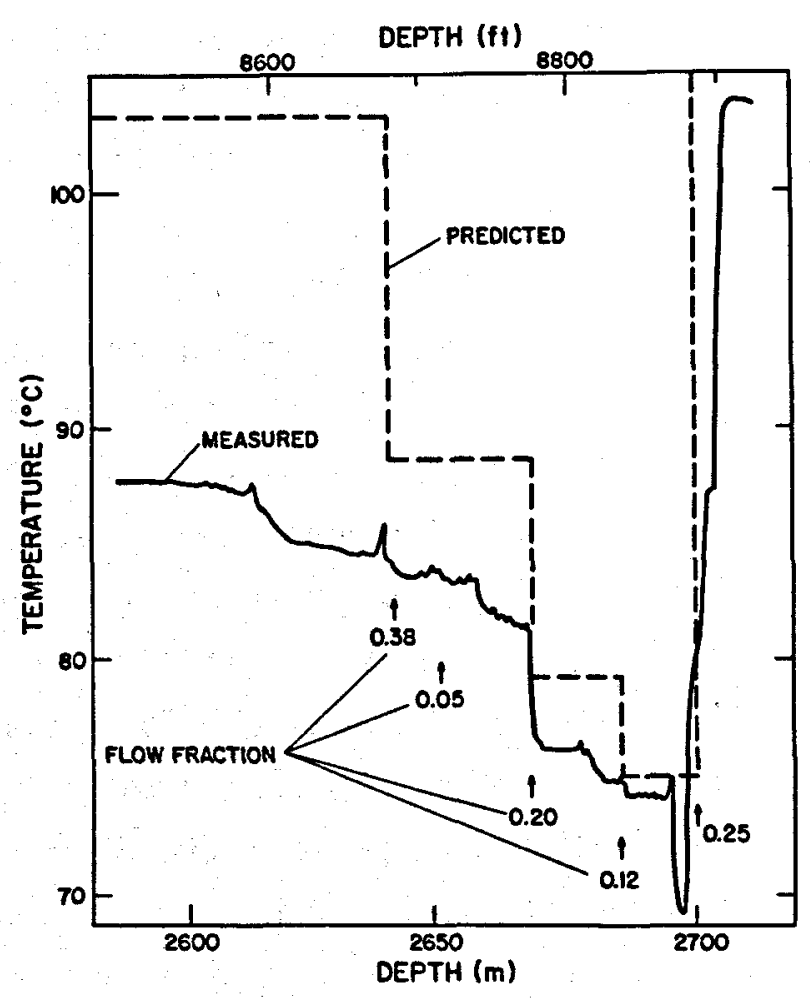

Fig. 5-31.

Spinner-determined flow fractions entering producing well superimposed upon temperature survey. 
connections. As expected, these are aligned at positions of sharp temperature change.

These flow-connection depths and flow-rate fractions were used in the model and the results for drawdown are presented in Fig. 5-32 for comparison with results for the two-outlet model shown in Fig. 5-28. For modeling convenience, the $5 \%$ connection shown in Fig. 5-31 was ignored in these calculations. Because the shallowest connection indicated in Fig. $5-31$ is above the top of the fracture shown in Fig. 5-29, the fracture, still assumed to be circular, in this case was assumed to have a radius of $75 \mathrm{~m}$. Outlets 1 and 2 in Fig. 5-32 correspond to those shown in Fig. 5-29. The new outlets are labeled $A$ and $B$. The positions of the fracture bottom, the inlet, and outlets 1 and 2 are unchanged from Fig. 5-29; thus, the incorporation of connection $B$ required an additional upward growth of

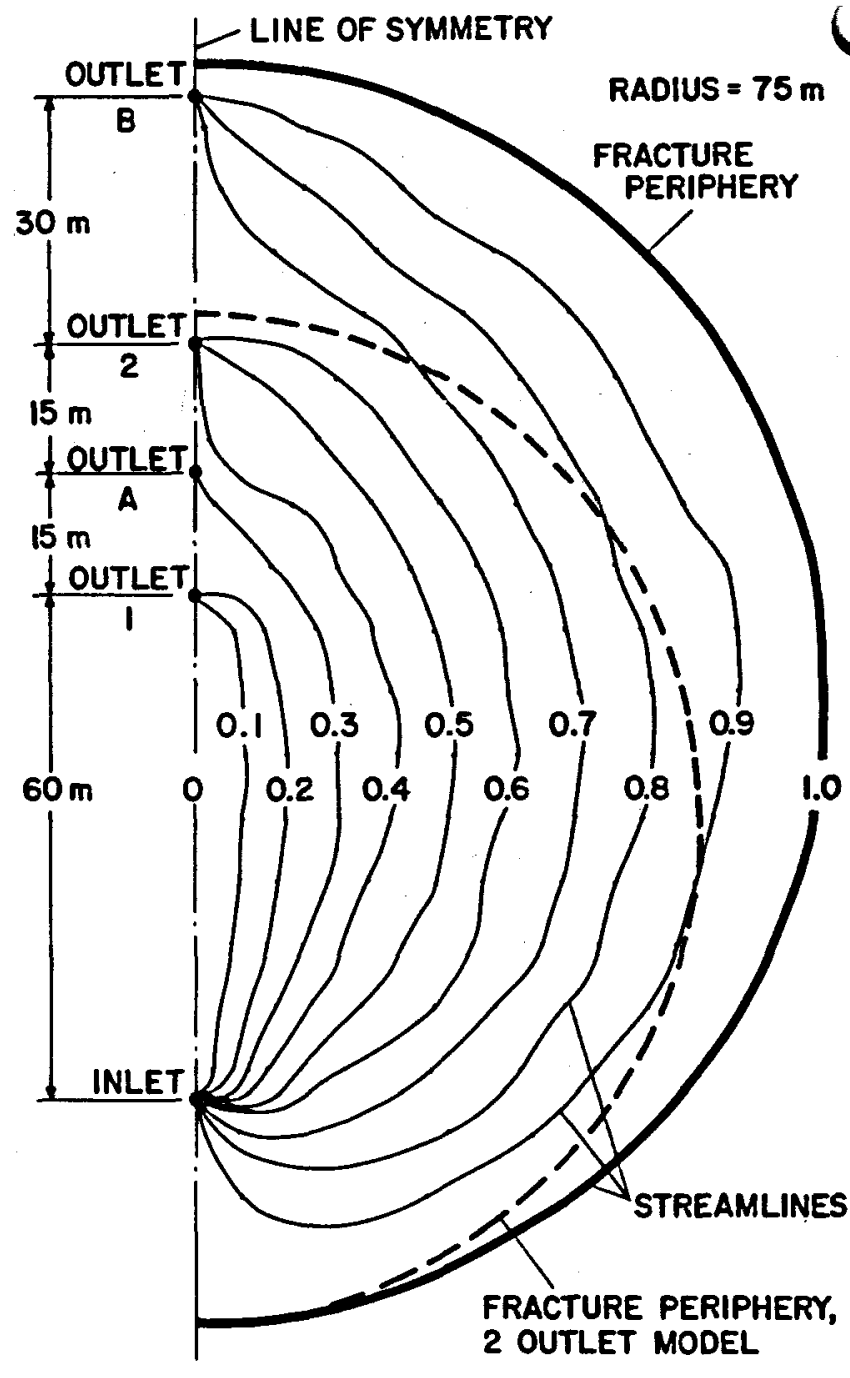

Fig. 5-32.

Flow streamlines for four-outlet model. $30 \mathrm{~m}$, and the requirement that the resulting fracture still be circular increased the area by $56 \%$. Such a large increase in area resulted in a relatively slow predicted drawdown so that, as indicated in Fig. 5-28, the agreement between theoretical drawdown with the four-outlet model and the measured drawdown is poor. It is true that had the geometry been altered (for example, by representing the upward extension of joint $B$ by an upward spur or lobe with small area) much better agreement could have been obtained (and newer calculations not reported here support this claim).

Two main points are focused upon here for further discussion. These are the (1) nonuniqueness results of modeling in the absence of precisely defined 
fractured geometries, and (2) disparities in area estimates obtained by pressure transient testing and heat-transfer modeling.

Precise physical reservoir descriptions are difficult to obtain, which leads to such idealizations as single circular fractures in the hot dry rock geothermal case, or perfectly homogeneous, isotropic, porous media for oil and gas reservoirs. The actual modeling of reservoirs with discrete but widely spaced fluid conductors (such as man-made and natural fractures) is difficult, and in the absence of complete data, is likely to be avoided by most modelers in view of the three-dimensional complexities required and the greatly increased computing expenses. Numerical modeling experiments show that equally good results as these above could have been obtained for elliptical instead of circular fractures, or for even more complex shapes. With both geometry and inlet locations as free parameters, reasonably good matches to the data can be obtained with any number of fracture shapes. The strongest conclusion to evolve from the modeling is that the available heat-transfer area corresponds to that of a circle approximately $60 \mathrm{~m}$ in radius. The lowest bound is $50 \mathrm{~m}$, as calculated from the perfect hydrodynamics of the analytical model. An upper bound, for a larger circular fracture with four production zones and a $75-\mathrm{m}$ radius, resulted in a calculated effective heat-transfer area that, relative to the observed drawdown, was too large.

It may be recalled that earlier estimates based upon pressure transient testing indicated a fracture radius of $140 \mathrm{~m}$, which is about two times greater in radius and four times greater in area than that estimated here. The discrepancy is not difficult to explain. The pressure transient analys is actually yields $A \sqrt{\mathrm{kC}}$, the product of the fracture area and the square root of the rock permeability and compressibility. ${ }^{26}$ Thus, the area estimate based upon pressure transient analys is depends upon the estimates of $k$ and c. Considering $k$ alone, permeability measurements of recovered core specimens that, by virtue of their intact recovery, were relatively free of joints and natural fractures, indicated the inherent permeability of the rock matrix to be in the nanodarcy range $\left(10^{-21} \mathrm{~m}^{2}\right)$. In contrast, drill stem tests reported by West et al..$^{27}$ suggested that $k$ was in the microdarcy range $\left(10^{-18} \mathrm{~m}^{2}\right)$; however, the results varied by over an order of magnitude depending upon position in the hole. It appears that the permeability of the rock matrix is so low that effective permeabilities are really controlled by the presence of 
discrete joints with finite flow conductivities. Thus, permeability in these formations is not a property, but a joint-system attribute that can be expected to vary widely depending upon the number, spacing, and aperture of the joints. In view of this discussion, a factor of 16 variation in $k$, accounting for a factor of 4 variation in $A$, is not surprising.

5.3.2. Flow and Pressurization in Fractured Rock. The flow behavior of water in rough-walled rock fractures is of interest in evaluating the hydraulic performance of hot dry rock geothermal reservoirs. Of particular importance is an understanding of the nature of the flow, laminar or turbulent, linear or nonlinear, and the corresponding effects on pressure losses and flow impedances. Simple theoretical relationships governing flow between parallel plates exist only for laminar flow over hydraulically smooth walls; beyond this, other analyses are semiempirical at best. This fact prompted a review of the literature regarding experimental work to characterize laminar and turbulent flow over rough surfaces. Attention was confined to flow situations typical of those deep within fractures, far away from either injection or production wells, so that the additional perturbations caused by radial acceleration as the flow diverges from or converges upon wells or by the actual turning of the flow from or into the wells could be avoided. In terms of the definitions developed in Sec. 5.3.3, "Flow Modeling at Wellbore-Fracture Intersections," the flows considered here are called regime-one flows.

Most of the published studies have been concerned with surface roughnesses that are small compared to the size of the flow-channel aperture (its smallest dimension). In the case of the in situ geothermal reservoir operating at pressures lower than the fracture closure stress, the fractures are selfpropped by the roughness asperities of the fractured surfaces, and so the roughness protruding into the flow stream is of the same order of magnitude as the fracture aperture. Even for laminar flow the expected linear relationship between fluid velocity and pressure drop is not always found because of pressure loss terms due to the continuous acceleration and deceleration as the flow is forced into the constricted regions between roughness constrictions and then expands into subsequent enlargements. The previously investigated effects of small-scale roughness on friction factors and on transition from laminar to turbulent flow would thus not be expected to be valid for the large-scale roughnesses encountered in self-propped HDR reservoirs. 
The difficulties encountered in characterizing the geometry for small-scale roughness are greatly compounded for 1 arge-scale roughness because the number of geometrical parameters to be specified increases. As discussed by $\mathrm{Iwai}^{28}$, these may include the degree and distribution of angularity of roughness elements, size and distribution of apertures, and the degree of contact area for self-propped fractures.

For flow at very low Reynolds number, $R e<100$, and fracture apertures, a, greater than about $20 \times 10^{-4} \mathrm{~cm}$, Iwai 28 states that the "cubic law"-relating the pressure gradient to flow rate divided by $a^{3}--$ is valid. This constitutes a linear flow law, i.e., pressure gradient is linearly proportional to flow rate, or velocity, $u$. Potential roughness or high Reynolds number limits to the linear flow law were not developed by Iwai; but Sharp ${ }^{29}$ observed the onset of nonlinear laminar flow at relatively low Reynolds numbers, fostered by increased angularity and increased contact area, and a prolonged "laminar to turbulent transition zone." Sharp's data appear to show nonlinear effects present at $R=200$ for a relative roughness of 0.40 . (The relative roughness is the ratio of the roughness amplitude, $k$, to the hydraulic diameter, $D_{H}$ which is twice the fracture aperture. Reynolds number, $R$, is defined as $u D_{H} / v$ where $u$ is mean velocity and $v$ is kinematic viscosity of the fracture fluid). Louis ${ }^{30}$ suggested a value of $R_{\text {nonlinear for }}$ nonlinear flow as $10 \mathrm{w}$ as 10 or 100 for very rough natural fractures. He did not attempt to define "very rough," though he may be referring to fractures in a basaltic type of rock. Goldstein and Sparrow ${ }^{31}$ found that in man-made corrugated wall channels secondary flow vortices began to be apparent at $R \approx$ of about 350. This situation is usually indicative of an impending transition to turbulent flow, but in any case the energy loss associated with the vortices would give rise to a nonlinear flow law. An analysis of Rissler's data ${ }^{23}$ indicates the start of a nonlinear relationship between pressure bases and $u$ at $R$ of 250 and a relative roughness of 0.15 .

Because of the large number of factors that are required to specify a fracture surface, a completely general flow law, expressed as a function of $R$ and $k / D_{H}$, will probably never be developed, and each case will require an empirical study, either in situ or in laboratory studies of large-scale rock cores containing fractures. In the latter category the work of most significance to the HDR Program appears to be that of Sharp and Maini. 33 


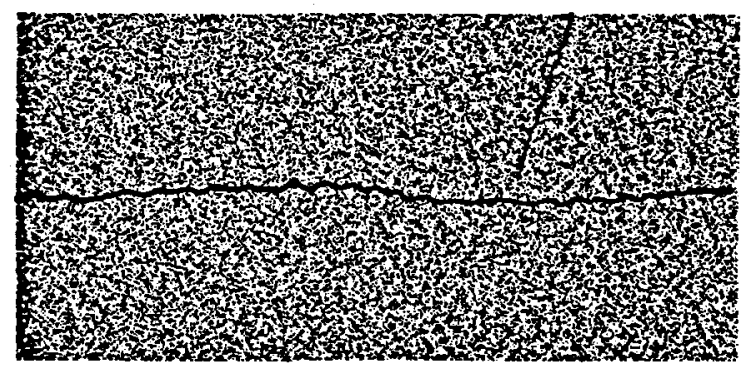

(o) SECTION THROUGH ROUGH NATURN FSSURE W NORPHRY

Fig. 5-33(a).

Geometrical characteristics of rough natural fissure (Sharp and Maini24).

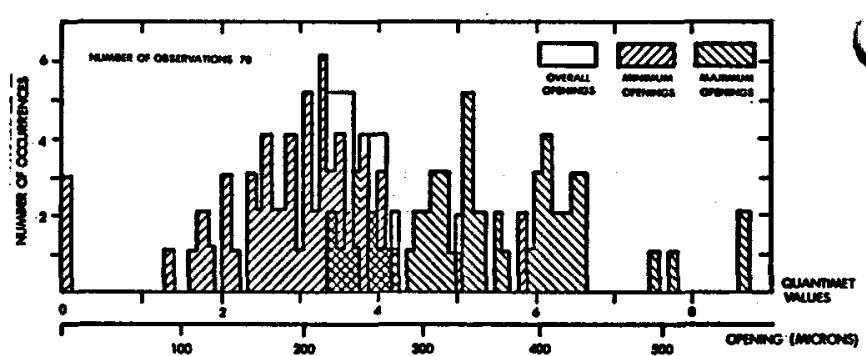

(b) STATSTICAL REPRESENTATION OF OPENING NONG CENTREINE OF FISSURE

Fig. 5-33(b).

Geometrical characteristics of rough natural fissure (Sharp and Maini 19).

Figure 5-33 indicates the geometrical properties of a natural fracture in porphyry. The mean aperture of this fracture was $0.25 \mathrm{~mm}$, close to the est imate 26,34 of the Fenton Hill self-propped fracture aperture based upon profilometer measurements of fracture roughness in a core from the GT-2 wellbore. This estimate was later confirmed by flow and heat-extraction tests at Fenton Hil1. ${ }^{20}$ Figure 5-34 presents the results of flow tests in which the hydraulic gradient, which is proportional to the pressure gradient, was changed and the effect on flow rate observed. A nonlinear flow law became apparent at a water flow rate (per unit width) of $0.011 \mathrm{~m}^{2 / \mathrm{s}}\left(0.12 \mathrm{ft}^{2} / \mathrm{s}\right.$ ) corresponding to a Reynolds number of only 25 .

Sharp and Maini ${ }^{33}$ also consider the changes in aperture potentially caused by pressurization of fractures. The pressure required simply to initiate flow may be sufficient to induce changes in aperture, thereby leading to significant changes in the fluid conductivity of the fracture. The focus here was upon flow laws at constant aperture, so the additional complexity of aperture change during flow testing was not considered; but it is mentioned now to indicate the potential complexity of interpretation

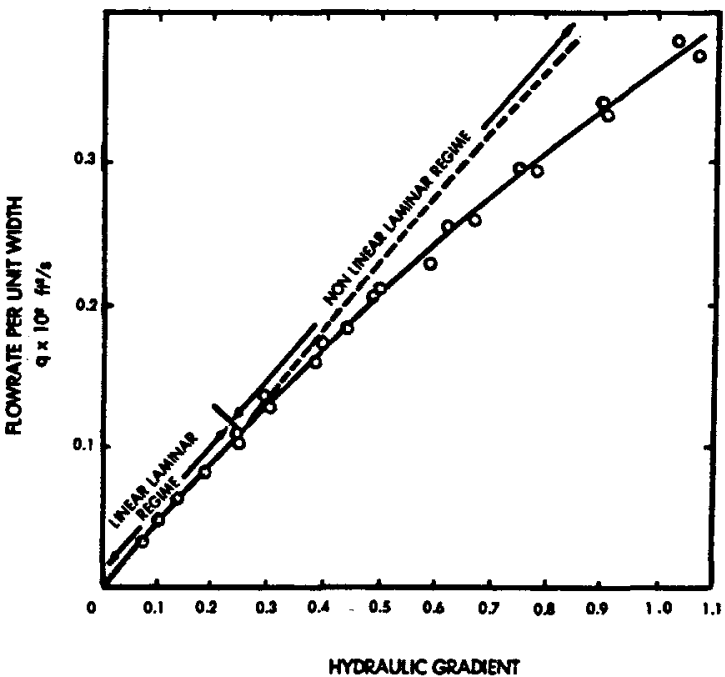

Fig. 5-34.

Results of flow test at low hydraulic gradients (Sharp and Maini24). 
of pressurization tests. Figure 5-35 indicates the behavior possible when aperture changes are possible.

In summary, the effects of largescale roughness are still not understood and few experimental investigations of flow through natural fractures have been performed at conditions appropriate for HDR reservoirs. Preliminary findings indicate nonlinear relationships between pressure gradient and flow velocity at Reynolds numbers as low as 25, and they are quite likely by $R=350$. Application of these results to the in situ reservoir at Fenton Hill indicates that for most typical flow conditions used in the past. nonlinear fracture flow laws should have been expected.

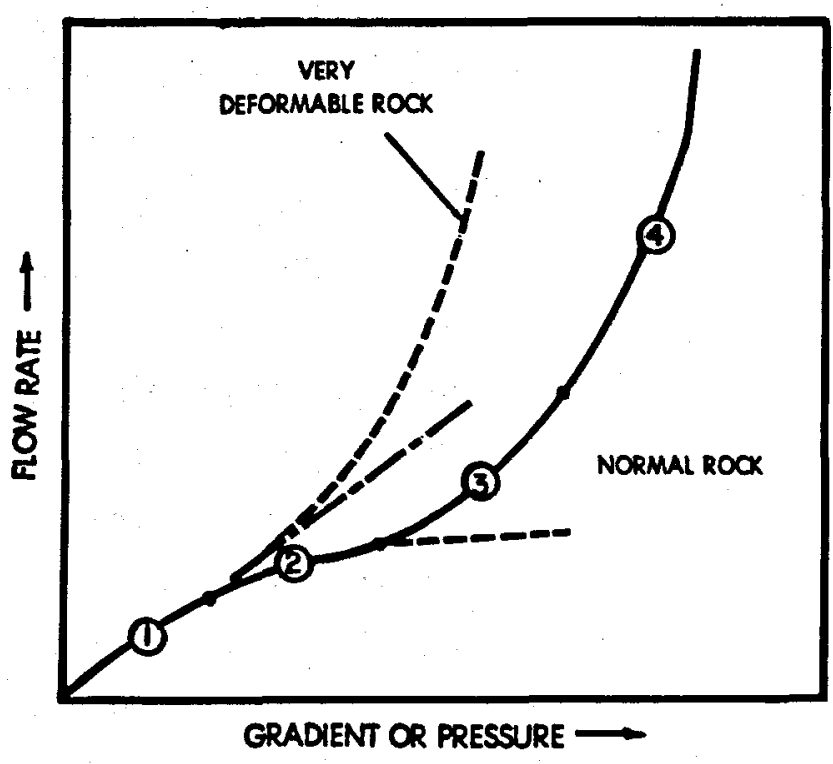

Fig. 5-35. Typical results of field test: (1) linear laminar flow, (2) nonlinear flow, (3) nonlinear flow offset by fracture expansion, (4) fracture expansion dominates.

Coupled Stress, Pressure, and Temperature Calculations. It is becoming increasingly important to understand the interactions and relative importance of the various stress fields surrounding the fractures in HDR reservoirs. These stress fields arise from several sources. The initial pressurization of the main fractures creates a stress throughout the reservoir as these fractures expand. The pore pressure field is established as the water flows through the various scales of permeability. As the reservoir cools, thermal stresses are induced. These three stress fields modify the initial in situ earth stresses. An understanding of these interactions and the effects of the changing stresses on the mechanical, flow, and thermal properties of the reservoir is necessary for the continued analys is of the data being obtained at Fenton Hill and, generally, for all HDR reservoirs.

A continuum mechanics code that calculates these combined effects is now being constructed by modifying TSAAS. ${ }^{35}$. This code was originally written to solve transient or steady-state thermoelastic stress problems on a twodimensional plane or axisymetric grid with orthotropic temperature-dependent 
properties. TSAAS will be modified in five major steps to accomodate coupled stress, temperature, and pore pressure effects.

Step 1: For porous flow with a Darcy-type flow law, the pressure obeys a diffusion equation. Hence, the heat-conduction equation in TSAAS can be used to solve for pore pressure, and the thermal strains in the stress-strain equations can be replaced by the strains produced by pore pressure. Temperature dependences in the material properties can be replaced by pressure dependences. In this mode TSAAS can be used directly for either temperature-stress problems or pore pressure-stress problems. Some of the results for these two types of problems are discussed below.

Step 2: The first major modification will be to add a flow law for pore pressure while retaining the heat-conduction equation. The first flow law to be added will be the diffusion equation for pressure. This will permit coupled pressure, temperature, and stress problems with pressure- and temperature-dependent properties.

Step 3: To complete the coupling, the stress dependence must be added to the flow parameters and rock moduli.

Step 4: The next step will be to add a more complicated flow law by replacing the Darcy flow with one in which the pressure gradient is determined by both a term linear in the flow rate and one quadratic in the flow rate.

Potential Uses in HDR Reservoirs. The potential uses of this code are numerous and include the possibility of unifying the analysis of several data sets. Some of these possibilities are reviewed here.

The Pressure and Flow Data: Until now the pressure and flow data for the Fenton Hill reservoir have been analyzed in a conventional manner with pressure-dependent flow properties in a model based on Darcy-type flow 9,2,36-39. This model used a low-pressure approximation for the system permeability, compressibility, and porosity. Now considerable data have been accumulated for tests with high specific flow rates and at pressures above the minimum earth stress. This will necessitate the extension of the model to non-Darcy 
flow, high pressure and stress forms for the system parameters, and the effects of the changing stress fields. This will be necessary to understand the inflation, flow-through, and mixing properties of the system and the water losses at high pressures in long-term experiments. For example, fracture volumes and dispersion properties will depend on aperture profiles and their response to internal pressurization and the state of stress in the surrounding reservoir.

Thermal Stress Effects. Thermal stresses can affect the performance of the systems in two ways. Since the parameters of the system are pressure- and stress-dependent, the thermal contribution to the stress can affect the performance of the reservoir under conditions for which no thermal stress cracking can occur. This, in addition to pressure effects, could have accounted for the long-term change of impedance during the Run Segment 2 75-day test. ${ }^{20}$ Also, the conditions governing the onset of additional fracturing can be estimated for the entire reservoir.

Seismic and Acoustic Data. The correct interpretation of acoustic data obtained by transmissions between wellbores requires knowledge of the distribution of rock properties in the pressurized portions of the reservoir. This can be done only if the distributions of water-filled porosity and stress fields can be determined. This code, coupled with a theoretical connection between static and dynamic rock moduli, may be helpful in the interpretation of this data set.

The same type of calculation may give correlation between the spatial distributions of microseismic events during inflation and the distributions of pore pressure and stress in the reservoir.

Earth Stresses. Extended parameter studies that determine the stress dependence of in-situ moduli and flow parameters may give additional information on the earth stress.

Interaction of Large Scale Fractures. Future reservoirs may consist of many large parallel fractures, as planned for Phase II. The interaction of the stress fields and the effect on the flow properties of individual fractures can be examined with this code. 
Laboratory Rock Mechanics. This code can be used to fit the results of laboratory experiments on rocks (in particular the Fenton Hill cores) with variable properties. These properties can then be used in the in situ calculations with the modifications dictated by the in situ conditions.

Surface and Wellbore Strains. At some time in the future it may be possible to measure surface strains or strains in remote wellbores with sufficient accuracy to obtain information about the reservoir in various stages of inflation. The code could be used for sensitivity studies or for interpretation of the data.

Outline of the Model. The model is a simple extension of the linear Biot theory to nonlinear materials. Since TSAAS is two-dimensional with planestress and plane-strain options, the plane stress formulation is presented here. All the moduli and flow parameters are pressure, stress, and temperature dependent.

The stress-strain equations are for two elongation strains of the form

$$
d \varepsilon_{i}=\frac{1}{E_{i}}\left(d \sigma_{i}-v_{i} d \sigma_{j}\right)+\frac{d P}{3 H_{i}}+\alpha_{i} d T,
$$

and a shear strain equation

$$
d \gamma_{i j}=\frac{d \tau_{i j}}{G_{i j}} .
$$

To these are added the two equilibrium equations and three strain-dependent equations.

The pore strains $\left(d \theta_{j}\right)$ must also be specified such that if $\theta$ is the total porosity

$$
d \theta=d \theta_{i}+d \theta_{j}
$$

and

$$
d \theta_{i}=\frac{d P}{3 R_{i}}+\frac{d \sigma_{i}}{3 H_{i j}}+\frac{d \sigma_{i}}{3 H_{i j}}+\alpha \theta_{i} d T .
$$


A permeability tensor must also be specified as a function of the pore strain porosities

$$
k_{i j}=k_{i j}\left(\theta_{i}, \theta_{j}\right)
$$

This allows the solution of a flow law. Two simple cases can be considered first. With $\phi=\rho \theta$

$$
\begin{aligned}
\nabla \cdot \dot{q} & =\frac{\partial \phi}{\partial t} \\
& =\frac{\partial \phi}{\partial P} \frac{\partial p}{\partial t}+\frac{\partial \phi}{\partial T} \frac{\partial T}{\partial t}+\frac{\partial \phi}{\partial \sigma_{i}} \frac{\partial \sigma_{i}}{\partial t}
\end{aligned}
$$

where $q$ is given either by Darcy's law

$$
q=\frac{p^{\bar{K}}}{\mu} \nabla p \text {, }
$$

or $\dot{q}$ is a solution of the nonlinear equation

$$
\nabla P=a \dot{q}+b \dot{q}^{2} \text {. }
$$

The heat conduction equation

$$
\nabla \cdot(\lambda \nabla T)=\rho_{R} \cdot C_{H R} \frac{\partial T}{\partial t}
$$

is needed to complete the system of equations.

Thermal and Pore Pressure Effect on HDR Reservoirs. A series of simplified problems relating effects of temperature and pore pressure on open and closed fractures has delineated stress fields near a HDR reservoir. With initial emphas is on closed fracture examples, indications are that a complicated stress field is imposed on in situ stress conditions affecting both fluid flow and heat transfer. Problems were run with constant material properties to show the different wave speeds for the temporal interaction of temperature and pore pressure.

A single idealized fracture, $50 \mathrm{~m}$ in length, is studied as heat flows from the rock to the circulating water and water diffuses into the rock. This fracture is placed on the boundary of the mesh and is subjected to mechanical, thermal, and pore pressure boundary conditions as shown in Fig. 5-36. 


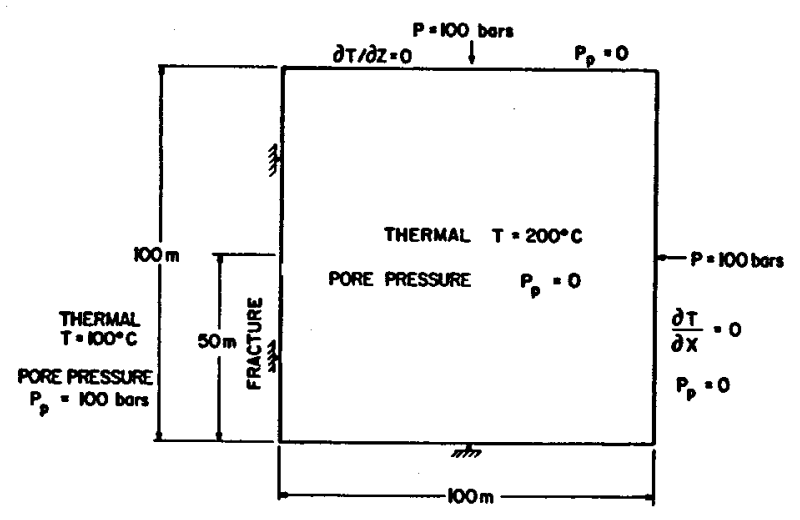

CLOSED FRACTURE CASE

Fig. 5-36.

Boundary conditions for the thermal $(T)$ and pore pressure $(P p)$ cases.

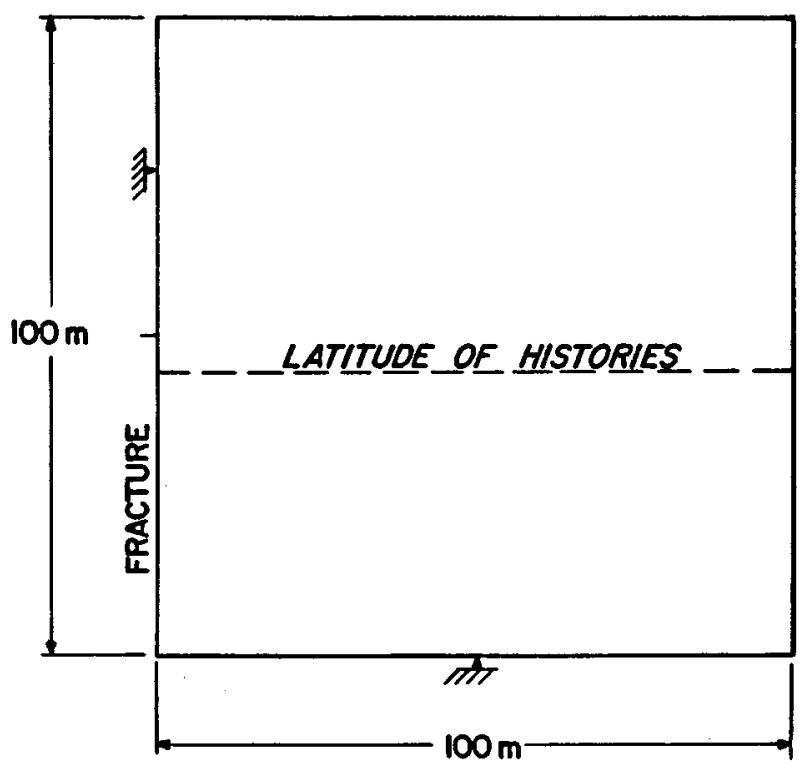

Fig. 5-37.

Horizontal position of thermal and pore pressure histories for HDR fracture.
Two classes of problems, that of a temperature wave moving into the contracting rock and that of a diffusion wave moving into the expanding rock using a range of permeabilities, will be discussed. Figure 5-37 shows the position of stress histories taken normal to the fracture near the crack tip.

The thermal problem assumes the rock to be at $200^{\circ} \mathrm{C}$ and the water to be at $100^{\circ} \mathrm{C}$. Using conventional material properties, the stress wave moves $\sim 5 \mathrm{~m}$ into the granite in 70 days.

The diffusion problem was solved using two different permeabilities of $0.2 \mu \mathrm{D}$ to $10 \mu \mathrm{D}$ to simulate "impermeable" granite and granite with microcracks. In addition, a constant 100 bars of pore pressure was assumed in the fracture and 0 bars in the surrounding rock initially. For the impermeable granite, the stress wave moves $\sim 10-15 \mathrm{~m}$ into the rock with $10<\mathrm{p}_{\mathrm{p}}<20$ bars of pressure. A granite with medium density of microcracks has a stress wave of $\sim 50$ bars at $50 \mathrm{~m}$ in 60 days. The thermal and pore pressure wave profiles are summarized in Fig. 5-38.

Variation of wave speeds for the uncoupled thermal and diffusion cases (a factor of 3 between temperature and impermeable granite) suggests 


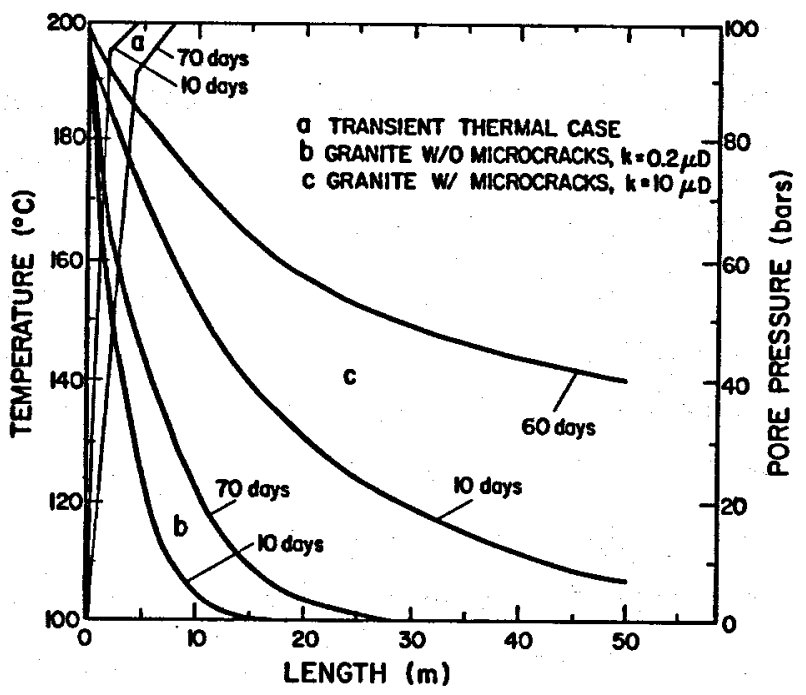

Fig. 5-38.

Summary of thermal and pore-pressure wave profiles for closed-fracture case. a complicated stress field affects reservoir dynamics during the 75-day test. If a modest distribution of microcracks is assumed, the porediffusion effect clearly dominates stress fields except in a localized region near the fracture.

\subsubsection{Flow Modeling at}

Wellbore/Fracture Intersections

Pressure Losses at the Transition from Radial Flow within Hydraulic Fractures to Longitudinal Flow within Production Wells. Efficient operation of hot dry rock geothermal reservoirs requires a better understanding than now exists of the fluid mechanics in the vicinity of fracture-wellbore intersections. Typically the apertures, i.e., the smallest dimensions of hydraulic fractures, are only of the order of $1 \mathrm{~mm}(0.04 \mathrm{in.})$ so that reasonable energy production rates require fairly large flow velocities within the fracture, which often result in non-Darcian flow. Several distinct flow regimes can be identified. Since these regimes are conceptually the same for both the inlet and the outlet, we start with the flow deep within the fracture and consider the changes that occur as the pumped reservoir fluid approaches the outlet, turns into the production wellbore, and then continues up this bore. For simplicity we consider the case where the fractures plane and production well are nearly orthogonal (see Fig. 5-39 for a sketch of the geometry).

In the first flow regime, deep within the fracture, i.e., far from either the inlet or outlet, the flow velocities and local Reynolds numbers (R) are relatively small compared to their values near the inlet and outlet. Here, if the walls of the confining rock can be considered hydraulically smooth, then the local velocities are related linearly to the local pressure gradients by means of the fluid viscosity and the fracture permeability, which in this 


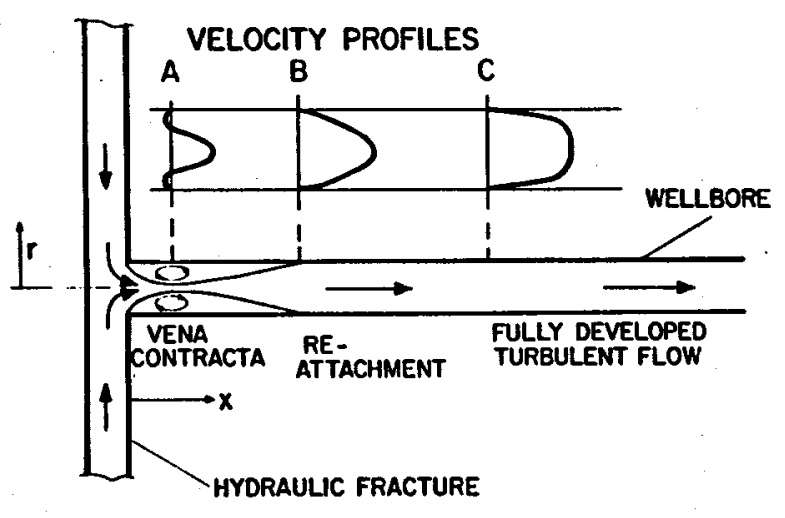

Fig. 5-39.

Flow geometry and velocity profile. Fracture aperture is shown exaggerated for clarity. case is one-twelfth of the square of the fracture aperture. As the outlet is approached, but is still far enough away that the effects associated with the turning of the flow into the production well can be ignored, an additional complexity is introduced. Now the flow-passage area, given by the product of aperture and $2 \pi$ times the radial distance measured from the outlet, continuously decreases as the outlet is approached. Thus, the local velocities increase and acceleration increases in importance. The required pressure drop must increase not only to account for this acceleration, but also because of the increased friction caused by the "blunting" of the velocity profile and the increased velocity gradients at the fracture walls. In regime 3, where the turn into the outlet well is approached, a significant component of momentum is directed in the longitudinal, or well-drilling, direction; however, since radial momentum still increases with decreasing radius, the flow at the turn resembles a vena contracta. In other words, the flow entering the wellbore appears as if it enters from a hole of diameter much smaller than the wellbore diameter, as sketched in Fig. 5-39. The flow then expands to fill the entire well diameter. The expansion is accompanied by a reduction of longitudinal flow momentum and results in an adverse pressure gradient in which the pressure increases in the flow direction. This results in enhanced turbulence, possibly flow separation (velocity profiles with negative values near the wall), and consequently greater viscous losses.

The radial unaccelerated flow of regime 1 is reasonably well understood, although there are some remaining questions regarding the effects of large roughness-to-aperture ratios on friction and laminar-to-turbulent transition that are currently under investigation. 40 Laminar accelerated radial flow within smooth walls, regime 2, has been investigated by Murphy, Coxon, and McEligot. 41 The remaining topic, the flow-turning effects of regime 3, was investigated experimentally and is reported here. The apparatus consisted of 
two flat, smooth, parallel discs of Plexiglas, each $0.597 \mathrm{~m}$ in diameter, connected to a Plexiglas tube with a $75-\mathrm{mm}$ inner diameter and a reversed blower. The discs simulated the fracture and the pipe simulated the exit wellbore. The working fluid, air, which was chosen for experimental convenience, was drawn between the two discs and then into the pipe. Static pressures were read along two different near-radial chords of each disc, and at increasing longitudinal distances along the pipe. Flow rates as well as simulated fracture apertures were varied so that results could be obtained as a function of Reynolds number, $R$, and the aperture-to-well-diameter ratio, 2t/D.

The most important results are summarized in terms of the vena contracta kinetic energy and the overall pressure loss, $\Delta p_{3}$ is the pressure drop associated with the flow turning, regime 3. Figure 5-40 presents the ratio of the kinetic energy within the vena contracta to that associated with fully developed flow in the pipe simulating the wellbore. The kinetic energy ratios show that the vena contracta flow area is more restricted at small ratios of $2 t / D$ and becomes independent of Reynolds number at large values of $R$. The dimensionless pressure losses, equivalent to loss coefficients where the dynamic pressure is based upon the average pipe velocity, are shown in Fig. 5-41.

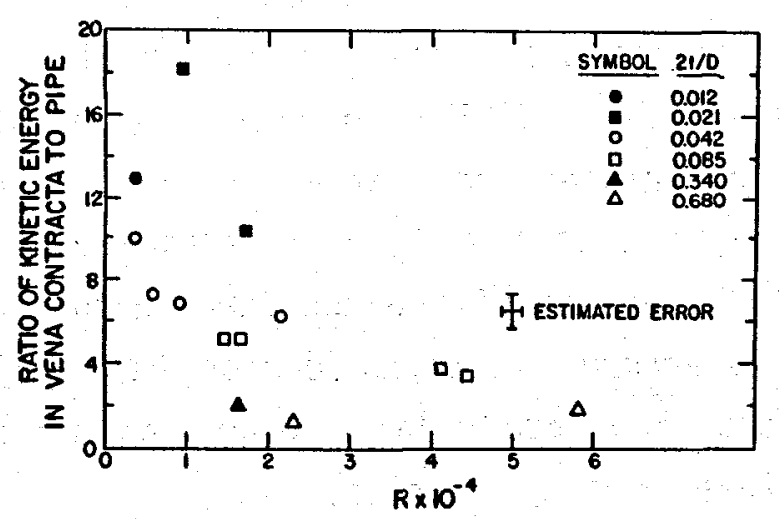

Fig. 5-40.

Relative constriction of vena contracta as a function of fracture aperture to wellbore diameter ratio, $2 t / D$, and pipe Reynolds number, $R$.

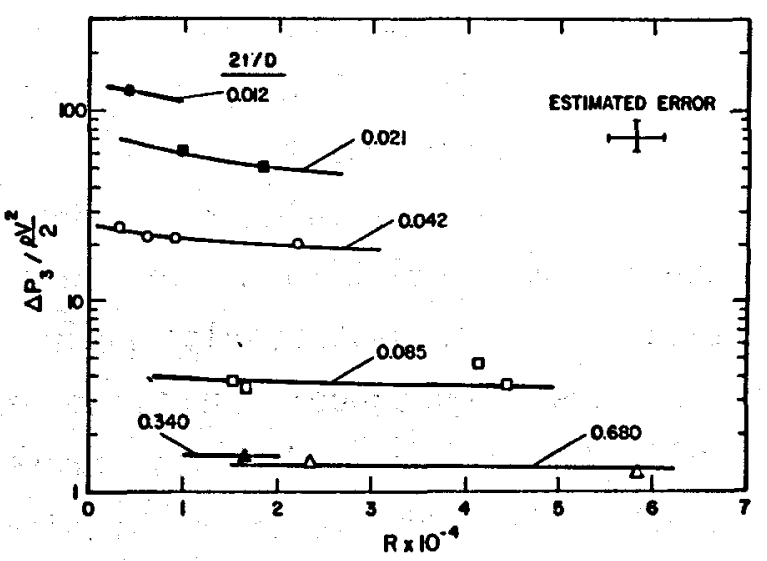

Fig. 5-41. Regime three pressure loss, $P_{3}$, as a function of wellbore Reynolds number for different fracture apertures. Pressure less is nondimensionalized in terms of average wellbore velocity. 
These loss coefficients also increase with decreasing 2t/D. For some extremes of $2 t / D$, the present flow has some similarities to flow through an abrupt collinear contraction or expansion, but important numerical differences in loss coefficients occur because of the radial-to-longitudinal changes in the nature of the flow. For example, at very small ratios of $2 t / D$, corresponding to an abrupt expansion, the "self-streamlining" of the radial flow as it first evolves into a longitudinal vena contracta results in loss coefficients 5 to 10 times lower than the usual collinear values.

These results have been applied to the hot dry rock geothermal reservoir planned in connection with the EE-2 (presently being drilled) and EE-3 boreholes. When the hydraulic fracture is inflated, i.e., held open against the closure stresses by internal pressurization, $\Delta P_{3}$ is only $0.8 \mathrm{MPa}$ (120 psi) for a flow rate of $0.06 \mathrm{~m}^{3} / \mathrm{s}(1000 \mathrm{gpm})$. However, when the reservoir is not inflated, corresponding to a condition of greater convenience for the operation of surface plant, then the aperture is reduced to its self-propped value $(0.2 \mathrm{~mm}$ or $0.008 \mathrm{in.})$, about one-fifth of its inflated value, and $\Delta P_{3}$ is increased to $13 \mathrm{MPa}(2000 \mathrm{psi})$ for the same flow rate. These calculations illustrate the important effect that the fracture flow passage area at the wellbore has upon the fractured reservoir flow impedance. To achieve low impedance one should (1) increase the local wellbore diameter by, e.g., underreaming; (2) increase the local aperture by acidization or the introduction of artificial proppants; or (3) increase the number of potential flow paths by explosive fracturing or jetting. In addition to these deliberate actions it is possible that thermo-elastic stresses and contraction induced by the thermal depletion of the reservoir might also result in impedance reductions. The present results point out that, because of the non-Darcy nature of the flow, impedance reductions due to aperture increases cannot be simply related via the usual linear pressure loss-flow rate relationships, no matter whether these are based upon radial or linear flow geometries.

Turbulent Shear Stress Fluctuations Near the Exit of a HDR Reservoir. As indicated above, the accelerated fracture flow regime 2 that occurs near the intersection of the fracture with the production wellbore, may be modeled using a radially converging sink flow. The laminar behavior of the flow through a smooth-walled duct has been analyzed and reported in Ref. 41. Wall shear stress measurements in turbulent and transitional flows performed by 
Murphy ${ }^{42}$, and summarized in Ref. 2, exhibited turbulent fluctuations that occurred for a wide range of dimensionless radii and acceleration parameters. Initial experiments were for the case of hydrodynamically smooth fracture walls, but in the future we hope to investigate rough walls also. It was found that as the flow was accelerated as it approached the outlet of the simulated fracture, the intensity and frequency of turbulent fluctuations were reduced, suggesting that strong acceleration led to more laminar-like flows. The relaminarization phenomenon is potentially of great practical significance, for the flow pressure loss characteristics, which ultimately translate to pumping power and flow impedance, undergo large changes in the transition from turbulent to laminar or nearly laminar flow. The relaminarization results were correlated in terms of $K_{v}=v / v^{2} \mathrm{dV} / \mathrm{dx}$, which represents the dimensionless velocity gradient in the flow direction. Here $v$ is the mean flow velocity, $v$ is the kinematic viscosity and $x$ is the streamwise coordinate. It was found that for $K_{v}<3 \times 10^{-7}$ time-mean measurements of the wall shear stress, $\tau$, and pressures were in good agreement with fully turbulent predictions, whereas when $K_{v}>2 \times 10^{-6}$ to $5 \times 10^{-6}$ the measurements were in good agreement with laminar predictions. In between these bounds was found a gradual transition from fully turbulent to laminar flow. Unlike fully developed nonaccelerated flows occurring, for instance in pipes, the transition phenomena could not be correlated with the local Reynolds number.

The fluctuating shear stress measurements made earlier by Murphy ${ }^{41}$ were only qualitative--the goal of the present study was to investigate these fluctuations in more detail. Of particular concern was the modification of turbulence produced by acceleration. The existence of well defined patterns in the velocity fluctuations (the so-called "coherent structures") in turbulent boundary layers has been well established. Recent efforts in basic turbulence research have focused up on the so-called wall "bursting" phenomenon in which high momentum fluid from the outer regions of the boundary layer sweeps inwardly toward the wall, and low momentum fluid burst rapidly outward from the inner layer. It is now known that the bursting phenomena is associated with most of the turbulent energy production in the wall region and thus is of great importance in the dynamics of the flow. Additional information can be found in the review articles by Willmarth ${ }^{43}$, Laufer ${ }^{44}$, and Kovasznay ${ }^{45}$.

To investigate the relaminarization phenomena more directly, a recently fabricated experimental flow duct was used that allows the variation a 
dimensionless acceleration parameter of $K_{V}$ from 0 to $10^{-5}$. Thus, turbulent, transitional, and laminar flows could be studied. As shown in Fig. 5-42, the flow was confined between two Plexiglas sheets separated by $25 \mathrm{~mm}$. The other two confining walls consisted of aluminum side rails, whose angle of convergence, 20 , can be varied from 0 to $30^{\circ}$. In this manner, acceleration and $K_{V}$ can be continuously varied. In operation, room air is drawn into the flow duct where the flow is accelerated, then directed into the horizontal tube shown in the lower portion of Fig. 5-42 and then into a reversed blower (not shown). In this experiment the use of air rather than water as a modeling fluid simplified the piping and pumping problems. Because of similitude principles, either fluid can be used in conjunction with the analysis.

Instrumentation consists of the pressure taps shown in vertical array in Fig. 5-42 and the shear-stress probe (Fig. 5-43) that was flush-mounted and maintained at constant temperature by means of a Thermo System, Inc., model 1050 anemometer. The shear stress instrument is ideal for these flows because the wall shear-stress is acutely sensitive to acceleration, and the fluctuations of the signal with time are related to the turbulence. The wall shear stress signals were recorded with an Ampex FR2000 tape recorder and processed with the Hewlett -Packard 5451C Fourier Analyzer that is usually used in connection with analysis of Fenton Hill seismic experiments.

Typical oscilloscope photographs of the fluctuating shear stress signals are presented in Fig. 5-44. To focus on acceleration effects only, these four 


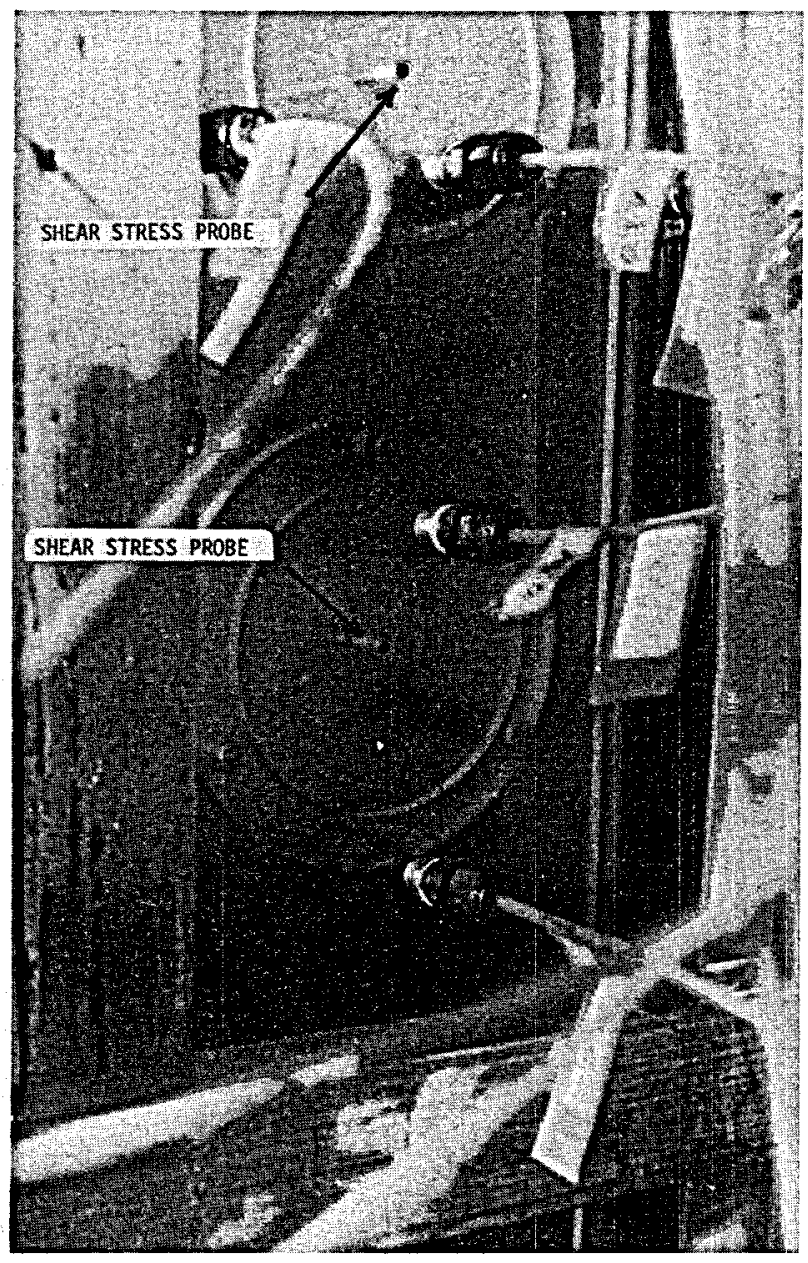

Fig. 5-43.

Shear stress probes--pressure tabs appearing in figure are on near wall, shear stress probes are on the far wall surface.

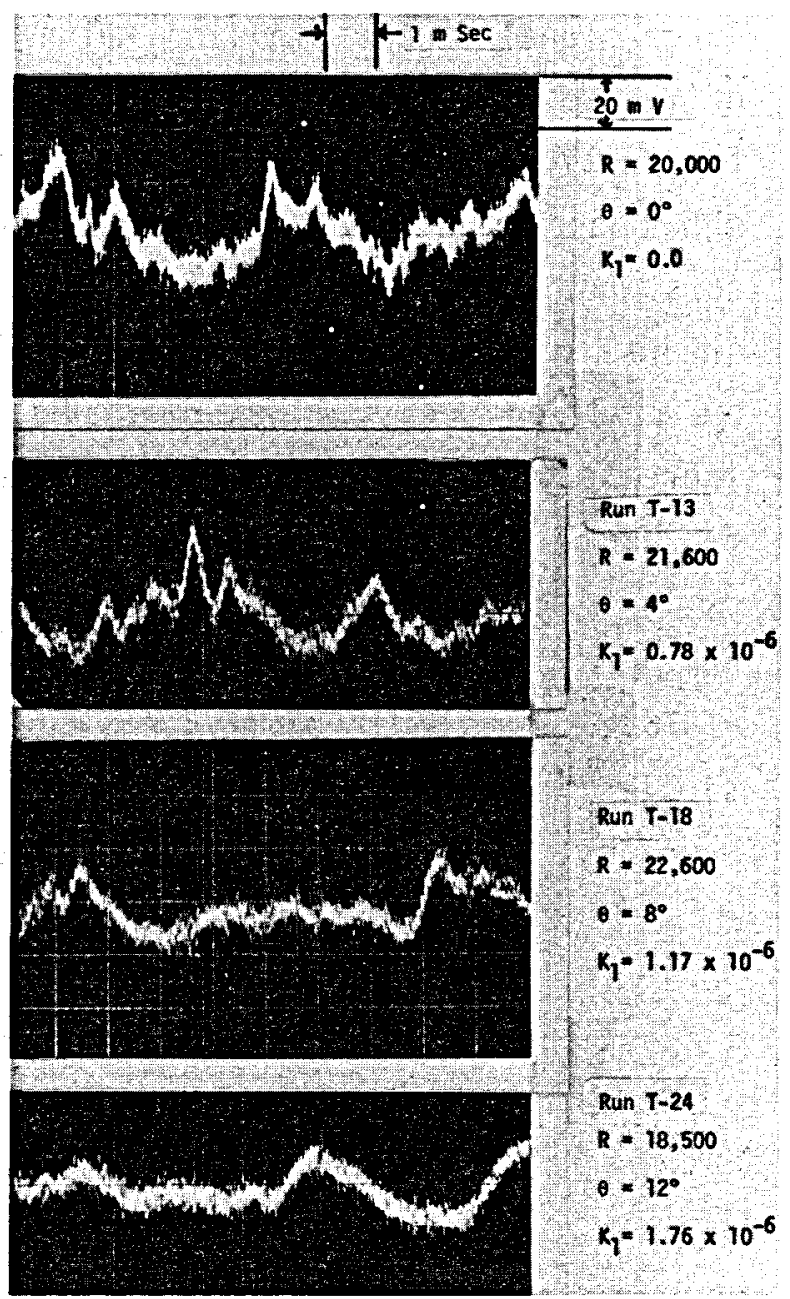

Fig. 5-44. Oscilloscope photographs of fluctuating shear-stress signals.

photos were taken for runs where the Reynolds number, $R$, was approximately the same. Unilike the previous section dealing with regime 3 flows, $R$ is defined as $V D / v$, where now $V$ is the average velocity within the duct at the axial position where the shear-stress instrument was measured; $D$, the hydraulic diameter, is twice the spacing between the two Plexiglas sheets; and $\nu$ is still the kinematic viscosity of the modeling fluid, air. Valves of the convergent angle, $\theta$, and therefore $K_{v}$, increase from the top to bottom, as shown in the photograph of Fig. 5-44. "To facilitate comparisons, each photograph has the same time and shear-stress signal-voltage scales, $1 \mathrm{~ms} / \mathrm{cm}$ per division and $20 \mathrm{mV}$ per division. The top photograph, $\theta=\mathrm{Kv}-0$, shows 
large signal fluctuations of $\pm 20 \mathrm{mV}$, corresponding to shear stress fluctuations of $\pm 15 \%$ of the mean value. The high-frequency noise superimposed up on the main fluctuations is due to the anemometer electronic circuitry. The top photo shows approximately four large fluctuations that might be associated with bursting. Typically these are characterized by sharp, sudden increases in shear stress accompanied by large changes in the fluctuating signal, followed by a slower decay. The lower photograph of Fig. 5-44 shows that as $\theta$ and $\mathrm{KV}$ increase, the amplitudes and frequency of the shear stress fluctuations decrease.

To study this trend more quantitatively, conditioned sampling of the signal was performed using the techniques described by Blackwelder and Kaplan (1976). The conditionally sampled burst frequencies are as presented in dimensionless terms in Fig. 5-45. The dimensionless frequency is scaled with the boundary layer outer region parameters $V$ and $\sigma$ where $\sigma$ is the boundary layer thickness; it is here taken to be onehalf the plate spacing. Figure 5-45

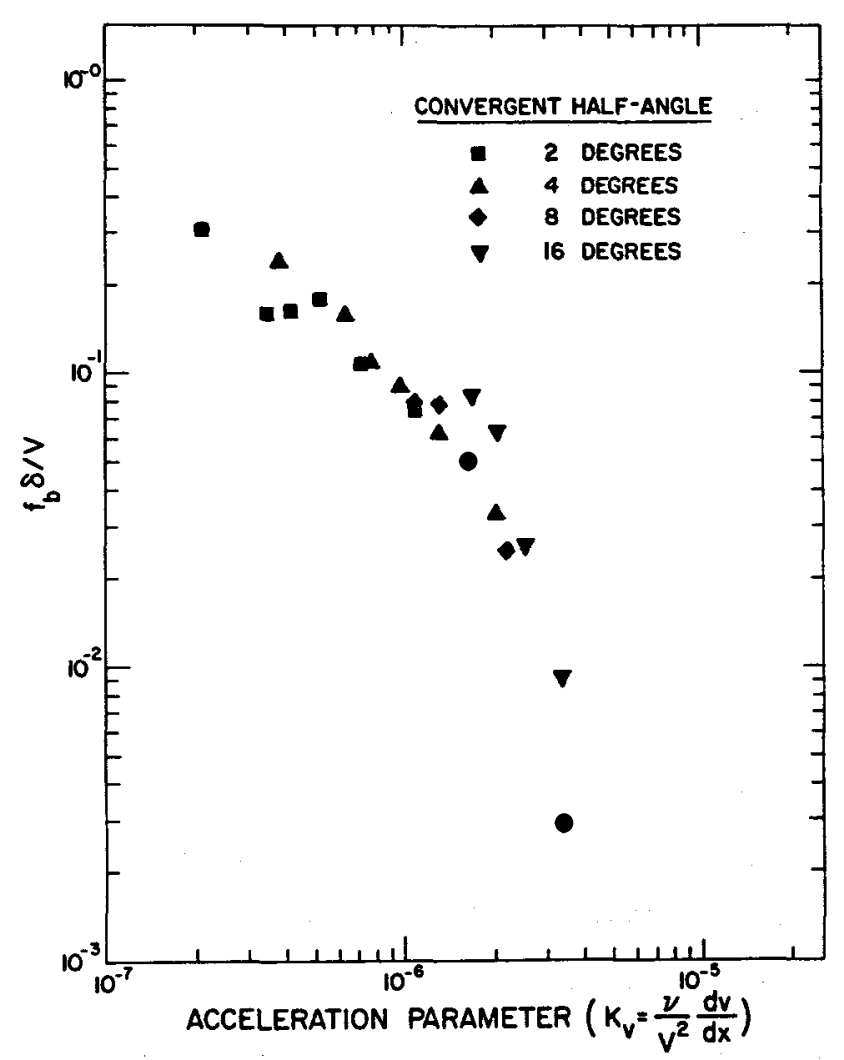

Fig. 5-45.

Decrease of turbulent burst frequencies caused by flow acceleration. displays a clear trend, showing a large decrease in dimensionless burst frequency as $\mathrm{Kv}$ increases. The bursting phenomenon is not completely eliminated, but near $K_{v}=2.0 \times 10^{-6}$ to $3.4 \times 10^{-16}$. There is a rapid decrease in bursting, suggesting that complete laminarization is being approached. This operation supports the earlier finding ${ }^{46}$, based primarily upon pressure measurements, that laminarization is complete at $k_{v}=2 x$ $10^{-6}$ to $5 \times 10^{-6}$.

\subsubsection{Wellbore Heat Transmis-} sion. A wellbore heat-transmission computer code (WBHT) was developed primarily to predict downhole temperatures from known surface temperatures. An important extension of the code was 
made in an effort to predict fluid temperatures in counter-current flow associated with drilling and cementing operations. The computer code is capable of handling temperature- and pressure-dependent fluid properties as well as variable rock properties.

To verify this finite difference-based code, it was checked against an existing finite element code in the standard (noncounter-current) flow configuration. The codes were in excellent agreement with differences in results of less than 1\%. As a further check the outlet temperatures in well GT-2 during Run Segment 4 (Expt. 215) were calculated and compared to the measured outlet temperatures. The results shown in Fig. 5-46 show discrepancies of about $10^{\circ} \mathrm{C}$, caused primarily because the formation had been preheated during the previous 75-day experiment. The consistently low temperatures computed are a result.

An important calculation that provides a good example of the code's capability is the calculation of the EE-1 bottom-krole temperature in the recent Expt. 215. Figure 5-47 shows the calculated bottomhole temperature at $2900 \mathrm{~m}$ $(9600 \mathrm{ft})$ as a function of time. Here, agreement with measured temperatures is excellent.

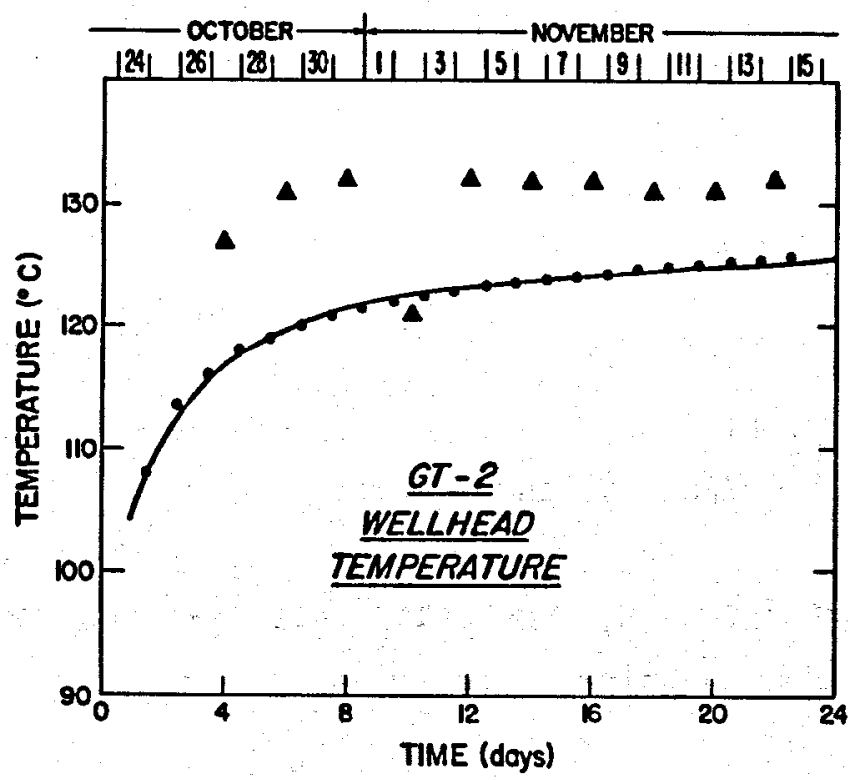

Fig. 5-46.

GT-2 well head temperature vs time at $100 \mathrm{gpm}$ flow rate.

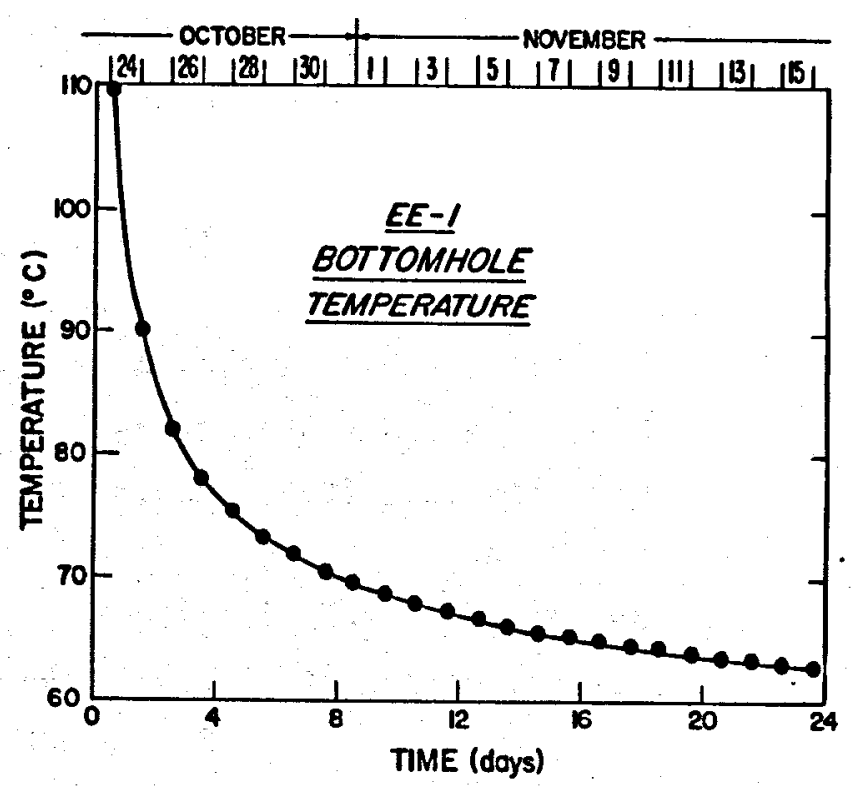

Fig. 5-47. EE- 1 bottomhole temperature vs time at $120 \mathrm{gpm}$ flow rate. 
5.3.5. Interwell Tracer Studies. Work has continued on using dye and radioactive isotope tracers to characterize flow in the Fenton Hill reservoir. Progress in this area is detailed in Ref. 33 and only the major results are cited here. Tracer profiles and residence time distributions have been used to delineate changes in the fracture system, particularly in diagnosing pathological flow patterns, establishing fracture volumes and areas, characterizing fluid dispersion, and in identifying new injection and production zones.

Data obtained from ${ }^{82} \mathrm{Br}$ and ${ }^{131_{\mathrm{I}}}$ tracer injections with downhole gamma monitoring were used to identify damaged regions of casing cement and to quantify flow fractions entering and leaving the GT-2/EE-1 reservoir at various depths. This information was then used in conjunction with other geophysical data to develop a consistent model of the vertical and $30^{\circ}$ off-vertical jointed fracture system contained between the injection and production boreholes.

Residence time studies utilizing pulsed injections of visible Na-fluorescein dye have been used to determine fracture size, volumetric sweep efficiencies and dispersion levels within the fractured reservoir. A twodimensional dispersional model was developed for type curve analysis of experimental results. In this case, a steady-state, two-dimensional flow field is assumed for the fracture system in the $x-y$ plane. With the dispersion/convection equation written as

where

$$
\nabla \cdot(D \nabla C)-\vec{U} \cdot \nabla C=\frac{\partial C}{\partial t}
$$

$$
\begin{aligned}
& D=\text { dispersion coefficient tensor, } \\
& C=\text { concentration of tracer }=C(x, y, t), \\
& U=\text { flow velocity vector }=U(x, y) \hat{\imath}+V(x, y) \hat{\jmath}, \text { and } \\
& t=\text { time. }
\end{aligned}
$$

By assuming only longitudinal (x-direction) and transverse (y-direction) dispersional components linearly dependent on flow velocity as

$$
\begin{aligned}
& D_{x}=\alpha_{x}|U|+D^{0} \\
& D_{y}=\alpha_{y}|V|+D^{0} .
\end{aligned}
$$


$D^{0}$ accounts for both molecular diffusion, tortuosity and other heterogeneous formation effects. All injection and production zones are treated as point sources and sinks with the velocity field specified by either potential flow or by the solution to the Murphy-McFarland heat-transfer and fluid-flow model.

Equation (5-20) was solved numerically for various values of $\alpha_{x}, k=$ $\alpha_{y} / \alpha_{x}$, and Pe* (dispersonal Peclet number) to produce a set of dimensionless type curves.

Figure 5-48 shows a typical type of curve match for a dye tracer study conducted on the GT-2/EE-1 reservoir at Fenton Hill. In this case, only the velocity dependent terms $x$ and $y$ are important. In addition, to obtain mixing parameters, information about fracture aperture profiles and volumes are obtained for known or assumed fracture geometries.

Modifications will be introduced during the next fiscal year to examine effects of buoyancy-dominated fracture flows on dispersion and their effect on active dissolution of rock within the fracture.

5.3.6. Geochemical Modeling. Because the water that is pumped through the reservoir is not in chemical equilibrium with the reservoir rock, dissolution, alteration, and precipitation reactions occur that modify the chemical composition of the fluid and the rock. A generalized model of the geochemical behavior of the geothermal fluid that takes into account the temperature distribution, flow rates, water loss or makeup rates, and the dissolution and precipitation rates of minerals is under development and has been

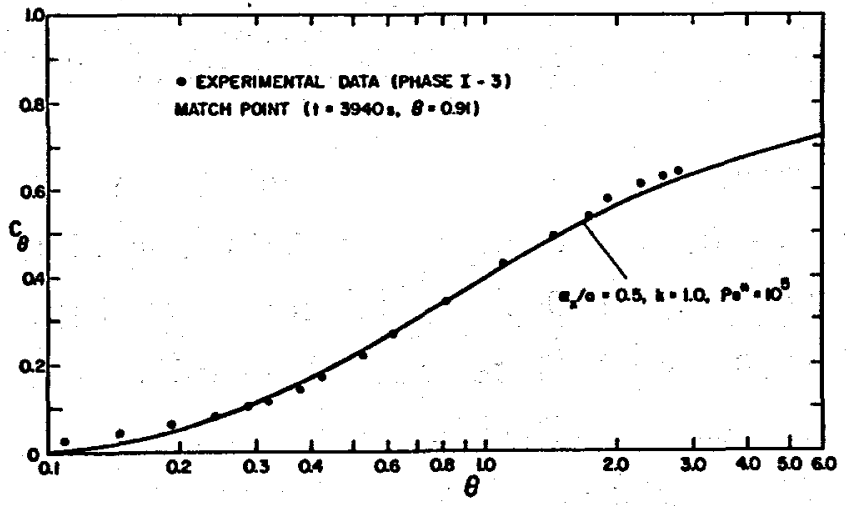

Fig. 5-48. GT-2/EE-1 dye tracer study. applied in an early form with some success in modeling the transient chemical behavior of the Fenton Hill system during the 75-day test.

The model was initially developed to explain the behavior of the silica content of the fluid during the 75-day test ${ }^{20}$. For that case, it was assumed that the flow in the reservoir was split into two parallel flow paths (1) the major portion of 
the flow accounted for the heat extraction in the system, but no quartz dissolution occurred in that region due to the cooling of the rock; and (2) a small fraction of the flow passed through an isothermal, high-temperature region that accounted for almost all of the silica in solution, but for only a small percent of the energy extracted (Fig. 5-49).

A mass balance on the fluid entering and leaving the system shows

$$
v \frac{d \bar{c}}{d t}=q_{m}\left(c_{m}-\bar{C}\right)+\frac{\dot{q}_{2}}{\dot{q}_{T}}\left(1-e^{-\sigma}\right)\left[(c \text { sat }-\bar{c}) \dot{q}_{T}+\left(\bar{c}-c_{m}\right) \dot{q}_{m}\right],
$$

where $\bar{c}$ is the mean concentration of silica at time $t, c_{m}$ is the concentration of silica in the makeup water; $c^{s \text { at }}$ is the saturation concentration at the temperature of the isothermal secondary flowpath; $\dot{q}_{m}, \dot{q}_{T}$, and $\dot{q}_{2}$ are the flow rates of the fluid from the makeup, injected, and isothermal paths respectively; $V$ is the total system volume (including both wellbores); and $\sigma$ is a lumped reaction rate parameter that includes terms for the rock area to fluid-volume ratio $a^{\star}$ in the isothermal path, the fluid residence time $\tau_{2}$ in that path, the overall rate constant for this reaction $k$, and the degree of dispersion in the path $f(0<f \leq 1)$.

In the original analysis, all terms on the right hand side of Eq. (5-22) were assumed to be constant, and for $\sigma>>1$ and $\dot{q}_{m}<<\dot{q}_{T} E q .(5-22)$ could be rearranged and integrated to the form

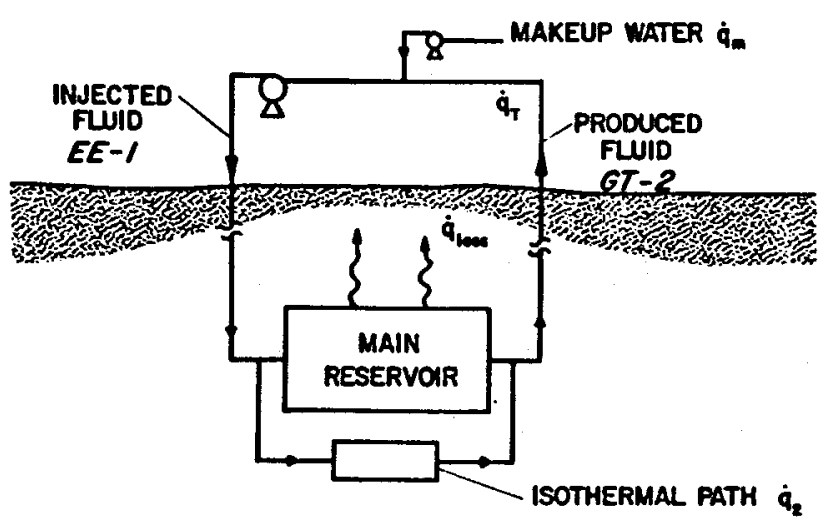

Fig. 5-49.

Schematic of Fenton Hill system.

$$
\tau=c^{\infty}-\left(c^{\infty}-c_{0}\right) \exp \left(\frac{-\dot{q}_{2} t}{V}\right),(5-23)
$$

where $C_{0}$ is the concentration at $t=0$. A solution of this equation for $\bar{c}=0.04 /$ day is shown in Fig. 5-50 for silica buildup during the Segment 2, 75-day test with $C^{\infty}=$ $c^{\text {sat }}=220 \mathrm{ppm}$ and $C_{0}=80 \mathrm{ppm} .20$

An extension of the original model that allows for a first-order linear displacement of pore fluid in 


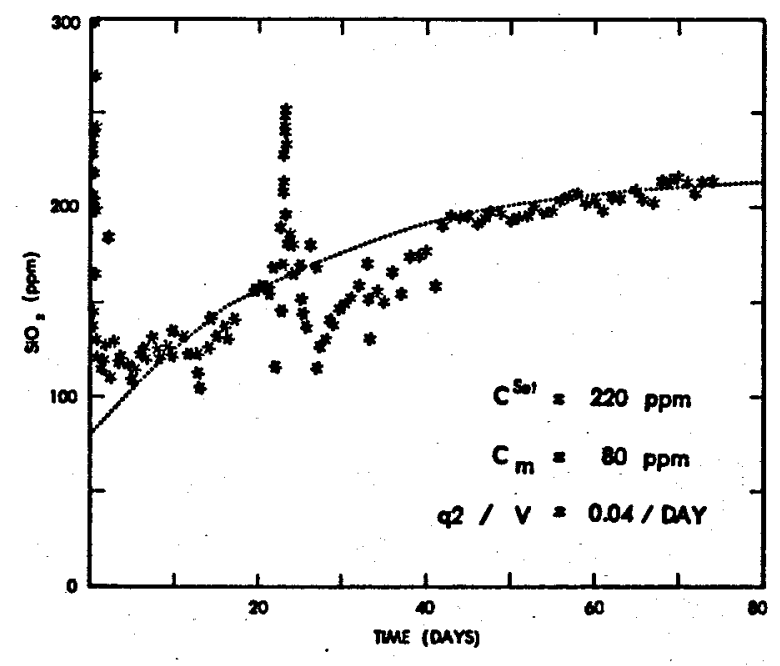

Fig. 5-50.

Experimental buildup of dissolved silica during the Run Segment 2 closedloop circulation test of the Fenton

Hill reservoir. A theoretical (dotted) line is shown following Eq. (5.23).

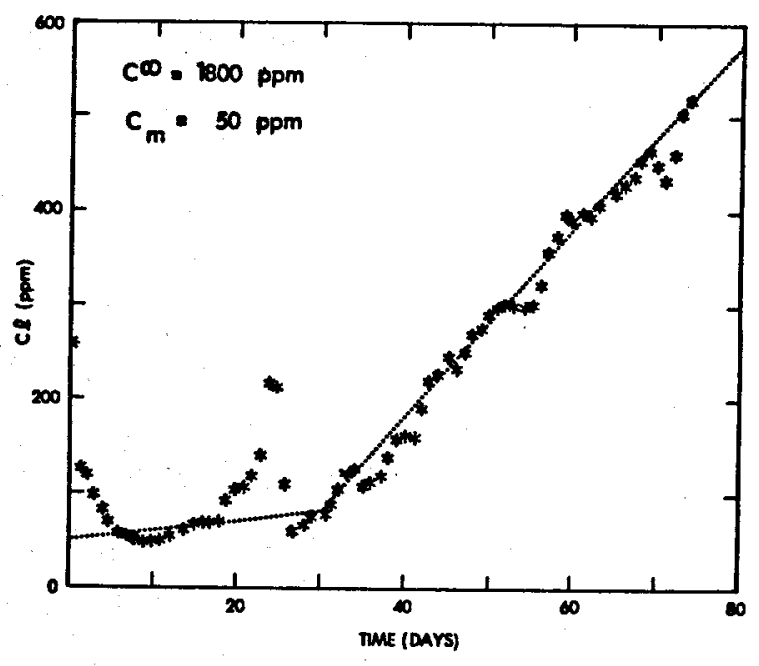

Fig. 5-51.

Experimental buildup of chloride ion concentration during Run Segment 2. A theoretical (dotted) line is shown for a linear pore fluid displacement model.

the isothermal path rather than reaction to produce a dissolved species has been applied to the chloride ion concentration history with good success (Fig. 5-51).

In this form, Eq. (5-22) can be rewritten as

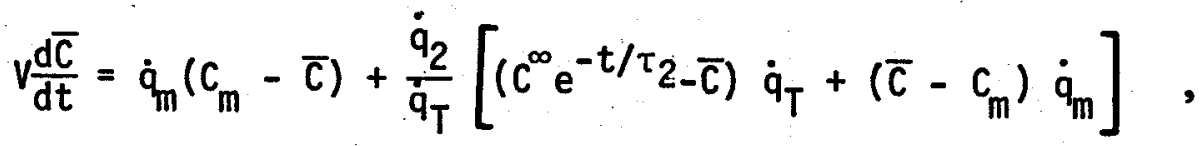

which can be simplified for the case of uniform pore fluid displacement from the secondary path (i.e., $\left.t / \tau_{2} \ll 1\right)$ to

$$
\frac{d \theta}{d t}=\frac{\dot{q}_{m}}{V}-\left(\frac{\dot{q}_{m}+\dot{q}_{2}}{V}\right) \theta \text { where } \theta=\frac{c^{\infty}-\bar{c}}{c^{\infty}-c_{m}} \text {. }
$$

A general solution to Eq. $(5-25)$ is

$$
\theta=\frac{1}{R V}\left[\int \dot{q}_{m} R d t+\text { Const }\right] \text {, }
$$

where

$$
R=\exp \left[\int \frac{\dot{q}_{m}+\dot{q}_{2}}{y} d t\right] .
$$


Because $R$ is of exponential order and $\dot{q}_{m}$ is only weakly dependent on $t$ at late times, the solution can be rewritten

$$
\theta=a e^{b t}
$$

or

$$
\bar{c}=C^{\infty}-\left(C^{\infty}-C_{m}\right) a e^{-b t},
$$

where $a$ and $b$ are complicated functions of t. For $a=1, E q .(6)$ can be solved by setting $C^{\infty}=1800, C_{m}=50$ and $\bar{c}=c(t)$ where $c(t)$ is the measured concentration at time $t$. The functional dependence of $b$ on $t$ is shown in Fig. 5-52 for this case. Applying these results with Eq. (5-27), sodium in the $\mathrm{Na}^{+}$concentration history using $\mathrm{C}^{\infty}=1250$ and $\mathrm{C}_{\mathrm{m}}=200$, can be predicted as shown in Fig. 5-53. While this fit is apparently not as close to the observed $\mathrm{Na}^{+}$history as might be expected, it is remarkable considering that $\mathrm{Na}^{+}$participates in reactions with feldspars while the chloride does not. Further modification of the model discussed will take this added reaction into account.

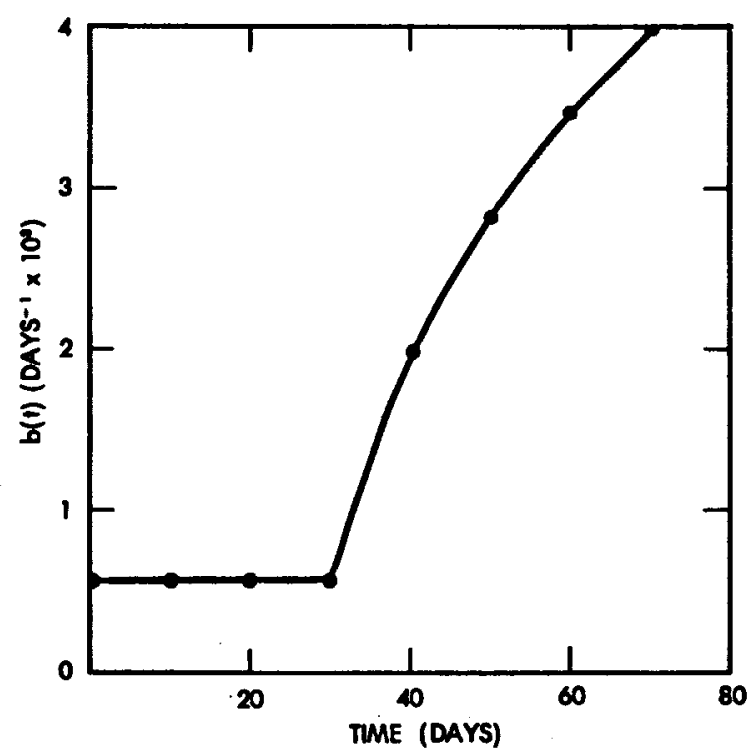

Fig. 5-52.

Empirical time constant b history during Run Segment 2.

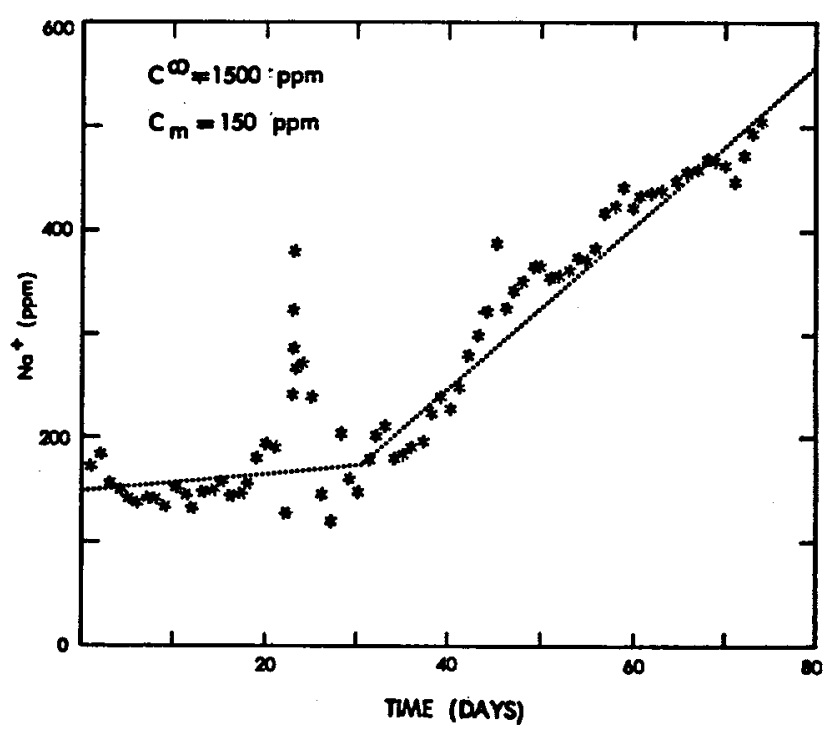

Fịg. 5-53.

Experimental buildup of sodium ion concentration during Run Segment 2. A theoretical (dotted) line is shown following Eq. (5-27). 


\subsubsection{Feasibility of Downhole Rock Fracturing with Impulsive Pressure}

Disturbances. In this section are discussed various methods of generating independent, impulsive pressure waves, which then propagate downward in wells. The goal is to propagate pressure disturbances of large amplitude and sharp rise time in order to fracture the rock formations surrounding the openhole section below the cased portion of a well. In the first subsection of this section, pressure waves generated with surface equipment such as a piston or a suddenly depressurized surface accumulator are considered. In the second subsection the sudden depressurization of a portion of the wellbore volume itself, analogous to the firing of a shock tube, is considered. Finally, in the third subsection, the response to impact loading, such as the dropping of a massive harmer on the water at the top of the we11, is calculated.

Impulsive Motions Imparted at the Surface. For the impulsive steppressure changes considered here, it is convenient to write the continuity and momentum equations for the fluid in the well, rather than to use a differential form. Such an approach is particularly useful for considering fluid conditions before and after passage of a step-wise pressure discontinuity. Figure 5-54(a) shows such a pressure discontinuity set up by, for example, a piston impulsively set into motion with the constant velocity $u$ in a fluid with undisturbed density $\rho_{0}$ and undisturbed pressure $P_{0}$. This results in a pressure discontinuity that moves with the constant sound velocity a. The analysis to follow also holds if the constant velocity piston is replaced with a surface accumulator of 1 arge volume filled with a compressible gas. The accumulator is initially pressurized to high pressure and connected to the well via a valve that is suddenly opened at time $t=0$. A large volume of highly compressible gas allows the assumption that the gas/water interface moves at roughly constant velocity, thus simplifying the analysis.

In Fig. 5-54(a) the coordinate system is attached to the ground so that the pressure discontinuity appears to be moving. In Fig. 5-54(b) the coordinate system is attached to the moving wave, so that conditions ahead of and behind the wave appear to be time independent. This steady-state behavior simplifies the analysis. Conservation of mass and momentum for the system sketched in Fig. 5-54(b) results in the following equations for the density disturbance $\rho$ and pressure disturbance $P$. 


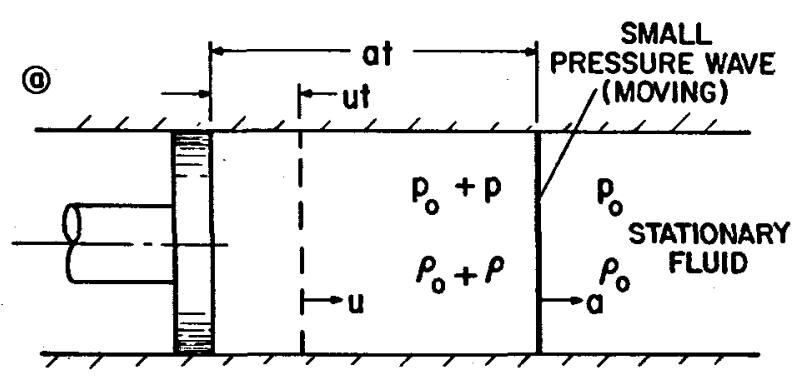

(b)

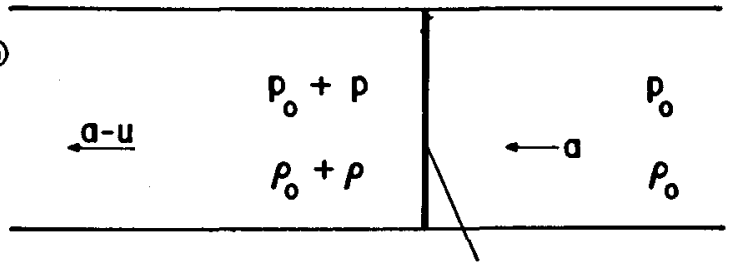

SMALL PRESSURE WAVE (STATIONARY)

Fig. 5-54.

Propagation of pressure discontinuities.

$$
\begin{gathered}
\rho_{0} a=\left(\rho_{0}+\rho\right)(a-u), \\
P=\rho_{0} a u .
\end{gathered}
$$

Equation (19) in its present form neglects friction, but friction can be incorporated in an approximate form as follows. The local velocity, $u(x)$ after the wave has passed can be shown from the continuity Eq. (5-28j and the equation of state to be

$$
u(x)=P(x) / \rho_{0} a,
$$

where $x$ is the distance down the well. Coincidentally this is the same form as the frictionless momentum Eq. (5-29). Substituting Eq. (5-30) in the Darcy Weisbach friction equation ${ }^{48}$ results in

$$
\frac{d P}{d x}=-\frac{f p^{2}}{D^{2} \rho_{0} a^{2}}
$$

where $D$ is the well diameter and $f$ is the friction factor. Usually one is interested in the pressure loss from the surface to the position where fracturing is desired. In the EE-1 well at Fenton Hill this distance is nearly equal to the total well depth L. Thus, integrating, it can be shown that the total pressure loss due to friction is

$$
\Delta P_{f}=\frac{f L u(L) P(L) / 2 D a}{1-f L u(L) / 2 D a},
$$

where $u(L)$ and $P(L)$ are the disturbances at the bottom, $P(L)=\rho_{0} a u(L)$. Typically, for EE-1 conditions it can be shown that $\Delta P_{f}=P(L) / 3$. Thus, perhaps one-third of the pressure disturbance generated would be lost to friction and the surface generated pressure might need to be adjusted accordingly to achieve the extent of fracturing desired. 
In actual operation the wellbore would be pressurized to just below the formation strength and a pressure pulse of approximately 100 bars (1500 psi) would be generated, requiring an average particle velocity, $u$, of about $7 \mathrm{~m} / \mathrm{s}$ $(23 \mathrm{ft} / \mathrm{s})$. About one-third of the generated pressure would be lost to friction, but upon reflection from the well bottom about twice the remaining pressure disturbance would be applied at the formation, so that perhaps $4 / 3$ of the generated pressure pulse would be effective in fracturing.

The rise time associated with the pressure wave can be calculated approximately as follows. Due to friction the pressure wave does not appear as a sharp discontinuity, but is instead diffused over a distance $x$. The spatial spreading $(\Delta x)_{\text {spread }}$ can be calculated as

$$
(\Delta x)_{\text {spread }}=\sqrt{\nu_{\text {eff }} t} \text {. }
$$

The time of primary interest is that time required for the wave to travel from the surface to the downhole formation, a total distance of nearly $L$. Thus $t=$ $L / a$. The effective kinematic viscosity $\nu_{\text {eff }}$ associated with turbulent flows can be crudely estimated from the relationship

$$
\tau=2 \rho_{0} \nu_{\text {eff }} u / D
$$

where $\tau$ is the frictional shear stress at the wall of the well. A static force balance gives $\tau=(D / 4) d P_{f} / d x$. Substituting this relationship for $\tau$ in Eq. (24) and using the friction Eq. $(5-31)$ to evaluate $d_{f} / d x$ yields

$$
\nu_{\text {eff }}=f \cdot u D / 16
$$

The ratio of the turbulent and molecular, or laminar, viscosities is $\nu_{\text {eff }} / \nu$ $=f R e / 16$, where the Reynolds number $R e$ is $u D / \nu$. For typical values, $R=10^{5}$ and $f=0.015, \nu_{\text {eff }} / v=100$. With these expressions for $t$ and $\nu_{\text {eff }}$, the spreading distance is

$$
(\Delta x)_{\text {spread }}=\sqrt{f D L u / 16 a} \text {, }
$$

and the rise time required for passage of the diffused pressure wave is 


$$
t_{\text {rise }}=(\Delta x)_{\text {spread }} / a=\sqrt{\text { fDLu/16a }} \text {. }
$$

For typical EE-1 conditions $t_{\text {rise }}$ is of the order of $1 \mathrm{~ms}$. As will be shown in the discussion, a rise time this fast is of the same order as that associated with explosive fracturing.

Sudden Depressurization of a Portion of the Well. Next consider part of the well above, say, a packer, pressurized to a high level, $P_{m}$, while the region below the packer is at ambient pressures, and suddenly a rupture diaphragm or valve in the packer is released so that a pressure discontinuity travels to the well bottom where it is then reflected. The calculations for this case stem from the analysis of a shock tube ${ }^{49}$. In this case a compressional wave travels down the well into the region where the pressure disturbance was initially zero and a rarefaction wave travels up from the packer into the region where the initial pressure was $P_{m}$. The intermediate region between the expanding compression and rarefaction waves can be shown, in the absence of friction, to have the pressure disturbance value $P_{m} / 2$. Upon reflection the downwardly traveling disturbance is doubled, so it is possible in the absence of friction to generate a fracturing pressure disturbance of $P_{m}$, exactly the value possible had the entire well, rather than just a portion, been pressurized to $P_{m}$ in the first $p l a c e$. Thus, it appears that the redeeming attribute of this method, as well as the other dynamic method discussed in the first subsection, is that the pressure disturbance is applied rapidly with fast rise times. Actual rise times can be calculated by the approximate method discussed earlier. The chief advantage of the presently discussed method compared to the other dynamic methods is that the packer can be located close to the formation to be fractured, so that the frictional pressure loss $\Delta \mathrm{P}_{f}$ and the rise time can be reduced nearly to zero. Unlike the previous method and the one that follows, there is no advantage to first statically pre-pressurizing the well below the packer, hoping for a cumulative pressure effect. It can be shown that the sum of the initial static pressure level below the packer (call this $P_{i}$ ) and the reflected (and doubled) dynamic pressure rise is independent of $P_{i}$ so long as $P_{i}$ is below the level to which the well above the packer was initially pressurized.

For discussion later it is convenient to calculate the potential energy, $E$, stored in the water above the packer. If the water volume above the packer 
is $V_{p}$ and this volume is pressurized to $P$ before initiation of the wave, then the energy is

$$
E=P^{2} V_{p} / 2 K
$$

where $K$ is the bulk elastic modulus of the water. Assuming that the packer is located so that $V_{p}$ is nearly equal to the total well volume, which is $94 \mathrm{~m}^{3}$ $\left(3300 \mathrm{ft}^{3}\right.$ ) for EE-1, and that a breakdown pressure of 300 bars (4500 psi) is required, then $E=22 \mathrm{MJ}\left(16 \times 10^{6} \mathrm{ft}-1 \mathrm{~b}\right)$.

Impact Loading. Armstead ${ }^{50}$ has proposed the dynamic fracturing method sketched in Fig. 5-55. Here the well would be statically pressurized to a leve 1 just below the estimated fracturing pressure of the rock. An additional dynamic pressure would then be exerted by impacting a harmer-weight upon the top of the water column by a device resembling a pile-driver.

The analysis for this situation proceeds easily by treating the entire water column as a single lumped mass rather than as a continuum. While this is a crude approximation, it leads to particularly simple results that are useful for a feasibility investigation. Let the hammer mass be $m_{h}$ and its downward velocity at any time after coming into concact with the water collumn be $u$. Assume that the impact is plastic enough so that the hammer does not bounce up and lose contact with the well head. Then, since there can be no velocity discontinuity at the hamer-water column

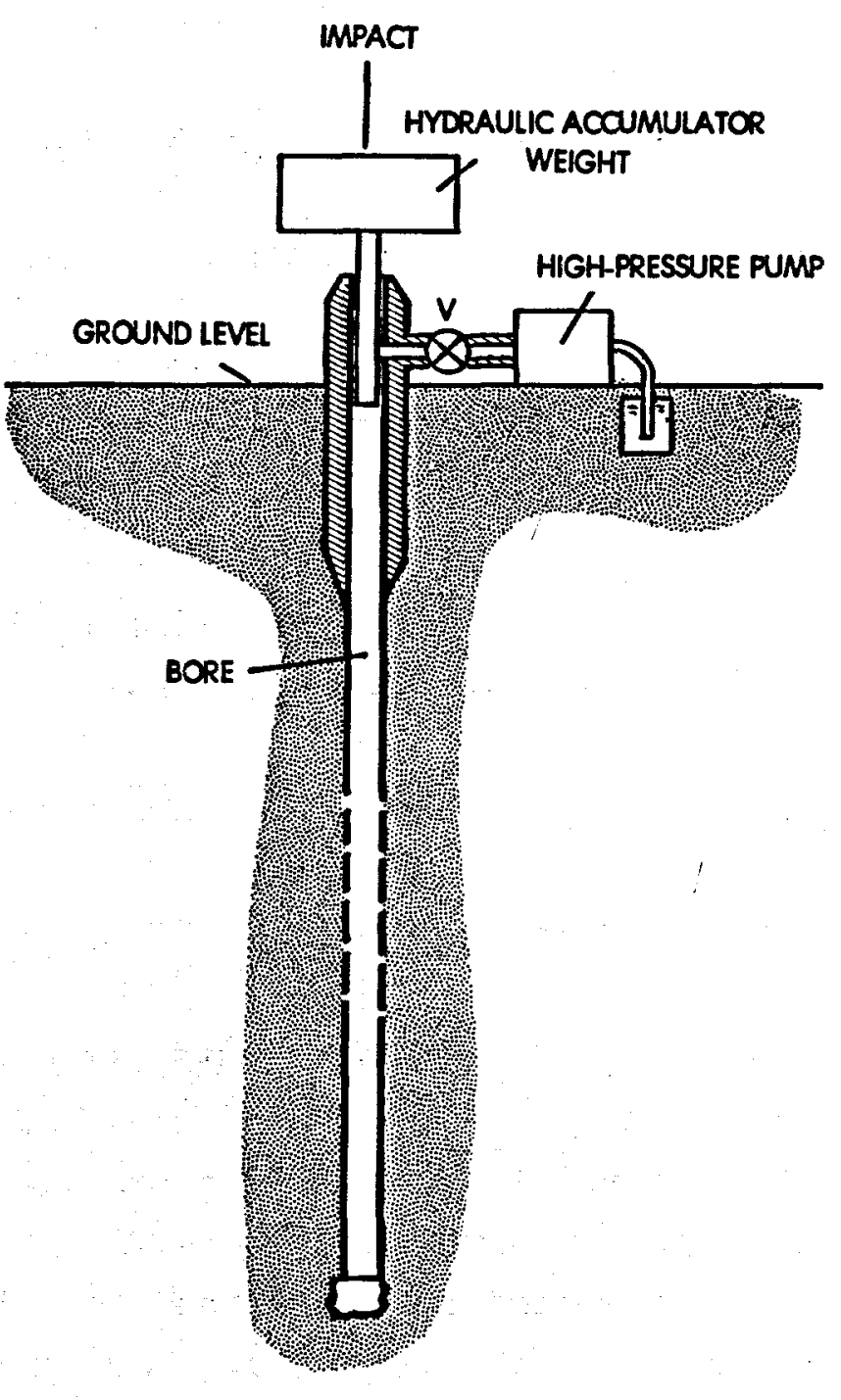

Fig. 5-55.

Proposal for rock-fracturing by means of dynamic impact. (Armstead50). 
interface, both the hammer velocity and the velocity of the water behind the moving pressure wave must be $u$. Consider the time interval, $\Delta t$, for the pressure wave to reach the uncased rock formation, which is nearly $\Delta t=L / a$. The average deceleration force of the hammer in this interval is $m_{h} a\left(u_{0}-u\right) / L$, where $u_{0}$ is the initial velocity of the hammer just before impact. This velocity can be estimated as $u_{0}=\sqrt{2 E / m_{h}}$, where $E$ is the kinetic energy of the harmer upon impact. The average acceleration force of the water column in the same time interval is $m_{w} a u / L$, where $m_{w}$ is the mass of the water column above the rock to be fractured, which is nearly the entire water mass. Because there are no external forces, the sum of the acceleration forces must be zero so that

$$
u=\sqrt{2 E m_{h}} /\left(m_{h}+m_{w}\right)
$$

The average downhole dynamic pressure during this time is

$$
\begin{aligned}
P & =\rho_{0} a u \\
& =\rho_{0} a \sqrt{2 E m_{h}} /\left(m_{h}+m_{h}\right) .
\end{aligned}
$$

For a given application $m_{w}$ is fixed, but $m_{h}$ can be a fracture design variable. Thus, it is convenient to define

$$
P=\rho_{0} a \sqrt{2 E / m_{w}} \phi\left(m_{h} / m_{w}\right),
$$

where

$$
\phi\left(m_{h} / m_{w}\right)=\sqrt{m_{h} m_{w}} /\left(m+m_{w}\right) \text {. }
$$

A plot of the dimensionless bottomhole pressure, $P / P_{0} a \sqrt{2 E / m_{W}}$ versus $m_{h} / m_{w}$ is shown in Fig. 5-56. It can be seen that for a given $E$ and $m_{w}$, peak bottomhole pressure is achieved when $m_{h} / m_{w}=1$. In fact, poor coupling of the energy into peak pressure rise occurs when $m_{h} / m_{w}<2$. This behavior is similar to elastic collisions between billiard balls or atoms--best momentum and energy interchanges occur when the two masses in question are nearly equal. 


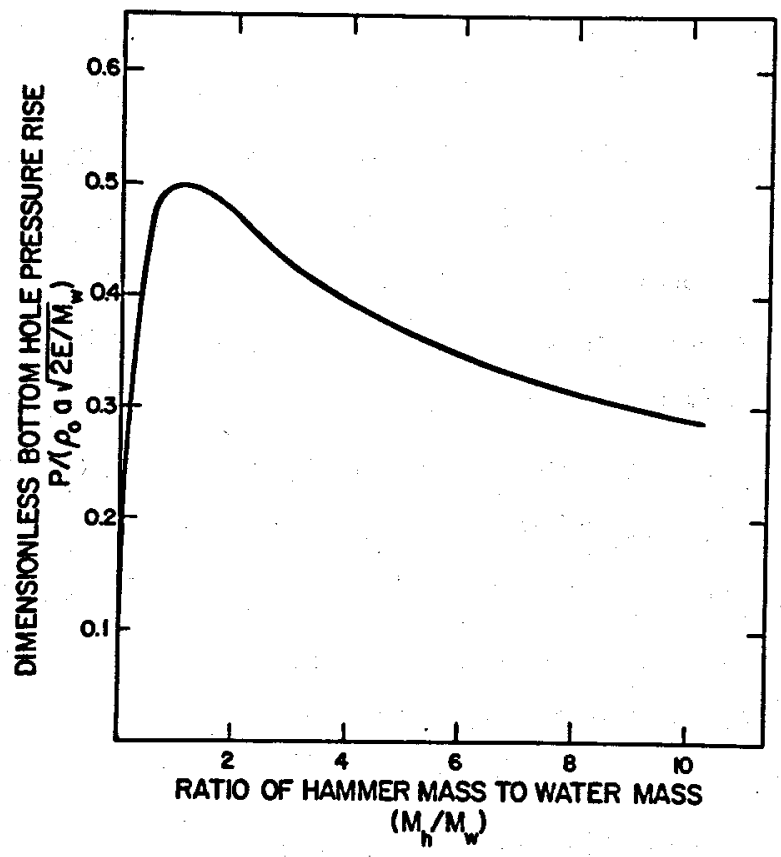

Fig. 5-56.

Pressure rise vs mass ratio. Maximum bottomhole pressure rise occurs when hammer mass equals mass of standing water in the well boat.
As a practical matter it can be found that the mass of water in EE-1 is $85000 \mathrm{~kg}$, corresponding to a weight of 85 metric tons ( 94 English tons), so for optimum conditions a hammer weight of 85 tons would be required. To attain a peak bottom hole dynamic pressure of 100 bars (1500 psi) would require a kinetic energy of $7.6 \mathrm{MJ}\left(5.6 \times 10^{6} \mathrm{ft}-1 \mathrm{~b}\right)$. This energy could be approximated by dropping the 85 ton weight from $10 \mathrm{~m}$ $(30 \mathrm{ft})$. It should be obvious by now that this will prove to be a cumbersome method of producing dynamic fractures.

Discussion. Dynamic fracturing with pressure waves in deep wells such as EE-1 will prove to be an operationally difficult and tedious task. All the methods described here will require either high pressures or very 1 arge weights. The method described last appears to be the most cumbersome. Not only will a very large hammer weight be required, but if an initial static prepressurization level is required, say 300 bars ( $4500 \mathrm{psi}$ ), then a separate accumulator weight (see Fig. 5-55) of 100 metric tons will need to be initially in place at the wellhead simply to react this initial pressurization. This reaction weight must be designed so as to be able to move down the well after being impacted by the hamer weight, which in turn weighs another 85 tons. A similar reaction weight is necessary for any of the other schemes where prepressurization is necessary and the dynamic pressure is superimposed with a moving piston.

One method of circumventing this difficulty is to use the wellbore depressurization method. Here the difficulties associated with the reaction weight and the moving piston, or a depressurized gas volume located at the surface, are traded for those associated with a downhole packer capable of withstanding high pressure and temperature. 
It is important to note that in all cases the ultimate value of the superimposed dynamic and initial static pressures is about the same as that which could be achieved by simple static pressurization of the entire well. The only advantage of the dynamic methods is their rapid rise time, which is achieved at the expense of using considerably more complicated procedures.

If the advantage of rapid rise times warrants the use of dynamic fracturing, one might want to consider the alternative of explosive fracturing. It is not the intention here to discuss the design of explosive fracturing. Instead, only a gross comparison of the theoretical aspects of pressure-wave and explosive fracturing is sought. In this connection it is noted that the operational convenience of explosive fracturing is unsurpassed. In theory one simply positions the charge, plus whatever stemming is required, at the formation to be fractured, and initiates the charge using a wire line. No static pre-pressurization should be required. While the safety problems are formidable, particularly so if a charge fails to explode and must be retrieved, these are somewhat offset by the safety problems of the high surface pressures required with some of the methods proposed earlier. An additional problem, particularly with high explosives, is the potential formation of a "stress cage" around the wellbore. 51,52 Following the passage of the shock wave through the rock, the elastic rebound of the far-field material loads the plastically deformed near-field material and produces a region with highly compressive stresses in the rock adjacent to the wellbore. ${ }^{51,52}$ The resulting stress cage makes it difficult for the residual explosive gas pressure in the well to result in significant extension of the shock wave initiated fractures and, in fact, could hinder all subsequent fracturing attempts.

The common explosives such as TNT, Dynamite, RDX, HMX, PETN, and ANFO have explosive energies ranging from 3.7 to $5.4 \mathrm{MJ} / \mathrm{kg}$ with densities ranging from 850 to $1900 \mathrm{~kg} / \mathrm{m}^{3}$ Johansson and Persson, ${ }^{53}$ ). In theory then just $2 \mathrm{~kg}$ of explosive, occupying only $2 \ell$, can deliver as much energy as the impact load method discussed above; and $6 \mathrm{~kg}$, occupying at most $7 \mathrm{l}$, could provide as much energy as pressurizing the entire well to 300 bars (4500 psi) as calculated earlier for the wellbore depressurization method. Unlike the pressure wavemethods, very high pressures can be obtained with explosives; in fact, one usually attempts to decouple the explosion from the rock (e.g., by increasing the annulus of water between explosive and rock) so that peak pressures are below the dynamic compressive strength of the rock. Otherwise, much of the 
explosive energy is fruitlessly expended in crushing the rock, rather than producing the desired tensile cracks that run for large radial distances. ${ }^{54}$ If it is assumed that sufficient decoupling is obtained by making the explosive in the form of a cylinder only $2.5 \mathrm{~cm}$ ( 1 in.) in diameter, then a 7 \& charge will require a length of $15 \mathrm{~m}(50 \mathrm{ft})$; and assuming a low detonation velocity of $7 \mathrm{~km} / \mathrm{s}^{53}$, the pressure rise time will be $2 \mathrm{~ms}$ if the charge is detonated from one end. It may be recalled that this is nearly equivalent to the rise times calculated earlier for pressure-wave techniques in which the wave has to travel all the way down from the surface. To sumarize, explosives appear superior in terms of convenience and energy and pressure levels, but are inferior when potential safety issues are of concern or the difficulties associated with the stress cage become paramount. 


\section{DRILLING AND COMPLETION TECHNIQUE DEVELOPMENT}

6.1. Directional Drilling

Directional drilling is required in EE-2 to place the hole in the desired location, at the proper angle from the vertical, and in the desired azimuthal direction. Some degree of control of hole direction can be accomplished by varying rotational speed and bit weight during rotary drilling, but the degree of control that is possible by this means is limited. Therefore, the directional drilling of .EE-2 is being done largely by the use of downhole motors attached below a "bent sub" at the bottom of a nonrotating drill pipe. The direction is monitored by either repeated "single-shot" surveys or by continuous-reading steering devices that allow the operator to read, at the surface end in real time, the direction that the bit is facing and the existing deviation angle and direction of the hole. Tricone button bits were used during this operation because previous operations had proven their capabilities. All of the directional drilling was performed in the 12-1/4-in. portion of the hole.

6.1.1. Downhole Motors. Three types of downhole motors were used in the directional drilling of EE-2. They were Smith International's Dyna-Drill, Baker Service Tool's downhole drilling motor, and a turbodrill designed specifically for drilling of hot granitic formations by Maurer Engineering, Inc. As there were only two Maurer turbodrills available, the Dyna-Drill and the Baker motor were used at shallower depths where their limited temperature capabilities would not prohibit their usage. The turbodrills were saved for the deeper, hotter drilling.

Dyna-Drills were used with some success at depths of 6500 to $6700 \mathrm{ft}$. Their use was discontinued after the elastomeric stator of one unit was damaged by the heat at a depth of $8200 \mathrm{ft}$. The Baker motors performed well at depths of about 6700 to $7000 \mathrm{ft}$. Their use was marginal at the 9800-ft depth, and at that depth the motor stalled when only $9000 \mathrm{lb}$ of bit weight was applied. This was thought to be the result of increased internal friction in the motor at the higher temperatures.

The Maurer turbine is a new design of downhole motor developed by Maurer Engineering, Inc., under contract to LASL. It is planned that a full report on the design and operation of this turbine will be issued in the near future. 
Its performance to date is noted only briefly here. The Maurer turbines were used successfully to depths of $10000 \mathrm{ft}$ with no indication of any problems caused by the high temperature of the hole (about $200^{\circ} \mathrm{C}$ ). Because this device had not been used before in the field, operational experience had to be acquired before satisfactory runs were produced. A turbine is not a positive displacement device (as are the motors of the Dyna-Drill and the Baker unit) and rotational speed varies not only with the flow of the drilling fluid, but inversely with the weight on the bit. Bit weight cannot be closely controlled in a deviated hole. However, runs exceeding $100 \mathrm{ft}$ of penetration were obtained with reasonable consistency during the last few attempts. The duration of operation on bottom was determined, not by the turbodrill directly, but by the lift of the bits at the high speeds required for the turbodrill to operate.

6.1.2. Steering Tools. Three steering devices were used to control the directional drilling of EE-2. They were Eastman Whipstock's Directional Orientation Tool (DOT), Sperry-Sun's "Hadies" tool, and Scientific Drilling Controls' "EYE." Eastman Whipstock's DOT had been heat shielded, especially for this job. In use, however, it proved to be only marginally useful because of problems caused by vibration and heat. The DOT was used from 8268 to 9632 $\mathrm{ft}$, where it reached the limit of its temperature capabilities. At this depth, we decided to try Sperry-Sun's "Hadies" tool, which was provided on short notice, and proved to be inadequately thermally protected for this job. Scientific Drilling Controls' "EYE," a small-diameter unit that was not thermally shielded, performed satisfactorily at $9632 \mathrm{ft}$, but showed signs of being affected by heat at $10035 \mathrm{ft}$. Marginal performance could be maintained by switching off system power during a large portion of each run.

The performance of these equipment items in the.EE-2 drilling indicates that none of the steering devices (in their present form) can be expected to perform satisfactorily at rock temperatures above about $200^{\circ} \mathrm{C}$.

\subsection{Drill-Bit Performance}

The drilling plan for EE-2 specified that four sizes of bits be used in the hole: 26 in. and 17-1/2 in. in the sedimentaries; 12-1/4 in. for drilling in the granite from approximate $1 y 760 \mathrm{~m}(2500 \mathrm{ft})$ to $23535 \mathrm{~m}(11600 \mathrm{ft})$, and 8-3/4 in. for the open hole below $11600 \mathrm{ft}$. The two larger sizes were to be 
steel tooth bits, while the two smaller sizes were to be carbide-button-insert bits for drilling in hard abrasive granite (AIDC types 637, 737, 837, etc.). An enumeration of the bits used in drilling to approximately $10000 \mathrm{ft}$ appears in Table 6-I. The table also notes briefly the types of drilling for which bits were used.

The 26-in. and 17-1/2-in. steel-tooth bits performed well in the upper portion of the hole, and drilling down to the granite was completed approximately on schedule.

The history of the carbide insert bits is complicated by the fact that they were used both for rotary drilling and with downhole motors for the directional work. A run with any of the types of downhole motors was terminated on some occasions because of bit wear and on other occasions because of motor problems. The drilling of EE-2 has continued into FY8O and more information on bit performance will be accumulated and reported at a future date.

The performance of the carbide-button bits during drilling in hard, abrasive granite has been fair, but not as good as had been anticipated. In rotary drilling, the load on the bit has been held at approximately 5000 $\mathrm{lb} /$ inch of diameter, and the rpm at 70 . In intervals of continuous rotary

TABLE 6-I

\begin{tabular}{|c|c|c|c|c|c|}
\hline $\begin{array}{l}\text { Bit S1ze } \\
\text { (in.) } \\
\end{array}$ & $\begin{array}{l}\text { Depth } \\
(f t)\end{array}$ & $\begin{array}{l}\text { LOG OF } \\
\text { Quantity } \\
\text { Ured } \\
\end{array}$ & $\begin{array}{l}\text { DRILLING } \\
\text { Trpe } \\
\text { (Trt-conel }\end{array}$ & $\begin{array}{l}\text { [TS USED IN } \\
\text { Manufacturer }\end{array}$ & Remarks \\
\hline 26 & 1785 & 5 & Steel tooth & $\begin{array}{l}2 \text { Hughes (OSC3A) } \\
3 \text { Smith (DTJ) }\end{array}$ & Abo formation with large boulders. \\
\hline $17-1 / 2$ & 2593 & 5 & $\begin{array}{l}2 \text { Steel tooth } \\
3 \text { Button Insert }\end{array}$ & $\begin{array}{l}\text { Security S4T, S3S, } \\
H-8, \text { S89, S8B }\end{array}$ & $\begin{array}{l}\text { Madera formation mostly, then } a 90 f \\
\text { into granite. }\end{array}$ \\
\hline \multirow[t]{5}{*}{$12-1 / 4$} & \multirow{5}{*}{$\begin{array}{l}10067 \text { Sept. } 30 \\
\text { (will be used to } \\
\text { vil 600) }\end{array}$} & \multirow[t]{5}{*}{67} & \multirow[t]{5}{*}{$\begin{array}{l}\text { 1 Steel tooth } \\
63 \text { Button insert }\end{array}$} & Smith, DTJ & $\begin{array}{l}\text { Rotary drill string, drilling cemen } \\
\text { Dlugs. }\end{array}$ \\
\hline & & & & $\begin{array}{l}8 \text { Hughes } \\
\text { J-55, J-77 }\end{array}$ & $\begin{array}{l}\text { Drtlling cement plugs, retainers } \\
\text { and granite formation--all rotary } \\
\text { drili string. }\end{array}$ \\
\hline & & & & 23 Security H-100 & $\begin{array}{l}\text { 11, Used for directional drilling } \\
\text { with motors--granite. }\end{array}$ \\
\hline & & & & & $\begin{array}{l}\text { 1. Used to drill and rean cement } \\
\text { plug--rotary. }\end{array}$ \\
\hline & & & & & $\begin{array}{l}\text { 11, Rotary drill sțring in granite } \\
\text { formation. }\end{array}$ \\
\hline \multirow[t]{3}{*}{$8-3 / 4$} & \multirow{3}{*}{\multicolumn{2}{|c|}{$\begin{array}{l}\text { Pl anned for open } \\
\text { to le below } थ 11600\end{array}$}} & & $\begin{array}{l}26 \text { Smith } \\
F-4, F-5, F-9, Q 9 J\end{array}$ & $\begin{array}{l}\text { 13, Used for directional drilling } \\
\text { with motors--granite. }\end{array}$ \\
\hline & & & & & $\begin{array}{l}\text { 13, Rotary orill string in granite } \\
\text { formation. }\end{array}$ \\
\hline & & & & $\begin{array}{l}6 \text { Reed } \\
\text { SJ4, S74J, S83J }\end{array}$ & $\begin{array}{l}\text { 2. Used for directional drilling } \\
\text { with wotors--granite. } \\
\text { 4, Rotary drill string in granite } \\
\text { formation. }\end{array}$ \\
\hline
\end{tabular}


drilling the average bit life has been approximately $220 \mathrm{ft}$ and the advance rate has been some $10 \mathrm{ft} / \mathrm{hr}$. The total number of hard-rock bits required for the drilling in granite has been larger than anticipated.

\subsection{Packers and Fracturing Systems}

To create the fracture systems required by the HDR concept, and then to provide for isolation of the various zones in the open borehole between the fractures so that flow control through the fracture can be realized, a number of $\mathrm{plans}$ have been pursued. These are intended to provide means for fracture initiation and extension and for control of the circulating fluid flow between the boreholes.

\section{Guiberson Packers}

In 1977, inquiry was made of the Guiberson Division of Dresser Industries as to the feasibility of reviving and upgrading a discontinued model of a steam-injection-type, asbestos-wrapped packer for use in the HDR environment. A contract was subsequently issued to Guiberson to fabricate a prototype hightemperature, compression-type, open-hole straddle-packer assembly for use in initiating and extending fractures in an uncased borehole. This prototype was successfully tested in Dallas in 1978 at $275^{\circ} \mathrm{C}$ and $5000 \mathrm{psi}$ differential pressure. Following that, a purchase order was issued to Guiberson to construct two packer-assembly mandrels and 18 packer redress kits. This work was completed in September 1979, and the packer assemblies are now ready for initial use in EE-2.

Specifications for the Guiberson packer required that it be set hydraulically, have a maximum 0. d. of $19.05 \mathrm{~cm}(7-1 / 2$ in.), minimum i.d. of $7.62 \mathrm{~cm}$ (3 in.), and seal in a $22.22-\mathrm{cm}(83 / 4-\mathrm{in}$.$) hole, which required sealing a radial$ gap of $1.58 \mathrm{~cm}(5 / 8 \mathrm{in.})$. Because the end use was as a straddle packer with $5000 \mathrm{psi}\left(3.44 \times 10^{7} \mathrm{~Pa}\right)$ between the two tools, a tensile strength capability of 300660 pounds was required for the entire system (Fig. 6-1).

These design requirements presented several problems to be solved before the design could be finalized. The 0-rings to seal the setting chamber had to withstand a dynamic setting pressure of 3000 psi $\left(2.07 \times 10^{7} \mathrm{~Pa}\right)$ at $149-316^{\circ} \mathrm{C}\left(300\right.$ to $600^{\circ} \mathrm{F}$ ) after soaking at that temperature for several 
days. A sealing element had to be developed that could withstand the high temperatures and pressures and yet bridge a 1.58-cm (5/8-in.) gap.

The Guiberson approach to solving the 0 -ring problem was threefold.

- Control all clearances and tolerances so that the maximum gap would be $0.101 \mathrm{~mm}(0.004 \mathrm{in.})$ per side.

- Use back-up rings on all stroking 0-rings to provide "zero" gap clearances. The back-up rings were machined from International Polymer Corporation's Ryton 5307 tubing, which has a continuous-use temperature rating of $260^{\circ} \mathrm{C}\left(500^{\circ} \mathrm{F}\right)$.

- An ethylene-propylene compound

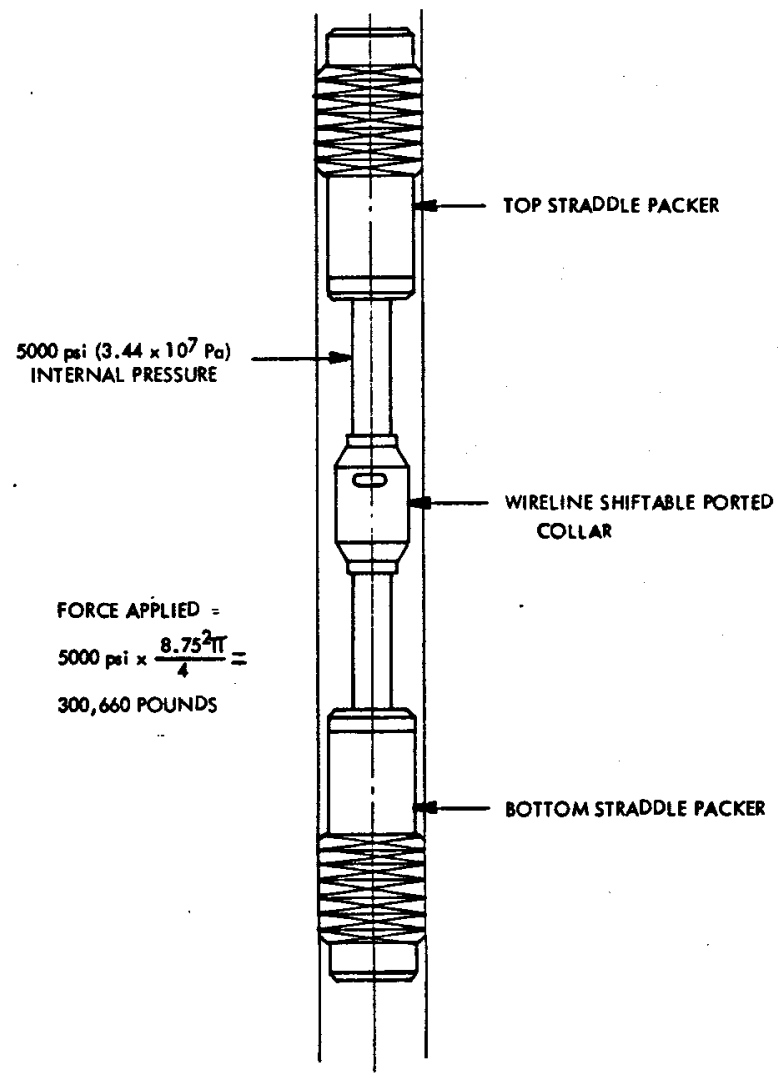

Fig. 6-1.

Guiberson compression-type packer. was chosen for the 0 -rings because of prior Dresser experience with logging tools in geothermal wells. This compound will withstand the temperatures expected in steam or hot water, but will degrade in oils.

The sealing-element problem was solved using prior Guiberson technology in conjunction with a special high-temperature packing element. The element consists of a $649^{\circ} \mathrm{C}\left(1200^{\circ} \mathrm{F}\right)$ plastic core of asbestos fiber treated with various fillers, including graphite suspended in gylcerin, and is formed in a die by compressing approximately 50\%. The formed core is then wrapped with a biased asbestos cloth to retain and protect it. The old Guiberson technology evolved because the plastic core would extrude through the asbestos wrap at high temperatures under pressure. It actually became fluid enough during tests to flow through a 1/4-in. needle valve. Sets of ten special 16-gauge steel expanding plates were added to each end of the seal-element system, creating a retaining bridge between the packer and the i.d. of the hole, which kept the plastic filler confined. The sealing system is illustrated in Fig. 6-2. 


\section{Lynes Packers}

Specifications were written in September 1978, outlining the requirements for inflation-type, hightemperature open-hole packers, as a back-up for the Guiberson packers. Because Lynes, Inc., had supplied successful inflation-type packers for use in GT-2B in 1976, a contract was let to that company to fabricate packers for the higher temperatures in EE-2 and EE-3. During the interim period, Lynes had continued to investigate new materials and to design improved prototypes. As a result, the Lymes

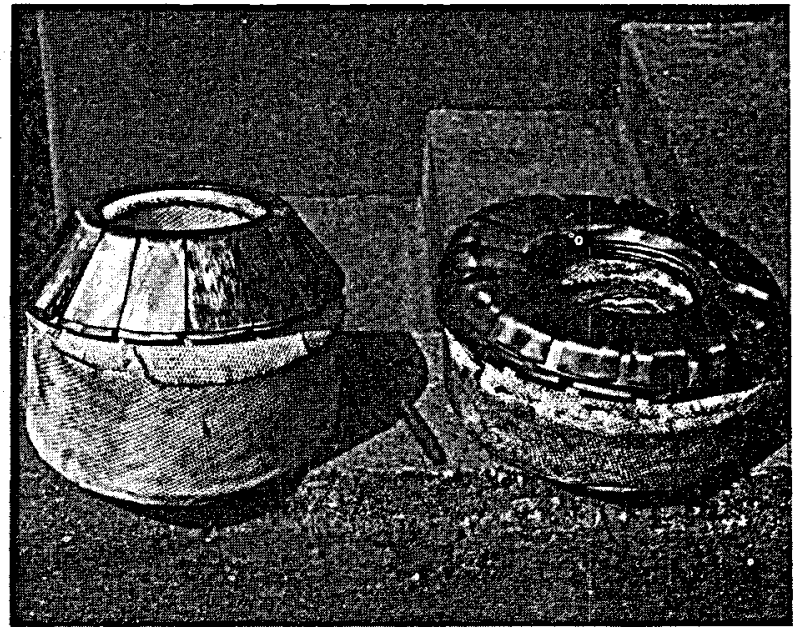

Fig. 6-2.

Guiberson compression packer elements and steel expanding plates, before (left) and after (right) testing.

high-temperature straddle fracture tool is now ready for use. One mandrel assembly and eight sets of two packer elements each have been fabricated for use in an 8-3/4-in. open hole. The elements are 8-1/4-in. 0.d., and consist of a sheath or bladder of an EPDM-based elastomeric compound, reinforced by underlying metal leaves. The packers have been tested at $265^{\circ} \mathrm{C}\left(525^{\circ} \mathrm{F}\right)$ and 5000 psi $\left(3.44 \times 10^{7} \mathrm{~Pa}\right)$ differential pressure. The lifetime in the inflated condition is calculated at 72 hours. No drill pipe manipulation is required to set or release the packers. All tool operations are carried out by use of dropped balls and drill-pipe pressure. On the basis of recent redress/rebuild experience of the packer elements, it appears that redressing can be accomplished on site, eliminating costly transportation charges to Lynes central facility in Houston, Texas.

\section{Pack/Perf Systems}

Completion plans for the EE-2/EE-3 circulation loop call for establishment of multiple, parallel, hydraulic fractures connecting the two wells, plus the capability to regulate flow through the separate fractures. A completion system that would allow both fracture extension and flow control was designed for initial testing in the EE-1 well in August 1979. This system, illustrated in Fig. 6-3, features cement-inflated packers on a 
liner-hanger assembly to isolate sections of the borehole with seal-bore valves (ported landing nipples) and wirelineoperated locking mandrels for flow control.

The packers for this system were 5-1/2-in. i.d. with 19-ft 6-in.-long elements, capable of expanding into a 16-in.-diameter borehole. Commercially known as Pack/Perf, the packers are manufactured by Completion Technology Company of Houston, with the hightemperature rubber elements furnished by Lynes/United Services.

The assembly was inserted to the correct depth in EE-1 on August 20, 1979. As the cement slurry mixture was being pumped downhole, a cement wiper plug did not seal and inflation of the packers was, therefore, not achieved. The cement slurry was immediately reversed and an attempt was made to pull the assembly from the hole. However, due to partial setting of the liner hanger packer at the top of the assembly, and because of the extreme amount of frictional resistance along the length of the assembly, it could not be removed without being cut into smaller sections. Removal of the upper part of the assembly was accomplished on September 22, 1979, so that flow testing of the new fracture system could be instituted.

\section{Cement Packers}

In recognition of the need to pursue and investigate alternative methods of zone isolation in the open borehole for fracture initiation and flow

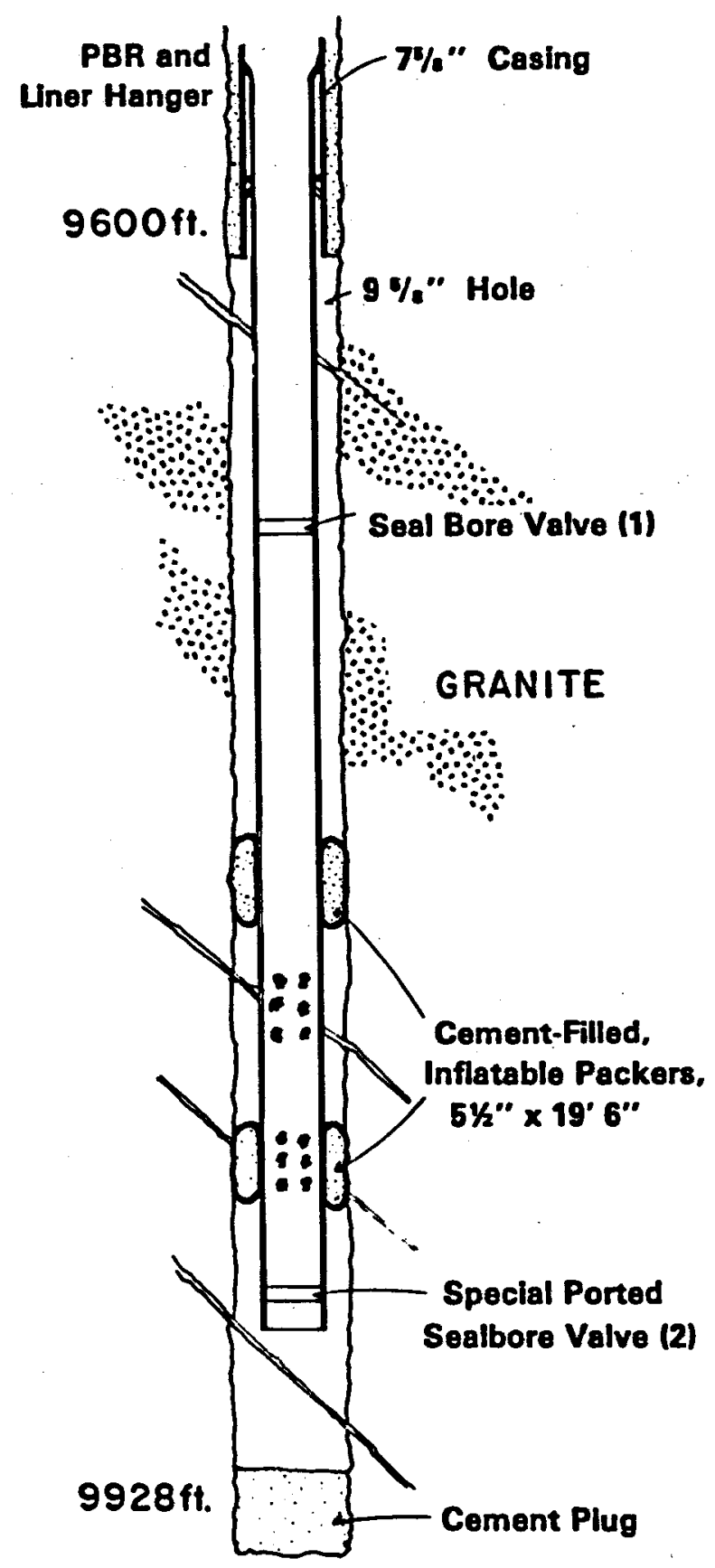

Fig. 6-3.

EE-1 completion system. 
control, an entirely new concept, differing from expandable packers, is also being actively investigated. Contacts with Halliburton $0 i 1$ Well Cementing Company have indicated a strong interest on their part to participate in the development of the concept of installing easily drillable, cemented-in, liner/hanger assemblies capable of withstanding the harsh HDR environment. This work will continue so that prototypes can be tested in the early stages of the creation of the EE-2/EE-3 fracture system.

\subsection{Cementing}

$\underline{E E-1}$

With continued intermittent flow between EE-1 and GT-2 during the testing, fracturing, and heat-extraction experiments, the well was subjected to cyclic temperature changes ranging from $40^{\circ} \mathrm{C}\left(104^{\circ} \mathrm{F}\right)$ to nearly $204^{\circ} \mathrm{C}$ $\left(400^{\circ} \mathrm{F}\right)$. A fracture opened at about the 2734-m (9000-ft) depth behind the casing, through which most of the water for the 75-day flow experiment circulated. The progressive deterioration of the cement bond behind the casing through 1977 is described in Fig. 6-4.

During a prolonged pumping experiment near the end of September 1978, a $0.2-$ gal/min leak up the EE-1 casing annulus to the ground surface was observed and monitored. The leak continued at that rate until the end of the pumping sequence on October 16, 1978. EE-1 was then shut in for a week, but when pumping was resumed on October 23, 1978, a flow of about $20 \mathrm{gal} / \mathrm{min}$ developed up the annulus to the surface, with total downhole water losses amounting to 40 gal/min. (Fig. 6-5). Pumping was terminated on October 27, 1978, as downhole water losses could no longer be accurately determined, and it was feared that significant quantities of water could be entering porous zones and/or aquifers in the upper section of EE-1.

In January 1979, the EE-1 casing was recemented using a mixture of Class $H$ cement and $80 \%$ silica flour. This design was based on the investigations performed by Gallus, Pyle, and Watters. 55 The volume of cement injected was designed to fill the large (now open) annulus behind the casing below the $2743-\mathrm{m}(9000-\mathrm{ft})$ depth, to allow some to enter the fracture at about that depth, and to allow some to travel up the microannulus above the fracture.

Cement bond logs run before and after the recementing indicated a greatly improved condition (Fig. 6-5). Shortly after the recementing, the well was 


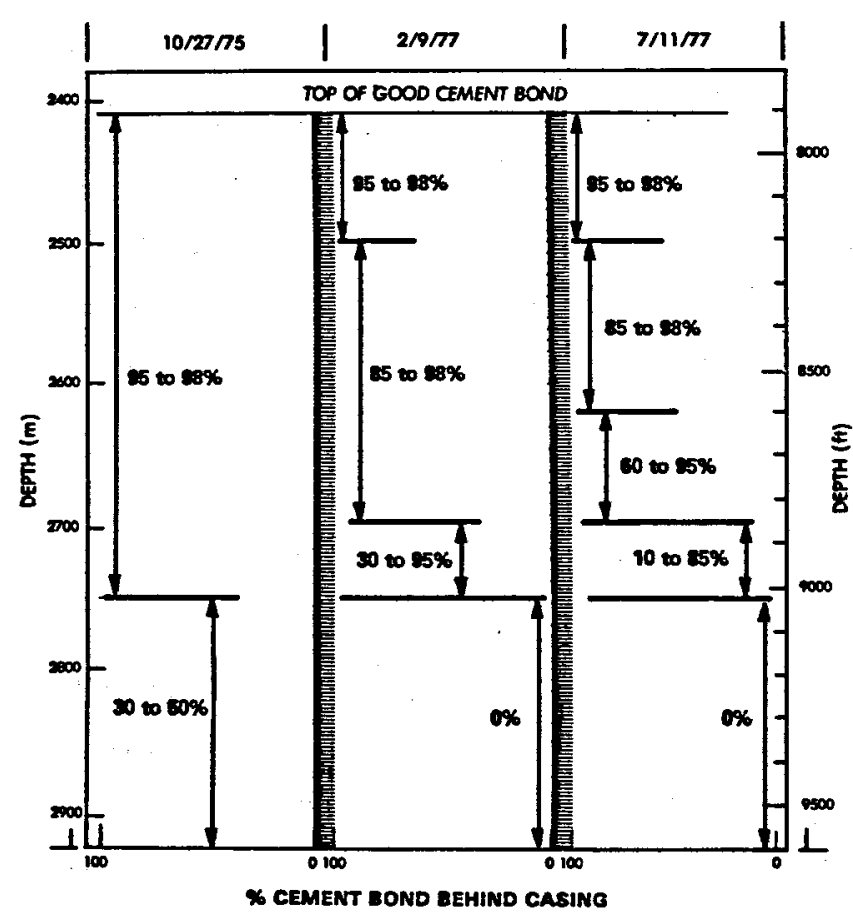

Fig. 6-4.

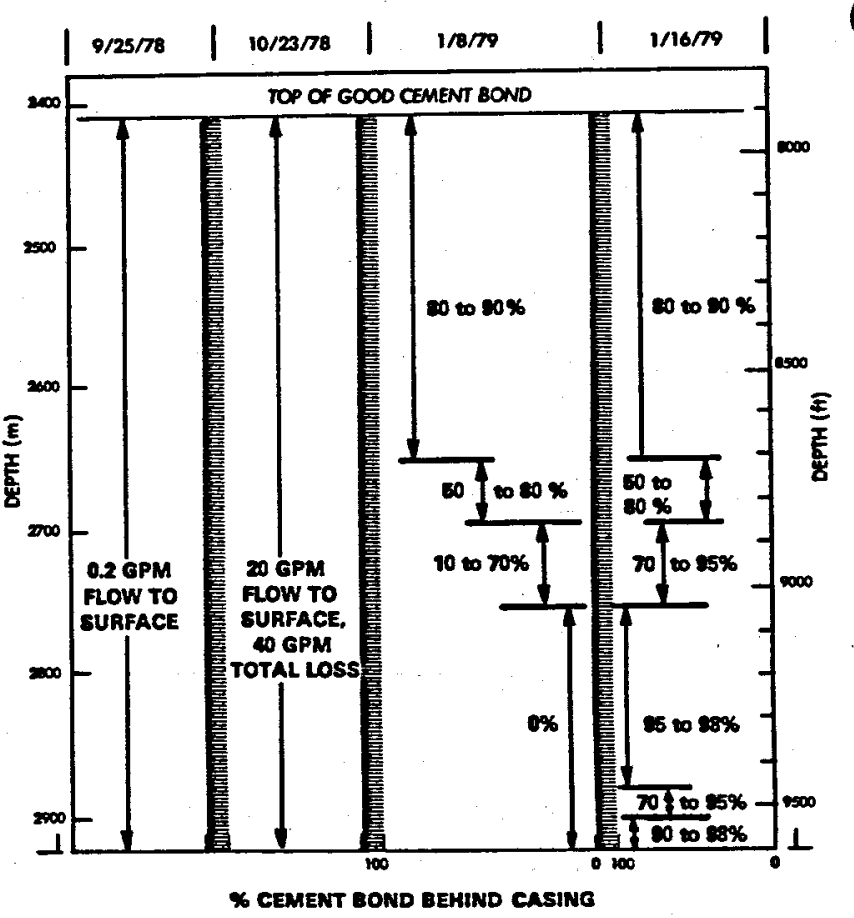

Fig. 6-5.

EE-1 cement bond 109,1975 through 1977. EE-1 cement bond $10 \mathrm{log}, 1978$ and 1979.

subjected to severe thermal shock by a $16 \mathrm{bbl/min}$ pumping operation to create another hydraulic fracture. A cement bond $\log$ run in 0ctober 1979 to assess the current condition of the casing bond, showed that continued deterioration of the cement behind the casing had occurred (Fig. 6-6).

\section{$\underline{E E-2}$}

Hole EE-2, now being drilled, is planned for a total depth of about $4300 \mathrm{~m}(14000 \mathrm{ft})$. A deep string of 9-5/8-in. casing will be run in the 12-1/4-in. hole to a depth of about $11600 \mathrm{ft}$, and cemented to the surface. A detailed plan for performing the cementing operation has been designed. The major points are as follows.

After much study, a detailed plan for performing the cementing operation was accepted. Initial versions of the cementing $\mathrm{plan}$ included the use of stage collars to cement the casing to the surface in four stages. However, the final plan that was adopted was patterned after methods used at Cerro Prieto, Mexico (for height of cement fill), Larderello, Italy (for inner 

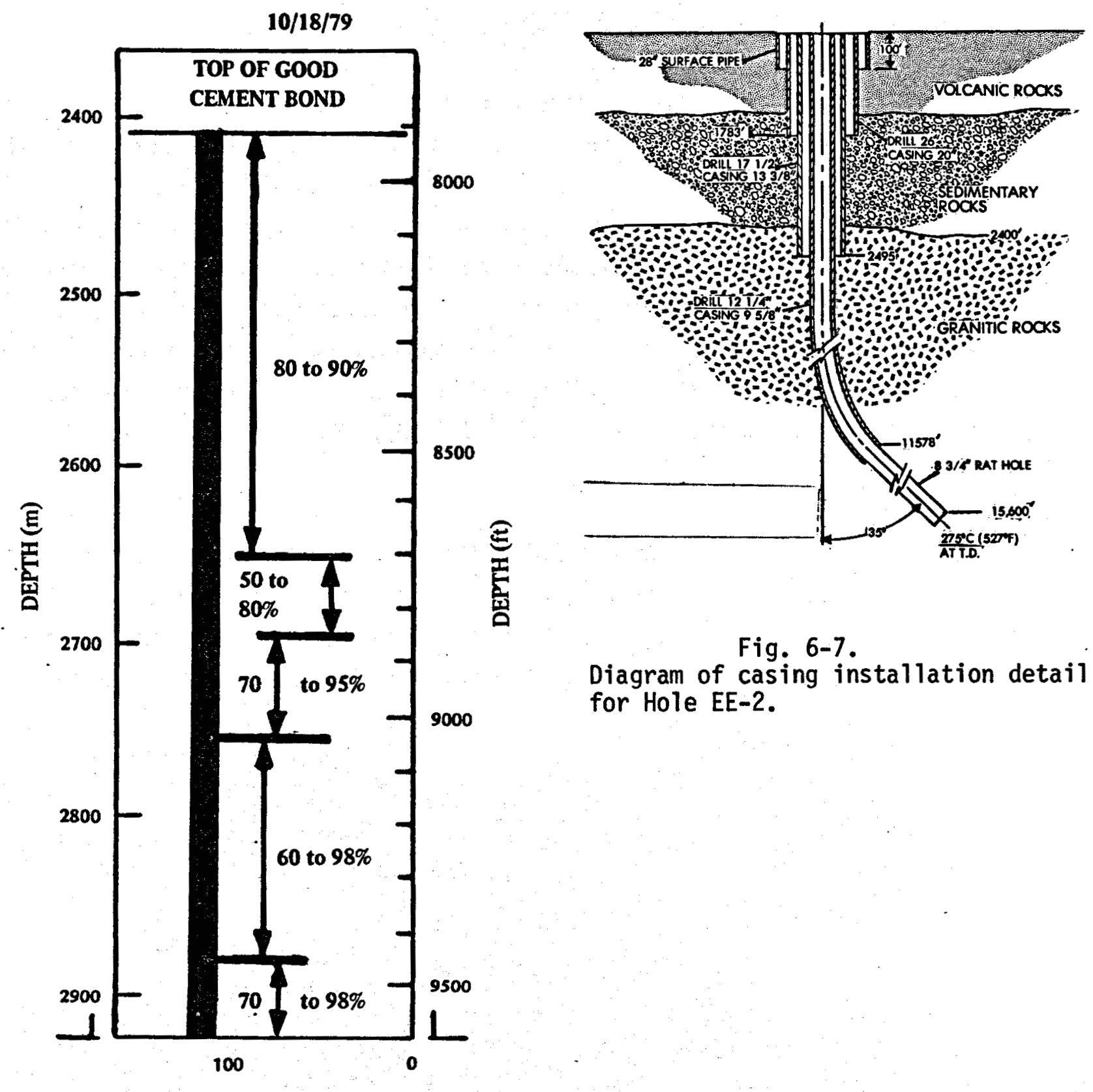

\% CEMENT BOND BEHIND CASING

\section{Fig. 6-6.}

Cement bond 109 , October 18, 1979.

string cooling while the cement hardened). A total of $1000 \mathrm{ft}$ of casing-rock annulus is scheduled to be cemented above the casing shoe, with float collars spaced one and two joints above the shoe. Special-constructed rigid centralizers are to be spaced across the cemented interval. The total casing program is shown in Fig. 6-7. 


\section{INSTRUMENT AND EQUIPMENT DEVELOPMENT}

Downhole instrumentation is required that is capable of characterizing the geothermal borehole environment, the hydraulic fracture system, and the resulting HDR geothermal reservoir. The instrumentation must have reliable sensors and electromechanical components that function properly in a hostile environment. Our continuing efforts, both in-house and with industrial contractors, have resulted in significant advances in several areas of downhole instrumentation and equipment development. Work accomplished during FY79 is described in the following sections. Instrument development experiments conducted during FY79 are 1isted in App. F.

\subsection{Caliper Tool}

The development of an independent multi-arm caliper tool began with the design and fabrication of a prototype three-arm sonde, which can readily be modified to have six independent arms. The arms are evenly spaced circumferentially and are capable of measuring radii from $63.5 \mathrm{~mm}(2.5 \mathrm{in.})$ to

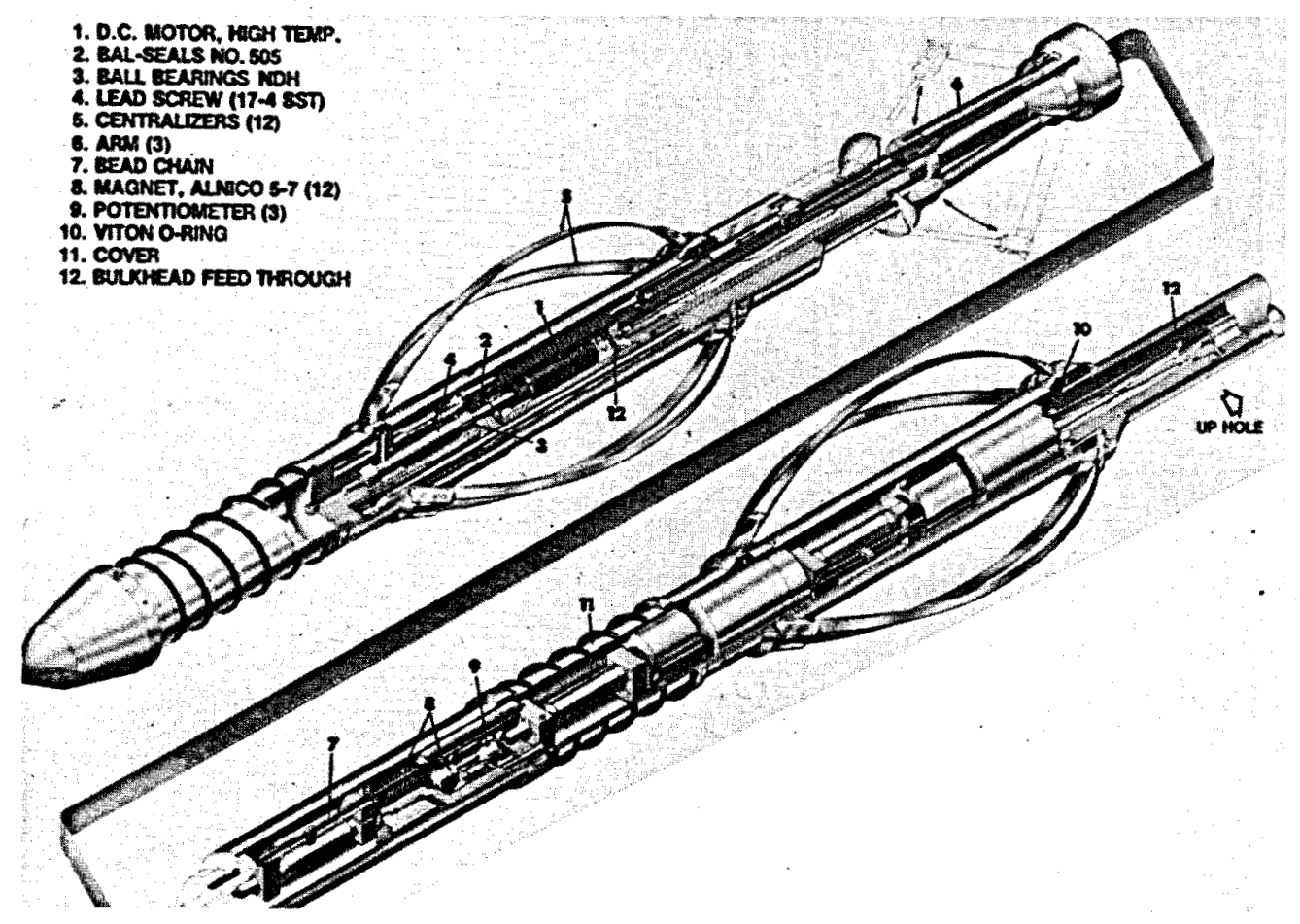

Fig. 7-1.

Prototype caliper and contour tool that features three independent arms, three independent contours on strip chart, magnetic couplings, motor-operated arms, and high sensitivity. 
$178 \mathrm{~mm}(7.0 \mathrm{in.})$ at a common depth (Fig. 7-1). Arm lengths can be varied to measure hole diameters up to $762 \mathrm{~mm}$ ( $30 \mathrm{in.}$ ) or can be designed for maximum sensitivity at given diameters. The arms are activated by a motor and can be extended or retracted on command from the surface. Should the sonde become jamed in the borehole, the lower link will buckle and permit the arms to collapse.

The caliper tool was designed to define the profile of geothermal boreholes such as those at Fenton $H i 11$. It is sensitive enough to detect accurately 1-m variations along the borehole wall. It has been used to determine where a hydraulic fracture intersected the boreholes and to assess the integrity of the borehole casing.

In the normal mode of operation, the arms are extended when the sonde is below the region of interest and the caliper is pulled up the borehole at velocities from $0.025 \mathrm{~m} / \mathrm{s}$ to $0.13 \mathrm{~m} / \mathrm{s}$ ( $5 \mathrm{fpm}$ to $25 \mathrm{fpm}$ ). Borehole detail is lost at high logging speeds, but a general borehole contour is obtained.

The arms are spring-loaded to provide approximately 45-N (10-lb) force against the borehole wall. Motion of the arm, as it follows the hole contours, is transformed to the vertical movement of a follower rod. The vertical travel of the follower rod is then transformed to rotational motion of the external magnetic coupling with reference to the centerline of the tool (vertical axis) by use of a bead chain. The coupling's azimuthal position is determined by the use of a $350^{\circ}, 5000$-ohm potentiometer. The potentiometer shaft rotates with feeler-arm motion, thus indicating arm position. The three potentiometers (one for each arm) are used as voltage dividers. A surface voltage feedback system monitors downhole voltage and maintains a constant $4 \mathrm{~V}$, as sensed downhole, across the resistance elements of the three potentiometers to the cable armor. The output signal is conditioned by low-pass filters at the surface. The data are stored on magnetic disks and plotted on-line by an HP $3050 B / 9830$ data acquisition system.

\subsection{Spinner}

Study of the Fenton Hill boreholes includes investigating the flow of the geothermal fluid throughout the system. In particular, information regarding flow rates at various positions in the boreholes, combined with data from the caliper tool, helps to ascertain the location of hydraulic fractures. For 
this purpose, a high-temperature $\left(200^{\circ} \mathrm{C}\right)$ downhole flow meter was purchased from Worth Well and modified to suit the Fenton Hill application.

The LASL version of the Worth Well spinner tool (Fig. 7-2) improved the sensitivity, repeatability, and resolution of the tool through modifications in several areas: the impeller size was increased from $34.5 \mathrm{~mm}(1.375 \mathrm{in.})$ to $74.2 \mathrm{~mm}(2.92 \mathrm{in.})$; the surface electronics were designed to provide better resolution and increase the analog output from $10 \mathrm{mV}$ full-scale to $10 \mathrm{~V}$ full-scale; and a flow concentrator was designed to increase sensitivity as well as to protect the impeller. This flow concentrator does not increase the local rate of fluid flow.

The analog output is linear to approximately $12 \mathrm{~V}$, corresponding to a fluid velocity of $1.8 \mathrm{~m} / \mathrm{s}(350 \mathrm{fpm})$. Minimum sensitivity was measured at an initial $0.09 \mathrm{~m} / \mathrm{s}(18 \mathrm{fpm})$ rising to $0.13 \mathrm{~m} / \mathrm{s}(25 \mathrm{fpm})$ after $5 \mathrm{~h}$ of operation in the borehole. New surface electronics have improved resolution of $\pm 1 \mathrm{fpm}$ at constant impeller speed.

The spinner is capable of logging the boreholes vertically in either direction. This tool is undergoing tests for sustained operation at $275^{\circ} \mathrm{C}$.

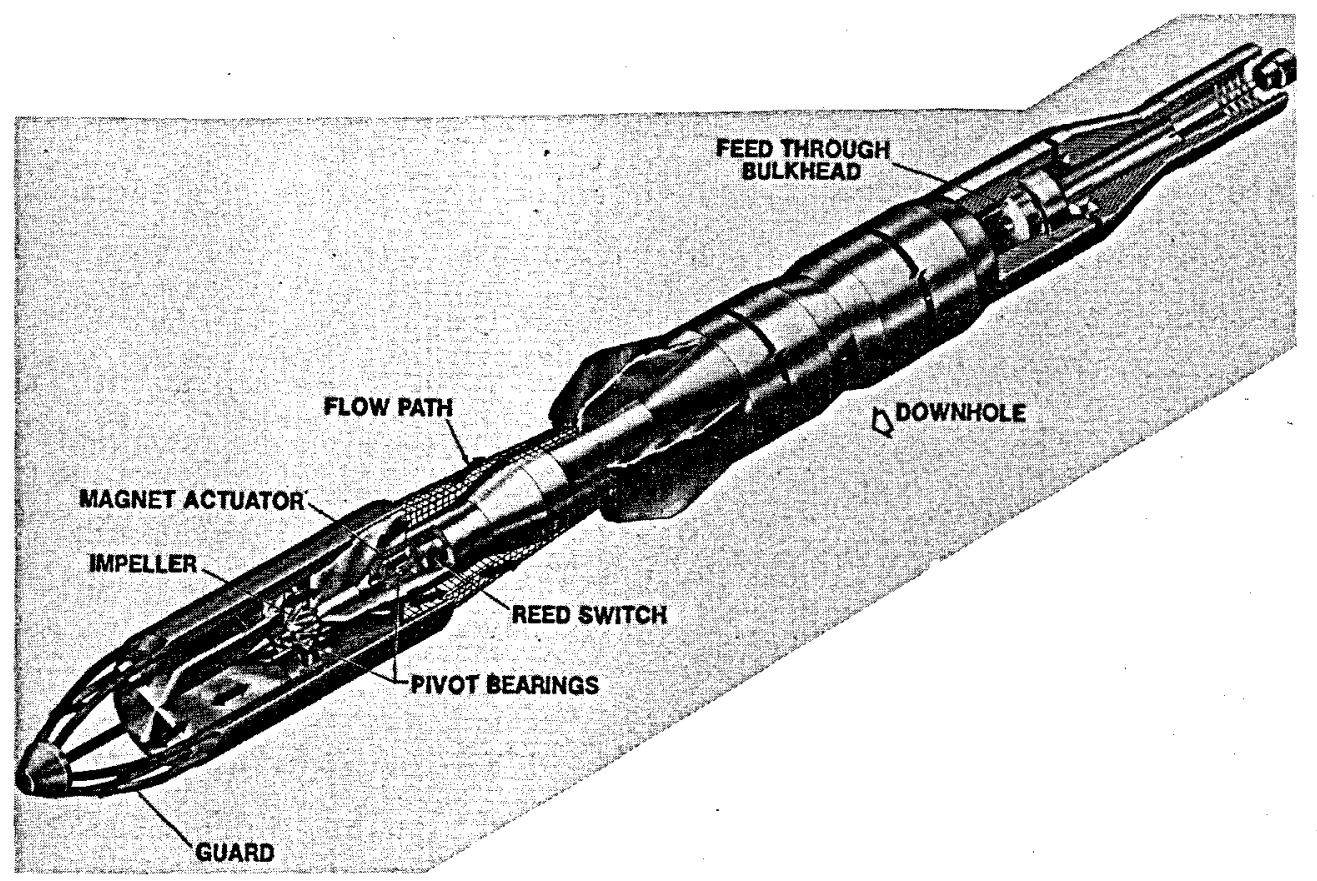

Fig. 7-2.

Fluid velocity spinner probe. 


\subsection{Dewar (Controlled-Environment Enclosure)}

The controlled-environment enclosure was designed to protect instruments from the hostile downhole environment of the geothermal wellbore. It provides housing for electrical components such as the geophone package, magnetic-ranging survey equipment, amplifiers, and inclinometers, and will house other electronic equipment in the future. The dewar package is held in a LASL-designed and fabricated pressure vessel made of AISI 4340 steel, heat treated to a yield strength of 1000-2000 MPa (145 000-175 $000 \mathrm{psi}$ ), and designed to withstand $69 \mathrm{MPa}(10000 \mathrm{psi})$ external pressure. The enclosure was fabricated and tested by Mechanics Research, Inc., under contract to LASL.

The dewar is the primary heat-transfer barrier. It has a large opening at the upper end to permit loading of the instrument package and heat-sink containers. The opening is then sealed with a MIN-K plug. An interconnect cable can pass through the lower end of the dewar to an adjoining vessel, if necessary.

Laboratory tests demonstrated that the dewar's instrument compartment temperature remains below $85^{\circ} \mathrm{C}$ for $12 \mathrm{~h}$ in an external temperature environment averaging $275^{\circ} \mathrm{C}$. A source in the cavity dissipated $15 \mathrm{~W}$ of heat during each of the tests to simulate the output of an electronic package.

There are four dewar sizes to hold electronics.

\section{External}

$2.2 \mathrm{~m} \times 114.3-\mathrm{mm} \operatorname{diam}(87 \times 4.5 \mathrm{in.})$

$0.96 \mathrm{~m} \times 88.1-\mathrm{mm}$ diam $(38 \times 3.47$ in.) $1.8 \mathrm{~m} \times 88.1-\mathrm{mm}$ diam $(71 \times 3.47 \mathrm{in.})$ $1.82 \mathrm{~m} \times 50.0-\mathrm{mm} \operatorname{diam}(72 \times 2$ in.)

\section{Internal}

$2.13 \mathrm{~m} \times 87.8-\mathrm{mm}$ diam $(84 \times 3.46$ in.) $0.91 \mathrm{~m} \times 66.7-\mathrm{mm}$ diam $(36 \times 2.55$ in. $)$ $1.75 \mathrm{~m} \times 66.7-\mathrm{mm}$ diam $(69 \times 2.55$ in. $)$ $1.77 \mathrm{~m} \times 38.6-\mathrm{mm}$ diam $(70 \times 1.52 \mathrm{in.})$

7.4. Downhole Injector and Gama-Ray Detector

Water circulation in the geothermal boreholes is studied with the injector-tracer sonde. Radioactive ${ }^{82} \mathrm{Br}$ or any other tracer is injected into one of the boreholes by an injector sonde developed by LASL, which delivers the material to the desired location within the borehole for release. The gamma-ray detector, purchased from Worth We11, is mounted in the same sonde as the injector.

High-purity ammonium bromide is prepared by irradiation with neutrons at a nuclear reactor at LASL. The ${ }^{82} \mathrm{Br}$ has a half life of $35.4 \mathrm{~h}$ and its 
principal garma energies are from 554 to $1474 \mathrm{keV}$. For irradiation, the solid $\mathrm{NH}_{4} \mathrm{Br}$ is sealed in a quartz ampoule. To prevent irradiation of personnel working with the sonde, the ${ }^{82} \mathrm{Br}$ is transported in a lead pig. The sonde is bolted onto the upper portion of the pig, which then comes apart to become a portion of the sonde (Fig. 7-3).

When the sonde has been positioned in the borehole for release, a dc motor propels a rod that is driven into the quartz ampoule, smashing it. To flush the ${ }^{82} \mathrm{Br}$ into the geothermal fluid, $199.39 \mathrm{~mm}^{3}$ (7.85 cu in.) of water is pushed out of the sonde, carrying the ${ }^{82} \mathrm{Br}$ with it. The gamma-ray detector is raised and lowered as necessary to follow the path of the ${ }^{82} \mathrm{Br}$, and is read out at the surface. The electronic circuitry will be repackaged in one of the dewar enclosures, which will upgrade this sonde for operation at $275^{\circ} \mathrm{C}$.

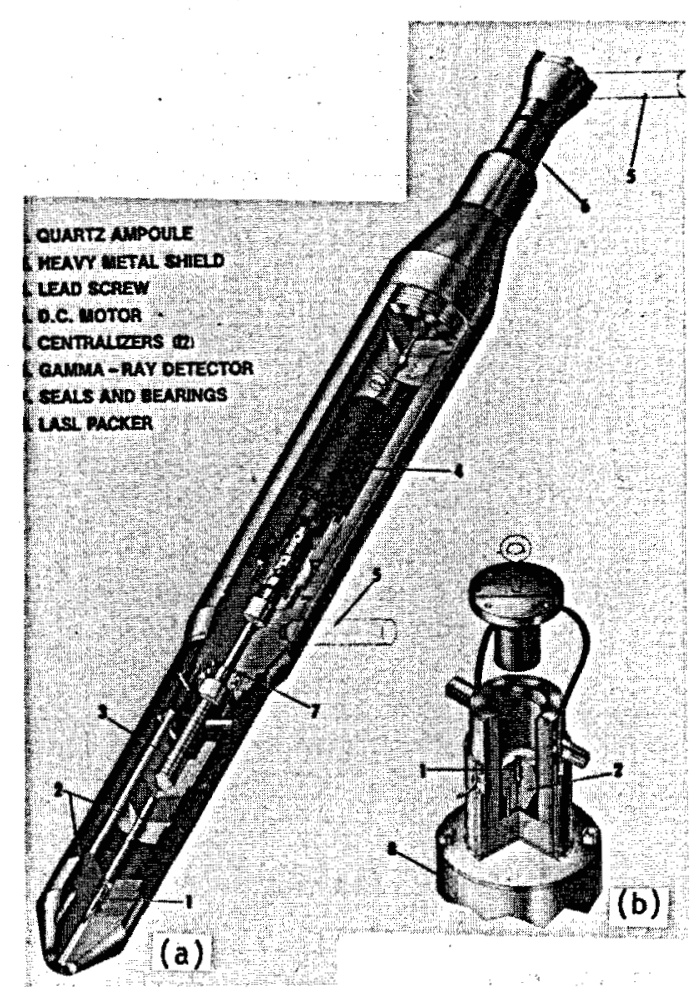

Fig. 7-3.

(a) Downhole 82BR injector and gamma-ray detector.

(b) Lead pig assembly fixture.

\subsection{Downhole Detonator Acoustic Source}

The high-temperature detonator is used as a downhole acoustic source in one method of mapping the hydraulic fracture and determining borehole locations. This requires that the geophone sonde be used in conjunction with the detonator package to register the acoustic signals generated by the explosives. The two tools are lowered into separate boreholes. The detonator can set off up to 12 charges sequentially at any desired location. The firing system consists of a downhole firing module, surface control unit, detonator rack, and high-temperature detonators (Fig. 7-4).

The downhole firing module includes an inverter to convert $20 \mathrm{Vdc}$ to 5000 $V d c$, which is then used to charge a 1- $\mu \mathrm{F}$ energy storage capacitor. The energy available in the capacitor is then distributed to 12 trigger tubes, any of 


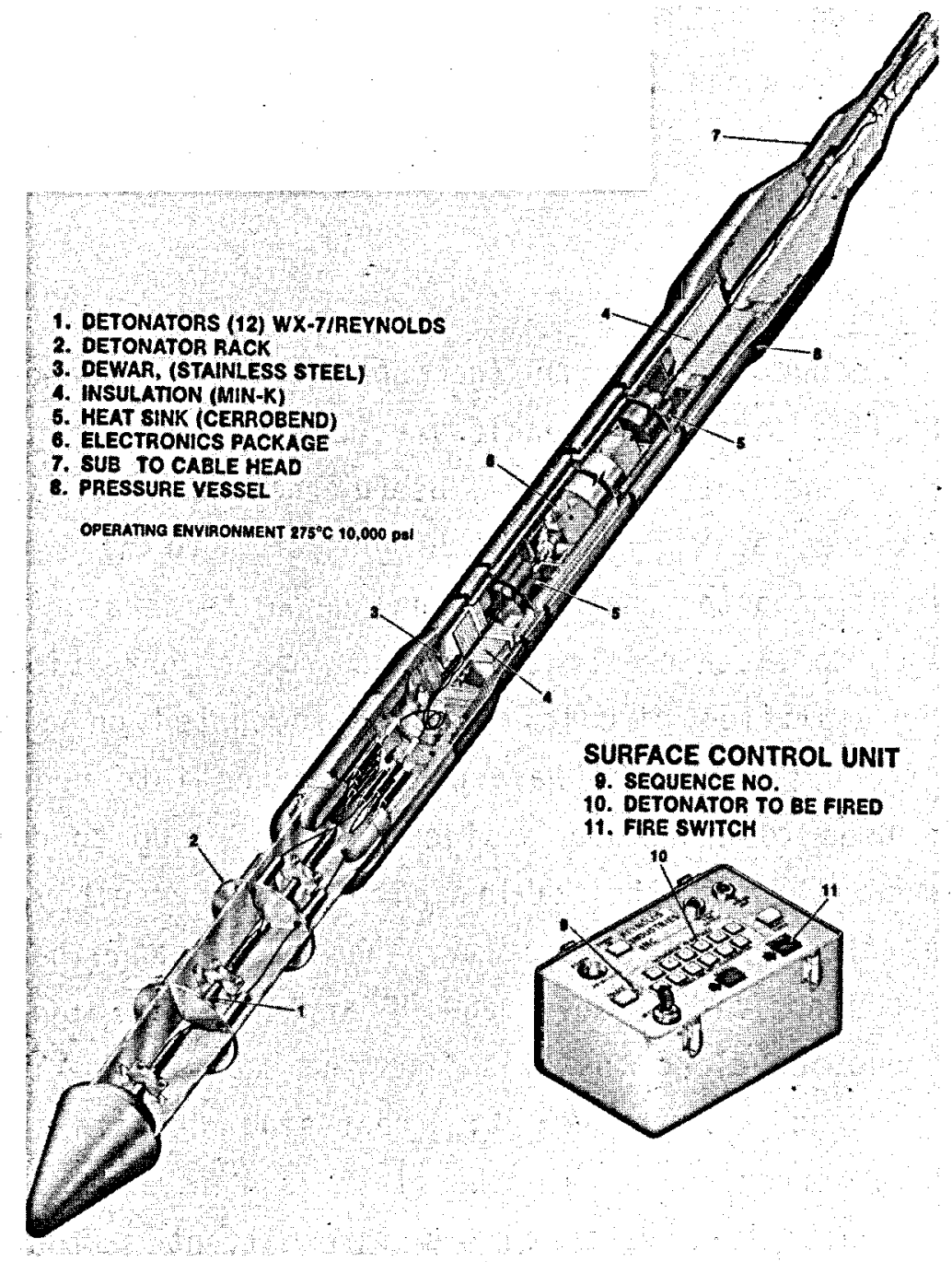

Fig. 7-4.

Acoustic source.

Which may be selected by means of a diode matrix. The downhole unit requires a 6-conductor cable to accommodate the following functions: +Vdc input, cormon, and four channel-selector conductors.

The uphole unit was designed by Reynolds Industries. It consists of a variable trigger voltage and special connector to select manually any one of the 12 channels. A timer was added by LASL to control accurately the capacitor charge and automatically trigger the downhole firing module.

The detonator rack has three levels, each of which will accommodate four detonators. Connections to the detonators are made through Kemon coaxial 
boots and feedthroughs. A11 the detonators (RP 84) are HNS exploding-foil type, designed to withstand high temperatures $\left(275^{\circ} \mathrm{C}\right)$ and pressures greater than 345 bars (5000 psi) and are inherently safe from accidental detonation during transit and handling.

\subsection{Geophone Sonde}

The downhole acoustic detector (geophone sonde) has been repackaged to utilize the controlled environment enclosure (dewar), thereby greatly simplifying field assembly and increasing the useful downhole operating time. The redesign also includes a downhole switching system to allow multiplexing of additional pertinent data to monitor internal dewar temperature, sonde orientation, and casing-bottom locator for depth-measurement correction (Fig. 7-5).

The downhole amplifier circuits have been mounted on a printed circuit board and, with the battery pack, have been inserted into the dewar assembly. The amplifier is used to establish a signal gain of 1000 to drive the surface recording equipment through the cable. The dewar assembly, as previously described, houses the electronic system. The phase-change heat-sink material in the dewar has the additional advantage of a relatively high thermal conductivity. Heat conduction along the axis from the ends to the center, away from the electronic package, is through the heat-sink container's copper wall. Maximum temperature difference within the flask is $4^{\circ} \mathrm{C}$.

The downhole multiplex system allows intermittent sampling of pertinent data. In addition to the geophone and associated amplifier, borehole slant angle is measured, referenced to the downhole sonde to provide geophone orientation. Provisions are also incorporated to measure internal dewar temperature and all downhole power supplies (battery packs).

Several instrument development experiments (see summary) were performed to compare the inclinometer readout with previous gyro surveys and multishot surveys of the GT-2B and EE-1 boreholes, to ensure optimum performance of the inclinometers as an orientation device.

The downhole multiplex is controlled from the surface data acquisition and control system (HP9835). The program is designed to step the downhole multiplexer by operator initiation of a keyboard command, allowing the measurement of auxiliary downhole data. Upon completion of this cycle (the time interval to be selected by the operator), the computer will return the multiplex to continuously monitor the geophone outputs. 


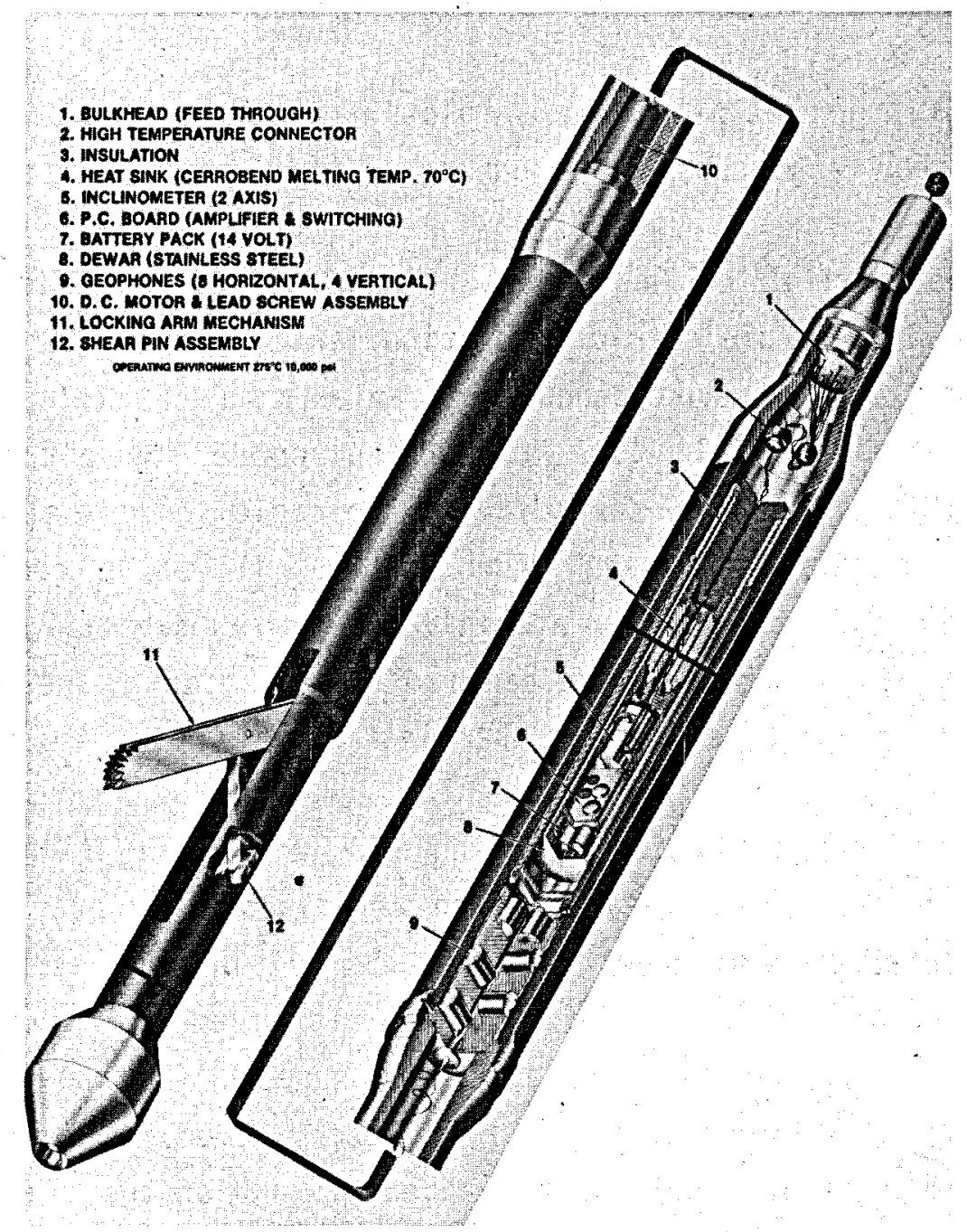

Fig. 7-5.

Acoustic detector.

The geophone sonde was field tested in the GT-2B borehole during a recent wellbore pressurization experiment (see Expts. 195, 196, and 203). The field test data (at a borehole temperature of $170^{\circ} \mathrm{C}$ ) were taken during continuous operation for $30 \mathrm{~h}$. Further laboratory experiments will test the sonde to design criteria of $14 \mathrm{~h}$ at $275^{\circ} \mathrm{C}$.

\subsection{Instrumentation Cable Samples for Evaluation}

The LASL Hot Dry Rock Geothermal Project has a need for a multiconductor/ coaxial cable that can operate satisfactorily when subjected to a hot water 
borehole environment of hydrostatic pressures up to 8500 psi and temperatures up to $275^{\circ} \mathrm{C}$.

Accordingly, prototype cable samples have been purchased from several manufacturers for engineering evaluation. Two categories of samples were purchased.

(a) The coaxial cable component sample: this consists of a center conductor, dielectric insulation, shield, and outer jacket.

(b) The armored multiconductor cable sample: this consists of a central coaxial cable element surrounded by either nine or ten outer conductors, depending on the cable vendor selected.

The samples from the several manufacturers differ in geometry, physical dimensions, type of insulation material, conductor material, armor package, etc. The samples purchased were each $1000 \mathrm{ft}$ long. The electrical and mechanical characteristics of the samples will vary with each particular design.

All vendors proposed either Teflon PFA or Teflon TFE for the primary dielectric material. The FEP-type Teflon was discounted because the operating temperature of $275^{\circ} \mathrm{C}$ equals or exceeds the known melt temperature of the material. The same applies to Tefzel, in addition to its known dramatic drop in insulation resistance at elevated temperatures. The only other materials seriously discussed with vendors were proprietary compounds that were presented strongly in the beginning, but did not appear in any of the final quotations.

The Teflon PFA material will be applied through pressure extrusion manufacturing methods, and the Teflon TFE will be applied to the conductor as a tape. Extruded TFE Teflon was not proposed because of the length limitations or ram extrusion of this material. Although the prototype could be manufactured with the extrusion method, a full-length cable could not. It should be noted that PFA-extrusion is a well-known process, while the taping process for Teflon TFE varies from vendor to vendor. For the prototype evaluation, there will be three different methods of applying TFE tape for evaluation. Teflon TFE, with its superior temperature resistance over PFA, is a strong candidate.

The filler compounds, jacket over the coax, and binders proposed by the vendors varied from Teflon-impregnated tape (presumably TFE Teflon), extruded Teflon PFA, Teflon TFE, polymide tape, glass tape, Teflon TFE braid, and glass twine to a proprietary TFE matrix filler. The major area of interest in this group of materials is the jacket over the coax, to ensure isolation of the 
coaxial return conductor from the other conductors and the bore fluid. For prototype evaluation, Tefion PFA, several types of taped Teflon TFE, and in one case a polymide tape, were chosen. The rated temperature resistances of the three materials should be sufficient, and we are evaluating primarily the manufacturing process of the Teflon TFE tape. The polymide material is rarely used as a primary dielectric, although it has outstanding mechanical properties and usually acceptable electrical properties. The early polymides performed well at high temperatures, but degraded quickly in the presence of moisture at these high temperatures.

The binder materials are generally viewed by the vendors as manufacturing aides, and if seriously attacked by the temperature and moisture (glass tape, for example), they should not pose a serious problem to the performance of the cable. Generally speaking, the vendors did not propose a completely filled cable, preferring to consider it a "free-flooding" cable. In two cases, there are fillers within the interties of the conductors in an attempt to provide a more stable core configuration. The two materials used are glass twine and a TFE matrix.

At the conclusion of the design trade-off study, the specification required one coaxial conductor approximately equivalent to RG-58 and a minimum of eight conductors of approximately 20 AWG size. The strength member was to be contrahelically armored steel. All proposals received were relatively similar with the coax running down the axis of the cable, encircled by the individual conductors, and over this the contrahelical armor. Because of the uniformity of design in the proposals, the material selection and the various processing of the materials had the greatest weight in the selection of the cables for testing.

Three 1000-ft multiconductor sample cables and four 1000-ft coaxial sample cables are being purchased for testing. Comparison of high-temperature materials, manufacturing process, electrical performance, and failure mode will be performed by LASL. A chamber has been designed that permits pressurizing, tensioning, and heating a 20-ft cable sample. Typical pressure, axial load, and temperature to simulate the average downhole environment have been

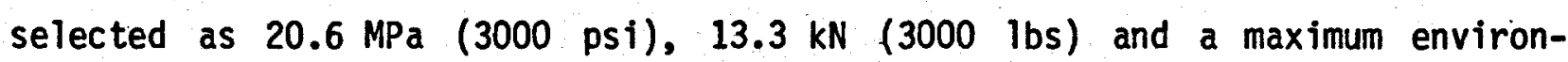
mental temperature of $275^{\circ} \mathrm{C}$. Terminal ends of the electrical conductors are accessible for electrical characterization measurements during testing. 
In addition to the in-house testing to be performed at LASL, a contract will be awarded to an industrial test facility to conduct independent tests on the cable samples. Test-measurement guidelines are given in Table 7-1. Table 7-II is a condensed description of the testing sequence to be performed at the contractor's facility. A comparison of test results will allow optimum design of future high-temperature armored instrumentation cables to be used in the HDR Program.

TABLE 7-I

TESTING MEASUREMENT GUIDELINES

1. Environment

(a) Pressure

(b) Temperature

(c) Load

2. Electrical

(a) DC Resistance

(b) DC Insulation Resistance

(c) Capacitance

(d) Impedance

(e) TDR

(f) Attenuation

$\frac{\text { Range }}{0 \text { to } 8500 \mathrm{psig}}$
0 to $275^{\circ} \mathrm{C}$
0 to $30000 \mathrm{Ib}_{\mathrm{f}}$

$10^{-3} \frac{\text { R ange }}{\text { to } 10^{3}}$

1 to $400 \times 10^{6}$ current limited to $10^{-12} \mathrm{~A}$

$1 \times 10^{-12}$ to $1 \times$ $10^{-3} \mathrm{~F}$ at $1 \mathrm{KHz}$

1 to 1000 Zo

Detect $5 \%$ variation

of signal level in any $10 \%$ gating interval

0 to $30 \mathrm{db}$ at 0.1 to $10 \mathrm{MHz}$ where (i) is from 10 to $50 \mathrm{ft}$ of sample length and (ii) is sample length $50 \mathrm{ft}$ or over.
System Accuracy

\pm psig

$\pm 5^{\circ} \mathrm{C}$

$\pm 100 \mathrm{lb}_{\mathrm{f}}$

System Accuracy

Full Scale $\times 10^{-3}$

Full Scale $\times 10^{-3}$

Full Scale $\times 10^{-3}$

Full Scale $\times 10^{-3}$ 
TABLE 7-II

CABLE TEST PROGRAM

Coax Element Only

\begin{tabular}{|c|c|c|c|c|}
\hline EST NO.: & 1 & & 3 & 4 \\
\hline PE: & Standards & $\begin{array}{l}\text { Temperature } \\
\text { Only } \\
\end{array}$ & $\begin{array}{l}\text { Temperature and } \\
\text { Low Pressure }\end{array}$ & $\begin{array}{c}\text { Temperature and } \\
\text { High Pressure }\end{array}$ \\
\hline & $\begin{array}{l}T=25^{0} \\
\text { Ref. Std. } \\
\text { Elec. } \\
\text { Data }\end{array}$ & $\begin{array}{l}T=25^{\circ} \text { to } \\
275^{\circ} \mathrm{C} \\
\mathrm{P}=0 \\
\mathrm{~N} 2 \\
\text { (Dry } \\
\text { Gas) }\end{array}$ & $\begin{array}{l}T=25^{\circ} \mathrm{C} \\
P=0 \text { to } 1000 \text { psi } \\
\text { Water }\end{array}$ & $\begin{array}{l}T=2750 \\
P=1000 \text { to } 8500 \text { psi } \\
\text { Water }\end{array}$ \\
\hline$\overline{N G T}$ & $000 \mathrm{Ft}$ & $400 \mathrm{Ft}$ & $400 \mathrm{Ft}$ & $20 \mathrm{Ft}$ \\
\hline
\end{tabular}

\section{Complete Cable}

TEST NO.

TYPE:

\begin{tabular}{|c|c|}
\hline 5 & $\frac{6}{\text { Temperature }}$ \\
\hline rds & Only \\
\hline & $\begin{array}{l}T=250 \text { to } \\
275^{\circ}\end{array}$ \\
\hline $\begin{array}{l}\text { Ref. Std. } \\
\text { Elec. } \\
\text { Data } \\
1000 \mathrm{Ft}\end{array}$ & $\begin{array}{l}\text { N2 } \\
\text { (Dry } \\
\text { Gas) } \\
400 \mathrm{Ft}\end{array}$ \\
\hline
\end{tabular}

\begin{tabular}{c}
7 \\
$\begin{array}{c}\text { Temperature and } \\
\text { Low Pressure }\end{array}$ \\
\hline
\end{tabular}

8

Temperature and High Pressure

$T=25^{\circ}$ to $275^{\circ} \mathrm{C}$

$T=275^{\circ} \mathrm{C}$

$P=0$ to 1000 psi

$P=1000$ to $8500 \mathrm{psi}$

Water

$400 \mathrm{Ft}$

Water

$20 \mathrm{Ft}$

TEST NO.:

\begin{tabular}{|c|c|}
\hline$\frac{9}{\text { Tension }}$ & $\frac{10}{\text { Tension and }}$ \\
\hline Only & Temperature \\
\hline $\begin{array}{l}F=0 \text { to } \\
150001 \mathrm{~b} \\
T=25^{\circ}\end{array}$ & $\begin{array}{l}F=150001 \\
T=25^{\circ} \text { to } \\
275^{\circ} \mathrm{C}\end{array}$ \\
\hline & \\
\hline
\end{tabular}

$\frac{11}{\text { Tension, Temp... and }}$

$\frac{12}{\text { Tension, Temp. and }}$

TYPE:

LENGTH:

$\underline{20 \mathrm{Ft}}$

$20 \mathrm{Ft}$ Low Pressure High Pressure

$F=15000 \mathrm{lb}$

$T=25^{\circ}$ to $275^{\circ} \mathrm{C}$

$P=0$ to 1000 psi Water

$20 \mathrm{Ft}$

\begin{tabular}{|c|c|c|}
\hline TEST NO.: & $\frac{13}{\text { Tension }}$ & $\frac{14}{\text { Tension and }}$ \\
\hline TYPE: & Only & Temperature \\
\hline & $\begin{array}{l}F=0 \text { to } \\
15000 \text { ib }\end{array}$ & $\begin{array}{l}F=0 \text { to } \\
15000 \text { lb (3) }\end{array}$ \\
\hline & $\begin{array}{l}T=25^{\circ} \mathrm{C} \\
\mathrm{P}=0\end{array}$ & $\begin{array}{l}T=275^{\circ} \mathrm{C} \\
\mathrm{P}=0\end{array}$ \\
\hline LENGTH: & $20 \mathrm{Ft}$ & $20 \mathrm{Ft}$ \\
\hline
\end{tabular}


7.8. Downhole Instrumentation/Industrial Contracts

7.8.1. Borehole Optical Survey System. The Phase I contract, a feasibility study, was awarded to two firms--Hydro Products, San Diego, California, and Measurement Analys is Corporation (MAC), Palo Alto Verdes, California. The purpose of this study was to determine the feasibility of developing a downhole borehole-optical-survey system, to identify design problem areas, and to provide a possible viable configuration. Both studies indicated that such a system is feasible, and that problem areas are due to the effect of high downhole temperature on electronics and lenses. Both provided designs that were capable of operation at $275^{\circ} \mathrm{C}$ for periods of approximately $12 \mathrm{~h}$.

The preliminary MAC design was selected by LASL for detailed design and testing of critical components for a black-and-white real-time optical survey system. Major development and research in the following areas will require: cabling, thermal protection of heat-sensitive electronics, and high-pressure/high-temperature lens seals.

A summarized description of the BOSS as it is currentiy visualized is given below.

(1) Real-time black-and-white system

(2) 114-mm diam (4-1/2 in.)

This compact diameter simplifies uphole handling, reduces weight, and provides a versatile system useable in most existing geothermal boreholes.

(3) Stainless-steel construction

A11 surfaces exposed to the downhole environment are corrosion resistant.

(4) 12-h operation at $275^{\circ} \mathrm{C}$

The thermal protection system uses water for the heat-sink material. The electronics are packaged inside a copper tube sealed from the surrounding liquid. A thermoelectric cooler is mounted on the CCD array to control the array temperature. 
(5) Resolution, focus, optics

Resolution of a $0.25-\mathrm{mm}\left(0.01-\mathrm{in}_{\text {. }}\right)$ vertical crack while descending or ascending at $9 \mathrm{~m} / \mathrm{min}(30 \mathrm{fpm})$; to cover a $40^{\circ}$ field of view; remote focusing; at $\mathrm{f} / 10$, depth of field is to be $100 \mathrm{~mm}$ (4.0 in.); capable of $360^{\circ}$ azimuthal viewing (panning).

(6) Operate on a single coaxial cable

(7) Lens filters and lighting will allow color synthesis and differential fluorescence studies.

(8) Orientation

The sonde orientation device will use the earth's magnetic field for azimuth sensing.

7.8.2. Acoustic Transceiver. The design review of the acoustic transceiver being developed by Simplec in Dallas, Texas, was held on February 5-6, 1979. Preliminary drawings of the transceiver were reviewed and design improvements were suggested. The mode of operation was discussed and complies with LASL specifications. Downhole electronics were also reviewed and will comply with specifications.

The transceiver system consists of the following components and subassemblies.

(a) Transmitter and associated electronics consisting of magnetostrictive transponding heads. One head to transmit a frequency of $8.5 \mathrm{KHz}$ and the second head to transmit at $17 \mathrm{KHz}$. The input energy to the transponder will be $2 \mathrm{~J}$ per pulse and the pulse repetition rate will be either 5 pps or 1 pps selectable from the surface console.

(b) Receiver and receiver electronics will include an automatic gain-control system operating over a range of attenuation from 1 to 100 in 8 steps $(6 \mathrm{~dB} / \mathrm{step})$. This automatic gain-control will have a manual override selected from the surface console. 
(c) Packaging of the transceiver system will include an attenuator in the housing to provide acoustic isolation between the transmitter and receiver sections. This attenuator will also provide mechanical damping to reduce noise when the tool is moving in the borehole.

(d) The assembled sonde will incorporate a suitable pressure housing and thermal protection to ensure operation in the geothermal borehole environment of up to $68.9 \mathrm{MPa}$ (10 $000 \mathrm{psi}$ ) external pressure and $275^{\circ} \mathrm{C}$ external temperature. The sonde will include centralizers that may also function as an acoustic reflector and attenuator.

(e) The surface control console will serve as the interface (via a high-temperature, seven-conductor, armored logging cable) between the downhole transceiver and to the LASL on-site recording facilities.

Final design review for the acoustic transceiver was held at the Simplec plant in Dallas on July 3, 1979. A new design for a more suitable autoranging circuit was submitted to Simplec for incorporation in the downhole circuitry. Fabrication of this system is in progress and it should be ready for testing in January 1980.

7.8.3. In Situ Stress Measurement. As was discussed in Sec. 5.1.5, a research and development contract has been awarded to Texas A\&M to design and fabricate a borehole sonde capable of measuring in situ stress in geothermal wellbore. The design will incorporate a prototype system developed by Earl Campbel1 of Texas A\&M and used to measure in situ stress on rock surfaces. LASL will design and furnish all electronic systems including downhole multiplex data collecting and control devices, data transmission, and surface interface.

The mechanical systems to be incorporated in the downhole sonde are intricate and complex, complicated by the high-temperature environment. The design of the mechanical components is still in the prototype stage and additional work is necessary. 


\section{INSTITUTIONAL AND INDUSTRIALIZATION ACTIVITIES}

\subsection{Economics}

Bechtel National, Inc., has been selected to conduct "An Industrial Assessment of the Economic Feasibility of Hot Dry Rock Geothermal Systems." The major tasks to be performed for this nationwide study are

- survey present HDR status and project reservoir and energy utilization concepts,

- survey current geothermal economic analysis methods and literature,

- identify and establish ranges of important factors in HDR comercialization,

- establish HDR cost and financial relationships,

- develop analysis methodology and model HDR systems, and

- define areas of insufficient information and data.

The products of this two-year effort are to be (1) a final report for wide distribution, particularly with in the industry, and (2) a series of related papers to be piblished in professional journals and presented at society conferences. The distribution, publications, and presentations are intended to reach a broad coverage within industry, government, and the public, and to achieve a high degree of credibility with all parties concerned.

\subsection{Legal Status}

Many legislative acts define geothermal energy in a manner that relates this resource to water or mineral, leaving the ownership of the heat in HDR open to a litigatory question. An analysis has been conducted that describes existing legislation and reveals weaknesses in some state statutes. Suggestions are presented for changing the definition of geothermal energy by including necessary physical characteristics of the resource in those statutes found lacking, and for new geothermal legislation to be considered by those states that have not so far promulgated such legislation. The report on this subject can be obtained by requesting LA-8027-HDR, "Hot Dry Rock Geothermal Resource Ownership and the Law," from the HDR Program Office.

A methodology is being designed to investigate potential legal constraints to HDR commercialization arising from existing water 1 aw and use. This envisions the use of both LASL program and outside personnel in conducting the study. 


\subsection{Regulatory Constraints}

Several institutional issues concerning HDR implementation by industry have been recognized. Among the more important are: economic feasibility, ownership and the right to use the resource, environmental acceptability, permit processes and requirements, and public acceptability as compared with other energy resources. A large body of information has been accumulated for several stztes concerning the permit processes, by type of 7 and ownership, as was discussed above in connection with site 2. The issues relative to the public perception of implementation desirability are purposely being left for a more appropriate time in the program schedule. However, the subjects of economic feasibility, ownership, and environmental acceptability have been considered in detail and are briefly discussed below.

\subsection{Environmental}

A general perception of reduced adverse environmental impacts from geothermal developments, in comparison with other energy-extraction and conversion technologies, seemingly exists. This perception is based primarily on the single example offered by experience gained at The Geysers, for electricity generation, and a few lesser known examples of direct use of geothermal heat. An "Environmental Analysis of the Fenton Hill Hot Dry Rock Geothermal Test Site," LA-7830-HDR, has been published, which concludes that no adverse environmental impacts have resulted and no detrimental social impacts are expected from the activities at that site. Additional monitoring data have since been obtained, are being analyzed, and will be included in a subsequent report. Report LA-7830-HDR is available from the HDR Program Office.

A methodology has been designed for a study that will compare the environmental residuals from HDR, hydrothermal, and the other presently used energy-producing technologies. The study may be performed by a university having a leading environmental science center and the necessary experience and resources to conduct it in a manner providing a high level of industrial, governmental, environmental, and public credibility. The final report will have widespread distribution and will serve as one basis for obtaining industry and public acceptance of HOR industrialization. 


\subsection{Drilling Equipment and Information}

During FY79 a number of significant drilling and well completion hardware-development projects have been completed. Most of these projects have consisted of modification and adaptation of commercial hardware or service tools for use at the high temperatures anticipated in the EE-2 drilling campaign. These upgrading efforts have necessitated a program at LASL to monitor fabrication and test procedures involving closely coordinated liaison with the several firms involved. Especially significant for HDR technology are two new types of high-temperature open-hole packer systems developed to HDR project specifications for hydraulic fracturing. These two packer systems were developed without use of R\&D funds from the HDR project. They are expected to contribute to other geothermal development projects of both the federal and private sectors, including stimulation experiments in hydrothermal reservoirs.

A major coordination and liaison effort was conducted to assure attainment of technical requirements and project schedules for the hightemperature turbodrill under development by Maurer Engineering, Inc. (MEI), in Houston, Texas. All fabrication and assembly are now complete for the 7 3/4-in.-diam unit, and flow tests have verified the basic fluid-mechanics aspects of the design. Following these ambient-temperature run-in tests, drilling tests in granite blocks at Terra Tek's Drilling Research Laboratory were completed in early April. Coordinated with the turbodrill project are the required high-temperature shock absorbers and steering-tool services. Both of these latter projects have also been accomplished with no R\&D funds contributed by the HDR project. These improvements can also be expected to contribute to cost reductions in the drilling of hydrothermal wells.

\subsection{Industrialization $P$ lanning and University Participation}

Figure 8-1 presents a summary of the relative amounts and type of commercial subcontracts performed for the HDR program. Such a sumary provides one measure of the importance of the contribution made by private firms to support of the LASL HDR technical effort. The period of time covered is FY79, but a projection of the private sector commitment anticipated in FY80 is also indicated. It is not possible to list the many other contributions made to the HOR Program that were furnished gratis as consultations and advice by many firms and individuals. 
During FY79, R\&D suport was provided by some 22 major subcontracts to 18 universities. These research tasks amounted to about 5\% of total program operating funds, and provided critically needed expertise, data, and analyses in a wide spectrum of problem areas.

The technical development at Fenton $\mathrm{Hill}$ and the milestone decision date of FY86 provides the time-frame within which certain industrial program activities will be conducted. These activities will be structured to provide a smooth and increasing level of interest to better achieve industrial support and to motivate private investment in HDR developments.

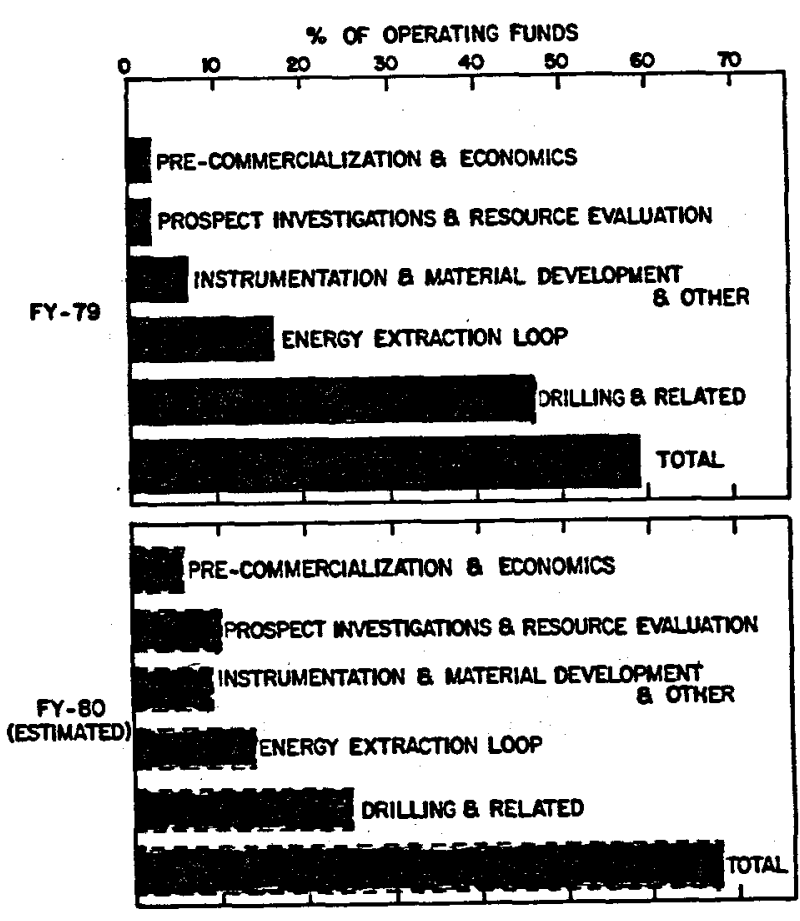

Fig. 8-1.

Amount and type of commercial contracts. 


\section{RESOURCE EVALUATION AND SITE SELECTION}

9.1. Introduction

The geologic activities discussed in this section have two major objectives: (1) to define large areas of the United States where HDR geothermal extraction techniques might be utilized, obtain an estimate of the number of sites that might be developed within these areas, and calculate the amount of thermal energy that might be ultimately available; (2) locate specific sites for testing the HDR method under different geologic conditions. The dual objectives of the work have led to the creation of two interacting and overlapping but separate series of tasks. Collection of new data for the evaluation of resource potential also leads to the selection of areas for reconnaissance and detailed siteselection investigations. In turn, data obtained from site-selection investigations further quantify our estimates of the HDR resource potential.

The evaluation of the HDR potential of the United States is closely tied to the geothermal assessment activities of the US Geological Survey (USGS) and state geological surveys. To ensure that the programs and activities are complementary, several meetings have been held between LASL staff and Robert Christiansen and Donald Klick of the USGS. Summaries of these meetings have been sent to both DOE/DGE and the USGS. Extremely good working relations have been established, and there is a very free exchange of data between the USGS and LASL. Quarterly USGS-LASL meetings will continue for the duration of the HDR program.

HDR program activities in resource-potential evaluation have concentrated on stimulating the production of high-quality heat-flow measurements by the academic heat-flow community. To help accomplish this task, a meeting was held at LASL in December 1978 which was attended by heat-flow experts from the USGS and many universities. Means of stimulating more heat-flow measurements were discussed, and ultimately several new proposals were received from the group. We are now funding Decker of the University of Wyoming for work in Wyoming, Colorado, Utah, and Nebraska; Eckstein, Heimlich, and Palmer from Kent State University for work in Ohio and Pennsylvania; Costain, Glover, and Sinha from Virginia Polytechnic Institute and State University (VPI and SU) for work in Maryland; Smith of the University of Florida for work in Florida, Mississippi, Alabama, and Louisiana; Roy from the University of Texas-El Paso for work in Arkansas; Steeples from the Kansas Geologic Survey for work in Kansas; and 
Simmons from the Massachusetts Institute of Technology for work in New England. In most cases, existing drill holes are used for the heat-flow measurements -- a cost-effective method of acquiring new data.

We are able to define large regions of high heat flow by deep penetrating geophysical methods. Presently, methods such as magnetotelluric (MT), gravity, and aeromagnetic (Curie-point-depth determinations) are being used. Several reconnaissance MT 1 ines have been run in New Mexico and Arizona, and additional work is being contracted for measurements in Oregon, Colorado, and Nebraska. A variety of geological and geophysical evidence of high geothermal gradients was used to select the MT sites.

About ten areas in the United States were examined for possible site prospects during FY78 and FY79. Results of these investigations were presented to the Site Selection Advisory Panel for their consideration. The Panel's deliberations will be discussed in the next section. In brief, however, the Panel recommended two areas to DGE for detailed investigation during the remainder of FY79 and early FY80.

Concurrently, reconnaissance work has continued on the remaining eight areas, not recommended at this time, and on several additional areas.

\subsection{Exploration Philosophy}

There are multiple goals for the HDR program. Of major importance is the need to find additional sites where the technology of HDR energy extraction may be tested successfully. A second important consideration is the need to demonstrate that energy can be extracted from hot, low-permeability rock in a variety of different geologic environments. This second consideration removes some of the constraints imposed by the very limited distribution of hydrothermal geothermal systems. These goals are to some degree contradictory because different geologic environments will require modifications of the extraction technology to accommodate the differences in permeability, physical nature, and chemistry of the potential reservoir rocks. Ideally, the current extraction technology would be tested in at least one other area as similar as possible to Fenton Hill. At that time, reservoir conditions could be gradually changed so that the extraction techniques would vary only slightly from one site to the next. Unfortunately, neither the time nor the money is available for such a logical but leisurely approach. More abundant heat sources must be sought and the extraction technology must be adapted rapidly to meet the new conditions. 
Successful exploration for any type of natural resource requires development of an exploration philosophy. This philosophy is simply a statement of a hypothesis or series of hypotheses that relates observations to the existence and genesis of the resource. In other words, the exploration philosophy postulates possible origins for the resource and then attempts to determine where these processes may have taken place by examining geological evidence. To be useful, the philosophy must specify the types of evidence that are suggestive of the occurrence of these processes.

Young, silicic calderas of the Valles Caldera type unquestionably represent some of the highest grade portions of the HDR resource base. Unfortunately, however, these features are relatively rare and usually not geographically convenient for users. Because of their very nature, they are scenic areas with particularly rigid environmental and institutional constraints on development.

Larger, lower grade, but more widely distributed heat sources appear to offer the greatest ultimate potential for widespread utilization of the HDR method. These heat sources can be produced in a number of ways. In the western United States, entire geologic or tectonic provinces have heat flows considerably above the worldwide average. Some of these, for example, the Rio Grande Rift, are related to deep crustal or mantle processes that heat the upper crust. Such regions are attractive prospects for HDR exploration. Widespread, voluminous, intermediate-to-basaltic volcanism of long duration can also cause thermal anomalies producing large areas suitable for HDR development. Examples include the Cascade Range, Snake River Plain, and Jemez Lineament.

In the eastern United States and in the mid-continent region, the absence of significant volcanism and tectonism and the concentration of population and hence of energy users, make still lower grade heat sources attractive targets for exploration and development. Much effort is currently being directed toward the search for plutons enriched in radioactive, heat-producing el ements, buried beneath thick blankets of insulating sediments. Impermeable basement rocks beneath deep basins may, in the future, become geothermal targets.

Each of these different heat sources has a different genesis and thus requires a different exploration philosophy. Although all require an integration of geological, geophysical, and geochemical methods, emphasis will vary with the type of heat source sought.

The high-heat-flow tectonic province is probably best sought by a combination of traditional geologic mapping, geophysical measurements, and modern 
tectonic theory. Aqueous geothermometry, as utilized by workers such as Swanberg, may also contribute to the recognition of such provinces. Although heat-flow measurements are undoubtedly important, this is not a particularly cost effective reconnaissance exploration method, and more emphasis should be placed on the correlation of other geophysical, geochemical, and geological methods with high heat flow.

Regions of voluminous intermediate-to-basaltic volcanism are more amenable to exploration because young igneous rocks serve as surface indicators of possible elevated heat flow. Again a combination of techniques is best suited for the characterization of these heat sources. Geologic mapping and geochronology define the igneous activity in space and time. Geochemistry, including radiogenic and stable-isotope tracer investigations, aids in evaluating the amount of crustal interaction. Geophysical investigations clarify geologic structure in potential reservoir rocks; the highest grade parts of the area are defined on the basis of heat-flow measurements.

The buried plutons of the eastern U.S. are the most obscure geothermal targets because of their great depth of burial and the blanketing effect of the overlying sediments. Detection of these "blind" targets requires use of geophysical techniques such as gravity, aeromagnetics, and seismic investigations. The VPI and SU group has demonstrated the effective use of heat-flow drilling after regional and detailed gravity, aeromagnetic, and seismic surveys. Analogy with known geologic features has also proven useful.

\subsection{Work in Progress}

9.3.1. Evaluation of Resource Potential. Some level of effort is now being expended in 30 states. These efforts, which are summarized in Table 9-I, vary from literature searches to heat-flow investigations, gravity and MT surveys, and reconnaissance geologic mapping. Because of the limited manpower available at LASL, much of this work is performed by academic and industrial subcontractors with LASL personnel acting as technical managers and coordinators. These subcontracts are summarized briefly in Table 9-II. Technical work by LASL staff has been concentrated in Arizona, New Mexico, Arkansas, and Idaho.

Some of the highlights of these efforts are summarized below.

(1) First heat-flow measurements were obtained in Ohio.

(2) Nine new heat-flow measurements were obtained in colorado. Values range from 1.58 to $3.62 \mathrm{HFU}$. 
TABLE 9-I

EVALUATION OF RESOURCE POTENTIAL

SUMMARY OF CURRENT ACTIVITIES

\begin{tabular}{|c|c|c|c|c|c|c|c|}
\hline $\begin{array}{r}\text { Litera } \\
\text { Sear } \\
\end{array}$ & $\begin{array}{l}\text { ture } \\
\text { ch }\end{array}$ & $\begin{array}{l}\text { Data } \\
\text { Compilation } \\
\end{array}$ & $\begin{array}{l}\text { Heat } \\
\text { Flow }\end{array}$ & Mapping & $\begin{array}{c}\text { Water } \\
\text { Geochemistry }\end{array}$ & $\begin{array}{c}\text { Other } \\
\text { Geophysics }\end{array}$ & $\begin{array}{l}\text { Geo- } \\
\text { chron- } \\
\text { ology }\end{array}$ \\
\hline Al abama & & & 1 & & & & \\
\hline Al aska & + & + & & & & & \\
\hline Arizona & + & + & + & + & + & + & + \\
\hline Arkansas & + & + & + & + & + & & \\
\hline California & + & + & $\cdot$ & & & & \\
\hline Colorado & + & + & + & & & 1 & \\
\hline Florida & & & + & & & & \\
\hline Georgia & & & + & & & & \\
\hline Idaho & + & + & + & + & + & + & \\
\hline Kansas & & & + & & & & \\
\hline Louisiana & & & + & & & & \\
\hline Massachusetts & & & 1 & & & & \\
\hline Maryland & + & + & + & + & & + & \\
\hline Mississippi & & & + & & & & \\
\hline Nebraska & + & + & & & & 1 & \\
\hline Nevada & + & + & $\cdots$ & & & & \\
\hline New Hampshire & + & + & 1 & & & & \\
\hline New Mexico & + & + & + & + & + & + & \\
\hline New York & + & + & + & & + & + & \\
\hline North Carolina & + & + & & & & + & \\
\hline Ohio & & & + & & & & \\
\hline Oregon & + & + & & & & 1 & \\
\hline Pennsylvania & & & + & & & & \\
\hline South Carolina & & & & & & & \\
\hline South Dakota & + & + & & & : & + & \\
\hline Texas & + & + & & & & & \\
\hline Utah & + & + & & & & & \\
\hline Virginia & + & + & + & + & + & + & \\
\hline Washington & + & + & & + & & & \\
\hline Wyoming & & & + & & & & \\
\hline
\end{tabular}


TABLE 9-II

\section{HDR FEDERAL PROGRAM SUBCONTRACTS \\ IN RESOURCE-POTENTIAL EVALUATION AND SITE SELECTION RESOURCE EVALUATION}

\begin{tabular}{|c|c|}
\hline Subcontractor & Institution \\
\hline Dennis Hodge & SUNY-Buffalo \\
\hline $\begin{array}{l}\text { John Costain } \\
\text { Lynn Glover III } \\
\text { Krishna Sinha }\end{array}$ & VPI and SU \\
\hline Paul Hammond & Portland State Univ. \\
\hline $\begin{array}{l}\text { Williston, McNeil } \\
\text { Associates }\end{array}$ & \\
\hline Stan Davis & Univ. of Arizona \\
\hline L. K. Lepley & Private Consultant \\
\hline Carlos Aiken & Univ. Texas-Dallas \\
\hline $\begin{array}{l}\text { Yoram Eckstein } \\
\text { Richard Heiml ich } \\
\text { Donald Palmer }\end{array}$ & Kent State Univ. \\
\hline E. R. Decker & Univ. of Wyoming \\
\hline $\begin{array}{l}\text { Paul Morgan } \\
\text { Randy Keller }\end{array}$ & $\begin{array}{l}\text { New Mexico State Univ. } \\
\text { Univ. of Texas-El Paso }\end{array}$ \\
\hline John Kaur & Digitgraph Computer \\
\hline Don Steeples & Kansas Geological Survey \\
\hline Robert Roy & Univ. of Texas-El Paso \\
\hline Douglas Smith & Univ. of Florida \\
\hline John Husler & Univ. of New Mexico \\
\hline John Husler & Univ. of New Kexico \\
\hline \multirow[t]{2}{*}{ Carl Schubert } & d'Appolonia \\
\hline & Harding-Lawson \\
\hline Dr. Merlivat & DRA/SRIRMA, France \\
\hline Robert Ferguson & Argonaut \\
\hline Marc Sbar & Univ. of Arizona \\
\hline D. Krumenacher & San Diego State \\
\hline Peter Hoyser & Washington State Univ. \\
\hline Gene Simmons & Mass. Inst. Tech. \\
\hline $\begin{array}{l}\text { University } \\
\text { Consortium, } \\
\text { U. Texas-EI Paso } \\
\text { U. Texas-Dallas } \\
\text { New Mexico S.U. } \\
\text { U. Pittsburgh } \\
\text { Purdue U. }\end{array}$ & $\begin{array}{l}\text { Purdue U. } \\
\text { (Manager) } \\
\text { W. Hinze }\end{array}$ \\
\hline P. Osberg & Univ. of Maine \\
\hline G. Issachsen & SUNY-Albany \\
\hline
\end{tabular}
Abbreviated Statement of Mork
Evaluation of HDR potential of New York and
Massachusetts using gravity, heat flow, and water
geochemistry.

Study contract to investigate distribution of 300 myr granites in eastern U.S. and their potential as HDR heat sources. Amendment covers heat-flow drilling of Baltimore gabbro.

Compile and publish geologic map of southern Cascade Range.

Magnetotelluric reconnaissance survey of parts of Arizona and New Mexico.

Chair a workshop on the hydrology of crystalline basement rocks.

Compile a geophysical lineament map of Arizona. Synthesize and interpret geophysical data along MT lines in Arizona.

Determine HDR potential in Ohio and Pennsylvania. Both heat-flow and heat-generation measurements being made.

Perform heat-flow measurements in Wyoming, Colorado, Ut ah, and Nebraska.

Passive and active seismic studies of potential HDR prospects Arizona and New Mexico. Investigations include fault detection and determination of baselevel seismic activity.

Gravity survey of N. Carolina, S. Carolina, and Virginia to assist in HDR evaluation of At lantic Coastal Plain.

Deepen two drill holes in Kansas Precambrian basement and obtain heat-flow measurements.

Perform heat-flow measurements in Arkansas.

Perform heat-flow measurements in Florida, Alabama, Mississippi, and Louisiana.

Perform water analysis for geothermometry.

Perform whole-rock chemical analysis for HDR exploration.

Perform detailed geologic, geophysical, and geochermical investigation of 100 sq mile area in western us. Perform detailed geologic, geophysical, and geochemical investigation of 100 sq mile area in western US. $H^{2}$ and $0^{18}$ analysis of geothermal water samples. Reconnaissance MT survey in Arizona and New Mexico. Seismic-refraction survey in Arizona to determine crustal thickness and nature of Colorado Plateau and Basin and Range boundary.

Perform K/Ar dating for HDR exploration.

Perform whole-rock chemical analysis for HDR exploration.

Geothermal evaluation of New England.

Integrated geophysical-geological study of potential HDR sites in the midcontinent U.S. (in Negotiation).

Heat-fl ow measurements in Conway granite, N.H. (in Negotiation).

Integrated geophysical-geological investigation of basement rocks in N.Y. (in Negotiation). 
(3) Three new heat-flow measurements were obtained in Colorado. Values range from 1.58 to $3.62 \mathrm{HFU}$.

(4) Residual Bouguer gravity map of New Mexico was published.

(5) Report of MT survey of Jemez Mountains, New Mexico published. J. Hermance, Brown University, recognized a 15-km deep magma body under the southeast side of the mountains.

(6) Reconnaissance MT survey of Arizona and New Mexico was completed.

(7) Gravity survey ( 4000 stations) was completed in Virginia, North Carolina, and South Carol ina to assist VPI group.

(8) A geophysical lineament map of Arizona has been published.

(9) Comprehensive field geophysical and geological studies of the Zuni region, NM, are finished and report writing is in progress.

(10) A strip from Kingman, Arizona to Williams, Arizona has been mapped. The geological and geophysical assessment of the HDR potential of that strip has been published by LASL staff.

(11) New heat-flow data on Alabama, Mississippi, and Florida has become available from $D$. Smith, University of Florida.

(12) LASL-sponsored workshop on the hydrology of crystall ine basement rocks was held in Tucson, Arizona at the University of Arizona.

The Hydrology of Crystalline Basement Rocks Workshop was conducted by the University of Arizona in Tucson, October 18-20, 1979, under contract to LASL. The meeting was attended by 24 geoscientists from the U.S. and four from foreign countries. The preliminary conclusions from the workshop were that in general the permeability of crystalline basement rocks decreases from darcy to microdarcy permeability rapidly, perhaps logarithmicalily, with depth. However, occasional fracture zones having moderate permeability (millidarcy) are encountered in a rather unpredictable manner at any depth. It was pointed out that young plutons and the zones around them are moderately permeable. Two participants emphatically stated their belief that the principal source of permeability in crystalline rocks, the fractures, is destroyed rapidly and ubiquitously by sealing.

Substantial progress has been made on regional geothermal exploration in New York, Pennsylvania, Ohio, Arkansas, Louisiana, Mississippi, Alabama, and Florida. Some of this information has been published; the remainder is being prepared for publication. 
A new map of geothermal gradients in western New York has delineated higher-than-normal gradients of $33^{\circ} \mathrm{C} / \mathrm{km}$ at East Aurora near Buffalo, of $36^{\circ} \mathrm{C} / \mathrm{km}$ between Elmira and Binghamton, and $36^{\circ} \mathrm{C} / \mathrm{km}$ near Lake Canandaigua, NY (Fig. 9-1). The high-gradient area between Elmira and Binghamton coincides with the most intensely negative Bouguer gravity anomaly in the state, suggesting that the gradient anomaly results from a granitic pluton in the crystalline basement. In western Pennsylvania, an area with gradients up to $30^{\circ} \mathrm{C} / \mathrm{km}$ was found in Venango County (Fig. 9-2). Thermal conductivity measurements of core samples from this area were completed during the year.

In southeastern Ohio, a heat-flow value of $1.36 \mathrm{HFU}$ was determined from core and gradient measurements in Washington County. Gradient data from bottom hole temperatures of 370 wells did not reveal any local anomalies. In Arkansas, six new heat-flow determinations were made this year. The values range from $1.09 \mathrm{HFU}$ in the Ouachita Mountains to $2.36 \mathrm{HFU}$ in the Mississippi embayment. In the southeastern U.S., 21 new heat-flow values were determined in the Gulf Coastal Plain. These range from $1.7 \mathrm{HFU}$ in northern Louisiana to $0.4 \mathrm{HFU}$ in northern Alabama and northeastern Florida. Although the data generally show low to normal gradients, an area with gradients up to $46^{\circ} \mathrm{C} / \mathrm{km}$ was found between Monroe, Loui siana, and Jackson, Mississippi.

9.3.2. Site Selection. During the past year, reconnaissance-scale exploration has begun or continued in several areas throughout the U.S. LASL internal efforts have concentrated on three general areas: Zuni Mountains, New Mexico to Springerville-St. Johns, Arizona; the Aquarius region of Arizona; and the Lucero Uplift area of New Mexico. LASL personnel have also worked closely with USGS personnel investigating the hydrothermal geothermal potential of the central Oregon and Snake River Plains regions. Much of the information generated by the USGS in these areas is pertinent to our investigations. Heat-flow measurements performed by the USGS in northwest Arizona have contributed significantly to our work in the Aquarius area.

Several new prospects have recently been selected for reconnaissance work during FY80. These include the Brothers fault-zone region in southeast Oregon, a portion of western Nebraska, an area of high heat flow near Yuma, Arizona, and the Williams Air Force Base near Phoenix, Arizona. Multiple lines of evidence suggest that these regions may be abnormally hot and suitable for HDR exploration. 


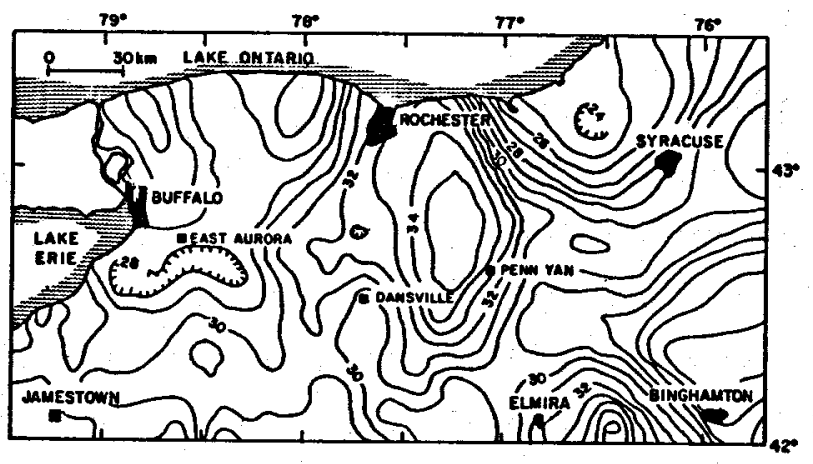

Fig. 9-1. Contoured temperature gradients for wells greater than $750 \mathrm{~m}$.

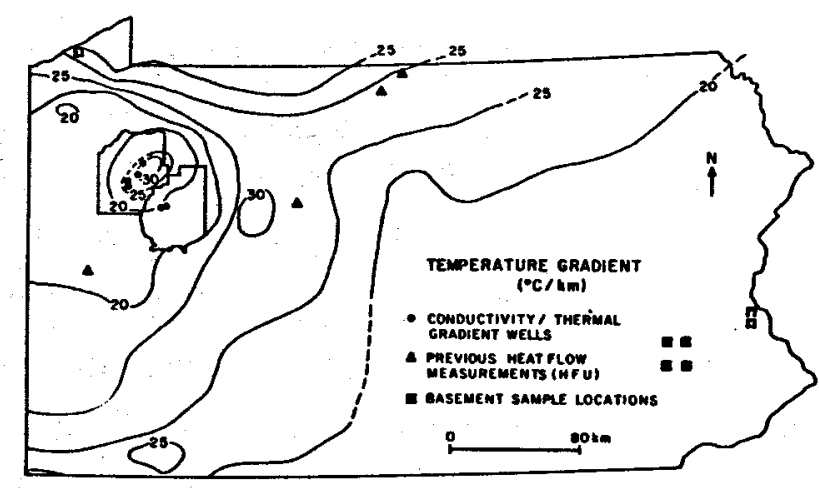

Fig. 9-2.

Tempercature gradient map of Pennsylvania. 56

In the eastern U.S., Dennis Hodge of SUNY-Buffalo, under a subcontract, has identified three regions of higher than average gradient near Buffalo, Elmira, and Syracuse, New York. Although these areas were not recommended for detailed investigations in FY79, the level of funding to this group has been increased to accelerate the reconnaissance exploration.

The Los Alamos Scientific Laboratory has subcontracted with VPI and SU to drill two heat-flow holes in the Baltimore gabbro. This work will be completed during the next 6 months. Arrangements were also made with DOE, VPI, and Gruy Federal for LASL to fund the deepening of the Gruy Federal drill hole near Crisfield, Maryland. Deepening of this hole provided information on the metamorphic basement, which presumably serves as a heat source in this area. It also provided the opportunity for hydraulic fracturing in a geologic environment different from that at Fenton Hill, which is described below.

9.3.3. Target Prospect Selection. On February 1 and 2, 1979, the HDR Site Selection Advisory Panel met at LASL. The panel consists of R. Christiansen, USGS; G. Crosby, Phillips Petroleum Co.; H. 0lsen, AMAX Exploration Co.; Y. Isachsen, New York State Geological Survey; and M. Wright, University of Utah Research Institute. R. Christiansen was elected chairman of the panel.

The first part of the meeting was devoted to presentations concerning the geologic and institutional aspects of seven potential HDR sites. Two of these areas were to be selected for detailed geologic and geophysical characterization during Fr79. 


\subsection{Summary of Site Presentations}

9.4.1. Atlantic Coastal Plain. (J. Lambiase and R. Gleason, VPI and SU.) Researchers at VPI are exploring low-temperature heat sources beneath the Coastal Plain and testing a model for predicting the location of these heat sources. The model predicts that granitic plutons with relatively high concentrations of $U$ and Th will serve as low-temperature radiogenic heat sources and that overlying Coastal Plain sediment will act as an insulator. VPI is testing aquifers, heated by these thermal sources, located at the base of the Coastal plain. This is a potential hydrothermal source but, if drilling is extended into the granitic plutons, a HDR resource may also be indentified.

Patterns of geothermal gradients $\left(75 \%\right.$ are $\left.>30^{\circ} \mathrm{C} / \mathrm{km}\right)$ and Bouguer gravity data suggest that numerous granitic plutons are located in the basement beneath the Atlantic Coastal Plain. These data indicate that the line of plutons extends under the Virginia Coastal Plain, encompassing much of the Chesapeake Bay and Delmarva Peninsula Region.

Two possible locations for HDR development are Stumpy Point, North Carolina, and Wallops Island, Virginia, because of relatively high geothermal gradients and thick sedimentary sections that should produce basement surface temperatures of $290^{\circ} \mathrm{C}$. The Stumpy Point area is located over a large, subcircular $45 \mathrm{Mgal}$ gravity low and the geothermal gradient is $13^{\circ} / \mathrm{km}$ higher than gradients located off of the gravity low.

Wallops Island, Virginia, is part of a belt of high geothermal gradients near Chesapeake Bay and the Delmarva Peninsula and is thought to be related to a large concordant pluton within a northward extension of the Hatteras Belt. Estimated basement surface temperature is $90^{\circ} \mathrm{C}$, below $2.16 \mathrm{~km}$ of coastal plain sediments. There is considerable interest at the NASA-Wallops Island flight Center in this potential resource.

9.4.2. Aquarius Plateau, Arizona. (F. Goff and F. West, LASL). In searching for a geothermal province to be developed as a HDR resource, a crosscorrelation of regional geophysical data for Arizona indicated a region of anomalously high heat flow in northwest-central Arizona. The region, named after the Aquarius Mountains, lies on the west edge of the Colorado Plateau at the boundary with the Basin and Range province. The geology of these mountains consists of Precambrian granitic and metamorphic rocks overlain by lavas and tuffs, predominantly of Miocene age. There have been three episodes of silicic volcanism in the area in the Fort Rock volcanic field (pre-17 Myr), Aquarius Mountains 
(pre-17 Myr) and Black Mesa volcanic field (past 17 Myr). Small isolated springs were sampled; chemical geothermometry and isotope data indicate that the waters have equilibrated at temperatures of $\leq 115^{\circ} \mathrm{C}$. There is little "wet" geothermal potential in the area, but HDR development may be possible in the structurally intact basement beneath the Aquarius Mountains if the geothermal gradient and heat flow are high enough.

9.4.3. Buffalo and Syracuse, New York. (D. Hodge, State University of New York-Buffalo and C. Swanberg and P. Morgan, New Mexico State University). Preliminary work, examining the American Association of Petroleum Geologists (AAPG) temperature-gradient maps, has revealed the existence of several areas in New York State that have higher-than-normal temperature gradients and may represent low-temperature geothermal prospects. Two of these anomalies are located just southeast of Buffalo, New York, and southwest of Syracuse, New York. Both have temperature gradients of $30^{\circ} \mathrm{C} / \mathrm{km}$ and are associated with negative gravity anomalies, which are being interpreted as granitic plutons, whose radioactivity is responsible for elevated temperatures. The basement is overlain by 1 to $2 \mathrm{~km}$ of Paleozoic age sedimentary rocks that may act as an insulator. Heat-flow measurements, with maximum values of 1.55 and $1.72 \mathrm{HFU}$, were made just south of the two anomalies.

9.4.4. Cascade Range, Washington and Oregon - General Case. (J. Eichelberger, LASL). The Cascade Range has been the site of persistent but episodic volcanism for the last $40 \mathrm{Myr}$. Tertiary- and Quaternary-age volcanic fields extend unbroken from Lassen Peak in California to Mt. Rainier in Washington. Within northern California and north of Mt. Rainier, Paleozoic and Mesozoic plutonic and metamorphic rocks underlie the volcanic fields. El sewhere the older basement is not exposed and may be more than $3-\mathrm{km}$ deep. However, isolated Tertiary-age plutons, comagmatic with the older Cascade volcanism, crop out within the high Cascades as far south as Mt. Hood. These may be present throughout the range at depth.

The southern Cascade Range has a history of extensive Pleistocene and Holocene volcanism where it is overlapped by Basin and Range structure in California and Oregon and by northwest-trending folds in Washington. Most of the major volcanoes have erupted within the last $10^{4}$ years. Lassen Peak erupted in 1915.

Young silicic lavas are more abundant south of Newberry Crater and Crater Lake, Oregon. Some of these fields may have active magma chambers within a few 
$\mathrm{km}$ of the surface. There are active fumaroles in Lassen Volcanic National Park. once the potential basement reservoir rocks are identified, there are many potential HDR reservoir sites in the Southern Cascade Range, associated with shallow silicic magma bodies.

The Mt. Shasta Region, northern California, will be considered as a possible HDR site due to the concentration of potential users (lumber mills).

9.4.5. Snake River Plain, Idaho. (D. Mabey, USGS and R. Pettitt, LASL). The Snake River PIain (SRP), a major tectonic feature, extends as a huge arc from eastern Oregon to the Yellowstone Plateau in western Wyoming. The western half of the Plain is a deep trough, originating 10 to 15 Myr ago and filled with Cenozoic volcanic rocks and sediments. The eastern part of the plain may be a regional downwarp, due to an episode of volcanism wihch progressed from southwest Idaho to Yellowstone Park. Silicic volcanic rocks have ages ranging from 9 to $13 \mathrm{Myr}$ in western Idaho to $0.6 \mathrm{Myr}$ in eastern Idaho. Young basalt flows (10 000-yr old) occur all along the SRP. On the southwest margin of the plain, in the Rexburg area, a large (45-km-diam) caldera has been identified and is partly covered by younger basalt flows.

Heat-flow values average $1.7 \mathrm{HFU}$ in the center of the western SRP and 2.5 HFU in granitic rocks along the margin. Heat-flow values of 1 HFU are encountered in the center of the eastern SRP, with values of 3 to $5 \mathrm{HFU}$ in the southern boundary.

The western SRP is characterized by large but relatively simple gravity and magnetic anomalies. A model that will produce the total combined gravity and magnetic anomalies assumes a simple deep structure producing the regional gravity high, with the local gravity lows reflecting shallow Cenozoic rocks. On the basis of a resistivity profile run across the eastern SRP, Paleozoic basement occurs at 3 to $4.5 \mathrm{~km}$ depths within the SRP.

9.4.6. Springerville, Arizona (C. Stone, State of Arizona). On the basis of moderate to high geochemical temperatures and the presence of very young volcanic rocks of the White Mountain volcanic field, an area between St. Johns and Springerville, Arizona may be anomalously hot. The volcanic field overlies sedimentary rocks of Pennsylvanian to Quaternary age. One drill hole located north of Springerville encountered bedrock at a depth of $700 \mathrm{~m}$. Active volcanism of the White Mountain volcanic field began in late Miocene and continued intermittently into recent time. High temperatures, as indicated by high $\mathrm{Na}-\mathrm{K}-\mathrm{Ca}$ 
geothermometers, coincide with deposition of youthful travertine mounds between St. Johns and Springerville.

Several lineaments intersect in this area and a negative Bouguer gravity anomaly coincides with a postulated rise of the Curie isotherm to a depth of 5 to $10 \mathrm{~km}$. A single gradient of $50^{\circ} \mathrm{C} / \mathrm{km}$ has been measured in the area.

9.4.7. Zuni Uplift and Volcanic Field, New Mexico. (G. Heiken, LASL). The Zuni Uplift is a northwest-trending, oval uplift about $120 \mathrm{~km}$ long and $50 \mathrm{~km}$ wide, located in west central New Mexico. Precambrian igneous and metamorphic rocks are exposed along the west, and Permian through Mesozoic age sedimentary rocks crop out along the flanks of the uplift. Heat-flow values around the upl ift range from 1.4 to $1.7 \mathrm{HFU}$ along the east and northeast flanks and 2.0 to 3.9 HFU on the southwest and northwest flanks. Within the uplift itself, heat flow values range from 1.4 to $2.4 \mathrm{HFU}$.

A positive, northeast-southwest trending gravity anomaly, $90 \mathrm{~km}$ long and about $30 \mathrm{~km}$ wide, extends southwest from the highland. The Zuni volcanic field, a line of basaltic vents, is parallel to the eastern edge of the gravity anomaly. Although data are incomplete, we think eruptions along this chain occurred over a period of about $3 \mathrm{Myr}$ to the present (youngest data is about $1000 \mathrm{yr}$ ).

The large gravity anomaly may be due to a large basement structure that has controlled sedimentary depositional patterns in the area since Cambrian time, the orientation of the volcanic chain, and deformation of the sedimentary section.

Elevated heat flow in the area may be due to young basaltic intrusions, radiogenic heat contributions from Precambrian granitic rocks, or both. 9.5. Recommendations of the HDR Site Selection Panel

The panel ranked the sites presented, through considerations of geology, demography, and institutional considerations. A major controlling factor in their ranking was the requirement of a $2125^{\circ} \mathrm{C}$ temperature at $3-\mathrm{km}$ depth. The rankings were as follows:

1. Snake River Plain (SRP) and Cascade Range,

2. Zuni Uplift and Springerville,

3. Aquarius Mountains, and

4. New York and Atlantic Coastal Plain.

The SRP was highly rated due to the high temperatures and known occurrence of crystalline rocks in the Idaho Batholith along the north flank of the SRP 
between Boise and Weiser. Access, permitting, and market within the region are also favorable.

The Cascade Range, with many appropriate heat sources in the form of shallow magma bodies, was also highly rated. The large extent of this region and limited knowledge of it make selection of specific sites impossible at this time. Due to new geologic work in the area, the Cascades may be the location of several prime HDR sites within several years.

The Zuni Uplift and volcanic field are promising, but more work, including heat-flow measurements, is needed before further consideration of the area for HDR development. (The field work recommended was finished during the summer and fall of 1979.)

The Springerville, Arizona, area was not rated highly due to lack of data at this time. The Aquarius Mountains were not highly rated due to lack of heat-flow data and indications that heat flow is normal for Basin and Range Provinces.

The New York State and Atlantic Coastal Plain areas were at the bottom of the list due to fairly low temperatures (which could, however, be used for heating and industrial processing).

9.6. Selection of Two Areas for Detailed Geological and Geophysical

Investigation

Two subcontracts, one for the eastern U.S. and one for the western U.S., were negotiated for detailed geological and geophysical characterization of areas of about $260 \mathrm{~km}^{2}\left(100 \mathrm{mi}^{2}\right)$ each. On the results from these investigations, HDR Site No. 2 may be selected. These subcontracts for the detailed investigation of the two target prospect areas were issued to Harding-Lawson for the western prospect and to d'Appolonia for the eastern prospect. (See App. G for work statement for the subcontracts for the western area.)

9.7. Target Prospect Descriptions

9.7.1. Mt. Home, Idaho. Following the recommendation of the HDR Site Selection Panel, LASL selected a western target prospect within the western Snake River Plain. This area was then approved by DOE/DGE and a contract was negotiated with Harding-Lawson Associates for its evaluation.

The prospect, which lies near Mountain Home, Idaho, was selected on the basis of geology, heat-flow and temperature gradient measurements, accessibility, and proximity to a potential user (Fig. 9-3). The area is on the northern edge of the Snake River Plain, southwest of the Mt. Bennett Hills and Camas 


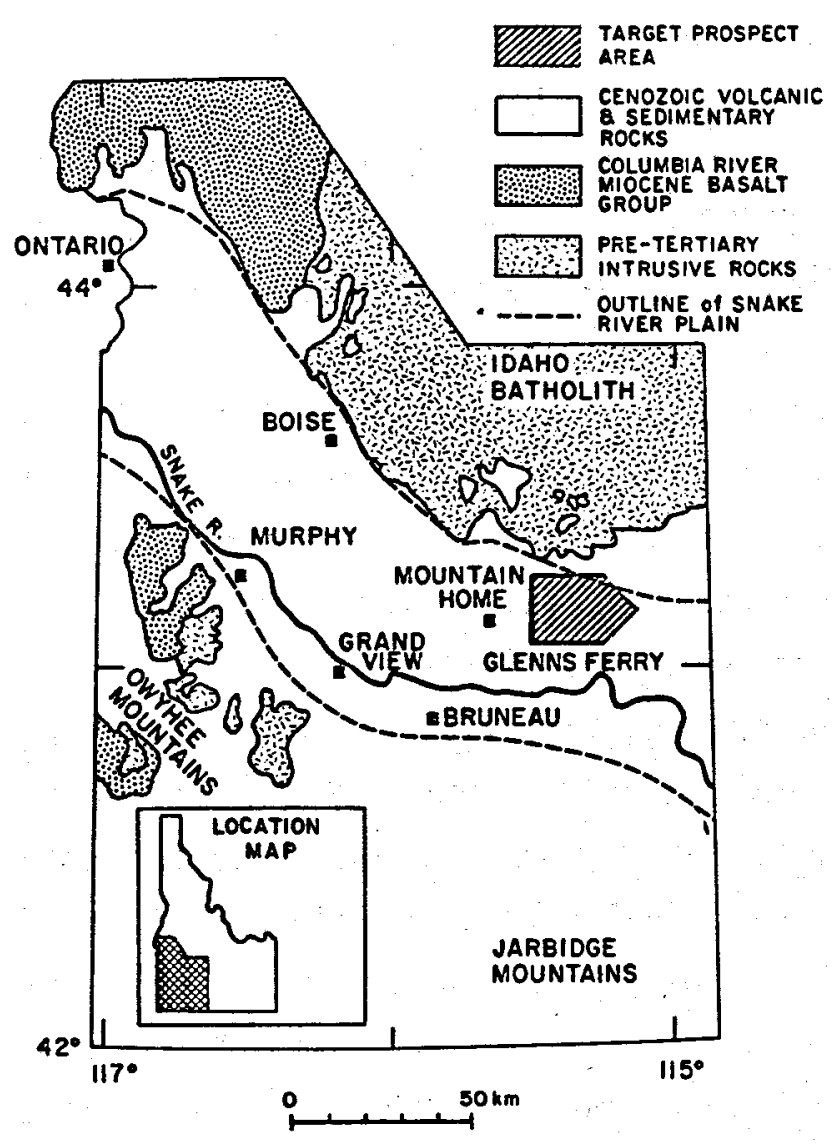

Fig. 9-3.

Location of the Mountain Home target prospect. 57

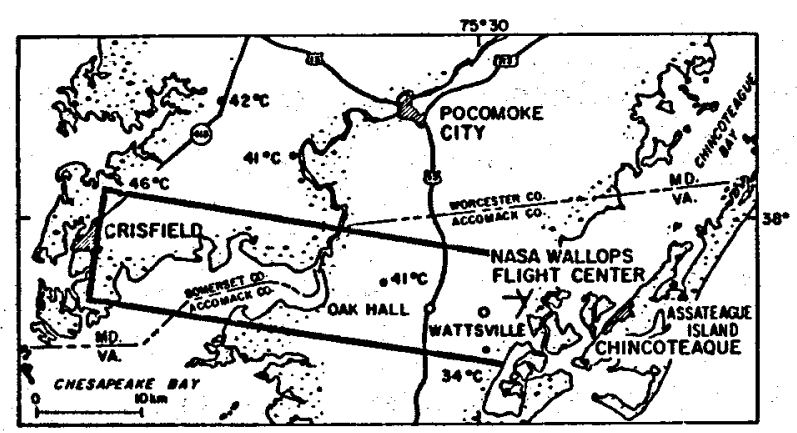

Fig. 9-4.

Area being investigated on the Delmarva Perinsula, Maryland-Virginia.

known geothermal gradients are plotted on the map.
Prairie. It is directly south of, but separated from the Idaho batholith. All of this region north of the Plain exhibits high geothermal gradient, but much of it is faulted, allowing deep circulation of fluids. Hot springs occur along many of the fault zones. More competent rocks may form the mountain peaks, but are virtually inaccessible. Once into the Snake River Plain, the granitic basement is thought to drop in large steps so that a short way out onto the plain it is probably below reasonable drilling depth. One advantage of the Mountain Home area is that the depth to granite is known at one point: $2941.5 \mathrm{~m}$ (9648 ft) in the Bostic 1A well (4S8E Sect 25).

There are many gradient and heat-flow measurements in the western Snake River Plain and bordering areas. Unfortunately, there are several deep aquifers in the region and few holes are deep enough to get below the hydrologic effects. The borders of the plain are faulted and this also influences some of the gradient measurements. The Mountain Home area has two good thermal gradient holes. One is the Bostic 1A well drilled to $2950 \mathrm{~m}$ $(9676 \mathrm{ft})$. The most recent bottom hole temperature is $204^{\circ} \mathrm{C}\left(400^{\circ} \mathrm{F}\right)$ at $2933 \mathrm{~m}$ (9620 ft), which indicates a gradient of $70^{\circ} \mathrm{C} / \mathrm{km}$. The second hole 
(4S10E Sect 30$)$ is $410 \mathrm{~m}$ (1345 ft) deep with a bottom hole temperature of $55.47^{\circ} \mathrm{C}\left(131.85^{\circ} \mathrm{F}\right)$ and a gradient of $58^{\circ} \mathrm{C} / \mathrm{km}$ in the lower $110 \mathrm{~m}$. Two of the desirable characteristics for present HDR technology are therefore known to be met: granitic basement and a temperature of $200^{\circ} \mathrm{C}$ at $3 \mathrm{~km}$. The surface geology of the area is mostly volcanic: basalt with some sediments interlayered in the plain, rhyolite on the edge of the mountains. Granitic batholith rocks outcrop north of the area on the northern border of the Mt. Bennett Hills. It is believed that the volcanic and sedimentary cover over the granitic rocks will serve as a blanket to keep the heat from dissipating. The source of heat is believed to be two-fold: heat produced by natural radioactivity in the granite, and heat refracted into the granite from the basalts at depth.

9.7.2. Crisfield, Maryland, to Wallops Island, Virginia. An area extending from Wallops Island, Virginia, to Crisfield, Maryland, on the eastern shore peninsula of these states, was selected as a hot dry rock target prospect site (Fig. 9-4). The proximity of energy consumers (NASA's Wallops Flight Center and local food processing plants) and available geologic and geophysical data were the basis for site selection. Evaluation during the year of competitive bids for investigation of the site led to award of two contracts to d'Appolonia Consulting Engineers.

The area is underlain by crystalline metamorphic basement rocks covered by nearly horizontal clastic sediments of Jurassic to Recent age. The depth to basement increases eastward from $1200 \mathrm{~m}$ near Crisfield to more than $1800 \mathrm{~m}$ at Wallops Island. The shallow sediments are generally unconsolidated. Some of the deeper, finer grained sediments are partially lithified. Deep borings in the vicinity of the site have encountered metavolcanics, metasediments, and gabbro in the basement. A deep well drilled by Gruy Federal for DOE/DGE at the Crisfield airport penetrated $330 \mathrm{~m}$ of metavolcanic basement under $1360 \mathrm{~m}$ of sediments. There is no history of seismic activity in the area, and no reported displacements in the sedimentary sequence.

Ten geothermal gradient test wells have been drilled in the vicinity of the prospect for a DOE-funded study by VPI and SU. These have gradients of 33 to $46^{\circ} \mathrm{C} / \mathrm{km}$ and heat flows from 1.2 to $1.8 \mathrm{HFU}$. An approximately circular negative Bouguer gravity anomaly of -24 milligals has been mapped near the eastern end of the prospect area. Studies by VPI el sewhere in the Atlantic Coastal Plain have shown that similar anomalies are underlain by granitic plutons having aboveaverage concentrations of radiogenic heat-producing minerals. Such a pluton 
would be a suitable target for HDR development. The exploration program to be done by d'Appolonia includes additional gradient test holes, seismic reflection surveying to measure basement topography, and magnetic surveying to determine the shape and size of the discernible contrasts in the basement rocks.

The following is a summary of logging and hydraulic fracturing tests completed by LASL staff at the Crisfield, Maryland target prospect area.

After the last core was taken, a background suite of wellbore logs was run which included:

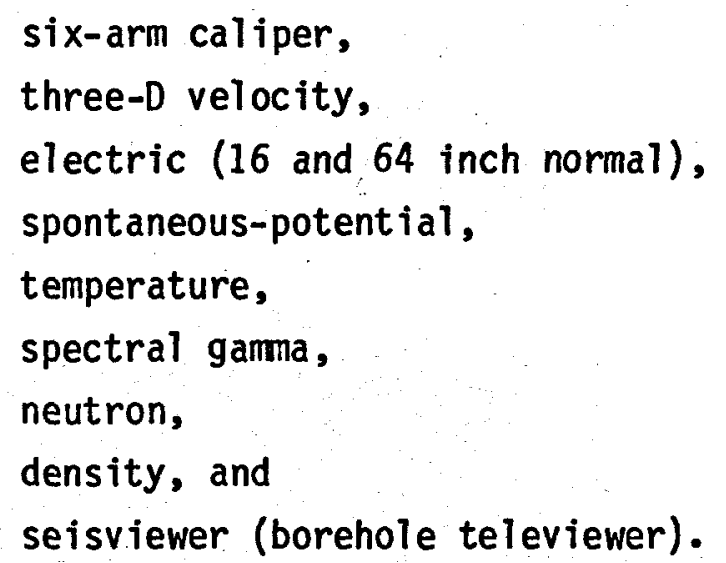

Examination of logs indicated a suitable packer site at a depth of $1625 \mathrm{~m}$ $(5333 \mathrm{ft}$ ). A permeability of $10 \mu \mathrm{D}$ for the $70 \mathrm{~m}$ of open borehole below the packer was obtained from an analysis of an initial $3.4 \mathrm{MPa}$ (500 psi) surface pressure shut-in. Figure 9-5 shows the results of a sequence of hydraulic fracturing and repressurization tests. Initial breakdown of the formation occurred at $11.3 \mathrm{MPa}$ (1670 psi). A total of $1050 \ell$ was injected at a rate of $\sim 1.25$ $\ell / \mathrm{s}(20 \mathrm{gpm})$ reaching a final pressure of $17 \mathrm{MPa}(2500 \mathrm{psi})$. After venting, the system was repumped at a similar rate. This time the formation accepted some fluid at a much lower pressure of $2.7 \mathrm{MPa}(400 \mathrm{psi})$ followed by a period in which the pressure rose at a rate identical to that occurring before the original breakdown. Flow into the formation started again at a pressure of $\sim 11 \mathrm{MPa}$ (1600 psi). A total of 2700 l was injected at rates up to $8 \mathrm{l} / \mathrm{s}$. The peculiar pressure profile was again repeated during the next pumping sequence, which terminated with the injection of $75,000 \mathrm{l}$ at a rate of $10.5 \mathrm{l} / \mathrm{s}$. After a sustained vent period, the fracture was sand propped using a total of $1800 \mathrm{~kg}$ of sand (equal amounts of $20 / 40$ and 10/20 sand). After venting the fluid used in the propping operation, the system was repumped at $\sim 1.25 \mathrm{l} / \mathrm{s}$ as shown in Fig. 9-5. The system started accepting fluid again at a pressure of $2.7 \mathrm{MPa}$ (400 psi) with a much lower rate of pressure increase. 
PUMPING TESTS CRISFIELD AIRPORT *I

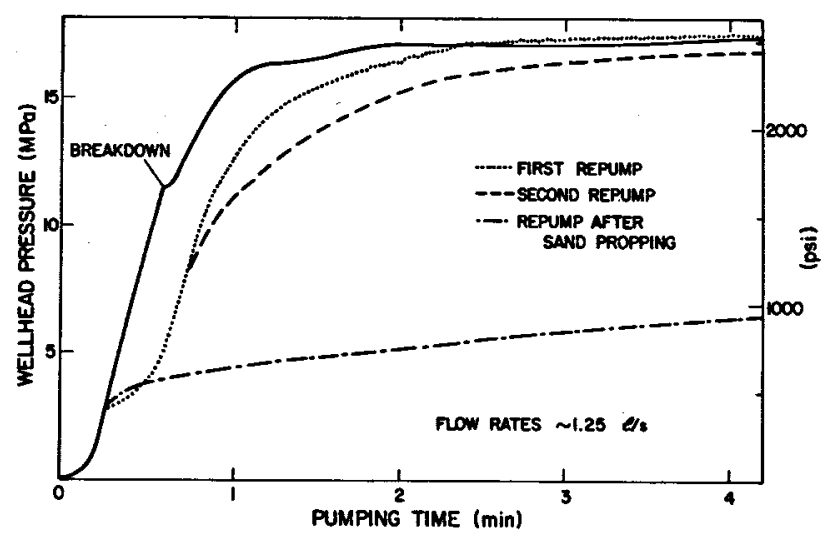

Fig. 9-5.

Breakdown and repumping pressure-time curves.

Examination of a suite of postfracturing logs shows that a 50-m-1ong zone with multiple fractures was created below $1640 \mathrm{~m}(5390 \mathrm{ft})$. Figures 9-6 and 9-7 show this zone in the caliper and three-D velocity logs, and are representative of logging techniques that can detect fracture intersections. Figures 9-8 and 9-9 are preand post-fracture temperature and electric logs and show changes that apparently are caused by the injection of fluid into a fracture system that grew upwards to a depth of about $1500 \mathrm{~m}$, well above the packer. Observation of temperature changes in the wellbore at a height greater than $100 \mathrm{~m}$ above the packer are best explained by the presence of a nearly vertical fracture system possibly containing many fractures. The extensive sealed fractures observed in the cores could provide a complex flow system under pressurization, with pressure-dependent flow properties such as those shown in Fig. 9-5.

\subsection{Site 2 Selection and Development}

Although the prospect areas discussed above appear to be excellent candidates for selection as the location for HDR Experimental Site 2, there are other

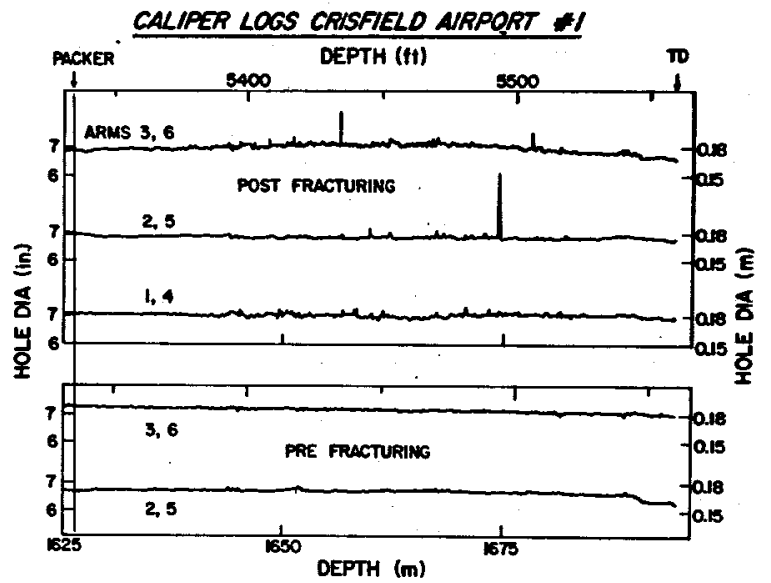

Fig. 9-6.

Pre- and post-fracturing caliper logs in the Crisfield wellbore.

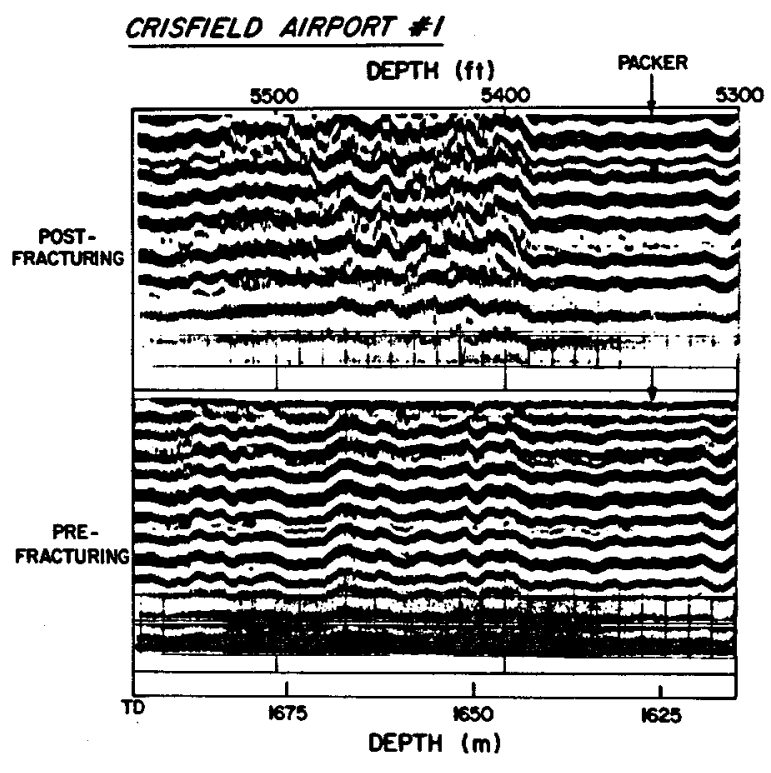

3-D VELOCITY LOGS

Fig. 9-7.

Pre- and post-fracturing three-D velocity logs in the Crisfield wellbore. 


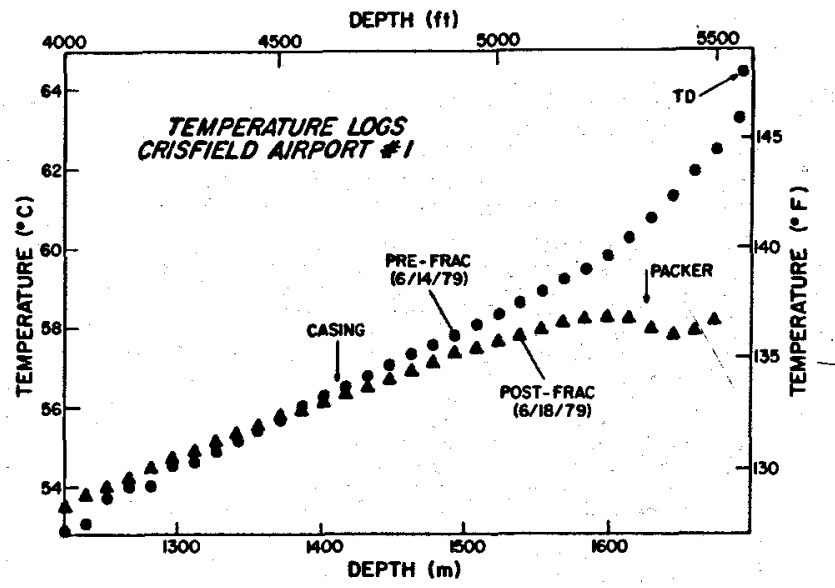

Fig. 9-8.

Pre- and post-fracturing temperature logs in the Crisfield wellbore.

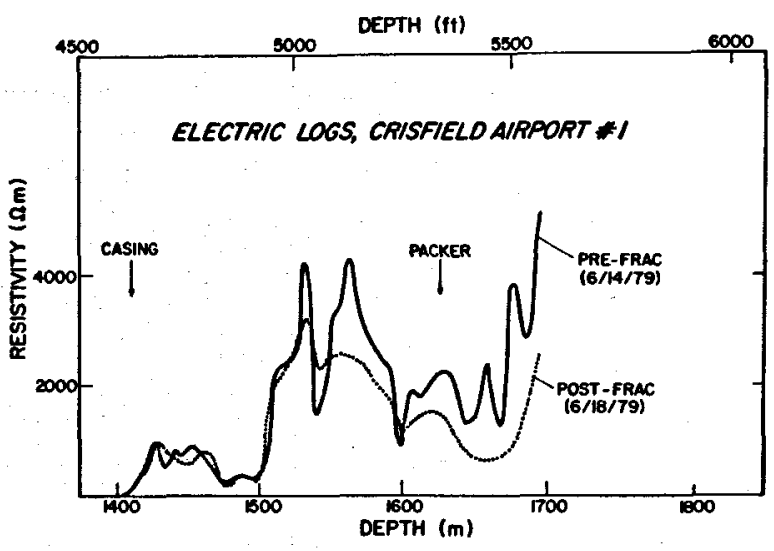

Fig. 9-9.

Pre- and post-fracturing electric logs in the Crisfield wellbore.

promising candidates--and more are expected to appear before the final selection is actually made. These include areas now being investigated by organizations such as the U.S. Geological Survey, and al so "Wells of Opportunity"--unproductivity wells with high downhole temperatures, drilled usually in unsuccessful explorations for hydrothermal reservoirs and offered by their owners for possible HDR development. Where such areas and "dry holes" appear promising and have been investigated in sufficient detail to justify it, they too will be considered as candidates for selection as Site 2.

In the meantime, bidding and contracting arrangements for development and experimental operation of Site 2 are very time-consuming and preparation for them has begun. It is intended that these activities will be undertaken by an industrial subcontractor with the HDR Program Office as Project Manager and Technical Advisor.

Two solicitations-of-interest have been prepared and issued, for the HDR Site-2 development contract and for possible well-acquisition or collaborative efforts in existing hot dry wells (Fig. 9-10). These solicitations were conducted following the widespread public notice of the HDR program that appeared in the national press, GRC journal, Geothermal Magazine (Fig. 9-11), and elsewhere. Each solicitation appeared as Comerce Business Daily announcements, journal advertisements, and direct mailing. The Site-2 development solicitation yielded a significant response and will augment the source list for that request-for-proposal (RFP). The dry-hole-availability solicitation elicited 


\section{Research and Development Project \\ Management and Technical Direction of Hot Dry Rock Experimental Field Project}

This proyxel iv en element in the DOE. Diviswon of Geothermal Energy (DGE) Hot Dry Rock Gevethermal Energy Program a DOE-Les Alamos Screntric Luborotor a ast) Hot Dry Rock Manugement Office has been established ot LASL to provide

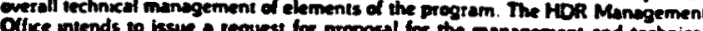
Olice miends so hasue e request for proposal for the monigement and technical direction ad the Hor Dry Roek (HDRI experiments to be conducted of o ezond HDR wre. as a part of the DOE' s Geothermal Energy Program. Which pleces emphosis on

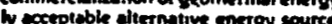

The selected fim. of censoriuum of forms. will be responsible for the menegement and direction of the HDR Sile-2 extivitues with the HDR Monagement Olice in ithe rele $\alpha$ technieal maneget The entent $\alpha$ and duration of the Sute. 2 activities will depend upon the mature and characteristics of the reservorr developed

The contracioe must be shoroughty fomiliet with DOE and Federal Procurement

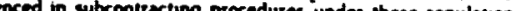
ind qualified to megotule subeontexts. to perlorm procurements end gulonins. both in en emvirenment of Federally regulated purchesing ond anberminister Familiarty with both non-covered and covered subcontracting sunder the Deve Becon Act and the Setvice Contract will be required

The research and developoment woek will involve an interdisciplinary research and manegement eftorn. Led by i commerciel or industrul firm that will prounde the echnical direction and site menegernent for a second HDR experimental'drilling beation. The initial efiort will include evaluation of the exasting exploration. environmental. end lond-use data. end the preparation of o technocal developation. plan and en environmental impect/assessment report. Alung lor permits for the planned development. preperations for. supervisuen of. on site construction. ecress control. housekeeping. eceess roads. And communicutions. errengements and sub centructs for muironmental base hine date collettion and montoring. extivives such dewowe concernad wim design and emplecement of a seismx monitoring metwork.

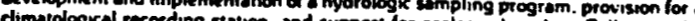

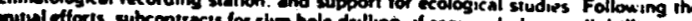
mins eflorts. subcentrects for slim hole driling of required deep well drilling and relard reservor. Oy hydroulc hacturing ar orher means. and tesing of the HDR reservor pillor plont susequenty. afrmafive decisions on prototype heat extrection and

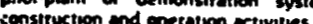

The contrector will be required to interext strongly with the HDR Manegement Airce and the propect technocel staff who will provide eccess to data and the detwils at the wehnueal aspects of the ongoung DOE DGE sponsored HDR geotherme energy research and developinent effort at LASL and especsully the he geothermal expetiment underway at experimental Site I. IFenton Hilli in north centrel New Mexico. As one mechenism to provide insught into and fomiluerty with the proget. en indusirial Staff Member (ISM) program is avalable Interested furms con ojet. prepreposal wecesss to the HDR projeci by aseignment of iechnxal steff to LASL The direct costs of the ISM assignments are lunded by ithe inierested froms Details

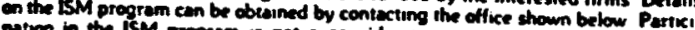
pation in the ISM program so not a consideration so particpation in the HDR

Site exploration and boction efforts ere curnently underwoy and it is plenned the tinal Sile-2 aelection will be made in about Seprember 1979. wrth tnituation of Sire.-2

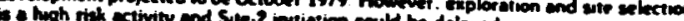
the ditand

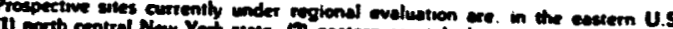
Morth central New Yort wate. 4 eastern coastal plains. and in the western

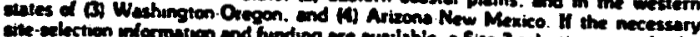

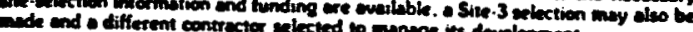

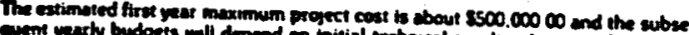

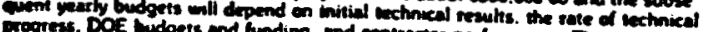

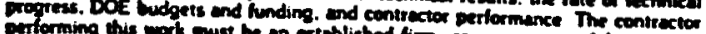

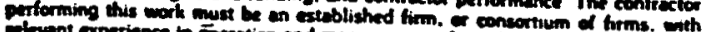

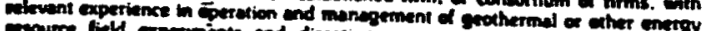

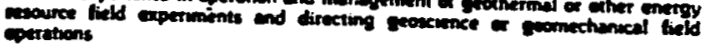

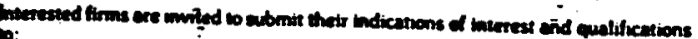

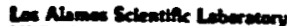
MDI Mascrevent Othe

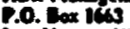
$\ln 1$

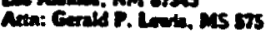
andind of errive in Les Alome o liter tan December 15 . int. This is not

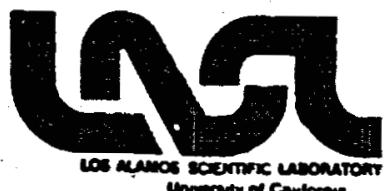
unometr of cambornes

\section{RESEARCH AND DEVELOPMENT} ORY GEOTHERMAL WELS FOR HOT DRY ROCK

As o part of the Depariment of Energr' (DOE) eeothermat Enerey Program, which emphasizes commerciolizalion mol Eneroy Progrom, which emphasizes commerciolizalion of geothermal onergy resources os economical and anvironmentally aceeplable alfernative onergy sources the DOE-LOs Geothermal Management Office is seeking information on Geothermal Monogement Office is eeking information on existing 'dry' geothermal wells thot might be technically mental sites. This project is an element in the DOE-Division of Geothermal Energy (DGE) federal Mot DrX Rock Geothormol Energy Development Program.

The HDR Manogement Office of LSt is soeking to locote owners of dry goothermal wells that could be made avall oble to LASL through transfer of ownership, loan, loose, or by formation of collaboralive or eooperative arrangements. or cost-shored projects, for possible experimental attes for HDR tests, experiments, and demonstrations.

Candidate dry wells will be expected to meet the follow ing technical requirements. They thould feach depths of which rock temperatures ore high enough for elther direst use or electric power generation, bottom in formations with very low frocture ond matrix pormeabilities, have beon logged lithologically or 10 be in areas whose tithology is logged lithologically or 10 be in areos whose thrology is wenifestation of present hydrothermal ectivity of to any monifestation of present hydrothermal ectivity of to any or from which tuction of steom, hot water, or hydrocorbons. or potentipl production of steom, hof water, or hydrocerbons. wight have a high probobility of being sullable for hrdromight have a high probobility of boing suliable for hrdro thermal stimulation, experiments. The well should have a minimum depth of $1 \mathrm{~km}$, be no eloser then $1 \mathrm{~km}$ to major After initial logging and resting. including frecturing and ceservoir tests and other downhole experiments, drilting of en adjocent woll moy be required to complete o heot-axtraction loop, followed possibly by construction of a pilot plan or demenstration sratem. Occupency of a surface area ef several ecres for a period of from a few months to suveral years moy be requirad.

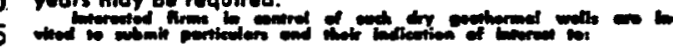

> Hot Or Rock Geothermal Management Ofitica Hot Dr Rock Geothermal Managem
ios ALMOS ScIENTIFIC uBonitory MDR Dry Woll Experimental sites

P. O. Lox 990, Los Alamos, NM 17545 ATTN: Mr. W. A. Larr

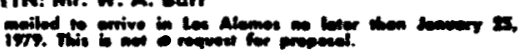
los ALAMOS SCIENTIFIC LABORATORY

Fig. 9-10.

Solicitation-of-interest issued for HDR Site 2. 
only five replies. An active search for other appropriate existing wells seems

necessary and has begun.

\section{LOS ALAMOS SCIENTIFIC LAB TO MANAGE NATIONAL HOT DRY ROCK GEOTHERMAL ENERGY PROGRAM}

LASL will manage national hot dry rock geothermal energy program in association with the U. S. Department of Energy. The program resulted from the Laboratory's successful geothermal reservoir experiments at Fenton Hill, New Mexico. Three 100-squaremile areas in the United States will be chosen as prospective sites for the development of prototype geothermal energy extraction systems. Choice of the sites will be made by LASL working with the National Hot Dry Rock Program Development Council. Industrial firms, under contract to the DOE and LASL, will investigate the sites for technical feasibility, and one or more areas will be pinpointed for a deeo drilling test and possibly a pilot or demonstration plant. Drilling at other sites may proceed after additional field studies and regional assessments. The national program will determine the potential of hot dry rock geothermal energy as a significant energy source and provide a basis for its timely commercial development. LASL's Geological Applications Group is conducting field studies in several states to assess hot dry rock potential; other Laboratory groups will provide management and technical expertise, and advice on legal and institutional questions. A major part of the national program will be conducted through contracts with private industry. The potential for hot dry rock geothermal energy is enormous, LASL scientists believe. They point out that the energy from i 40-cubicmile block of hot granite equals the energy from about 12 billion barrels of oil, or nearly the total energy used in the United States in 1977. The new manager of the national program is Dr. Gerald P. Lewis, former director of technical programs for Allied Chemical Corporation in New Jersey. Lewis joined the LASL staff September 25.

Fig. 9-11.

Public notice of HDR Program. 


\subsection{Fenton Hill Project}

10.1.1. Fenton Hill Phase I. Evaluative testing (Run Segment 4) began in October 1979. Among the items evaluated in this fourth run segment are (a) the results of attempted deflagrative pneumatic fracture initiation and extension by massive hydraulic fracturing, (b) degree of extension of the Phase 1 system, and (c) variation of impedance in the modified system under operation.

In FY80, this reservoir will continue to provide an expendable system for evaluating high-risk/high-payoff reservoir extension workover technique and for conducting a small preliminary electric generation experiment.

Run Segment 5, a long-term heat extraction test of the enlarged EE-1/GT-2B system and associated diagnostic experiments, started in March 1980. The following specific objectives have been established for this series of experiments.

- Examine the thermal and flow properties of the present EE-1/GT-2B system for changes resulting from Expt. 215 and provide new information concerning the relationship of impedance and flow rate by means of a series of discrete injections into both wellbores with each injection at an increased level of flow rate.

- Improve lower bound estimates--under steady-state, low back-pressure conditions--of effective heat transfer, flow impedance, long-term water losses, flow through volume, and degree of mixing. This stage will also establish background behavior prior to any attempts at reducing impedance.

- Establish baseline levels of induced microseismic events under long-term normal pressurization conditions.

10.1.2. Fenton Hill Phase II. In parallel with the completion of the Phase I effort as described in the preceding section, planning and initiation of a Phase II system has been proceeding. The primary objective of this effort is to demonstrate reservoir scale-up and longevity by creating a pilot plant sized system (20 to $50 \mathrm{MWt}$ ) with a projected life in excess of 10 years. A third well, EE-2, is being drilled at the site to a bottom-hole temperature of 
$250^{\circ} \mathrm{C}$ to $275^{\circ} \mathrm{C}$ and will serve as the injection well for the Phase II system. Orilling of EE-2 began in April 1979 during preparations for the Segment 4 test of the Phase I system. Upon completion of the EE-2 we11, the rig will be skidded to another location near EE-2 to drill a fourth well, EE-3, which will serve as the Phase II production well. It is anticipated that the drilling of EE-3 will begin in the third quarter of FY80. A nine-month period devoted to completion of the subterranean system and a comprehensive set of comunication tests will follow.

Planning of the Phase II surface system will parallel establishment of the reservoir. Some long-lead procurements will have to be initiated early, including the following: high-pressure, remote operated valves; additional air-cooled heat-exchanger units; and appropriate additional larger circulation pumps, if required. Construction of the surface system will begin in the third quarter of FY80, partially overlapping the drilling of EE-3, and be completed in FY81. The installation will be designed such that most of it, other than the air rejection heat exchangers, will be usable by the possible follow-on electric pilot plant. (The heat exchangers will be reusable in reservoir evaluation tests at subsequent HDR sites). Upon completion of construction, the Phase II loop will be activated for a protracted energy extraction test. It is estimated that after 6 to 9 months of continuous operation, it will be possible to define the minimum reservoir lifetime with adequate confidence to permit a go-ahead decision on pilot plant construction. This would occur at about the end of FY82.

The first priority in FY80 will be the completion of Phase II system drilling along with the necessary downhole evaluations. The Phase I experimental program should be completed and that system's components made available for other parts of the project. Work must be started on the Fenton Hill water system expansion and on the Phase II flow system.

\subsection{Site-2 Project}

10.2.1. Site Selection. Two major contracts were awarded in late FY79 for the detailed evaluation of prospect areas. One in the eastern United States, with D'Appolonia, is for a study of about $260 \mathrm{~km}^{2}$ in the Crisfield, Maryland/Wallops Island, Virginia ("CRIS-WAL"), area. 
The selected prospect ("BOISE") area in the western United States is in the Snake River Plain in southern Idaho, a short distance south of Boise. A contract for the study of this areas was awarded to Harding-Lawson in July 1979. Most of the work in the contract will be in FY80.

With the site selection process underway, data will continue to be collected on sites that might be developed beyond 1986 by industry and government. The plan calls for the consideration of, perhaps, ten sites each year, with one or two target prospects evaluated each year. These additional sites will be fully characterized and would be considered ready for exploratory development after 1986.

10.2.2. Site-2 Development. The late FY80 schedule for completion of Site-2 target prospect evaluations and site selection dictated an early start on the definition of the procurement schedule and preliminary inputs to the RFP solicitation process for the contractor to develop Site 2. Inputs to an Advanced Procurement Plan (APP) have included definition of scope, technical, and procurement objectives, government-furnished data and information, background, proposed contract phasing and duration, draft statement of work, evaluation criteria, suggested source lists, and other elements of a preliminary draft RFP have been supplied to Albuquerque Operations Office (AL00). The APP for Site-2 solicitation should be completed in early FY80. It will be forwarded to the DOE via ALOO-DOE. The initial action requested will have to have the source selection responsibilities delegated to the Manager of ALOO. This action will place the Source Selection Official (SSO) in the field and, thus, expedite the procurement activities resulting in a timely RFP solicitation.

\subsection{Other Program Elements}

The determination of resource potential effort will continue in FY80 with an ever-broadening base of data input. The first edition of a U.S. Geothermal Gradient map will be published in cooperation with the USGS toward the end of the fiscal year. A preliminary analysis--estimating the magnitude of the HDR resource base, accessible resource base, and economic resource--will be published in the same time frame. These documents will be refined and updated on a one-year basis thereafter. 
The development of required materials, equipment, and instrumentation will continue this fiscal year. Test specimens of potentially suitable high-temperature $\left(275^{\circ} \mathrm{C}\right.$ continuous capability) instrument cable will be tested for meeting the common needs of the HDR Program, the Sandia Laboratories Geothermal Logging Instrument Development Program, and the USGS field instrumentation activities. The high-prototype temperature, magnetostrictively.driven, downhole acoustic transceiver unit will be completed and delivered for testing at Fenton Hill about mid-FY80. Phase II of the Borehole Optical Survey System development--the testing of critical components and subassemblies--will be conducted during the fiscal year. Analytical and laboratory feasibility studies of microwave fracture mapping techniques aimed at the critical issues of coupling, penetration, and resolutions will be continued. The prototype Instrument Sonde Test Facility (ISTF), an inground autoclave for bottom hole environment simulation, will be completed and activated in about February 1980. Its initial operational capability will be $41 \mathrm{MPa}(6500 \mathrm{psi})$ at $260^{\circ} \mathrm{C}\left(500^{\circ} \mathrm{F}\right)$; an upgraded pressure vessel will also be designed to provide a final operational capability of $69 \mathrm{MPa}(10000 \mathrm{psi})$ at $300^{\circ} \mathrm{C}\left(572^{\circ} \mathrm{F}\right)$.

A multifaceted effort will continue in the environmental, institutional, and precommercialization program element. The first year of the two-year HDR economics study, being conducted by an industrial consortium headed by Bechtel, will culminate in a mid-term review and interim report. Contracts will be placed to study water rights laws and HDR development, and comparative environmental residuals. In addition, an update of the Fenton Hill environmental analysis will be initiated, pursuant to the drilling of the EE-3 well and the construction of a storage pond.

\section{ACKNOWLEDGMENTS}

We thank N. L. Bazzell for her assistance in preparation of this report. 


\section{REFERENCES}

1. D. W. Brown (Ed), "Further Testing of a Hot Dry Rock Geothermal Reservoir at Fenton Hill--Under High Back-Pressure Condition--Run Segment 3 of Phase I," Los Alamos Scientific Laboratory report (to be published).

2. M. C. Brown, R. B. Duffield, C. L. B. Siciliano, and M. C. Smith (Compilers), "Hot Dry Rock Geothermal Energy Development Program, Annual Report, Fiscal Year 1978," Los Alamos Scientific Laboratory report LA-7807-HDR (Apri1 1979).

3. W. D. Purtymun, R. W. Ferenbaugh, A. K. Stoker, W. H. Adams, and J. W. Owens, "Water Quality in the Vicinity of Fenton Hill Site, 1978," (in press).

4. W. D. Purtymun, W. H. Adams, and J. W. Owens, "Water Quality in Vicinity of Fenton Hill Site, 1974," LoS Alamos Scientific Laboratory report LA-6093 (December 1975).

5. W. D. Purtymun, W. H. Adams, A. K. Stoker, and F. G. West, "Water Quality in Vicinity of Fenton Hill Site, 1975," Los Alamos Scientific Laboratory report LA-6511-MS (September 1976).

6. W. D. Purtymun, W. H. Adams, and A. K. Stoker, "Water Quality in Vicinity of Fenton Hill Site, 1976," LoS Alamos Scientific Laboratory report LA-7307-MS (May 1978).

7. W. D. Purtymun, A. K. Stoker, W. H. Adams, and J. W. Owens, "Water Quality in the Vicinity of Fenton Hill Site, 1977," Los Alamos Scientific Laboratory report LA-7468-PR (September 1978).

8. C. A. Newton, D. J. Cash, K. H. 01sen, and E. F. Homuth, "LASL Seismic Programs in the Vicinity of Los Alamos, New Mexico," Los Alamos Scientific Laboratory report LA-6404-MS (November 1976).

9. LASL HDR Project Staff, "Hot Dry Rock Geothermal Energy Development Project, Annual Report, Fiscal Year 1977," Los Alamos Scientific Laboratory report LA-7109-PR (February 1978).

10. K. H. Rea, "Environmental Investigations Associated with the LASL Hot Dry Rock Geothermal Energy Development Project," Los Alamos Scientific Laboratory report LA-6972 (December 1977).

11. C. A. Newton, D. J. Cash, K. H. 01sen, and E. F. Homuth, "LASL Seismic Programs in the Vicinity of Los Alamos, New Mexico," Los Alamos Scientific Laboratory report LA-6406-MS (November 1976).

12. S. M. Spottswoode and A. McGair, "Source Parameters of Tremors in a DeepLevel Gold Mine," Bull. Seism. Soc. Am. 65, 93-112 (1975).

13. J. N. Brune, "Tectonic Stress and Spectra of Seismic Shear Waves from Earthquakes," J. Geophys. Res., 75, 4997-5009 (1970). 
14. J. D. Achenbach, Z. P. Bazant, J. Dundurs, L. M. Keer, S. Nemat-Nasser, T. Mura, and J. Weertman, "Hot Dry Rock Reservoir Characterization and Modeling," Los Alamos Scientific Laboratory report LA-8343-MS (May 1980).

15. W. C. Overton, "Feasibility of Detecting Artificial Magnetic Anomalies in Hydrofractured Rock by Superconducting Gradiometer-SQUID Systems," LoS Alamos Scientific Laboratory report LA-6626-MS (December 1976).

16. D. C. Gates and R. A. Armistead, "Use of Advanced Technologies for Locating Underground Obstacles," Stanford Research Institute, EPRI Report No. 78-20-0 (PB-237690) (August 1974).

17. L. A. Rubin, "Application of a Prototype Borehole Ground-Probing Radar at the Forest Glen Research Site," Conference on Site Exploration in Rock for Underground Design and Construction, March 1978.

18. J. C. Cook, "Radar Transparencies of Mine and Tunnel Rocks," Geophysics 80, pp. 865-885, 1975.

19. R. Aguilerz and H. K. Van Poolen, "Current Status on the Study of Naturally Fractured Reservoirs," The Log Analyst (May-June 1977).

20. J. W. Tester and J. N. Albright, "Hot Dry Rock Energy Extraction Field Test: 75 Days of Operation of a Prototype Reservoir at Fenton Hill, Segment 2, Phase i," LoS Alamos Scientific Laboratory report LA-7771-MS (April 1979).

21. R. Iler, The Chemistry of Silica (John Wiley and Sons, New York, 1979), p. 31 .

22. R. J. O'Connell and B. Budiansky, "Viscoelastic Properties of Fluidsaturated Cracked Solids," Journal Geophys. Res., 82, 5719-5735, 1977.

23. A. J. Kumnick and P. Halleck, "The Influence of Orientation on Fracture Toughness and Tensile Modulus in Berkeley Granite," (to be published).

24. H. D. Murphy and J. W. Tester, "Heat Production from a Geothermal Reservoir formed by Hydraulic Fracturing-Compression of Field and Theoretical Results," SPE Paper 8265, 54th Annual Meeting of Soc. Pet. Eng. of AIME, Las Vegas, Nevada, September 23-26, 1979.

25. H. D. Murphy, "Fluid Injection Profiles Analysis of Wellbore Temperature Surveys," SPE Paper 6783, 52nd Annual AIME Fall Technical Conference and Exhibition, Denver, Colorado, October 9-12, 1977.

26. H. D. Murphy, R. G. Lawton, J. W. Tester, R. M. Potter, D. W. Brown, and R. L. Aamodt, "Preliminary Assessment of a Geothermal Energy Reservoir Formed by Hydraulic Fracturing," Soc. Petr. Engr. J. 17, 317-326 (1977).

27. F. G. West, P. R. Kintzinger, W. D. Purtymun, "Hydrologic Testing Geothermal Test Hole No. 2," Los Alamos Scientific Laboratory report LA-6017-MS (July 1975). 
28. K. Iwai, Fundamental Studies of Fluid Flow through a Single Fracture, Ph.D. Dissertation, Univ. of Calif., Berkeley, 1976.

29. J. C. Sharp, "Fluid Flow through Fissured Media," Ph.D. Thesis, Univ. of London, Imperial College of Science and Technology, 1970.

30. C. Louis, "Stromungsvorgangt in Klutigen Medien und Ihre Wirkung auf die Standsicherheit von Bauwerken und Boschungen im Fels," .Ph.D. Dissertation, Univ. Karlsruhe, 1967, also appears as "A Study of Groundwater flow in Jointed Rock and Its Influence on the Stability of Rock Masses," Rock Mechanics Research Report 10, Imperial College, London, 1969.

31. L. Goldstein and E. M. Sparrow, "Mass Transfer Experiments on SecondaryFlow Vortices in a Corrugated Wall Channel," Int. J. Heat Mass Transfer, Vol. 19, pp. 1337-1339 (1976).

32. P. Rissler, "Determination of the Permeability of Jointed Rock," Ph.D. Dissertation, RWTH (Univ.) AACHEN, English Edition, Vol. $\underline{5}, 1978$.

33. J. C. Sharp and Y. N. T. Maini, "Fundamental Considerations on the Hydraulic Characteristics of Joints in Rocks," Proc. of Symp. on Percolation through Fissured Rock, Stuttgart, 1972.

34. H. D. Murphy, "Roughness Measurements Performed on GT-2 Core .Specimens," internal document, December 31, 1975.

35. R. V. Browning, "TSAAS: Finite Element Thermal Stress Analys is of Axisymetric Solids with Orthotropic Temperature Dependent Material Properties," Los Alamos Scientific Laboratory report LA-5599-MS (May 1974).

36. A. G. Blair, J. W. Tester, and J. J. Mortensen, "LASL Hot Dry Rock Geothermal Project, July 1, 1975-June 30, 1976," Los Alamos .Scientific Laboratory report LA-6525-PR (October 1976).

37. H. Murphy, R. G. Lawton, J. W. Tester, R. M. Potter, D. W. Brown, and R. L. Aamodt, "Preliminary Assessment of a Geothermal Energy Reservoir Formed by Hydraulic Fracturing," Soc. Pet. Eng. 17, 317-326 (August 1977).

38. Fisher, H. N., "An Interpretation of the Pressure and Flow Data for the Two Fractures of the LOS Alamos Hot Dry Rock (HDR) Geothermal System," Proc. of the 18th U.S. Symposium on Rock Mechanics, Keystone, Colorado, (June 22, 1977).

39. H. N. Fisher and J. W. Tester, "An Analysis of the Pressure Transient Testing of a Manmade .Fractured Geothermal Reservoir," Stanford Workshop on Geothermal Reservoir Engineering, Stanford, California, December 1979.

40. R. Pearce and H. D. Murphy, "Roughness Effects on Flow in Hydraulic Fractures: Survey of the Literature," Los Alamos Scientific Laboratory, report (in press). 
41. H. D. Murphy, M. Coxon, and D. M. McEligot, "Symmetric Sink Flow Between Parallel Plates," J. Fluids Engr. 100, pp. 477-484, 1978.

42. H. D. Murphy, "Flow Near the Outlet of Geothermal Energy Reservoir," Los Alamos Scientific Laboratory report LA-7906-T (July 1979).

43. W. W. Willmarth, "Structure of Turbulence in Boundary Layers," Adv. in App 1. Mech. 15, pp. 159-254, Academic Press (1975).

44. J. Laufer, "New Trends in Experimental Turbulence Research," Ann. Rev. of Fluid Mech. 7, pp. 307-326, Annual Reviews, Inc. (1975).

45. L. S. G. Kovasznay, "The Turbulent Boundary Layer," Ann. Rev. of Fluid Mech. 2, pp. 95-112, Annual Reviews, Inc. (1970).

46. R. F. Blackwelder and R. E. Kaplan, "On the Wall Structure of the Turbulent Boundary Layer," J. Fluid Mech. 76, 2, pp. 89-112 (1976).

47. J. W. Tester, R. M. Potter, and R. L. Bivins, "Interwell Tracer Analyses of a Hydraulically Fractured Granite Geothermal Reservoir," .Soc. of Pet. Eng. SPE 8270 (presented at the SPE-AIME 54th Annual Fall Technical Conference and Exhibition, Las Vegas, Nevada, September 23-26, 1979).

48. R. C. Binder, Advanced Fluid Dynamics and Fluid Machinery, Prentice-Ha11, pp. 67 and 306-310, 1951.

49. F. H. Harlow and A. A. Amsden, "Fluid Dynamics, a LASL Monograph," Los Alamos Scientific Laboratory report LA-4700, (June 1971).

50. H. C. H. Armstead, Geothermal Energy, E. and F. N. Spon Ltd., London, pp. 309-310, 1978.

51. T. F. Adams, S. C. Schmidt, and W. J. Carter, "Permeability Enhancement using Explosive Techniques," Paper presented at 1980 Energy Sources Technology Conference, New Orleans, Lou isiana, Feb. 3-7, 1980.

52. C. W. Smith and R. C. Bass, "Puff Too--A Residual Stress Experiment," Trans. Amer. EOS, 60, 952 (Abstract) 1979.

53. C. H. Johansson and P. A. Persson, "Detonics of High Explosives," Academic, pp. 8-13, 1970.

54. H. K. Kutter and C. Fairhurst, "On the Fracture Process in Brasting," Int. J. Rock Mech. Min. Sci. $\underline{8}$, pp. 181-202, 1971.

55. J. P. Gallus and D. E. Pyle, Union 0 il Co.; L. T. Watters, Halliburton Services; SPE Paper 7591.

56. Y. Eckstein, unpublished manuscript, 1979.

57. C. P. Russ and J. D. Forrester, Geologic Map of the State of Idaho, U.S. Geological Survey and Idaho Bureau of Mines and Geology, 1947. 
Summary of Talks, 2nd Annual Hot Dry Rock Geothermal Conference, September 17-18, 1979.

G. Heiken, "Geology of Geothermal Systems," in "Geothermal Energy: An Alternate Energy Source," L. Edwards, ed., Gulf Publ. Co., Houston (in press).

G. H. Heiken, R. V. Fisher, and N. V. Peterson, "A field trip to the Maar Volcanoes of the Fort Rock-Christmas Lake Valley Basin, Oregon," in "Field Guide to Central Oregon," D. Johnston, ed., Oregon Dept. of Geology and Mineral Industries (in press).

G. Heiken, "Holocene Plinian Tephra Deposits of the Medicine Lake Highland, California," in "Field Guide to Central Oregon," D. Johnston, ed., Oregon Dept. of Geology and Mineral Industries (in press).

G. Heiken, "Pyroclastic Flow Deposits," American Scientist, 67, 564-571 (1979).

G. Heiken and J. Eichelberger, "Eruptions at Chaos Crags, Lassen Volcanic National Park, California," Jour. Volc. and Geothermal Res. (in press).

M. Ander, G. Heiken, J. Eichelberger, and S. Huestis, (abs.) "Geologic and Geophysical Investigations of the Chimney Hill Gravity High, NM," Trans. Amer. Geophys. Union (1979).

M. C. Brown, R. B. Duffield, C. L. B. Siciliano, "Hot Dry Rock Geothermal Energy Development Program Annual Report," Los Alamos Scient if ic Laboratory report LA-7807-HDR (1978).

John J. McNamara and E. L. Kaufman, "Hot Dry Rock Geothermal Resource Ownership and the Law," Los Alamos Scient if ic Laboratory report LA-8027-HDR.

M. C. Brown, G. J. Nunz, G. M. Cremer, "Hot Dry Rock Geothermal Energy Development Program Semiannual Report for the Period October 1, 1978-March 31, 1979," Los Alamos Scientific Laboratory report LA-9759-HDR.

E. L. Kaufman and R. W. Vogel, "Energy Policy and Decision Analysis: New Concepts and Mechanisms," Los Alamos Scientific Laboratory report LA-79-7909-MS.

H. D. Murphy, "Flow Near the Outlet of a Geothermal Energy Reservoir, "Los Alamos Scientific Laboratory report LA-7906-T.

D. G. Davis, S. K. Sanyal, "Case History Report on East Mesa and Cerro Prieto Geothermal Fields," Los Alamos Scientific Laboratory report LA-7889-MS.

E. L. Kaufman, C. L. B. Siciliano, "Environmental Analysis of the Fenton Hill Hot Dry Rock Geothermal Test Site," Los Alamos Scientific Laboratory report LA-7830-HDR. 
Preprints from: Third National Congress Pressure Vessel and Piping Division of the American Society of Mechanical Engineers Session on Hot Dry Rock

Utilization, San Francisco, California, June 24-29, 1979, LASL-79-68 (August 1979).

Abstracts: Hot Dry Rock Geothermal Energy, January 1978-August 1979, LASL-79-76.

Reprints: Geothermal Resource Council Annual Meeting, Reno, Nevada, September 24-27, 1979, LASL-79-75.

"Hot Dry Rock Geothermal Energy Development Program, A Brief Summary," LASL-79-72.

"Expanding the Hot Dry Rock Program, Reprinted from the Atom, June 1979, Los Alamos Scientific Laboratory," LASL-79-60.

Preprints: Society of Petroleum Engineers of AIME--Annual Technical Conference and Exhibition, session on Geothermal Engineering, Las Vegas, Nevada, September 23-26, 1979, LASL-79-80.

Description of the Geosciences Division Industrial Staff Member Program, December 1978.

"Mining Earth's Heat: Hot Dry Rock Geothermal Energy," Reprinted from Technology Review, Vo1. 81, Number 4, February 1979, Alumni Association of the Massachusetts Institute of Technology, Cambridge, Massachusetts.

F. West, A. W. Laughiin, "Aquarius Mountain Area Arizona, A Possible HDR Prospect;" Los Alamos Scientific Laboratory report LA-7804-MS.

J. N. Albright, R. L. Aamodt, C. F. Pearson, R. M. Potter, "Microseismicity Associated with Hydraulic Fracturing of Basement Rocks," presented at the American Geophysical Union (AGU) 1979 Fall Meeting, San Francisco, California, December 3-7, 1979.

J. N. Albright, "Hot Dry Rock Geothermal Research and Development in the US: Recent Resuits and Plans for Fenton Hil1," submjtted to European Hot Dry Rock Contractors Conference European Economics Community (EEC), Brussels, Belgium, July 30-31, 1979.

H. D. Murphy, "Hot Dry Rock Geothermal Heat Extraction," submitted to Geothermal Resources Council, 1979 Annual Meeting Program, P.0. Box 98, Davis, California.

H. N. Fisher, "A Case History of Pressure Transient Testing of a Manmade Geothermal Reservoir," submitted to 54th Annual Technical Conference and Exhibition Society of Petroleum Engineers, Las Vegas, Nevada, September 23-26, 1979.

H. D. Murphy, P. Nabholz, S. Faas, "Laboratory Investigations of Combined Natural and Forced Convection in Faults and Fractures," presented at AGU 1979 Spring Meeting, May 30-June 2, 1979, Washington, D.C. 
LA-7466-MAP Residual Bouguer Gravity Anomaly Map of New Mexico. (Aiken, Laughlin, West, 1978).

LA-7656-MS Informal report, Toward Assessing the Geothermal Potential of the Jemez Mountains Volcanic Complex: A

Telluric-Magnetotelluric Survey. (Hermance, 1979).

LA-7657-MS A Time Domain Survey of the Los Alamos Region, New Mexico. (Williston, McNeil, and Associates, 1979).

LA-7693-MS Geothermal Well Log Interpretation Midterm Report. (Sanyal, Wells, Bickham, 1979).

LA-7757-MS "Wet" Geothermal Potential of the Kingman-Williston Region, Arizona. (Goff, 1979).

LA-7804-MS Aquarius Mountain Area, Arizona: A Possible HDR Prospect. (West, Laughlin, 1979).

LA-7922-MS Informal Report, Benefit/Cost Analysis for Research in Geothermal Log Interpretation--Final Report. (Rigby, Reardon, 1979).

LA-7923-MS Uranium, Thorium, and Lead Concentrations and Lead Isotopic Composition of Biotite Granodiorite. (Sample 9527-2b) from LASL Dri11 Holes GT-2. (R. E. Zartment, USGS, 1979).

LA-7953-MS Geophysical Lineaments of Arizona. (Lepley, 1979).

LA-7993-MS Thermal Gradients and Heat Flow Data in Colorado and Wyoming. (Decker, Bucher, 1979).

Maxwe 11, Pettitt, 1979, LASL Reprints from a Symposium of Geothermal Energy and its Direct Uses in the Eastern U.S.

ERDA 77-74 (Dist. Cat. UC-66A), Hot Dry Rock Geothermal Energy: Status of Exploration and Assessment--Report No. 1 of HDR Assessment Panel. 
APPENDIX B

INTERNATIONAL ENERGY AGENCY

IMPLEMENTING AGREEMENT

FOR A PROGRAMME OF RESEARCH,

DEVELOPMENT, AND DEMONSTRATION

ON. HOT DRY ROCK TECHNOLOGY

The Contracting Parties

Considering that the Contracting Parties, being either governments of International Energy Agency ("Agency") countries, governments of other countries invited by the Governing Board of the Agency to be contracting Parties, international organizations or parties designated by their respective governments, wish to take part in the establishment and operation of a Programe of Research and Demonstration on Hot Dry Rock Technology ("Project") as provided in this Agreement;

Considering that the Contracting Parties which are governments of Agency Countries; and the governments of Agency Countries which have designated Contracting Parties (referred to collectively as the "Governments") have agreed in Article 41 of the Agreement on an International Energy Program (the "I.E.P. Agreement") to undertake national programmes in the areas set out in Article 42 of the I.E.P. Agreement, including energy research and development, and have referred in Chapter IV of the Long-Term Co-operation Programme, adopted by the Governing Board of the Agency on 30th January, 1976, to the establishment of a co-operative programme on Geothermal Energy;

Considering that in the Governing Board of the Agency on 28th June, 1977 the Governments approved the Programme as a special activity under Article 65 of the I.E.P. Agreement; 
Considering that the Agency has recognized the establishment of the project as an important component of international co-operation in the field of geothermal energy research and development;

Have agreed as follows:

Article 1

OBJECTIVES

The Contracting Parties, in accordance with the provisions of this agreement, agree to co-operate in research activities on the development of hot dry rock technology. The activities shall be comprised of those of the Fenton Hill Project managed by the Los Alamos Scientific Laboratory (LASL) which is operated by the University of California under a contract with the United States Department of Energy and additional tests, studies, analyses and experiments. These activities shall be known collectively as the Project which is set forth in the Annex hereto.

Article 2

SCOPE OF PROGRAMME

A. Areas of Cooperation.

Areas of cooperation between the Contracting Parties in the activities to be conducted under this Agreement shall include:

1) Exchange of information between the Contracting Parties in the areas set forth in the Annex;

2) Assignment of up to three experts from each Contracting Party for as long as 4 years to participate in the planning, conduct and analysis of the work described in the Annex; and

3) Assignment of a maximum of three additional experts from a Contracting Party at any one time for limited periods of time ( 3 to 6 months). 
B. Department of Energy Responsibility. Aside from the responsibilities of the Executive Committee as set forth in paragraph C of Article III, the U.S. Department of Energy shall have the sole responsibility for the planning, implementation and supervision of the Project. Control of the research activities of the Project in which the contracting Parties take part shall be exercised by DOE in accordance with the aforementioned contract.

C. Participation in Meetings.

The experts of each Contracting Party have the right to participate in the meetings of LASL review or planning groups concerned with the Project, and may make suggestions to those groups.

D. Availability of Data.

All data and information associated with the planning, conduct and analys is of the work described in the Annex shall be made available to the Contracting Parties and its personnel assigned.

E. Reports.

Reports of joint activities carried out under this Agreement generally shall be published as joint publications, as mutually agreed by the Contracting Parties.

F. Arrangements for Personnel Assignments.

All cooperative activities involving assignments of the experts shall be carried out in accordance with specific arrangements between the sending Contracting Party and LASL. 


\section{Article 3}

\section{STEER ING COMMITTEE}

A. Composition.

There is hereby established a Steering Committee consisting of four members. Each Contracting Party shall designate members of the Steering Committee in proportion to its financial contribution to the Project. In addition, each Contracting Party may designate technical advisors to attend the meetings of the Steering Committee.

B. Procedures

The Steering Committee shall carry out its responsibilities set forth below in accordance with the following procedures:

1) The Steering Committee shall meet in regular session twice each year at LASL. A special meeting shall be convened upon the request of any Contracting Party which can demonstrate the need therefor.

2) The Steering Committee shall each year elect a Chairman and one or more Vice-Chairmen.

3) The Steering Committee may establish such subsidiary bodies and rules of procedure as are required for its proper functioning. A representative of the Agency may attend meetings of the Steering committee and its subsidiary bodies in an advisory capacity.

4) At least twenty-eight days before each meeting of the Steering Committee, notice of the time, place and purpose of the meeting shall be given to each Contracting Party and to other persons or entities entitled to attend the meeting. Notice need not be given to any person or entity otherwise entitled thereto if notice is waived before or after the meeting. 
5) The quorum for the transaction of business in meetings of the Steering Committee shall be one-half of the members plus one.

6) Where this Agreement requires the Steering Committee to act by unanimity, this shall require the agreement of each member present and voting at the meeting at which the decision is taken, and in respect of all other decisions and recommendations for which no express voting provision is made in this agreement, the Steering Committee shall act by a majority vote of those present and voting. With the agreement of each Contracting Party a decision or recommendation may be made by telex or cable without the necessity for calling a meeting. The Chairman of the Steering Committee shall have the responsibility of ensuring that all Contracting Parties are informed of each decision or recommendation made pursuant to this Article.

C. Responsibilities.

The Steering Committee shall have the following responsibilities:

1) Adopt by unanimity any major changes in the scientific, technical, schedule and financial terms of the Annex hereto. A "major change" means any modification to the Project defined in the Annex which would result in a change of more than $24 \%$ in the annual contribution of each Contracting Party other than the U.S. Department of Energy or a variation in the schedule in excess of three months.

2) Propose such rules and regulations as may facilitate the sound management of the Project.

3) Review each year's program of work together with an indicative program of work for the following year. 
4) Review the progress of the work whenever any Contracting Party so requests.

5) Consider any matters submitted to it by a Contracting Party.

D. Reports

The Steering Committee shall, at least annually, provide the Agency with periodic reports on the progress of the activities.

\section{ARTICLE 4}

FINANCE

A. Determination of Contributions.

In consideration of the participation afforded and data received under this Agreement, each contracting Party other than the U.S. Department of Energy shall make a cash contribution equivalent to 25 percent of the annual U.S. Department of Energy funding of the Project budget, up to 2.5 million dollars per year calculated from 1st October 1979. In addition, each Contracting Party, other than DOE, shall spend up to $\$ 500,000$ per year for the support of its personnel assigned to work on the Fenton Hill Project. Such costs shall include salaries, living and travel expenses. The contributions of all Contracting Parties other than the U.S. Department of Energy shall be limited to a maximum of $50 \%$ of the DOE Project costs for the period covered by the Agreement.

B. Form of Contributions.

The cash contribution under paragraph $A$ above shall be made in U.S. dollars in quarterly payments in advance upon receipt of an invoice and in accordance with procedures to be identified by DOE prior to the first payment. 
C. Costs of Parties.

Aside from the contributions described in paragraph $A$ above each Contracting Party shall bear all costs of its own participation in the Project.

D. Availability of Funds.

Each Contracting Party's obligation under the Agreement is subject to the availability of appropriated funds. In the event of the inability of the U.S. Department of Energy to carry out the Project as set forth in the Annex, in whole or in part, for lack of appropriated funds, the settlement of payments from each Contracting Party to the U.S. Department of Energy and the furn ishing of information from the U.S. Department of Energy to each Contracting Party shall be negotiated on a pro-rate basis.

E. Financial Records.

DOE shall maintain complete financial records for contributions from the other Contracting Parties which shall clearly account for all such funds coming into the possession of the U.S. Department of Energy. The U.S. Department of Energy shall annually provide a certification to the other Contracting Parties of the amount of such funds utilized; such certification shall be transmitted by DOE to the other Contracting Parties within three months following the end of each fiscal year and bearing a certification common at the U.S. Department of Energy. Overpayments of funds by a Contracting Party within a fiscal year as determined on the basis of the above certification shall be credited to the contribution required by that Contracting Party in the following year. Any overpayments at the termination of the Agreement are to be repaid without delay. The U.S. Department of Energy shall provide to 
the other Contracting Parties within 3 months after the end of the fiscal year an accounting of the total funds expended on the Project for the fiscal year.

\section{Article 5}

\section{INFORMATION AND INTELLECTUAL PROPERTY}

A. Right to Publish.

Subject only to patent and copyright restrictions, Contracting Parties shall have the right to publish all information provided to or arising from this Agreement, except proprietary information. However, in order that public disclosure of inventions will not adversely affect the particular interest of the Contracting Parties, patent approval for release or publication of results from this Agreement shall be obtained from the U.S. Department of Energy prior to any release or publication.

B. Confidential Information.

If a Contracting Party has access to confidential information which would be useful to the activities under this Agreement, such information may be communicated to personnel within the U.S. Department of Energy and LASL charged with the management of the Hot Dry Rock Geothermal Energy Program but shall not be accepted for the Project except as agreed in writing between the U.S. Department of Energy and the Contracting Party which supplies such information and on terms and conditions stipulated in such writing.

C. Proprietary Information.

The Contracting Parties shall take all necessary measures in accordance with this Article, the laws of their respective countries and international law to protect proprietary information provided to or arising from the Agreement. For the purposes of this Agreement, 
proprietary information shall mean information of a confidential nature such as trade secrets and know-how (for example, computer programmes, design procedures and techniques, chemical composition of materials, or manufacturing methods, processes or treatment) which is appropriately marked, provided such information:

1) Is not generally known or publicly available from other sources;

2) Has not previously been made available by the owner to others without obligation concerning its confidentiality, and

3) Is not already in the possession of the recipient Contracting Party of its Contractor without obligation concerning its confidentiality.

It shall be the responsibility of each Contracting Party supplying proprietary information to identify the information as such and so ensure that it is appropriately marked.

D. Production of Relevant Information by Governments.

The Contracting Parties should encourage the governments of all Agency Participating Countries to make available or to identify to Contracting Parties all published or otherwise freely available information known to them that is relevant to the Agreement.

E. Provision of Available Information Contracting Parties. Each Contracting Party shall provide to the other Contracting Parties all previously existing information, and information developed independently of the cooperative activities under this Agreement, which is relevant to the work to be conducted under this Agreement and which is freely at the disposal of the Contracting Party and the transmission of which is not subject to any contractual and/or legal limitations. 
F. Arising Inventions

Inventions made or conceived in the course of or under the Agreement (arising inventions) shall be owned by each Contracting Party in its own country and by DOE in third countries. Each Contracting Party agrees to grant to the other Contracting Parties a non-exclusive, royalty-free license to all such arising inventions.

G. Report on Work Performed.

Reports of all work performed under this Agreement and the results thereof, including studies, assessments, analyses, evaluations and other documentation, but excluding proprietary information, shall be issued in the form of annual joint reports of the Contracting Parties.

H. Inventors.

Each Contracting Party will, without prejudice to any rights to inventors under its national laws, take necessary steps to provide the cooperation from its inventors required to carry out the provisions of this Article. Each Contracting Party will assume the responsibility to pay awards or compensation required to be paid to its employees according to the laws of its country.

Article 6

ASSIGNMENT OF PERSONNEL

A. Procedures.

For each assignment of personnel pursuant to Article 2 the following procedures shall be applied:

1) Each Contracting Party shall submit its nominations to the U.S. Department of Energy at least three months prior to the expected assignment date. Each such nomination shall specify the 
qualifications of the expert and the intended work plan to be followed by the expert at LASL.

2) The U.S. Department of Energy shal1, as soon as practicable, notify the assigning Contracting Party of the acceptability of the assignment; and

3) The assignment of personnel may be implemented only after the assigning Contracting Party and LASL have concluded a personnel assignment agreement setting forth the specific terms applicable to the assignment.

B. Expenses.

All personal expenses associated with an assignment shall be borne by the assigning Contracting Party unless the U.S. Department of Energy agrees otherwise. Such expenses shall include, but not be limited to, salaries, costs of travel, insurance and living expenses of the assigned personnel.

C. Assistance.

The U.S. Department of Energy shall provide all necessary assistance to the Contracting Parties' assigned personnel and to the ir families as regards administrative formalities, travel arrangements, and other personal arrangements.

D. Work Rules and Safety.

The assigned personnel of the Contracting Parties shall conform to the general rules of work and safety regulations in force at LASL. E. Status of Assigned Personnel.

Assigned personnel shall in no way be deemed to be employees of LASL or the U.S. Department of Energy by virtue of their assignment. 
F. Legal Responsibility.

The assigning Contracting Party agrees to indemnify and hold harmless the U.S. Department of Energy, and any person acting on its behalf for any damages, liabilities or costs arising out of the assigninent of personnel under an agreement entered into in accordance with sub-paragraph $A(3)$ of this Article; provided, however, this provision shall not apply to damages, liabilities or costs insofar as and to the extent that they arise out of the gross negligence or intentional misconduct of the U.S. Department of Energy or persons acting on its behalf.

\section{Article 7 \\ LEGISLATIVE PROVISIONS}

A. Accomplishment of Formalities.

Each Contracting Party shall request the appropriate authorities of its country (or its member States in the case of an international organization) to use their best endeavours, within the framework of applicable legislation, to facilitate the accomplishment of formalities involved in the movement of persons, the importation of materials and equipment and the transfer of currency which shall be required to conduct the Project.

B. Applicable Laws

In carrying out this agreement, the Contracting Parties shall be subject to the appropriation of funds by the appropriate governmental authority, where necessary, and to the constitution, laws, and regulations applicable to the respective Contracting Parties, including, but not limited to laws establishing prohibitions upon the payment of 
commissions, percentages, brokerage or contingent fees to persons retained to solicit governmental contracts and upon any share of such contracts accruing to government officials.

C. Decisions of Agency Governing Board.

The Contracting Parties shall take account, as appropriate, of the Guiding Principles of Cooperation in the Field of Energy Research and Development and any modification thereof, as well as other decisions of the Governing Board of the Agency in that field. The termination of the Guiding Principles shall not affect this agreement, which shall remain in force in accordance with the terms hereof.

D. Settlement of Disputes. Any dispute among the Contracting Parties concerning interpretation or the application of this Agreement which is not settled by negotiation or other agreed mode of settlement shall be referred to a tribunal of three arbitrators to be chosen by the Contracting Parties concerned who shall also choose the Chairman of the tribunal. Should the Contracting Parties concerned fail to agree upon the composition of the tribunal or the selection of its Chairman, the President of the International Court of Justice shall, at the request of any of the Contracting Parties concerned, exercise those responsibilities. The tribunal shall decide any such dispute by reference to the terms of this Agreement of any applicable laws and regulations, and its decision on a question of fact shall be final and binding on the Contracting Parties concerned.

E. Right to Enter into Other Arrangements. Nothing in this Agreement shall affect the Contracting Parties' rights to enter into other arrangements for the conduct of activities associated with the subject matter of this Agreement. 
Article 8

ADMISSION AND WITHDRAWAL OF CONTRACTING PARTIES

A. Admission of New Contracting Parties: Agency Countries. Upon the invitation of the Contracting Parties, acting by unanimity, admission to this Agreement shall be open to the government of any Agency Participating Country (or national agency, public organization, private corporation, company or other entity designated by such government), which signs or accedes to this Agreement, accepts the rights and obligations of a Contracting Party, and is accepted for participation by the Contracting Parties, acting by unanimity. Such admission of a Contracting Party shall become effective upon the signature of this Agreement by the New Contracting Party of its accession thereto and its giving notice of participation and the adoption of any consequential amendments thereto.

B. Admission of New Contracting Parties: Other OECD Countries. The government of any Member of the Organization for Economic Co-operation and Development which does not participate in the Agency may, on the proposal of Contracting Parties acting by unanimity, be invited by the Governing Board of the Agency to become a Contracting Party to this Agreement (or to designate a national agency, public organization, private corporation, company or other entity to do so), under the conditions stated in paragraph $A$ above.

C. Participation by the European Communities.

The European Communities may participate in this Agreement in accordance with arrangements to be made by the Contracting Parties, acting by unanimity. 
D. Contributions.

The Contracting Parties may require, as a condition to admission to participation, that the new Contracting Party shall contribute (in the form of cash, services, materials or intellectual property) an appropriate proportion of the prior budget expenditure.

E. Replacement of Contracting Parties.

With the agreement of the Contracting Parties, acting by unanimity and upon the request of a government, a Contracting Party designated by that government may be replaced by another party. In the event of such replacement, the replacement party shall assume the rights and obligations of a Contracting Party as provided in paragraph $A$ above and in accordance with the procedure provided therein.

F. Withdrawal.

Any Contracting Party may withdraw from this Agreement either with the agreement of the Contracting Parties, acting by unanimity, or by giving twelve months written Notice of Withdrawal to the Executive Director of the Agency, such notice to be given not less than one year after the date hereof. The withdrawal of a Contracting Party under this paragraph shall not affect the rights and obligations of the other Contracting Parties.

G. Change of Status of Contracting Party.

A Contracting Party other than a government or an international organization shall forthwith notify all the other Contracting Parties of any significant change in its status or ownership, or of its becoming bankrupt or entering into liquidation. All the Contracting Parties jointly shall determine whether any such change in status of a Contracting Party significantly affects the interests of the other 
Contracting Parties; if the other Contracting Parties so determine, acting by unanimity:

1) That Contracting Party shall be deemed to have withdrawn from the Agreement under paragraph $F$ above on a date to be fixed by the other Contracting Parties, acting by unanimity; and

2) The Contracting Party shall invite the government which designated that Contracting Party to designate, within a period of three months of the withdrawal of that Contracting Party, a different entity to become a Contracting Party. If approved by the other Contracting Parties, acting by unanimity, such entity shall become a Contracting Party with effect from the date on which it signs or accedes to this Agreement and gives the Executive Director of the Agency a notice of participation.

H. Failure to Fulfill Contractual Obligations. Any Contracting Party which fails to fulfill its obligations under this Agreement within sixty days after its receipt of notice specifying the nature of such failure and invoking this paragraph, may be deemed by the other Contracting Parties, acting by unanimity, to have withdrawn from this Agreement.

\section{Article 9}

FINAL PROVISIONS

A. Term of Agreement.

This Agreement shall enter into force on 1st 0ctober 1979 and remain in force for an initial period of four (4)years, and shall continue in force thereafter if the Contracting Parties so decide, acting by unan imity. 
B. Legal Relationship of Contracting Parties. Nothing in this Agreement shall be regarded as constituting a partnership between any of the Contracting Parties.

C. Amendment.

This Agreement may be amended at any time by the Contracting Parties, acting by unanimity. Such amendments shall come into force in a manner determined by the Contracting Parties, acting by unanimity.

D. Deposit.

The original of this Agreement shall be deposited with the Executive Director of the Agency and a certified copy thereof shall be furnished to each Contracting Party. A copy of this Agreement shall be furnished to each Agency Participating Country, to each Member country of the Organization for Economic Co-operation and Development and to the European Communities. 
SECOND ANNUAL HOT DRY ROCK GEOTHERMAL ENERGY INFORMATION CONFERENCE, SANTA FE, NEW MEXICO

The second Annual Hot Dry Rock Geothermal Energy Information Conference was held in Santa Fe, New Mexico, 17-18 September 1979. One and one-half days of technical sessions were followed by a special tour of Fenton Hill.

The purpose of the conference was to provide a broad overview of the Hot Dry Rock Geothermal Energy Program. The topics for discussion, speakers, and agenda were chosen to provide a review most informative for industrial firms that might be considering future activities in hot dry rock geothermal development. Thus, the presentations addressed technical and nontechnical issues, data, and results to date with emphasis on a brief review of past tests at Fenton $\mathrm{Hill}$, results of recent experiments, the drilling of Energy Extraction Hole No. 2 (EE-2), and an overview of exploration work for a second hot dry rock experimental site. Approximately 230 attendees participated in the conference, representing a broad spectrum of industrial firms, university researchers, and investment interests. Representatives from 11 countries attended and attested to the growing international interests and activities in hot dry rock.

A compilation of the abstracts of the talks has been prepared and will be distributed to the attendees and other interested individuals. The final agenda for the conference is attached. 


\author{
SECOND ANNUAL \\ HOT DRY ROCK GEOTHERMAL ENERGY \\ INFORMATION CONFERENCE
}

September 17-18, Santa Fe, New Mexico

\title{
AGENDA
}

\section{Monday, 17 September}

Session I - E. F. Hammel, LASL. Presiding

$$
\begin{aligned}
& \text { 8:45 AM } \\
& 8: 50-9: 00 \\
& 9: 00-9: 15 \\
& 9: 15-9: 45
\end{aligned}
$$

CALL TO ORDER

GREETING AND WELCOME - Bruce King, Governor of New Mexico

CONFERENCE KEYNOTE, Frank DiLUzio, LASL

THE FEDERAL GEOTHERMAL ENERGY DEVELOPMENT PROGRAM -

Bennie DiBona, Director, DOE Division of Geothermal

Energy

$9: 45-10: 15$

THE HOT DRY ROCK PROGRAM: STATUS OVERVIEW AND MEETING INTRODUCTION - Greg Nunz, LASL Prog. Mgr.: HDR Program

$$
\star \star * \text { COFFEE BREAK } * * *
$$

Session II - W. Porter Grace, DOE/AL00-SPD, Assoc. Prog. Mgr.: HDR Program, Presiding

$$
\begin{array}{r}
\text { 10:35 - 10:55 AM HDR GEOTHERMAL CONCEPTS AND HISTORICAL PERSPECTIVES - } \\
\text { R. B. Duffield, LASL Consultant, HDR Program }
\end{array}
$$

$10: 55-11: 40$ REVIEW OF FENTON HILL (SITE 1) EXPERIMENTS TO DATE -

J. W. Tester, LASL; Mgr. Reservoir Engrg., HDR Program $11: 40-12: 00$ PRESENT AND FUTURE FENTON HILL ACTIVITIES - R. W. Spence, LASL, Project Mgr.: Fenton Hill Project, HDR Program 
Session III - S. Prestwich, DOE/IDO0, Presiding

HDR RESOURCE EVALUATION AND SITE SELECTION -

A. W. Laughlin, LASL, Mgr.: Resource Eval. \& Site

Explor., HDR Program

$1: 55-2: 05$

EASTERN SITE CHARACTERIZATION - C. Schubert, D'Appolonia

Consulting Engineers, Inc.

$2: 05-2: 15$

WESTERN SITE CHARACTERIZATION - F. Kresse, Harding-Lawson Associates

$2: 15-2: 45$

DRILLING WELL EE-2: START OF THE PHASE 2 SYSTEM -

R. E. Williams, LASL, Mgr.: FH Drilling \& Completions,

HDR Program

$2: 45-3: 00$

CEMENTING AND COMPLETION - R. A. Pettitt, LASL,

FH Drilling and Completions Staff, HDR Program

$3: 00-3: 15$

INSTRUMENTATION DEVELOPMENT AND TEST FACILITIES -

B. R. Denn is, LASL, Mgr.: Mtls., Instrumentation \&

Equipt. Devt., HDR Program

$$
\star \star \star \text { COFFEE BREAK } * \star *
$$

Session IV - E. Wellbaum, Republic Geothermal Inc., Presiding

3:35 - 3:55 PM ECONOMIC ANALYSIS OF HDR/ELECTRIC SYSTEMS - G. E. Morris, LASL, Institutional \& Industrialization Activities Staff, HDR Program

$3: 55-4: 10$

HDR DRILLING COST ESTIMATES - R. Nicholson, Terra

Services, Inc.

4:10 - 4:25 HDR COMMERCIAL ECONOMICS - J. Hankin, Bechtel Corp.

4:25 - 4:40 PLANNING NEEDS FOR ALTERNATE ENERGY RESOURCES -

S. K. Bazant, Plains Electric Generation and

Transmission Cooperative, Inc.

$4: 40-5: 00$

PERFORMANCE AND ECONOMIC ANALYSIS OF AN HDR "HUFF-\&-PUFF"

PROCESS - L. Kern, Atlantic Richfield Corp.

* * * END FIRST DAY TECHNICAL SESSIONS * * *

EVENING

$5: 30-7: 00$ PM

No Host Reception, Inn at Loretto

7:00 - 9:00

Speaker: Bob Greider, Intercontinental Energy, Inc. 
Tuesday, 18 September

Session V - P. R. Franke, LASL, Mgr.: Planning and Administration, HDR Program, Presiding

$8: 30-8: 50$ AM

GEOTHERMAL DEVELOPMENTS IN THE FEDERAL REPUBLIC OF

GERMANY - R. Hanel, 0. Kappelmeyer, J. Wohlenberg,

F.R.G. Geological Survey

$8: 50-9: 10$

AN UPDATE ON EEC-SPONSORED HDR ACTIVITIES - C. M. Pearson,

Cambourne School of Mines, UK

$9: 10-9: 30$

LEGAL ISSUES - R. Meyer, Western Energy Planners

$9: 30-9: 45$

SEISMIC MONITORING - J. N. Albright, LASL, Reservoir

Engineering Staff, HDR Program

$9: 45-10: 05$

ENVIRONMENTAL MONITORING OF HDR DEVELOPMENT -

F. R. Miera, Jr., LASL, Mgr.: FH Environmental

Surveillance, HDR Program

* * * COFFEE BREAK $* * *$

Session VI - P. M. Wright, UURI/Earth Science Laboratory, Presiding $10: 25$ - 10:40 AM

FRACTURE MAPPING BY SEISMIC \& ACOUSTIC TECHNIQUES -

J. N. Albright, LASL, Reservoir Engineering Staff,

HDR Program

$10: 40-10: 55$

ADVANCED RESERVOIR MAPPING CONCEPTS - R. M. Potter,

LASL, Reservoir Engineering Staff, HDR Program

$10: 55-11: 10$

ANALYSIS OF PRESSURE TRANSIENT TESTING - H. N. Fisher,

LASL, Reservoir Engineering Staff, HDR Program

$11: 10-11: 25$

HEAT EXTRACTION AND FLUID FLOW MODELING - H. D. Murphy,

LASL, Reservoir Engineering Staff, HDR Program

$11: 25-11: 40$

HDR GEOCHEMISTRY C. 0. Grigsby, LASL, Analytical \&

Experimental Support Staff, HDR Program

$11: 40-12: 00$

PREVIEW OF FENTON HILL TOUR - R. H. Hendron, LASL,

Fenton Hill Test Site Manager, HDR Program

* * * END TECHNICAL * * *

12:30 PM

Fenton Hill Tour Bus No. 1 - Departs Hilton

1:30 PM

Fenton Hill Tour Bus No. 2 - Departs Hilton 
APPENDIX D

FIELD EXPERIMENTS CONDUCTED DURING FY79

\section{Expt. \\ No. Date Description \\ $186 \quad$ High back-pressure \\ long-term flow.}

$188 \quad 10 / 12 / 78$ Downhole spinner survey in GT-2B to measure flow from fracture intersections.

189 10/13/78 Na-fluorescein dye tracer injected in EE-1 and mon itored output in GT-2B.

190 10/23/78 Low back-pressure impedance measurement after Exp. 186.

$19211 / 19 / 78$ Radioactive 82BR tracer experiment to determine flow of fluid up behind the EE-1 casing and detect arrival of tracer in GT-2B borehole.

$1912 / 12 / 79$ Caliper survey in EE-1 using the Sperry-Sun multishot to orient the caliper tool.

$1942 / 14 / 79$ Bromine tracer study in EE-1 and GT-2B following the recementing of $\mathrm{EE}-1$ casing.

$1962 / 26$ to Kine-Frac experiment to $2 / 28 / 79$ test the use of a propellant explosive mixture to initiate fractures in the EE-1 wellbore.

\section{Results}

A significant reduction in system impedance was obtained in this experiment. No change in heat transfer area was noted.

Changes in the flow distribution measured during this experiment relative to those of the 75-day test indicate the opening of a vertical fracture at the bottom of the GT-2B wellbore.

The volume of the fracture system under high back pressure was was measured.

Experiment terminated after 4 days due to EE-1 cement failure. The measured impedance was 5.7 psi/ gpm.

The flow rate of fluid exiting behind the EE-1 casing was determined to be $40 \mathrm{gpm}$.

Some correlation between features detected in this survey and those of a USGS televiewer survey were noted.

The tracer was released and followed in both boreholes. Further definition of fracture openings was obtained.

Several firings of the Kine-Frac system at different depths in EE-1 were made. Later pressure and tracer tests showed no evidence of wellbore fracturing. (See Expt. 208). 
3/14/79 High Flow/High Pressure Pump Test to ensure integrity of recement work in EE-1 and to determine pressurization and breakdown behavior. Flow rate of $10 \mathrm{bbl} / \mathrm{min}$ to a wellhead pressure of 2800 psi for about $6 \mathrm{~h}$ was sustained.

$1953 / 21 / 79$ To extend and enlarge fractures originating in the open-hole region of EE-1 (9600 to $10000 \mathrm{ft})$ and to provide improved connections with GT-2B.

$2043 / 22 / 79$ Measure the high backpressure flow impedance in the EE-1/GT-2B fracture system.

$2053 / 28 / 79$ Temperature Survey in both GT-2B and EE-1 to determine frarture intersections with the wellbores following Expt. 203, 195, and 204.

208 4/3/79 Caliper Survey of EE-1 Borehole to determine extent and depth of obstruction in the EE-1 wellbore that appeared after the Kine-Frac test.

$209 \quad 7 / 26 / 79$ Caliper Survey in EE-1 to determine suitable location for insertion of Pack-Perf

$211 \quad 7 / 27 / 79$ Flowing Temperature Log in EE-1.

209A 7/31/79 A repeat of Expt. 209, Caliper of EE-1, in preparation for the insertion of Pack-Perf system.
The mapping of numerous microseismic signals in this experiment along with measurement of the flow into GT-2B was used in modeling the new fracture system.

Se ismic measurements indicated a general upward growth of the fracture with time. An aseismic zone was detected near the original fracture system.

A value of impedance of $10-12 \mathrm{psi} /$ gpm was measured.

Recovery temperature profiles were obtained in both boreholes.

Survey indicated obstruction resulted from pieces of cement presumably dislodged from the Kine-Frac tests.

Survey indicated complete removal of cement from the open hole by underreaming section of EE-1.

Main fracture entrace in EE-1 open hole located at $9620 \mathrm{ft}$.

Confirmed results from Expt. 209. 
GRACE, SHURSEN, AND MOORE ASSOCIATES DRILLING PLAN FOR EE-2

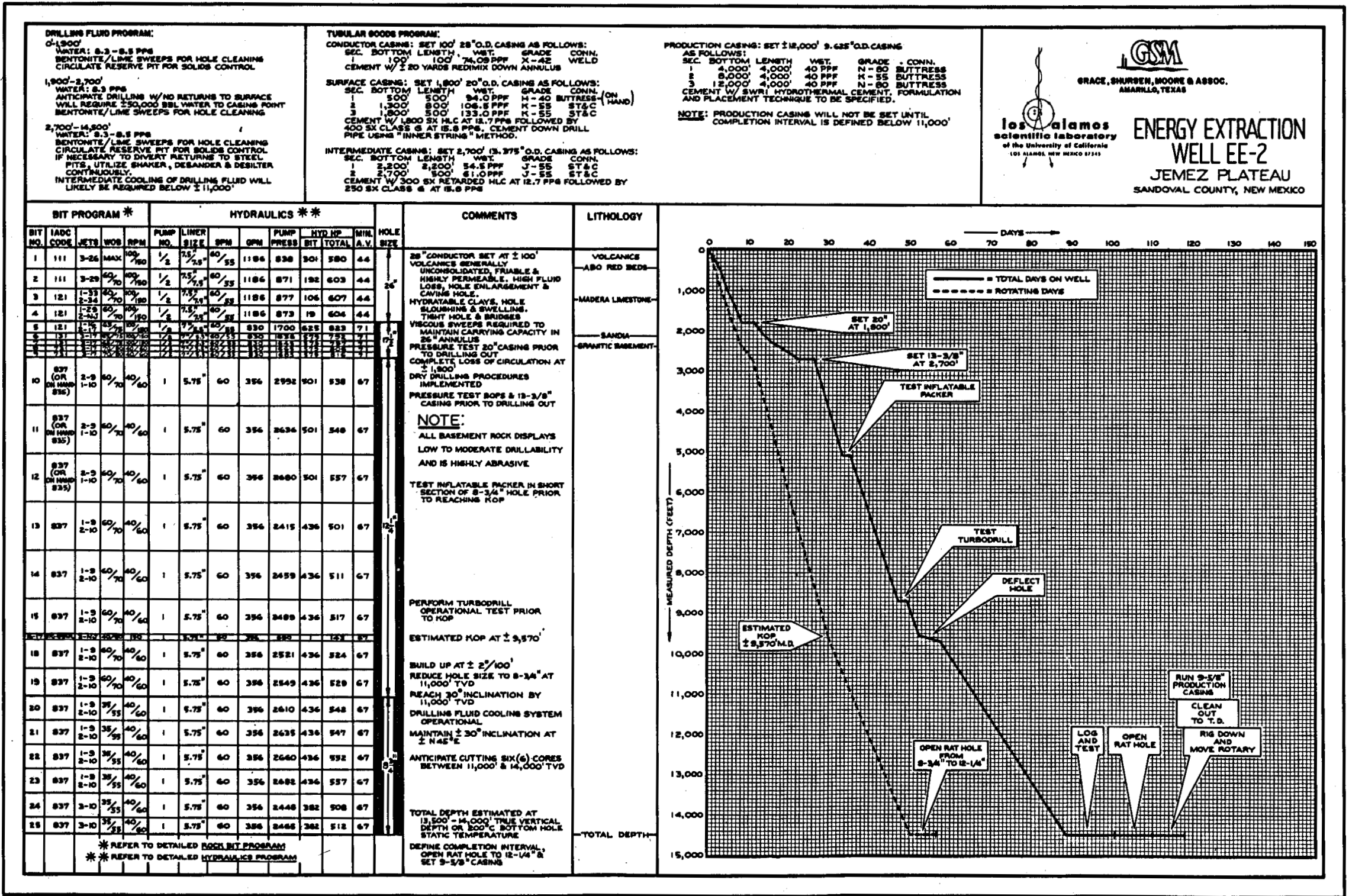


Expt.

No. Date Description

186

188 10/12/78 Downhole spinner survey in GT-2B to measure flow from fracture intersections.

189 10/13/78 Na-fluorescein dye tracer injected in EE-1 and monitored output in GT-2B.

$19010 / 23 / 78$

$19211 / 19 / 78$ Radioactive 82BR tracer experiment to determine flow of fluid up behind the EE-1 and monitored output in GT-2B.

191 11-19-78 Radioactive 82BR tracer experiment to determine flow of fluid up behind the EE-1 casing and detect arrival of tracer in GT-2B borehole.

$1912 / 12$ to Caliper survey was run in GT-2 12/13/78 and EE-1 boreholes. The caliper tool was oriented using Sperry-Sun mu1tishot device.

191 2/12/79 Caliper survey in EE-1 using the Sperry-Sun multishot to orient the caliper tool.

$1942 / 14 / 79$ Bromine tracer study in EE-1 and GT-2B following the recementing of EE-1 casing.

196 2/26 to Kine-Frac experiment to test $2 / 28 / 79$ the use of a propellant explosive mixture to initiate fractures in the EE-1 wellbore. 
3/14/79 High flow/high pressure pump test to ensure integrity of recement work in EE-1 and to determine pressurization and breakdown behavior. Flow rate of $10 \mathrm{bbl} / \mathrm{min}$ to a wellhead pressure of 2800 psi for about $6 \mathrm{~h}$ was sustained.

$1953 / 21 / 79$ To extend and enlarge fractures originating in the openhole region of EE-1 (9600 to $10000 \mathrm{ft}$ ) and to provide improved connections with GT-2B.

$2043 / 22 / 79$ Measure the high back-pressure flow impedance in the EE-1/ GT-2B fracture system.

$2053 / 28 / 79$ Temperature surveys in both GT-2B and EE-1 to determine fracture intersections with the wellbores following Expts. 203, 195, and 204.

208 4/3/79 Caliper survey of EE-1 borehole to determine extent and depth of obstruction in the EE-1 wellbore that appeared after the Kine-Frac test.

$2097 / 26 / 79$ Caliper Survey in EE-1 to determine suitable location for insertion of Pack-Perf for Expt. 213.

$2117 / 27 / 79$ Flowing temperature $\log$ in EE-1.

209A 7/31/79 A repeat of Expt. 209, Caliper of EE-1, to confirm insertion of Pack-Perf system.

The remainder of this fiscal year through September 30th was spent in the workover operations on EE-1, attempting to insert the Pack-Perf system. The insertion of this equipment failed and much effort was spent trying to remove the equipment from the wellbore. 


\section{APPENDIX G \\ RESEARCH EVALUATION AND \\ SITE SELECTION}

Objectives. The primary objective of this effort is the detailed evaluation of the hot dry rock potential of a previously selected prospect comprising an area of approximately 100 square miles ( 3 townships). This evaluation shall consist of determination of the geothermal gradient present within the prospect and an assessment of the expected reservoir permeability at a depth where the temperature appears to be sufficiently high for utilization for either electrical generation or direct application of thermal energy (DATE). The evaluation shall conclude with recommendations for a specific deep exploratory drilling program, including site locations, specified additional exploration work, abandonment of the prospect, or perhaps testing for the existence of possible hydrothermal systems.

A secondary objective is to record the contribution of this detailed prospect evaluation to the development of a cost-effective exploration program for locating HDR deposits and selecting sites for their development.

In summary, the objectives of this Target Prospect evaluation shall be:

(1) determination of thermal gradient,

(2) estimation of reservoir rock permeability at depth,

(3) recommendations for further action, and

(4) identification of HDR contribution exploratory techniques.

Background. Although differences exist among estimates of the size of the HDR resource base, all agree that it is immense. If even a fraction of this resource base can eventually be tapped as an alternate energy source, the effect upon the world's budget will be tremendous. The first step in moving from resource base to resource has been made at the LASL Fenton Hill site in northern New Mexico, where it has been demonstrated that artificial geothermal systems can be created in and energy extracted from hot dry rocks.

To advance from resource base to resource, two other demonstrations must be made concurrently. The economic feasibility of the extraction system must be evaluated and additional sites must be selected to demonstrate the widespread nature of the resource. This effort addresses the second of these demonstrations, locating and evaluating additional sites. 
In 1971, several LASL staff members conceived the HDR geothermal energy extraction concept, and the search began for a region in which to test this method. The intent of the exploration was to provide a drill site at which to develop a method for extracting geothermal energy that was broadly applicable, particularly in regions where natural hydrothermal resources are lacking, or in portions of geothermal systems where hydrothermal resources are known not to exist. Because the first site was intended to be used as a test of the extraction method, it was decided to minimize costs by selecting an area where adequate rock temperatures could be reached at moderate depths. Thus, at the first drill site, it was hoped that impermeable rock (less than 0.01 millidarcy) at a temperature of at least $200^{\circ} \mathrm{C}$ would be encountered at depths of less than 3 $\mathrm{km}$. In addition, it was recommended that to prevent fluid leakage to the surface, the top of the artificially generated fracture should lie at a depth below the surface at least equal to the diameter of the fracture. Environmental criteria for the drill site such as low seismic activity, minimal disturbance of land, water, vegetation, and aesthetics were also proposed.

The area selected by LASL for the location of Geothermal Test Hole No. 2 (GT-2) and the first borehole of the energy extraction system (EE-1) is at Fenton Hill, within the Jemez Mountains, Sandoval County, New Mexico. It is located on the western flank of the Valles Caldera, about 32-km west of the city of Los Alamos, with access provided by the New Mexico Highway 126. The area lies within a large burned-over area on US Forest Service land where the environmental impact of drilling has been minimal. In terms of regional geologic setting, the Valles Caldera is a large, young silicic volcanic complex occurring along the western margin of the Rio Grande Rift.

The selection of the Fenton Hill site was unique in the sense that the goal of LASL, as originators of the hydraulic-fracture concept for HDR geothermal energy extraction, was to locate a test site where the extraction method could be tested and demonstrated. Location of impermeable rock suitable for an experimental program to test the feasibility of the extraction technology was of primary importance. At the time the Jemez Mountain region was selected, no formal geothermal energy project existed at LASL, and evaluation of regional and areal geology for targeting a drill site was done by volunteers in the evenings and on weekends. This limited the area that could be evaluated to one near Los $A l$ amos. In addition, only limited funding was available for regional evaluation 
and collection of new data. Because of these two constraints, considerable reliance was placed on published maps and reports, and on open-file maps and reports made available by the Department of Interior, USGS.

Despite the unique purpose anticipated for the Fenton Hill area, its selection and evaluation proceeded logically in a series of phases or steps. The first phase consisted of the selection of a suitable general region (the caldera) and the collection and assessment of available data for that region. During the second stage, new data were collected and evaluated, narrowing the region to the west side of the caldera. In the third phase, a slim hole was drilled into the Precambrian basement rocks, confirming that the western side of the caldera contained suitable hot dry rock. At the end of the third phase, the Fenton Hill area was selected for deeper drilling and as a test site for the hydraulic-fracture and energy-extraction experiments.

As stated previously, the area available for evaluation by project personnel was restricted because of shortages of manpower and funding. Fortunately, LASL is situated on the eastern flank of the Valles Caldera, one of the youngest large calderas in the II.S., a recognized geothermal system, and designated a known geothermal resource area (KGRA) by the USGS. An excellent geologic map and an interpretative cross section of the caldera indicate that a magma chamber or pluton probably exists beneath the caldera. The cross section shows a diameter for the pluton approximately equal to the diameter of the caldera ring faults, that is, about $24 \mathrm{~km}$. The volcanic activity that produced the caldera occurred in two major episodes, 1.4 and $1.1 \mathrm{Myr}$ ago, and the youngest dated volcanism in the area occurred about 40000 years ago. The youth, magnitude, and duration of activity suggested that a local heat source was still available beneath the caldera. Supporting this conclusion is the presence of numerous hot springs within and adjacent to the caldera. The Valles Caldera is obviously a major geothermal system.

At the time of the first phase of operations, preliminary drilling had been completed within the caldera by private interests in an attempt to locate natural hydrothermal resources. Newspaper accounts indicated that high temperatures and geothermal fluids had been encountered in some drill holes.

With a heat source indicated, it was then necessary to locate impermeable reservoir rocks which would lead to the selection of a drill site, that is, determine what parts of the geothermal system might contain HDR. The geologic map and cross sections showed that Precambrian igneous and metamorphic rocks were 
exposed locally at the surface on the west side of the caldera. It was apparent from the geologic map and cross sections that areas could be found west of the caldera where the overlying Paleozoic and Cenozoic cover was less than $1 \mathrm{~km}$ (3000 ft) thick. Mineralogical and textural evidence from exposures of the Precambrian rocks indicated that these rocks should be impermeable. The relative scarcity of large faults on the west side also suggested that impermeable hot rock could be found there.

Thus, at the conclusion of the first phase, it seemed likely that both adequate temperatures and impermeable rock could be found associated with the Valles Caldera geothermal system, particularly on the west side of the caldera, outside the ring fracture.

The second phase of the site selection and evaluation consisted primarily of collecting new heat-flow data near the caldera to confirm the presence of hot dry rock.

Because the presence of numerous faults within the interior of the caldera suggested that it would be difficult to find impermeable rock in this area, heat-flow measurements were confined to the area outside the ring faults. Initially, seven shallow holes were drilled around the periphery of the caldera. These holes, which penetrated to depths of up to $30 \mathrm{~m}$, indicated that the heat flow was indeed highest on the west side of the caldera. Conductive gradients in shallow holes are readily perturbed by the local hydrology; therefore, four additional heat-flow holes were drilled to depths of 152 to $229 \mathrm{~m}$ to confirm the shallower heat-flow results. Three of these, forming an arc $2.4 \mathrm{~km}$ outside the western caldera ring fault, indicated high heat flow (5.5 HFU). A decrease in heat flow with radial distance from the caldera was shown by the fourth drill hole where the heat flow was $2.2 \mathrm{HFU}$ at a distance of $6.4 \mathrm{~km}$ from the ring fault. This value falls within the range (1.5 to $2.5 \mathrm{HFU})$ reported for the Basin and Range Province, which may represent a background value for the Jemez Plateau area.

Because of the necessity of selecting an area where impermeable rocks could be found, considerable attention was paid to the tectonic setting of the caldera. Faulting is more common on the east side of the caldera where it overlaps the Rio Grande Rift. This area is broken by many north striking faults, apparently associated with the rifting. The Precambrian basement is not exposed on this side of the caldera and, because of faulting, it is assumed to be buried to a considerable depth. 
The USGS provided unpublished geological and geophysical data suggesting that the west side of the caldera is structurally simple and therefore would be better suited for the HDR extraction experiment.

At the conclusion of the second phase, it was apparent that the magma chamber or pluton beneath the Valles Caldera had thermally perturbed the rocks in the immediate area. The magnitude of the perturbation decreased with radial distance from the caldera. High heat flow and a higher probability of finding impermeable rock on the west side of the caldera indicated that further work was warranted in that area. To test this conclusion and to provide a borehole for initial hydraulic-fracturing experiments, a deep, slim hole, GT-1, was located at a drill site in Barley Canyon. It was anticipated that this hole would intersect the Precambrian basement at a depth of considerably less than $1 \mathrm{~km}$. The drilling and subsequent experiments and measurements composed the major portion of the third phase of the exploration efforts. The initial results of a study of faults and seismicity and a report on seismic activity also became available at this time.

These preliminary reports indicated that the Barley Canyon drill site and Fenton Hill area were within a large fault block bounded by the caldera ring fault to the east, the Virgin Canyon and Jemez Springs faults to the southeast, the Caldera Canyon fault to the north, and the Rio Cebolla fault to the west. The closest of these is one of the caldera ring faults, 1.5-km east of the Fenton Hill area. The main ring fault is about $3-\mathrm{km}$ east of the site. The interior of this block is free of observable faults.

The seismic history of the area was reviewed and it was concluded that the area is seismically quiet. This work indicated that the seismic-energy release per unit area is about an order of magnitude less than in California and Nevada. There have been no reported earthquakes with epicenters near the drill sites.

The location for GT-1 was selected on the basis of the results of the prior heat-flow measurements, shallow depth of the Precambrian basement, and absence of faults in the area. GT-1 was drilled to a total depth of $785 \mathrm{~m}$, intersecting the Precambrian unconformity at a depth of $642 \mathrm{~m}$. Continuous coring was used for the botton $47 \mathrm{~m}$ of the hole, within the crystalline rock.

After GT-1 was drilled, temperature measurements were made in the hole. The average gradient was $129^{\circ} \mathrm{C} / \mathrm{km}$ in the Paleozoic sedimentary rocks and $45^{\circ} \mathrm{C} / \mathrm{km}$ in the top of the Precambrian rocks. An abrupt change in gradients occurs in the lower Madera Limestone near the contact with the underlying Sandia 
Formation. This is undoubtedly due to the movement of warm water through the permeable limestone downdip away from the caldera.

The expected impermeability of the resource rocks was confirmed by a variety of direct and indirect evidence. In situ permeability measurements made in GT-1 gave values of $5 \times 10^{-8}$ to $6 \times 10^{-3}$ darcys for overpressures of 13 to 177 bars. Eight successful hydraulic fracturing experiments at pressures of approximately 100 bars also indicated that the rocks were impermeable. Indirect evidence for impermeable rock was obtained from the petrographic study of GT-1 cores. It was found that most of the core consisted of granitic gneisses with minor amphibolite content. Although fractures were common in the cores, they were almost invariably sealed by calcite or chlorite.

At the completion of the third phase and before the commencement of the drilling of the deep boreholes, GT-2 and EE-1, it was possible to postulate a refined model for the Fenton Hill area. The heat source had locally perturbed an already high geothermal gradient providing temperatures sufficiently high for the proposed experiments.

Mapping of fault locations indicated that the proposed site lies within a large block of crystalline rock that is free of any faults with surface expression. This information, in addition to the evidence that most fractures in the Precambrian rocks were sealed suggested that low permeability rocks could be found within the Precambrian section. Slim-hole drilling of GT-1 indicated that the basement rocks would be encountered at a depth of about $640 \mathrm{~m}$.

The fourth phase of operations began in February 1974 with the drilling of GT-2 and has continued through the drilling of EE-1, the hydraulic fracturing experiments, loop formation, and the current circulation experiments. The drill site was selected for GT-2 and EE-1 with the belief that it was geologically similar to the GT-1 site but better situated logistically.

To demonstrate the widespread occurrence of hot dry rock, it has been determined that the target prospect to be evaluated next in this work is not to be associated with a young silicic volcano, but will derive its heat from some other type of source.

Regional. LASL is collecting, interpreting, and evaluating regional data in the Arizona-New Mexico and Washington-Oregon areas, preparatory to identifying target prospects areas in each. The rest of the target prospect areas will then be selected for further study. This selection will be concluded in late September 1979. The factors being used in this evaluation include 
- elevated heat flow; that is, above 2.5 HFU's,

- heat source other than a young silicic volcano,

- low incidence of faulting and fracturing in potential reservoir rocks,

- absence of significant apparent hydrothermal system,

- low seismicity activity, and

- institutional and economic factors, such as land ownership, prior leasing agreements, proximity to potential users, environmental issues, and estimated extent of thermal system.

Scope. The target prospect area to be evaluated in this effort will consist of an area of approximately $100 \mathrm{mi}^{2}$ located within one of the following two geographic regions or general areas: Arizona/New Mexico or Washington/Oregon. On the basis of the geologic and other information about the regions or general areas, as summarized by LASL, a prospect will be selected by LASL to have a high HDR potential. The selected subcontractor of the target prospect area shall be expected to design, implement, and manage a program to achieve the objectives stated above through a detailed evaluation of the target prospect area as outlined in the Tasks below.

Specific Tasks. To complete the required detail target prospect area evaluation, the subcontractor shall (a) conduct all eleven required Tasks and (b) select from a list (as indicated in Task 4 below) of surveys or methods as out lined in optional Tasks 12 through 37.

Required Tasks. To achieve the objectives of the hot dry rock target prospect evaluation, the subcontractor shall complete the required Tasks 1 through 11.

\section{Task 1 - Assignment of Target Prospect}

The selected subcontractor shall meet with LASL HDR staff as soon as this subcontract is issued, and (1) learn of their assigned prospect, (2) receive and review a11 data used by LASL to select prospect.

Task 2 - Data Compilation

A data compilation and literature search shall be conducted.

Task 3 - Permitting for Required Tasks

Permit requests needed for conduct of the evaluation shall be initiated.

Task 4 - Review and Agreement, Final Plan

Within 30 days of contact award, the subcontractor shall submit a final plan to LASL for those Tasks 12 through 37 to be accomplished. After discussions and review, mutual (written) agreement shall be reached on the complete 
final plan for the detailed evaluation of the assigned TP. This final plan decision shail be decided on a bilateral mutual agreement basis.

In the development of the final $\mathrm{plan}$, the subcontractor shall consider the following selection criteria for the location of a deep drill hole:

- confirmed local extent of elevated heat flow,

- high probability of permeability of reservoir rock,

- depth to reservoir rock not to exceed $3 \mathrm{~km}$, and

- area of low seismicity risk.

Task 5 - Permits

All needed permits shall be obtained for all subsequent work as necessitated by the final plan.

Task 6 - Map of Surface Geology

Field work and photo interpretation necessary to generate $1 / 24000$-scale map of surface geology shall be performed. Particular attention shall be paid to faults which may intersect potential reservoir rocks at depth.

Task 7 - Fracture Analyses

Using the geologic map produced in Task 6 , fracture analyses with results displayed as rose diagrams, shall be performed.

Task 8 - Heat Flow Survey

Using shallow $(-150 \mathrm{~m})$ heat-flow holes, geothermal gradient within prospect shall be determined. The results shall be overlaid on the geologic map of Task 6.

Task 9 - Hydrology

Using surface data information obtained from heat-flow holes and other available data, hydrology of the prospect shall be evaluated. The results shall be summarized as an overlay on the geologic map of Task 6 .

Task 10 - Seismicity

Existing seismic data shall be compiled and new data sufficient to evaluate seismic activity of the prospect shall be collected. These data shall be summarized as an overlay on geologic map of Task 6.

Task 11 - Comprehensive Final Report

Following the completion of Tasks 1-10 and completion of those selected in the final $\mathrm{plan}$ from Tasks 12 through 37, the subcontractor shall forward a draft comprehensive report (scheduled to arrive at LASL not later than September 15, 1979). This draft final report shall summarize the data collected, evaluation of the prospect, and recommended actions. The draft report shall be returned to 
the subcontractor for revisions (if any) and five copies of the final report shall be forwarded to LASL no later than October 15, 1979.

Optional Tasks. In addition to the required Tasks 1 through 11, which are applicable at any site, there are other optional Tasks that may be site-specific. These include, but are not necessarily limited to the following:

Task 12. Using $\mathrm{K}-\mathrm{Ar}$ method, determine age of young ( $\sim 3 \mathrm{Myr})$ igneous rocks, which may have served as heat sources.

Task 13. Perform detailed MT-AMT survey of the prospect or a portion thereof.

Task 14. Perform resistivity survey of prospect or a portion thereof.

Task 15. Perform thin-section analysis (including preparation of section, identification of minerals, modal analysis, and interpretation) on pertinent samples of igneous rocks, which may have acted as a heat source and/or potential reservoir rocks.

Task 16. Identify and characterize, if samples are available, potential reservoir rocks. Characterization should include but not necessarily be limited to mineralogy, modal composition, whole rock chemistry, primary and secondary permeability.

Task 17. Using surface geologic data and pertinent geophysical data, estimate depth to potential reservoir rocks.

Task 18. Perform analyses of spring and well water samples.

Task 19. Apply silica and/or cation geothermometers to results of water analyses to obtain estimate of reservoir temperature.

Task 20. Perform aerial photography.

Task 21. Perform low sun angle photography.

Task 22. Perform IR photography.

Task 23. Perform lithologic logging of heat flow holes.

Task 24. Perform hydrologic testing of heat flow holes.

Task 25. Perform microseisms (ground noise) survey.

Task 26. Perform teleseisms survey.

Task 27. Perform reflection seismic profiling.

Task 28. Perform refraction seismic survey.

Task 29. Perform self-potential survey.

rask 30. Perform telluric profiling survey.

Task 31. Perform AFMAG survey.

Task 32. Perform TDEM survey. 
Task 33. Perform electrical soundings.

Task 34. Perform gravity survey.

Task 35. Perform aeromagnetics survey.

Task 36. Calculate depth to Curie isotherm.

Task 37. If a geothermal resource is identified, develop conceptual model of the system.

Specific tasks from this list, or additional items as proposed by the subcontractor in Task 4, shall be selected by the subcontractor and LASL staff to complete the detailed HDR evaluation of the assigned target prospect area.

Deliverables. In addition to the final report (Task 11) informal-letter monthly status reports shall be submitted to LASL by the subcontractor. These will summarize accomplishments and problems of the previous month and display the expenditures of manpower and funds.

Copies of all supporting data maps, field notes, etc. shall be prepared and forwarded to LASL in a form suitable for open file records by LASL.

A draft of the final report shall be required by September 15, 1979, with the final draft submitted to LASL at completion of the contract. This report will summarize all results obtained during the evaluation. The final report shall conclude with a recommendation of an HDR drilling site, abandonment of the prospect, or perhaps specific additional work. The final report shall also contain a section indicating how the evaluation has contributed to HDR exploration technology.

Information to be Furnished to Subcontractor. LASL shall provide to the subcontractor all geologic and other data used for the selection of the target prospect area. LASL shall also furnish to the subcontractor all new data acquired by LASL during the period of the subcontract.

Monitoring of Subcontract. LASL shall provide a technical monitor for the evaluation program. This individual will monitor the implementation of this program, review data periodically, and provide technical advice to the subcontractor. 